UNIVERSIDADE DE SÃO PAULO

FACULDADE DE ECONOMIA, ADMINISTRAÇÃO E CONTABILIDADE DEPARTAMENTO DE ADMINISTRAÇÃO PROGRAMA DE PÓS-GRADUAÇÃo EM ADMINISTRAÇÃO

RELAÇÃO ENTRE MONITORAMENTO DO AMBIENTE E ORIENTAÇÃO ESTRATÉGICA: UM ESTUDO DA PERCEPÇÃO DE PROFISSIONAIS DE INTELIGÊNCIA COMPETITIVA

Maria Cristina Pereira Pimentel

Orientador: Prof. Dr. Fernando Carvalho de Almeida 
Prof. Dr. Prof. Dr. João Grandino Rodas

Reitor da Universidade de São Paulo

Prof. Dr. Reinaldo Guerreiro

Diretor da Faculdade de Economia, Administração e Contabilidade

Prof. Dr. Adalberto Américo Fischmann

Chefe do Departamento de Administração

Prof. Dr. Lindolfo Galvão de Albuquerque

Coordenador do Programa de Pós-Graduação em Administração 


\section{RELAÇÃO ENTRE MONITORAMENTO DO AMBIENTE E ORIENTAÇÃO ESTRATÉGICA: UM ESTUDO DA PERCEPÇÃO DE PROFISSIONAIS DE INTELIGÊNCIA COMPETITIVA}

Dissertação apresentada ao Programa de PósGraduação em Administração da Faculdade de Economia, Administração e Contabilidade da Universidade de São Paulo, para obtenção do título de Mestre em Ciências.

Orientador: Prof. Dr. Fernando Carvalho de Almeida

\section{Versão Corrigida}

(Versão original disponível na Faculdade de Economia, Administração e Contabilidade)

SÃo PAULO 
Pimentel, Maria Cristina Pereira

Relação entre monitoramento do ambiente e orientação estratégica: um estudo da percepção de profissionais de inteligência competitiva / Maria Cristina Pereira Pimentel. - São Paulo, 2013.

$210 \mathrm{p}$.

Dissertação (Mestrado) - Universidade de São Paulo, 2013.

Orientador: Fernando Carvalho de Almeida.

1. Inteligência competitiva 2. Estratégia organizacional 3. Ambiente organizacional I. Universidade de São Paulo. Faculdade de Economia, Administração e Contabilidade. II. Título.

CDD -658.472 
Aos meus pais,

Fernando e Angela, pela dedicação e carinho. 


\section{AGRADECIMENTOS}

Agradeço em primeiro lugar, ao Prof. Dr. Fernando Carvalho de Almeida por ter me recebido como sua orientanda, pela passagem de conhecimentos no campo da Inteligência Competitiva e pelas valiosas contribuições para o desenvolvimento deste estudo.

Aos professores Nicolau Reinhard e Flávio Urdan pela participação na banca do exame de qualificação e por suas preciosas recomendações para o aperfeiçoamento deste trabalho de pesquisa.

Ao professor Adolpho Canton pelos ensinamentos em sala de aula e pelas importantes contribuições para o desenvolvimento deste trabalho.

Aos demais professores da FEA USP pela atenção dedicada dentro e fora de sala de aula e, em particular, ao professor Cesar Alexandre de Souza pela amizade e incentivo ao desenvolvimento de publicações científicas.

Aos colegas, com quem tive o privilégio de compartilhar a vida acadêmica, pela convivência, amizade, debates de rico conteúdo e desenvolvimento de trabalhos e estudos.

Aos funcionários da Secretaria da Pós-Graduação/FEA pelo zeloso apoio institucional.

Aos funcionários da biblioteca da FEA USP, sempre prestativos e atenciosos.

Aos amigos da SCIP, em particular ao colega da FEA USP Alexandre Del Rey, pelo apoio na aplicação do questionário desta pesquisa em evento da entidade.

A todos os profissionais ligados à Inteligência Competitiva que se dispuseram a responder o questionário deste estudo.

A todos que de alguma maneira colaboraram para o desenvolvimento deste trabalho, deixo meu imenso agradecimento. 
"A melhor maneira de prever o futuro é criá-lo." 


\section{RESUMO}

O presente trabalho estuda a existência de relação entre o monitoramento do ambiente externo por uma organização e sua orientação estratégica. A abordagem metodológica é empíricopositivista de natureza quantitativa com método de pesquisa survey (levantamento). Elaborouse um questionário fundamentado na tipologia de Miles e Snow (2003) para identificar a orientação estratégica e no estudo teórico de Daft e Weick (1984) para identificar o modo de monitoramento. Analisaram-se 120 questionários respondidos por profissionais relacionados ao monitoramento em organizações de grande porte. Empregaram-se técnicas de análise multivariada para identificar e classificar o modo de monitoramento em procura formal e procura informal. Classificou-se a orientação estratégica em Prospectora (inovação), Defensiva (eficiência), Analítica (híbrida) e Reativa por meio de questões da escala de Conant et al. (1990). Os dados da amostra indicam o predomínio de organizações Analíticas. As Prospectoras parecem mais presentes entre as organizações multinacionais. No geral, o monitoramento procura informações quantitativas de fontes claramente definidas, sendo os concorrentes o principal foco de atenção. Os aspectos econômicos, de inovações tecnológicas e regulatórios são mais observados do que os socioculturais e políticos. A falta de apoio da Alta Direção é percebida como a principal dificuldade da prática do monitoramento. A estruturação das atividades, a estruturação das informações coletadas e a ocasionalidade das pesquisas qualitativas são aspectos que diferenciam a procura formal da procura informal. Como principal resultado, encontraram-se indícios de que o modo de monitoramento varia com a orientação estratégica, com uma tendência da procura formal ser mais utilizada pelas organizações Analíticas e Prospectoras e da procura informal, pelas Defensivas e Reativas. Daft e Weick (1984) pressupõem a ocorrência maior de uso da procura formal pelas Analíticas do que pelas Prospectoras, o que não foi evidenciado neste trabalho de investigação. Considera-se que o viés da inovação presente nas Prospectoras e o viés do seguimento de inovações bem-sucedidas nas Analíticas demandam uma observação mais abrangente e constante do ambiente, justificando nestas organizações a tendência ao monitoramento do tipo procura formal pela sua maior estruturação e regularidade.

Palavras-chave: Inteligência Competitiva; Estratégia Organizacional; Ambiente Organizacional. 


\begin{abstract}
This research investigates the relationship between the scanning of the external environment by an organization and its strategic orientation. The approach was the quantitativeempirical-positivist method together with the survey research method. It was developed a questionnaire based on the typology of Miles and Snow (2003) to identify the strategic orientation and the theoretical study of Daft and Weick (1984) to identify the scanning mode. One hundred twenty questionnaires completed by professionals involved with scanning in large organizations were analyzed. Techniques of multivariate analysis were used for identifying and classifying the scanning mode in formal search and informal search. The strategic orientation was classified as Prospector (innovation), Defender (efficiency), Analyzer (hybrid), and Reactor by using questions of Conant et al. (1990) scale. The sample data indicate the predominance of Analyzer organizations. The Prospector organizations seem more prevalent among multinational companies. Overall, scanning seeks quantitative information from clearly defined sources, with competitors being the main focus of attention. Economic, technological innovation and regulatory aspects were more observed than sociocultural and political aspects. The lack of support from top management is perceived as the main difficulty in the practice of scanning. Activity structuring, structuring of gathered information, and the occasional qualitative research are aspects that differentiate formal search from informal search. As a main result, it was found evidence that the scanning mode varies with strategic orientation, with a tendency of formal search being more used by Analyzer and Prospector organizations, while informal search is more frequent among Defender and Reactor organizations. Daft and Weick (1984) assume a higher use of formal search by Analyzers than by Prospectors; however, this was not evidenced in this study. It was considered that the bias of innovation present in Prospector organizations and the bias of following successful innovations in Analyzer organizations require a more broad and continuing observation of the environment, which explains the tendency to the formal search type scanning mode in these organizations due to its greater structuring and regularity.
\end{abstract}

Keywords: Competitive Intelligence; Organizational Strategy; Organizational Environment. 



\section{SUMÁRIO}

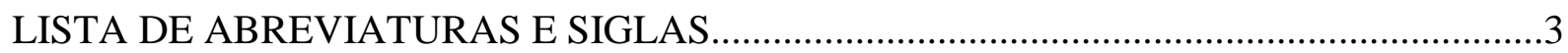

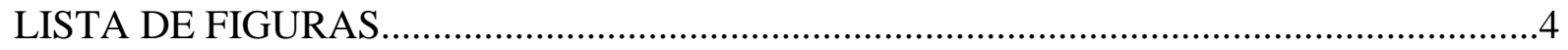

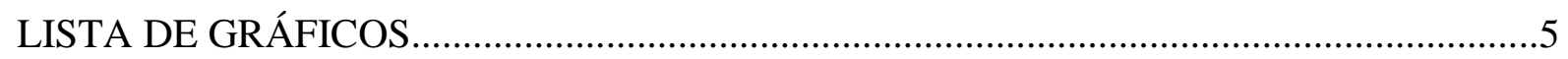

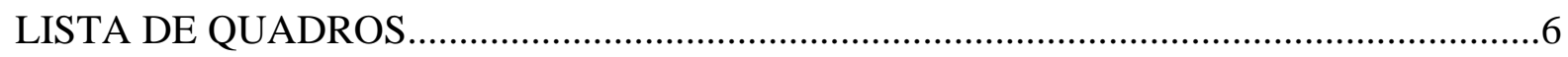

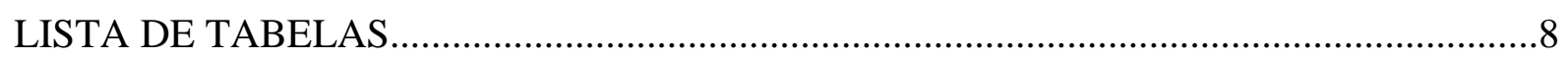

1. INTRODUÇÃ

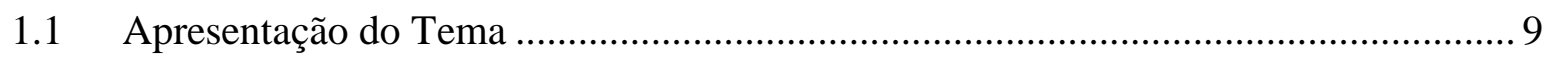

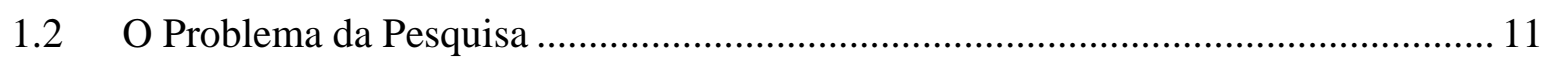

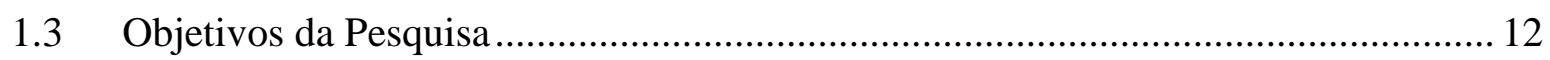

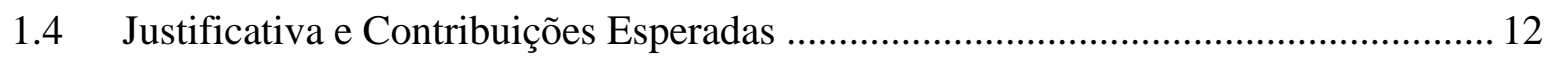

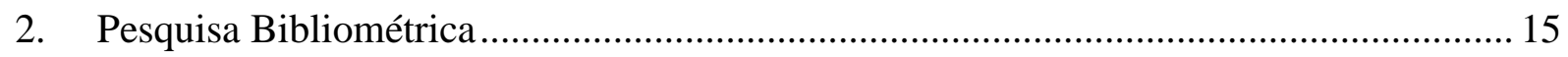

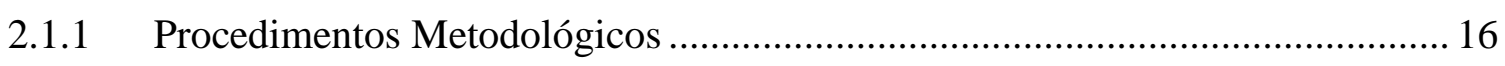

2.1.2 Apresentação dos Resultados ................................................................... 18

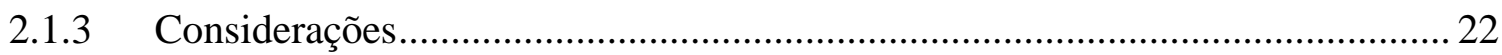

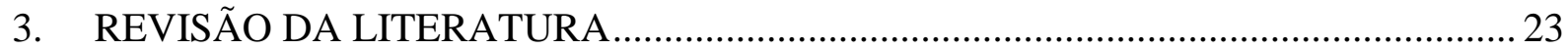

3.1 Relação entre Monitoramento e Orientação Estratégica ......................................... 24

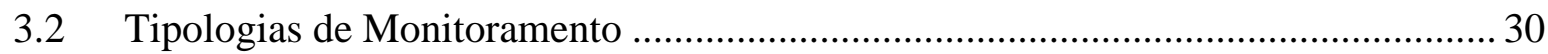

3.2.1 A Tipologia de Monitoramento de Aguilar...................................................... 31

3.2.2 A Tipologia de Monitoramento de Fahey e King …....................................... 37

3.2.3 A Tipologia de Monitoramento de Jain........................................................ 42

3.2.4 A Tipologia Organizacional de Daft e Weick ................................................... 48

3.2.5 A Tipologia Organizacional de Choo............................................................. 55

3.3 A Tipologia de Orientações Estratégicas de Miles e Snow ...................................... 62

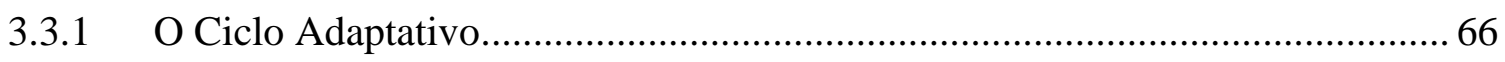

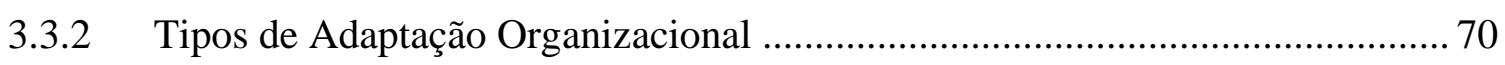

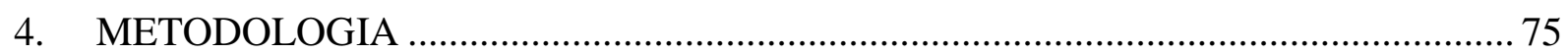

4.1 Abordagem, Estratégia e Método de Pesquisa ........................................................ 75 


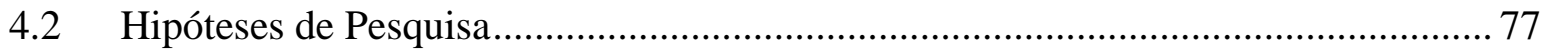

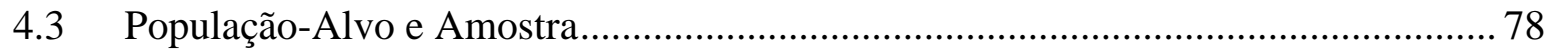

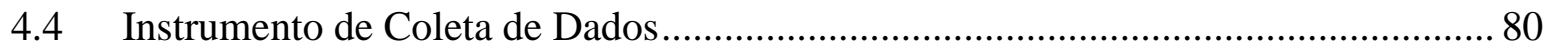

4.4.1 Bloco de Questões 01 - Modo de Monitoramento ............................................ 81

4.4.2 Bloco de Questões 02 - Fontes de Informação.................................................. 84

4.4.3 Bloco de Questões 03 - Escopo do Monitoramento .......................................... 85

4.4.4 Bloco de Questões 04 - Dificuldades do Monitoramento ................................... 87

4.4.5 Bloco de Questões 05 - Orientação Estratégica .............................................. 89

4.4.6 Bloco de Questões 06 - Dados da Organização .................................................. 95

4.4.7 Bloco de Questões 07 - Dados do Respondente................................................. 96

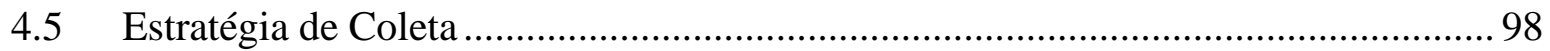

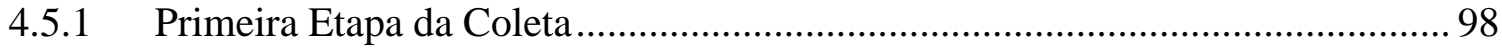

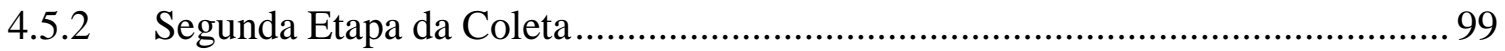

4.5.3 Coleta em Formulário Impresso .................................................................. 101

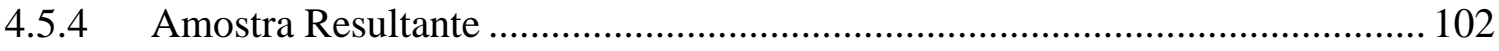

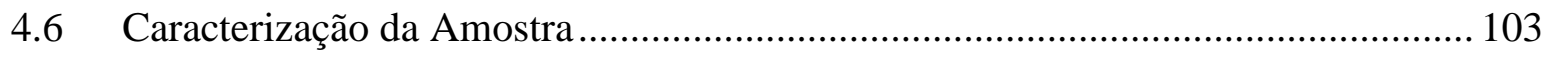

4.6.1 Porte das Organizações dos Respondentes...................................................... 103

4.6.2 Características das Organizações na Amostra Efetiva ...................................... 105

4.6.3 Características dos Respondentes na Amostra Efetiva ................................... 108

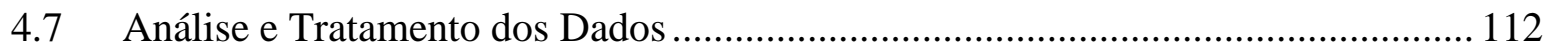

4.7.1 Identificação da Orientação Estratégica ....................................................... 115

4.7.2 Identificação do Modo de Monitoramento.................................................... 120

4.7.3 Relação do Modo de Monitoramento e Orientação Estratégica........................ 152

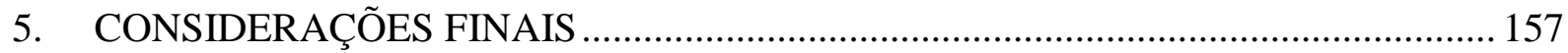

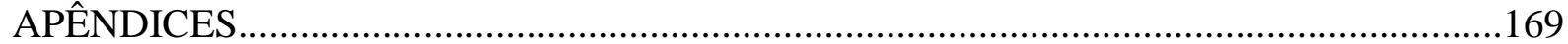




\section{LISTA DE ABREVIATURAS E SIGLAS}

3ES: $\quad$ Encontro de Estudos em Estratégias

A: Analítica

BNDES: Banco Nacional de Desenvolvimento Econômico e Social

CAPES: Comissão de Aperfeiçoamento de Estudos Superiores

CV: $\quad$ Coeficiente de Variação

D: Defensiva

DP: $\quad$ Desvio Padrão

EGEPE: $\quad$ Encontro de Estudos sobre Empreendedorismo e Gestão

de Pequenas Empresas

ENEGEP: Encontro Nacional de Engenharia de Produção

ENANPAD: Encontro da Associação Nacional de Pós-Graduação e Pesquisa em Administração

FIPE: $\quad$ Fundação Instituto de Pesquisas Econômicas

g.l.: $\quad$ graus de liberdade

IC: $\quad$ Inteligência Competitiva

MBA: $\quad$ Master Business Administration

MM: $\quad$ Modo de Monitoramento

OE: $\quad$ Orientação Estratégica

P: $\quad$ Prospectora

P\&D: $\quad$ Pesquisa e Desenvolvimento

PF: $\quad$ Procura Formal

PI: $\quad$ Procura Informal

R: Reativa

SCIP: $\quad$ Strategic and Competitive Intelligence Society

SEBRAE: Serviço de Apoio às pequenas e Médias Empresas

sig. assint.: significância assintótica

SPSS: $\quad$ Statistical Package for Social Sciences

WoS: $\quad$ Web of Science

WoK: Web of Knowledge 


\section{LISTA DE FIGURAS}

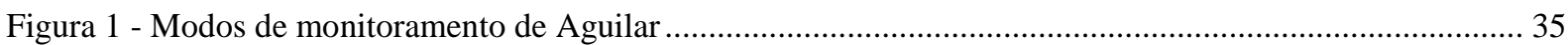

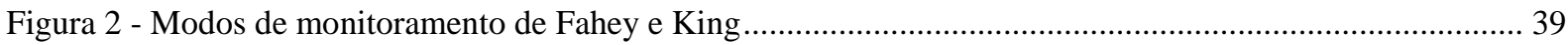

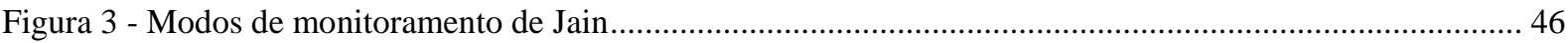

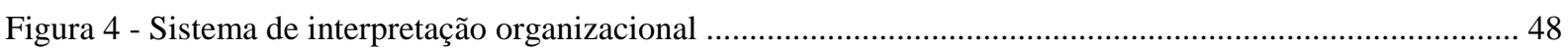

Figura 5 - Modos de interpretação organizacional de Daft e Weick ............................................................ 51

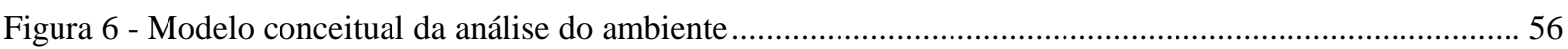

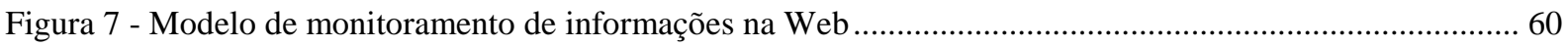

Figura 8 - Ciclo de adaptação da organização ao ambiente externo ...........................................................69

Figura 9 - Relação entre modo de monitoramento e orientação estratégica ................................................... 154 


\section{LISTA DE GRÁFICOS}

Gráfico 1 - Distribuição anual das publicações no período de 1977 a 2012

Gráfico 2 - Distribuição anual das publicações no período de 2003 a 2012 ................................................. 18

Gráfico 3 - Citações dos 130 artigos no período de 2003 a 2012 ................................................................. 19

Gráfico 4 - Citações anuais de Hambrick (1982) no período de 2003 a 2012 ................................................... 21

Gráfico 5 - Publicações anuais mencionando o modelo de Miles e Snow ....................................................... 62

Gráfico 6 - Função discriminante para o grupo procura formal .................................................................... 132

Gráfico 7 - Função discriminante para o grupo procura informal ........................................................... 132 


\section{LISTA DE QUADROS}

Quadro 1 - Autores com dois trabalhos publicados

Quadro 2 - Periódicos com mais de três publicações

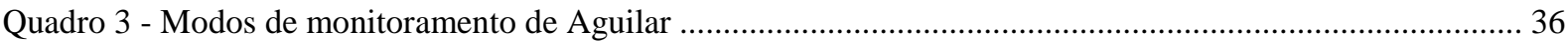

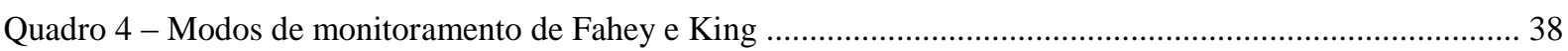

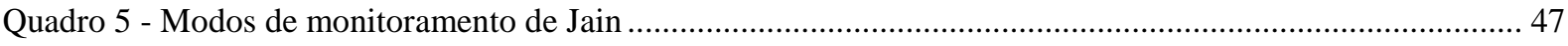

Quadro 6 - Modos de interpretação do ambiente propostos por Daft e Weick ............................................... 54

Quadro 7- Modos de monitoramento e interpretação de Choo ...................................................................57

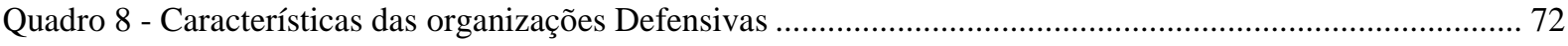

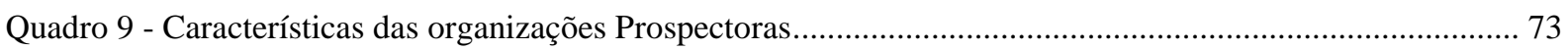

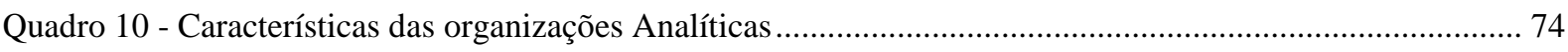

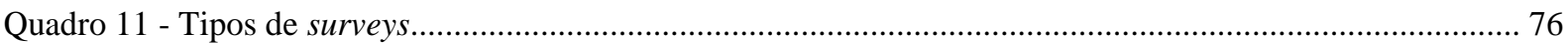

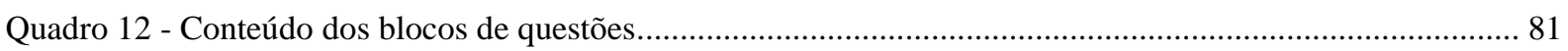

Quadro 13 - Questões para avaliação do modo de monitoramento ............................................................. 83

Quadro 14 - Questões para avaliação das fontes de informação .................................................................. 85

Quadro 15 - Questões para avaliação do escopo do monitoramento .......................................................... 87

Quadro 16 - Questões para avaliação dos problemas do monitoramento...................................................... 89

Quadro 17 - Dimensões das questões de orientação estratégica ……............................................................90

Quadro 18 - Questões para avaliar a orientação estratégica ..................................................................... 91

Quadro 19 - Exemplos da aplicação da "Regra da Maioria" ..................................................................... 94

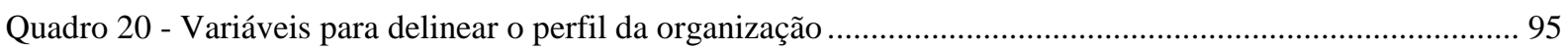

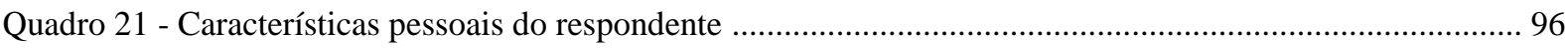

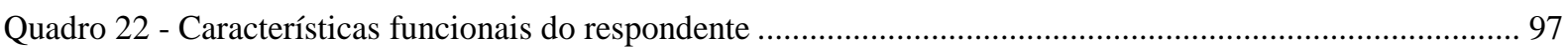

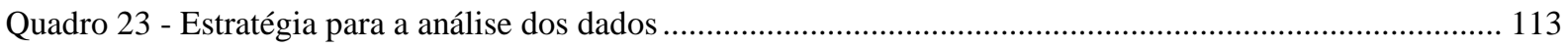

Quadro 24 - Orientação Estratégica versus Grupo Setorial.................................................................. 118

Quadro 25 - Orientação Estratégica versus Nacionalidade ............................................................................ 119

Quadro 26 - Ranking das variáveis pelo grau de concordância ............................................................... 122

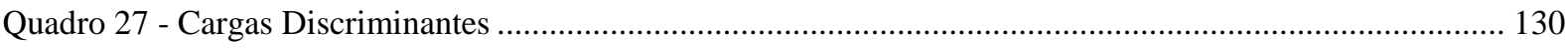

Quadro 28 - Classificação prevista pela Análise Discriminante .................................................................. 131

Quadro 29 - KMO e Teste de Esfericidade de Bartlett ......................................................................... 133

Quadro 30 - Estatísticas descritivas dos tipos de fontes de informação ......................................................... 140

Quadro 31 - Aspectos do ambiente externo para monitoramento ............................................................... 142

Quadro 32 - Estatísticas descritivas dos aspectos ambientais de mercado .................................................. 143

Quadro 33 - Estatísticas descritivas dos aspectos macroambientais ............................................................... 144

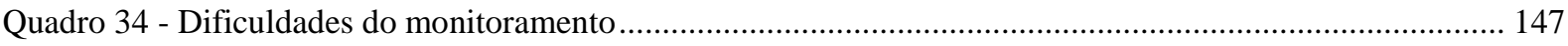

Quadro 35 - Estatísticas descritivas das dificuldades organizacionais ...................................................... 148

Quadro 36 - Estatísticas descritivas das dificuldades técnicas ...................................................................... 150

Quadro 37 - Orientação Estratégica versus Modo de Monitoramento ......................................................... 153

Quadro 38 - Modo de monitoramento e orientações estratégicas A e P.......................................................... 155 


\section{LISTA DE TABELAS}

Tabela 1 - Distribuição dos artigos pelos países de origem .................................................... 21

Tabela 2 - Coleta através de convites coletivos do LinkedIn.................................................99

Tabela 3 - Coleta através de convites individuais no LinkedIn ......................................... 100

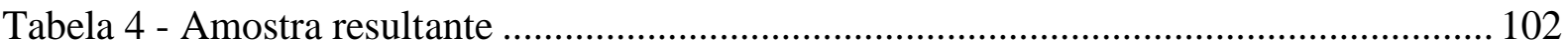

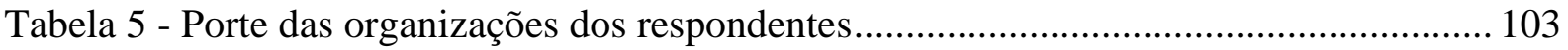

Tabela 6 - Número de funcionários das organizações dos respondentes ................................ 104

Tabela 7 - Maturidade das organizações dos respondentes.................................................. 104

Tabela 8 - Número de funcionários das organizações dos respondentes .............................. 105

Tabela 9 - Maturidade das organizações dos respondentes................................................. 106

Tabela 10 - Origem do capital das organizações dos respondentes ..................................... 106

Tabela 11 - Nacionalidade das organizações dos respondentes .............................................. 106

Tabela 12 - Grupos setoriais das organizações dos respondentes ......................................... 107

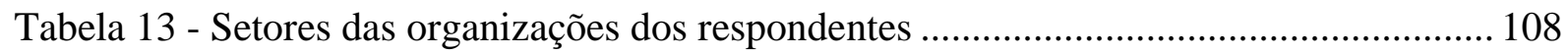

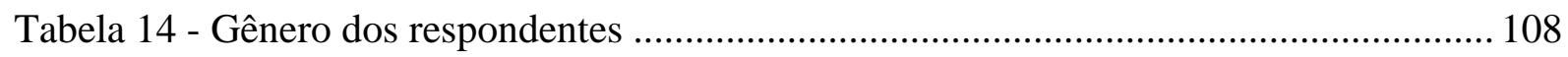

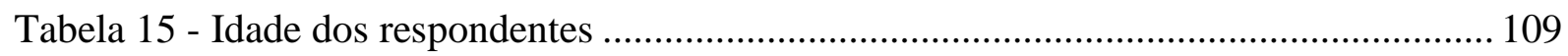

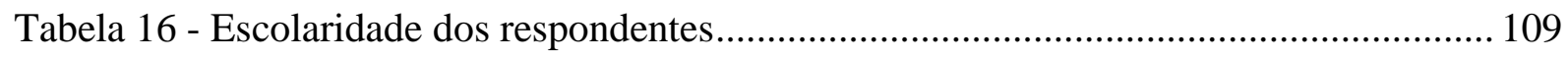

Tabela 17 - Tempo de atuação dos respondentes nas organizações ....................................... 110

Tabela 18 - Áreas de atuação dos respondentes nas organizações ........................................ 110

Tabela 19 - Cargos dos respondentes nas organizações ........................................................ 111

Tabela 20 - Orientação estratégica das organizações dos respondentes ................................ 115

Tabela 21 - Resumo das respostas das questões do primeiro bloco ..................................... 121

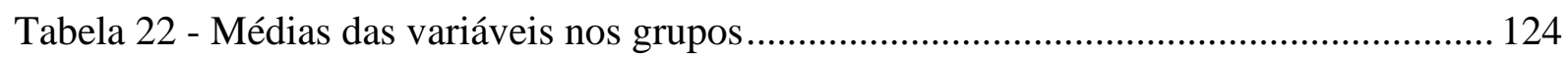

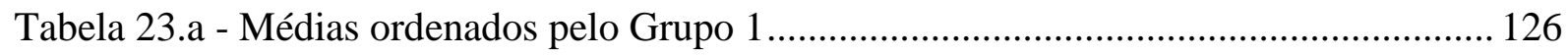

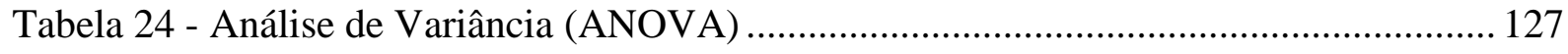

Tabela 25 - Autovalores e \% de variância explicada pelos fatores ....................................... 134

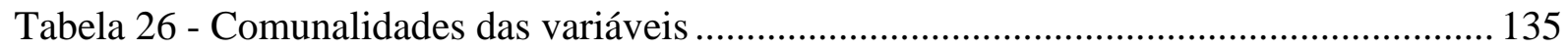

Tabela 27- Estrutura fatorial (correlações entre variáveis $e$ fatores) .................................... 136

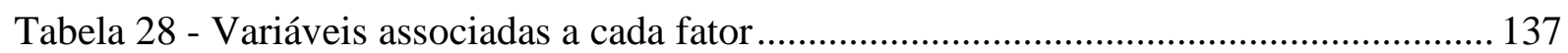

Tabela 29 - Teste da diferença das médias dos escores fatoriais ........................................ 138 


\section{INTRODUÇÃO}

\subsection{Apresentação do Tema}

A utilização das informações do ambiente externo às organizações com o objetivo de criar e manter vantagem competitiva sustentável é um tema que desperta interesse tanto no meio acadêmico quanto no meio empresarial. Através do tratamento das informações relevantes para detectar ou mesmo antecipar as mudanças das condições externas, as organizações buscam o fortalecimento, melhorando suas escolhas e, por consequência, seu desempenho (ANTIA; HERSOFORD, 2007). Assim, as disciplinas que tratam da utilização das informações do ambiente externo ganham importância na medida em que aumentam a complexidade ambiental e a consequente dificuldade para coletar e selecionar as informações de fato relevantes para o desempenho das organizações.

Considerando-se esse cenário, escolheu-se como tema para o presente estudo a investigação dos fatores que influenciam o modo como as organizações monitoram seu ambiente externo, ou seja, a maneira como coletam e selecionam informações com o objetivo de reduzir as incertezas relativas às condições ambientais externas e, consequentemente, aumentar a qualidade das decisões. O fator de influência escolhido como foco desta investigação é a orientação estratégica, ou seja, a maneira escolhida pelos gestores da organização para competir no ambiente de negócios. Dessa forma, será investigada a relação entre o modo de monitoramento do ambiente externo por uma organização e sua orientação estratégica.

Francis J. Aguilar em sua obra clássica Scanning the Business Environment, datada do final dos anos de 1960, já descrevia o monitoramento como crítico para o desempenho das organizações. Entretanto, descrevia também como sendo uma atividade de difícil implementação dado que os eventos que afetam o futuro das organizações podem ocorrer em qualquer lugar e de muitas formas. $\mathrm{O}$ interesse pelos fatores que influenciam o modo de monitorar o ambiente externo está associado a essa dificuldade de implementação, a qual

permanece como um desafio para as organizações. A quantidade de iniciativas de monitoramento nas organizações que são descontinuadas algum tempo após a sua 
implantação, ou mesmo, que não chegam a ser implantadas é razoável (LESCA; CARONFASAN, 2008; FONSECA, 2012).

As organizações que seguem uma estratégia competitiva, tal como a diferenciação de produto, liderança em custo ou foco (PORTER, 1980), ou que adotam uma orientação estratégica Prospectora, Analítica ou Defensiva (MILES; SNOW, 2003), buscam empregar um modo de monitoramento que forneça informações para perseguir seus objetivos (CHOO, 2002). Quando o modo de monitoramento adotado pela organização se mostra eficaz para essa finalidade, permitindo lidar com a complexidade do ambiente, as iniciativas de monitoramento apresentam maiores chances de continuidade na organização.

Tomando-se em conta o exposto, propõe-se como finalidade para o presente estudo dar continuidade à investigação da existência ou não de relação entre o modo de monitoramento e a orientação estratégica das organizações. Observa-se que estudos já foram desenvolvidos sobre este tema em diferentes perspectivas, e alguns autores concluíram que existe tal relação (SUBRAMANIAN et al., 1993) e outros não (HAMBRICK, 1982). Assim, espera-se dar continuidade a esse debate através dos resultados do presente estudo.

Considera-se que um melhor entendimento da relação entre orientação estratégica e o modo de monitoramento poderá contribuir para a implementação de práticas de monitoramento mais eficazes para a melhoria do desempenho das organizações e, portanto, de maior perenidade nas organizações. A contribuição deste estudo é a avaliação desta questão sob a perspectiva dos profissionais envolvidos nas atividades de monitoramento em organizações, os quais de fato acompanham a maneira como as organizações efetivamente executam suas práticas de monitoramento. 


\subsection{O Problema da Pesquisa}

A temática geral deste estudo consiste nos fatores que influenciam o modo como as organizações monitoram o ambiente externo. Neste contexto, considera-se o ambiente externo como o conjunto de todos os fatores externos a uma organização que podem influenciar seu desempenho ou até mesmo sua sobrevivência (MILES; SNOW, 2003). São exemplos de fatores que impactam organizações, clientes, fornecedores, concorrentes, aspectos econômicos, tecnológicos, políticos e socioculturais (DAFT, 2005).

A orientação estratégica de uma organização traduz-se pela maneira escolhida por seus gestores para competir no ambiente de negócios, sendo uma das principais finalidades do monitoramento suportá-la (KUMAR et al., 2001). Assim, coloca-se como questão básica do presente estudo a influência que a orientação estratégica de uma organização exerce sobre o modo como monitora seu ambiente externo. Entre outros atributos, o modo de monitoramento é caracterizado pela formalização, estruturação e regularidade com que é praticado nas organizações (AGUILAR, 1967; FAHEY; KING, 1977; CHOO, 1999; SAAYMAN et al., 2008).

Para o presente estudo, estabeleceu-se então a seguinte indagação de pesquisa:

\section{"Existe relação entre o modo de monitoramento do ambiente externo por uma organização e sua orientação estratégica?"}

Segundo Gil (2010), a indagação de pesquisa pode ser apresentada sob a forma de objetivos, o que contribui para a operacionalização da pesquisa e esclarecimento dos resultados esperados. Assim, para responder à indagação de pesquisa estabeleceram-se os objetivos descritos no tópico a seguir. 


\subsection{Objetivos da Pesquisa}

O objetivo principal desta pesquisa é buscar evidências da existência ou não de relação entre o modo de monitoramento e a orientação estratégica das organizações na forma como estes constructos são percebidos pelos profissionais de monitoramento.

Em relação aos objetivos específicos, pretende-se:

a) identificar a orientação estratégica das organizações na percepção de seus profissionais de monitoramento; e

b) identificar o modo de monitoramento das organizações na percepção de seus profissionais de monitoramento.

\subsection{Justificativa e Contribuições Esperadas}

Existem estudos que evidenciam que o monitoramento do ambiente externo contribui positivamente para o desempenho das organizações (DAFT et al., 1988). Entretanto, para essa contribuição existir, faz-se necessário que o monitoramento apresente como resultado a aquisição de informações que sejam relevantes para definir e manter a orientação estratégica das organizações (KUMAR et al., 2001; CHOO, 2002). Assim, justificam-se os estudos com o intuito de confrontar teoria e realidade para esclarecer questões conceituais e metodológicas do monitoramento e seu relacionamento com a orientação estratégica.

Ainda, segundo Gilad (2011), há estudos que indicam que de $35 \%$ a $55 \%$ de todas as falhas de negócio são atribuídas a equívocos de estratégia. Assim, o estudo do relacionamento entre monitoramento e orientação estratégica adquire importância, não apenas para a compreensão dos processos de alinhamento da estratégia com o ambiente competitivo, mas também para o entendimento do monitoramento como fator de gerenciamento de riscos para mitigar equívocos estratégicos. 
Subramanian et al. (1993) também sugerem outros três motivos para a condução de estudos para a compreensão do relacionamento entre a orientação estratégica e o monitoramento:

a) primeiro, contribuir para que os gestores avaliem o quanto as práticas de monitoramento estão adequadas a suas organizações através de um melhor entendimento dessa atividade;

b) segundo, o estabelecimento de uma relação entre monitoramento e orientação estratégica contribui para relacionar o monitoramento com seu propósito. Daft et al. (1988) sugerem que a avaliação do ambiente é geralmente aceita como o primeiro passo do processo da gestão estratégica das organizações; e

c) terceiro, é possível que uma relação adequada entre orientação estratégica e monitoramento do ambiente competitivo também constitua uma competência diferenciada e ajude os gestores a melhorar o desempenho de suas organizações.

Na literatura, encontra-se um debate já estabelecido sobre a existência ou não de relação entre a orientação estratégica e o modo de monitoramento das organizações. A contribuição esperada do presente estudo é dar continuidade a esse debate, porém sob a perspectiva dos profissionais que atuam em organizações desempenhando atividades de monitoramento relacionadas à aquisição de informação do ambiente externo. Espera-se apresentar a percepção desses profissionais sobre a temática do presente estudo, tomando-se em conta que essas pessoas possuem efetivamente a visão do modo como o monitoramento é praticado pelas organizações. 


\section{PESQUISA BIBLIOMÉTRICA}

A pesquisa bibliográfica é uma etapa mandatória em qualquer trabalho científico, pois busca conhecer, analisar e explicar as contribuições existentes sobre o tema a ser investigado (MARTINS; THÉOPHILO, 2009). Segundo Sampieri et al. (2012, p. 52), "é sempre importante revisitar o passado, para construir o presente e visualizar o futuro", ainda que o pesquisador escolha por desenvolver uma abordagem totalmente diferente das encontradas na literatura.

Entretanto, fazer o levantamento das contribuições existentes requer o emprego de métodos para mapear globalmente e de forma confiável a pesquisa científica nos vários contextos, assegurando a legitimidade e a originalidade do conhecimento a ser produzido pelos novos estudos (KOBASHI; SANTOS, 2006). A bibliometria é um campo da ciência da informação que oferece métodos estatísticos e matemáticos para avaliar quantitativamente a produção científica, tendo atualmente os artigos científicos como objetos de interesse (SANTOS; KOBASHI, 2003). Os artigos em revistas e periódicos permitem ao pesquisador conhecer os estudos mais atualizados e recentes sobre o tema da investigação, o que justifica este interesse privilegiado (MARTINS; THÉOPHILO, 2009).

A avaliação quantitativa da produção científica é suportada por três princípios básicos citados por Santos et al. (2011):

a) a lei de Lotka que se refere ao cálculo da produtividade, considerando que autores mais produtivos coexistem com autores menos produtivos;

b) a lei de Bradford que trata da formação de núcleos de periódicos que concentram determinado tema, definindo critérios para a seleção de periódicos; e

c) a lei de Zipf que aborda a frequência de ocorrência de palavras em textos longos norteada pelo princípio geral do "esforço mínimo".

A aplicação dessas leis caracteriza a pesquisa bibliométrica como um método para direcionar a pesquisa bibliográfica, pois auxilia no mapeamento da produção científica existente. Santos et al. (2011, p. 4) comentam que, "na prática, os estudos bibliométricos baseiam-se em indicadores e em técnicas de visualização da informação de correlação dos elementos 
bibliográficos disponíveis em bases de dados". As bases informatizadas hoje são utilizadas para avaliar o estado da arte da ciência e da tecnologia, pois permitem o acesso sistemático à produção científica de referência (KOBASHI; SANTOS, 2006).

A plataforma Web of Knowledge $(W o K)$ da Thomson Reuters é uma das principais bases online de publicações acadêmicas internacionais acessada via Internet (WEB OF KNOWLEDGE, 2013). Essa plataforma oferece ferramentas para consulta de conteúdos científicos datados a partir de 1900, análise de citações, referências e índice h, facilitando as análises bibliométricas. Entre suas bases, inclui-se a Web of Science (WoS) cujo conteúdo consiste em mais de 12.000 periódicos internacionais relevantes e mais de 150.000 anais de encontros científicos, estando integrada localmente à base da Coordenação de Aperfeiçoamento de Pessoal de Nível Superior (WEB OF SCIENCE, 2013; CAPES, 2013).

Considerando-se o reconhecimento científico da base $W o K$ e o fato de possuir inúmeras ferramentas para apoio à pesquisa bibliométrica (WEBSTER; WATSON, 2002; SANTOS et al., 2011; KRAKAUER et al., 2013), escolheu-se essa base para a extração de dados para a pesquisa bibliométrica do presente estudo. A finalidade desta pesquisa foi realizar o mapeamento de artigos relevantes para atingir os objetivos do presente estudo, bem como a verificação do histórico da produção acadêmica sobre o tema escolhido.

\subsubsection{Procedimentos Metodológicos}

A pesquisa bibliométrica realizada para o presente estudo baseou-se nos procedimentos empregados por Krakauer (2010) listados a seguir e descritos nesta seção:

a) seleção e extração dos dados da base $W o K$, utilizando-se palavras-chave;

b) formatação dos dados extraídos, utilizando-se o software Bibexcel ${ }^{1}$; e

c) elaboração de gráficos e tabelas para a análise dos dados coletados.

\footnotetext{
${ }^{1}$ O Bibexcel é um software desenvolvido pelo pesquisador Olle Persson da Universidade Umea (Suécia) para apoiar a análise de dados bibliográficos e encontra-se disponível no site www.umu.se/inforsk/Bibexcel.
} 
$\mathrm{Na}$ etapa inicial, primeiro levantaram-se os dados da produção relativa ao tema do monitoramento ambiental e depois levantaram-se os dados da relação deste tema com a orientação estratégica. Os mecanismos disponíveis na $W o K$ foram utilizados para selecionar e extrair os dados de artigos do período de janeiro de 1990 a dezembro de 2012, observando-se que o inglês é o idioma de pesquisa da base. Para refinar os resultados, delimitou-se o campo da WoK "domínio de pesquisa” ao conteúdo "Social Sciences" e o campo "áreas de pesquisa", a "Business Economics". Pesquisaram-se apenas os artigos publicados em periódicos científicos, pois estes foram submetidos a uma rigorosa revisão por pares.

O método para seleção dos artigos foi a pesquisa por palavras-chave que são elementos que consolidam as características da informação procurada. O desafio para a definição de uma palavra-chave é conseguir encontrar termos que não sejam excessivamente genéricos, perdendo-se a capacidade de filtrar a informação relevante, e também que não sejam tão específicos ao ponto de não se detectá-la.

Considerando-se esse desafio, escolheram-se as palavras-chave "enviromental scanning" e "competitive intelligence" para a pesquisa isolada do tema do monitoramento. Para a pesquisa cruzada dos temas monitoramento e orientação estratégica, acrescentaram-se as palavraschave "strategic orientation", "strategic type" e "strategic typology", resultando em seis combinações de palavras-chave. As ferramentas de pesquisa da WoK procuraram pelas palavras-chave nos campos título, resumo e palavras-chave do autor nos registros dos artigos da base.

Na segunda etapa, os arquivos-texto gerados pela WoK com os dados dos artigos selecionados foram processados pelo software Bibexcel de apoio à análise bibliométrica. Essa ferramenta foi utilizada para a formatação e a interpretação das informações da WoK, para que os artigos pudessem ser listados e tabulados. Um dos principais recursos utilizados dessa ferramenta foi a separação dos autores em artigos com múltiplos autores, para a análise da produtividade individual. Observa-se que os arquivos gerados pelo Bibexcel são compatíveis com o software MS-Excel de planilhamento eletrônico (PERSSON et al., 2009).

$\mathrm{Na}$ etapa final, geraram-se as tabelas e os gráficos com o software MS-Excel. A seguir, apresentam-se os dados obtidos e as análises resultantes, considerando-se os princípios de Zipf, Lotka e Bradford mencionados anteriormente. 


\subsubsection{Apresentação dos Resultados}

Encontraram-se referências na base WoK de 130 artigos sobre monitoramento publicados no período de 1977 a 2012, conforme mostrado no Gráfico 1.

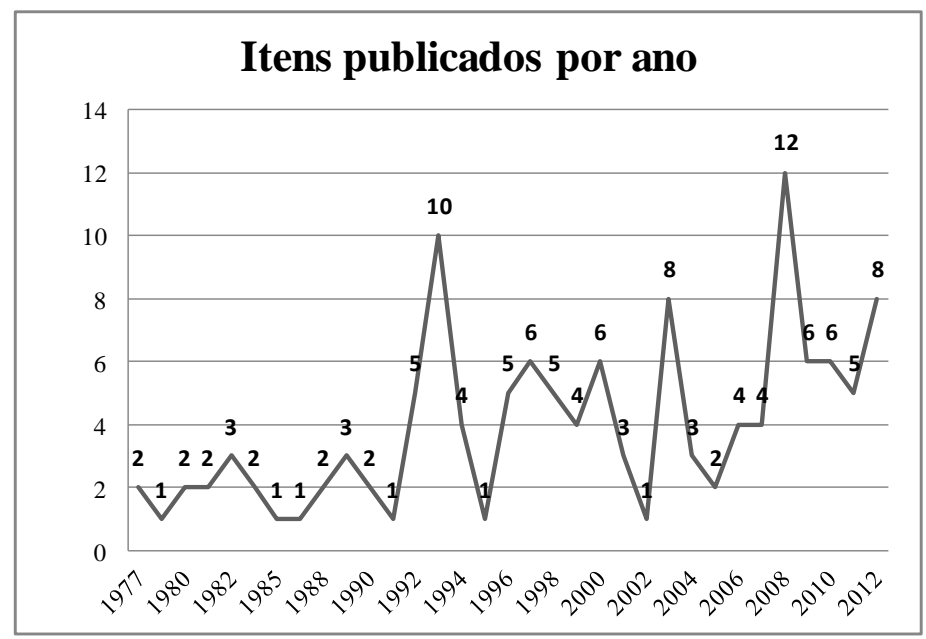

Gráfico 1 - Distribuição anual das publicações no período de 1977 a 2012

No Gráfico 2, mostram-se as informações quantitativas das publicações nos últimos dez anos de forma isolada.

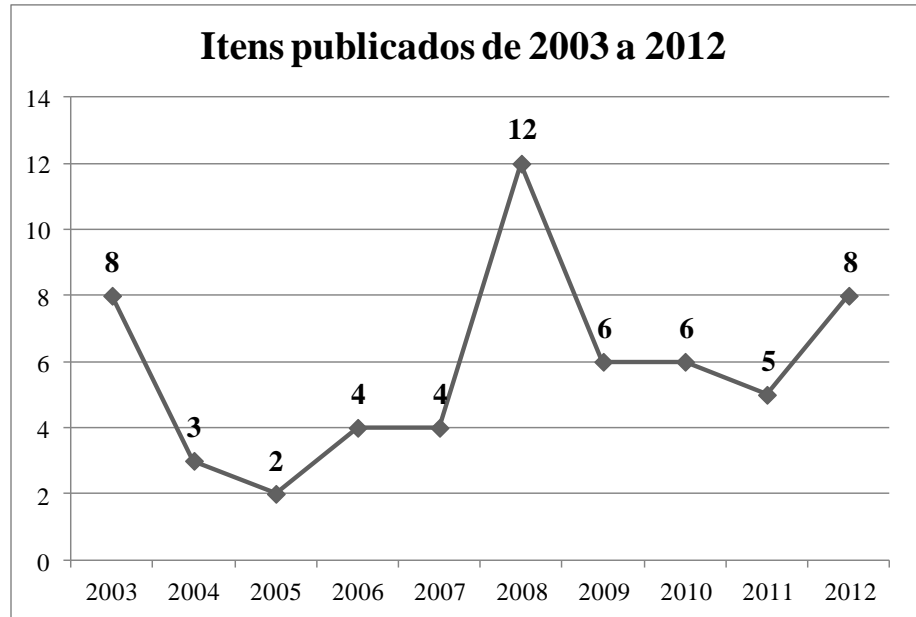

Gráfico 2 - Distribuição anual das publicações no período de 2003 a 2012 
No Gráfico 3, mostra-se a distribuição anual das 1.691 citações registradas nos últimos dez anos relativas aos 130 artigos selecionados, observando-se um pico em 2011 com 269 citações e um salto de 148 para 225 citações do ano de 2007 para 2008.

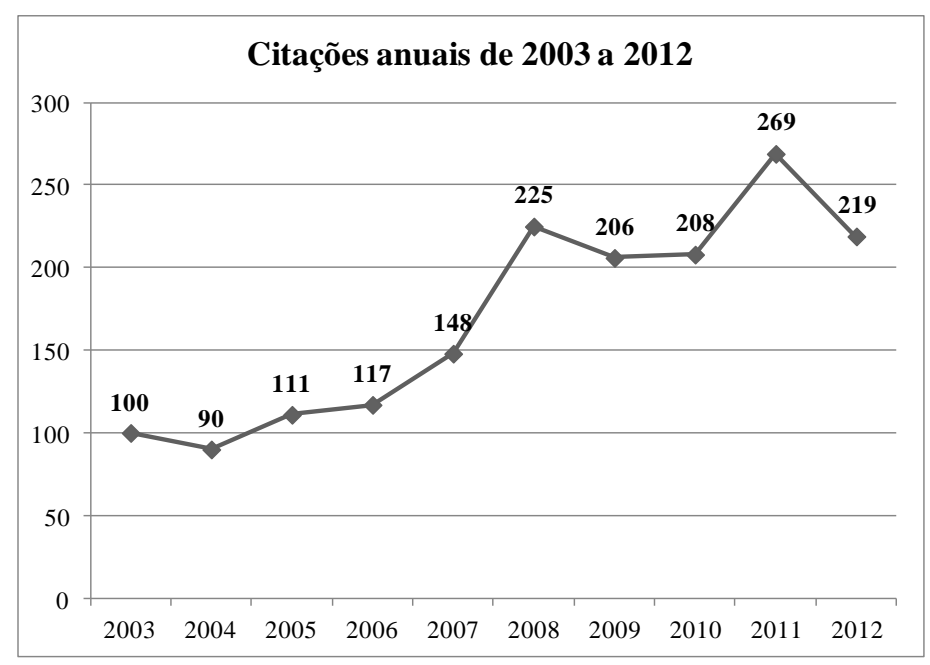

Gráfico 3 - Citações dos 130 artigos no período de 2003 a 2012

Para as 130 publicações selecionadas, há um total de 258 autores, dos quais a maioria apresenta apenas um trabalho ou no máximo dois trabalhos neste conjunto de publicações. Esse número remete à lei de Lotka, evidenciando que autores mais produtivos convivem com autores menos produtivos. Os únicos 11 autores que apresentaram duas publicações encontram-se listados em ordem alfabética em dois blocos no Quadro 1.

Quadro 1 - Autores com dois trabalhos publicados

\begin{tabular}{|l|l|}
\hline \multicolumn{2}{|c|}{ Autores } \\
\hline B. Gilad & L. Fahey \\
D. C. Hambrick & O. O. Sawyerr \\
D. F. Jennings & S. Sarker \\
J. O. Schwarz & V. Yanes-Estevez \\
J. R Lumpkin & W. R. King \\
J. R. Oreja-Rodriguez & \\
\hline
\end{tabular}


Há um total de 54 periódicos para o conjunto de artigos selecionados, e em 28 periódicos foi publicado apenas um artigo e em 11, foram publicados apenas dois artigos no período pesquisado. No Quadro 2, apresentam-se os 15 periódicos com três ou mais publicações no período. Essas contagens relacionam-se à lei de Bradford que trata de periódicos que concentram artigos sobre determinado tema.

Quadro 2 - Periódicos com mais de três publicações

\begin{tabular}{|lc|}
\hline \multicolumn{1}{|c|}{ Periódicos } & Itens \\
\hline Long Range Planning & 17 \\
Technological Forecasting and Social Change & 9 \\
Futures & 8 \\
European Journal of Marketing & 6 \\
International Journal of Technology Management & 6 \\
Research-Technology Management & 6 \\
Information \& Management & 5 \\
Journal of Small Business Management & 4 \\
Industrial Marketing Management & 3 \\
Journal of Business Venturing & 3 \\
Management Decision & 3 \\
MIS Quarterly & 3 \\
Strategic Management Journal & 3 \\
Technology Analysis \& Strategic Management & 3 \\
Technovation & 3 \\
\hline
\end{tabular}

Considerando-se que a WoK é uma base internacional de artigos, na Tabela 1 apresenta-se a distribuição dos artigos pelos países de origem. Observa-se a predominância de artigos de origem norte-americana com quase $60 \%$ da produção, seguindo-se o Canadá com quase $10 \%$. 
Tabela 1 - Distribuição dos artigos pelos países de origem

\begin{tabular}{lcc}
\hline \multicolumn{1}{c}{ Países } & Itens & \% \\
\hline EUA & 76 & $58,5 \%$ \\
Canadá & 12 & $9,2 \%$ \\
Inglaterra & 8 & $6,2 \%$ \\
Alemanha & 6 & $4,6 \%$ \\
França & 4 & $3,1 \%$ \\
Cingapura & 3 & $2,3 \%$ \\
Espanha & 3 & $2,3 \%$ \\
Suíça & 3 & $2,3 \%$ \\
Outros & 15 & $11,5 \%$ \\
\hline Total & 130 & $100,0 \%$ \\
\hline
\end{tabular}

Também, identificou-se o artigo com o maior número de citações, que se intitula "Environmental scanning organizational strategy" de autoria de Charles Hambrick, publicado no periódico Strategic Management Journal no ano de 1982. Segundo Jennings e Lumpkin (1992), esse foi o primeiro estudo a testar empiricamente a relação entre monitoramento e orientação estratégica. Hambrick (1982) apresenta 196 citações na base WoK no período desde sua publicação até o final de 2012, sendo 87 nos últimos 10 anos, conforme mostrado no Gráfico 4.

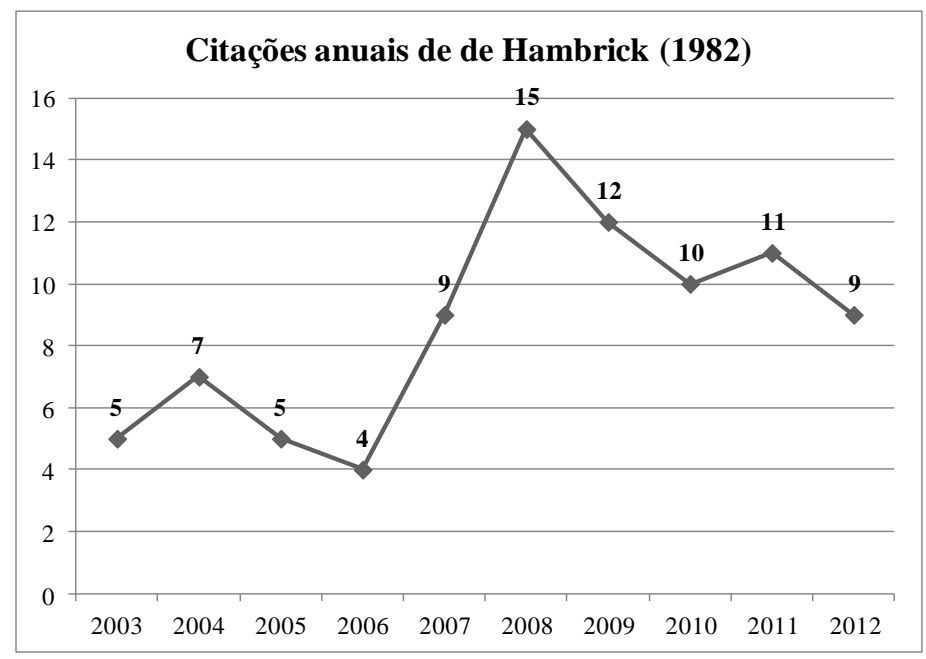

Gráfico 4 - Citações anuais de Hambrick (1982) no período de 2003 a 2012 
A pesquisa cruzada na base $W o K$ dos temas monitoramento ambiental e orientação estratégica, através das palavras-chave escolhidas, resultou na identificação de um único artigo que trata da relação entre a orientação estratégica e a inteligência competitiva em organizações na Malásia (YAP et al., 2012). Em uma nova triagem na WoK, acrescentou-se a palavra-chave "organizational strategy" para cruzamento com "environmental scanning" e "competitive intelligence", resultando apenas no artigo de Hambrick (1982) citado anteriormente nesta seção. Outras tentativas de busca com palavras-chave menos restritivas como "strategy" e "strategic" resultaram em perda de foco da seleção de artigos.

\subsubsection{Considerações}

Tomando-se em conta a representatividade da base $W o K$, esta pesquisa bibliométrica resultou em uma visão panorâmica da produção acadêmica internacional sobre o tema do presente estudo, bem como na identificação de artigos relevantes para a revisão da literatura. Saayman et al. (2008) comentam que há pouca pesquisa empírica sobre monitoramento, o que ainda é evidenciado pelos dados coletados.

Este estudo bibliométrico não encerrou a identificação de bibliografia relevante para este trabalho de investigação, sendo apenas uma etapa preliminar. Deve-se tomar em conta que esta pesquisa bibliométrica apresenta limitações relativas à identificação de estudos brasileiros, apesar de a WoK contemplar mais de 200 periódicos locais (THOMSON REUTERS, 2013). Outro aspecto importante consiste nas limitações decorrentes da pesquisa por palavras-chave e da predefinição de áreas de conhecimento, podendo ocultar obras relevantes para o estudo.

$\mathrm{Na}$ elaboração desta dissertação, considerou-se a recomendação de Martins e Théophilo (2009) para a inclusão das obras de referências na revisão da literatura, as quais normalmente conduzem o pesquisador às obras clássicas e seminais. Martins e Théophilo (2009, p. 54) afirmam que "os clássicos não envelhecem", resumindo bem o valor deste acervo para a pesquisa acadêmica. 


\section{REVISÃO DA LITERATURA}

A revisão da literatura do presente estudo foi estruturada em três partes descritas a seguir.

Na primeira parte, buscou-se levantar os principais estudos existentes sobre a relação entre a orientação estratégica e o modo de monitoramento das organizações. Encontraram-se estudos do período de 1978 a 2012, evidenciando a existência de um debate na literatura sobre a temática do presente estudo.

$\mathrm{Na}$ segunda parte, resgataram-se as principais tipologias de modos de monitoramento estratégico ambiental, com a finalidade de obter a fundamentação teórica para classificar as organizações quanto ao modo de monitorar o seu ambiente externo.

$\mathrm{Na}$ terceira e última parte da revisão da literatura, resgataram-se os principais fundamentos da tipologia proposta por Miles e Snow (2003) para a classificação das organizações quanto à orientação estratégica. Adianta-se que a escolha por utilizar essa tipologia no presente estudo ocorreu pelos seguintes motivos:

a) modelo amplamente utilizado e validado em pesquisas acadêmicas (FISS, 2011) ;

b) utilização em estudos anteriores sobre a relação entre estratégia e monitoramento (HAMBRICK, 1982; DAFT; WEICK, 1984; SUBRAMANIAN et al., 1993; CHOO, 2002);

c) existência de escalas validadas para a pesquisa empírica como o questionário de parágrafo único e escalas multi-itens (CONANT et al., 1990); e

d) sua aplicação independe do segmento de indústria e analisa a organização como um sistema completo (SUBRAMANIAN et al., 1993; MILES; SNOW, 1978, 2003).

Nas próximas seções, apresentam-se os resultados obtidos nas etapas propostas para a revisão da literatura. 


\subsection{Relação entre Monitoramento e Orientação Estratégica}

Aguilar (1967, p. 1) conceitua o monitoramento como "a aquisição de informação sobre eventos e relações no ambiente externo à organização para a construção do conhecimento para o suporte dos executivos na tarefa de traçar o curso futuro da organização". O autor destaca em seu estudo questões sobre a disponibilidade, a relevância, o volume e a confiabilidade das informações externas, descrevendo o monitoramento como uma atividade complexa. Zhang et al. (2010) afirmam que esse foi o primeiro estudo notável sobre monitoramento, e muitos dos estudos posteriores reforçaram essa definição, sem alterar sua perspectiva.

Culnan (1983) sintetiza que o monitoramento é a aquisição de informações sobre os eventos que correm externamente à organização, sendo uma estratégia que a organização pode empregar para se adaptar ao ambiente e também mudá-lo. Choo (1999) considera que o monitoramento analisa cada aspecto do ambiente que pode contribuir para o planejamento do futuro da organização pelos gestores. Ou seja, o monitoramento não cobre apenas os competidores, clientes e fornecedores, mas também aspectos tecnológicos, econômicos, regulatórios, sociais e demográficos.

Antia e Hersoford (2007) sugerem que a coleta, a análise e a distribuição de informações do ambiente competitivo, bem como das capacidades, vulnerabilidades e intenções dos competidores, constituem a prática da Inteligência Competitiva. Saayman et al. (2008) consideram a Inteligência Competitiva como o processo sistemático e ético de coletar, analisar e gerenciar informações externas que possam afetar os planos, decisões e operações da organização.

Qiu (2008) emprega em seu estudo a expressão "monitoramento por inteligência competitiva" ou "scanning for competitive intelligence", referindo-se à inteligência competitiva como um resultado ou objetivo da atividade de monitoramento. Calof e Wright (2008), por sua vez, sugerem que a Inteligência Competitiva é um sistema de monitoramento que integra o conhecimento de todos os indivíduos em uma organização.

Do exposto, conclui-se que na literatura não há uma definição única para a prática de coletar e utilizar informações do ambiente externo à organização com o objetivo de melhorar as 
decisões que influenciam a competitividade ou mesmo a sobrevivência das organizações. Deve-se tomar em conta que o ambiente externo é muito amplo e complexo, o que contribui para que os autores atribuam diferentes nomenclaturas à prospecção do ambiente, conforme os critérios que adotam.

No presente estudo, optou-se por empregar o termo monitoramento na concepção original de Aguilar (1967), por entendê-lo como mais abrangente. Considera-se que Inteligência Competitiva pode ser uma expressão equivalente, que não se limita na literatura à observação dos competidores (PORTER, 1980) e, sim, pode abranger os demais aspectos do ambiente externo que afetam o desempenho das organizações.

A orientação estratégica refere-se a como uma organização utiliza a estratégia para se adaptar e/ou mudar aspectos de seu ambiente para um alinhamento mais favorável, sendo um sinônimo para escolha estratégica (MANU; SRIRAM, 1996). Segundo Porter (1980), a escolha estratégica refere-se à alternativa que melhor relaciona a organização às oportunidades e ameaças do ambiente externo. De uma forma simplificada, a orientação estratégica caracteriza a maneira escolhida pelos gestores da organização para competir no ambiente de negócios, sendo um sinônimo também para estratégia competitiva (MORGAN; STRONG, 1998).

$\mathrm{Na}$ literatura, a orientação estratégica é usualmente examinada sob uma abordagem classificatória, que tenta agrupar as estratégias segundo uma base conceitual, resultando em tipologias de estratégias genéricas. Segundo Herbert e Deresky (1987, p. 135), "uma estratégia genérica é uma categorização ampla de escolhas estratégicas que podem ser aplicadas de forma generalizada a qualquer indústria, a qualquer tipo ou tamanho de organização, etc.".

As tipologias de estratégicas genéricas permitem agrupar as organizações de acordo com a ênfase de sua orientação estratégica. Por exemplo, Miles e Snow $(1978,2003)$ sugerem que as organizações podem ser agrupadas em quatro tipos:

a) Prospectoras, que são orientadas à inovação;

b) Defensivas, que são orientadas à eficiência;

c) Analíticas, que combinam traços das orientações Defensiva e Prospectora; e 
d) Reativas, que não possuem uma orientação estratégica definida.

Porter (1980) propõe uma outra classificação das organizações segundo três categorias de orientação estratégica:

a) liderança em custo total, que são orientadas à eficiência e controle de custos;

b) diferenciação, que são orientadas à oferta de algo único ao mercado; e

c) foco, que são orientadas a um alvo específico na indústria.

As estratégias genéricas de Porter tornaram-se rapidamente um dos paradigmas mais populares na literatura sobre estratégia organizacional. Segundo Kumar et al., (2001), um dos possíveis motivos foi o fato de esse modelo parecer englobar alguns conceitos centrais de outras tipologias. Por exemplo, a estratégia genérica de liderança em custo total é semelhante à orientação estratégica Defensiva proposta por Miles e Snow (1978), bem como a diferenciação contém elementos da orientação estratégica Prospectora proposta pelos mesmos autores.

Posteriormente, Porter (1985) revisa as estratégias competitivas e apresenta a liderança em custo e a diferenciação como fontes de vantagem competitiva e o escopo competitivo, como sendo de alvo amplo ou restrito. Esses dois tipos de vantagem competitiva combinados com o tipo de escopo competitivo resultam nas mesmas três estratégias genéricas anteriormente propostas. Entretanto, Porter (1985) propôs a subdivisão do foco entre as estratégias competitivas, resultando em "custo com foco" e "diferenciação com foco", considerando-se que o escopo competitivo é de alvo restrito quanto há foco. Não obstante, permanece uma polarização em liderança em custo e diferenciação, mantendo-se a semelhança com as orientações estratégicas Defensiva e Prospectora de Miles e Snow (1978).

Na revisão da literatura, encontraram-se estudos abordando a existência de relação entre o modo de monitoramento e a orientação estratégica das organizações, os quais se fundamentam em tipologias de estratégias genéricas. A seguir, apresentam-se os principais estudos resgatados e suas conclusões:

a) Miles e Snow (1978) fizeram especulações, não testadas, sobre a existência de relação entre os tipos de orientação estratégicas propostos em seu estudo - 
Prospectora, Defensiva, Analítica - e as atividades de monitoramento das organizações. Sugeriram que as organizações Prospectoras, com foco na inovação, monitoram o ambiente de forma mais abrangente do que as Defensivas, com foco na eficiência.

b) Hambrick (1982) investigou a relação entre a estratégia de negócios da organização e a ênfase do monitoramento em setores específicos do ambiente. Neste estudo, utilizou uma amostra de 17 organizações e a tipologia de orientações estratégicas de Miles e Snow (1978). Não foram encontradas evidências de que a estratégia, de forma isolada, influenciasse a ênfase do monitoramento em aspectos específicos do ambiente.

c) Daft e Weick (1984) descreveram conceitualmente as organizações como sistemas de interpretação do ambiente, classificando-as em quatro categorias: atuação, descoberta, visão não dirigida e visão condicionada. Especularam sobre a relação dos tipos de orientação estratégicas de Miles e Snow (1978) e o modo de monitoramento das categorias propostas. Sugeriram que as organizações com orientação estratégica Analítica, que adotam as inovações bem-sucedidas dos líderes, empregam um modo de monitoramento mais formal e estruturado para procurar informação no ambiente do que as organizações com orientação estratégica Prospectora, que lideram pela inovação.

d) Hrebiniak e Joyce (1985), em uma abordagem conceitual, propuseram que as organizações com orientação estratégica Defensiva ou de liderança em custo realizam atividades de monitoramento para encontrar soluções imediatas para baixar custos ou melhorar as margens. As organizações com orientação estratégica Prospectora ou de diferenciação de produto, por sua vez, executam atividades de monitoramento de uma maneira não dirigida, procurando por oportunidades.

e) Jennings e Lumpkin (1992) investigaram a relação entre as atividades de monitoramento e a orientação estratégica em 49 organizações do setor de crédito e poupança, empregando as estratégias genéricas de Porter (1980). Concluíram que as organizações com estratégia de diferenciação monitoram focando 
oportunidades e clientes, e as organizações com estratégia de liderança em custo monitoram com foco nos concorrentes.

f) Subramanian et al. (1993) investigaram a relação entre a orientação estratégica e o monitoramento em 68 organizações da Fortune 500. Empregaram a tipologia de orientações estratégicas proposta por Miles e Snow (1978) e os modos evolutivos de monitoramento primitivo, ad hoc, reativo e proativo propostos por Jain (1984). Foram encontradas evidências de que as organizações Prospectoras apresentam os sistemas mais avançados de monitoramento, seguidas pelas Analíticas e Defensivas.

g) Cartwright et al. (1995) investigaram 74 organizações para avaliar a relação entre a orientação estratégica e a percepção de utilidade do monitoramento. Empregaram a tipologia de orientações estratégicas de Miles e Snow (1978) e uma classificação de modos de monitoramento baseados em Fahey e King (1977). Concluíram que as organizações Prospectoras e Analíticas percebiam maior utilidade no modo de monitoramento contínuo do que as Defensivas e Reativas. O monitoramento na forma de um projeto singular, com um objetivo específico de entrega de informação, era percebido como útil independentemente da orientação estratégica.

h) Kumar et al. (2001) realizaram um estudo com 159 executivos do segmento hospitalar para investigar a relação entre a orientação estratégica, o monitoramento e o desempenho utilizando as estratégias genéricas de Porter (1980). Concluíram que as organizações com estratégias de diferenciação focam o monitoramento nas oportunidades, e as organizações com estratégias de liderança em custo focam nas ameaças. As organizações que conseguem alinhar o foco do monitoramento com a orientação estratégica apresentam melhor desempenho.

i) Walters et al. (2005) investigaram a relação entre a orientação estratégica e o modo de monitoramento em 64 pequenas empresas, utilizando as estratégias genéricas de Porter (1980). Encontraram-se evidências de que as empresas com estratégia de diferenciação colocam maior ênfase no monitoramento dos setores de mercado do que as empresas com estratégia de liderança em custo. 
j) Yap et al. (2012) utilizaram a tipologia de Miles e Snow (1978, 2003) para investigar a relação entre monitoramento e orientação estratégica em 93 empresas de vários setores na Malásia. Encontraram-se evidências de que as organizações Analíticas, comparadas com as Defensivas, monitoram com maior ênfase os setores tecnológicos e econômicos e também utilizam mais as informações obtidas para suportar as decisões estratégicas. 


\subsection{Tipologias de Monitoramento}

As organizações são entidades complexas dado que são vastas, fragmentadas e multidimensionais. Daft e Weick (1984) citam Pondy e Mitroff (1979) para afirmar que as organizações apresentam características típicas do nível oito da hierarquia de complexidade de nove níveis proposta por Boulding (1956). O próprio autor da hierarquia afirma que as organizações estão entre os sistemas mais complexos concebíveis. Assim, métodos e técnicas tornam-se necessários para lidar com a complexidade em estudos sobre temas organizacionais.

No campo da administração estratégica, um método usual para lidar com a complexidade é o emprego de tipologias, que consistem em uma importante maneira de organizar relações complexas, principalmente as de causa e efeito, constituindo parte importante da literatura da estratégia das organizações (FISS, 2011). Mcphee e Poole (2001) afirmam que as tipologias são úteis porque simplificam as múltiplas relações causais em poucos perfis categorizados de fácil memorização ou Gestalten, combinando complexidade com parcimônia.

Doty e Glick (1994) consideram que as tipologias não devem ser confundidas com sistemas de classificação, pois devem atender a importantes critérios de teorias que traduzem argumentos lógicos que especificam relações entre conceitos, constructos e variáveis. Mckinney (1969) considera que a função primária das tipologias é identificar, simplificar e organizar dados de forma que eles possam ser descritos em termos que os tornem comparáveis. De modo geral, as tipologias permitem aos pesquisadores simplificar cognitivamente um ambiente complexo pelo destaque das semelhanças entre os objetos, o que permite estabelecer comparações (HAMBRICK, 1983).

No presente estudo, as tipologias foram utilizadas para investigar a existência de relação entre o modo de monitoramento e a orientação estratégica das organizações. Nas próximas cinco seções, apresentam-se as tipologias encontradas na revisão da literatura relativas ao modo de monitoramento ambiental. 


\subsubsection{A Tipologia de Monitoramento de Aguilar}

A obra clássica "Scanning the Business Environment" de F. J. Aguilar publicada no final dos anos de 1960 é uma referência básica. Muitos estudos posteriores sobre monitoramento empregaram os conceitos propostos por esse autor. Por este motivo, essa obra é a primeira a ser abordada na revisão da literatura do presente estudo.

O monitoramento é descrito por Aguilar (1967) como a maneira pela qual os gestores obtêm informação sobre eventos que ocorrem fora da organização com o propósito de direcionar o curso futuro de ação. Uma das contribuições do autor para o estudo do monitoramento foi a criação de uma tipologia de modos de monitoramento que serviu de base para estudos posteriores (DENNING, 1973; DAFT; WEICK, 1984; CHOO, 1999; 2002).

Um dos fatores que tornaram esta tipologia duradoura foi o fato de o autor empregar um critério simples e ao mesmo tempo exaustivo para classificar os modos de monitoramento. $\mathrm{O}$ critério adotado foi a existência de intenção de busca de informação no ambiente, significando na prática empregar ou não esforços para adquirir informação. Desse critério, o autor derivou duas abordagens de monitoramento:

a) visão - viewing - o indivíduo encontra-se exposto diretamente ao ambiente, obtendo a informação ao acaso, sem que se tenha estabelecido um objetivo de busca.

b) procura - search - existe um esforço intencional para encontrar a informação no ambiente, pois houve uma demanda por parte dos tomadores de decisão para que a informação fosse procurada no ambiente.

Com base nessas duas abordagens, o autor derivou uma tipologia de quatro modos de monitoramento, constituindo uma escala em que a forma de adquirir informação evolui de uma abordagem totalmente casual para uma abordagem estruturada na medida em que aumentam os esforços para obter a informação (DENNING, 1973). 
A seguir, descrevem-se os quatro tipos de monitoramento propostos por Aguilar (1967):

a) visão não dirigida - undirected viewing - ocorre a exposição a vários tipos e fontes de informação sem que haja uma necessidade específica de informação. Os indivíduos utilizam as informações do ambiente de forma casual na medida em que percebem alguma relevância. Nesse modo, obtêm-se alertas casuais de que alguma coisa mudou no ambiente;

b) visão condicionada - conditioned viewing - o indivíduo começa a prestar atenção a determinados tópicos ou a certos tipos de informação, filtrando as informações do ambiente na medida em que detecta alguma relevância. Usualmente, essas informações servem como um aviso de que um monitoramento mais intensivo deve ser realizado, pois algo de impacto pode estar acontecendo no ambiente.

c) procura informal - informal search - busca-se ativamente por informações sobre um tópico específico. O esforço de procura é limitado e não é estruturado, pois se desconhece a priori como obter a informação. Ou seja, experimentam-se diversas formas de encontrar a informação desejada, agindo-se para aumentar a possibilidade de encontrá-la.

d) procura formal - formal search - há um esforço intencional e planejado para obter uma determinada informação. A procura é formal porque é estruturada de acordo com procedimentos e metodologias pré-estabelecidos. O objetivo é obter informações relevantes sobre um tópico para embasar uma decisão estratégica, como, por exemplo, a aquisição de uma empresa.

Caso a obtenção de informação estratégica fosse o único objetivo do monitoramento, a procura formal seria sempre o modo escolhido por apresentar o mais elevado nível de esforço e atenção. Entretanto, Aguilar (1967) argumenta que uma empresa não satisfaz todas suas necessidades de informação por esse modo. Primeiro, porque ele considera que uma empresa não é capaz de definir de antemão todas as informações estratégicas necessárias, e mesmo as informações podem aparecer repentinamente em qualquer lugar. Segundo, porque as necessidades identificadas de informações podem exceder a capacidade da empresa de fazer 
uma procura formal, considerando-se que esse monitoramento é custoso pela alocação de pessoas e demais recursos.

Para escolher o modo de monitoramento, Aguilar considera primordial a avaliação da relação custo versus benefício, observando que o benefício de uma informação depende de sua relevância para a organização. Além dessa relação, sugere que a opção pela procura formal depende da análise das variáveis agrupadas conforme segue:

a) Variáveis relativas à questão:

- o escopo ou a magnitude da questão avaliada em termos de seu impacto no retorno de longo prazo ou em metas da organização;

- a urgência ou prazo para resolver a questão;

- o quanto a questão constitui um problema ou uma melhoria para um processo já existente;

- o quanto a questão está prontamente definida; e

- o relacionamento da questão com o planejamento de longo prazo.

b) Variáveis relativas à informação:

- a adequação das informações existentes;

- a disponibilidade de informações adicionais; e

- a previsibilidade ou regularidade com que uma informação pode aparecer.

c) Variáveis relativas à capacidade:

- o tempo, a energia e outros recursos que os gestores podem alocar ao monitoramento;

- o número e a natureza das questões importantes que competem por atenção; e

- o interesse e os valores dos indivíduos que monitoram. 
O autor argumenta que, na prática, a escolha do modo de monitoramento resultará da análise integrada dessas variáveis. Por exemplo, quanto menos conhecida for a fonte da informação e quanto menor o tempo para identificá-la, tanto mais provável que o monitoramento seja por visão condicionada ou procura informal. Nessas condições, o autor considera que a procura formal, que é o modo mais intensivo de monitoramento, poderia se tornar excessivamente custosa.

Aguilar (1967) entende que uma organização pode utilizar todas as formas de monitoramento, e considera que a visão não dirigida é o modo de monitoramento mais comum, porém o menos efetivo. Por outro lado, a procura formal é o modo de monitoramento mais efetivo, apesar de não ser o mais comum. Além disso, se uma organização trabalhar somente com a visão não dirigida, os resultados do monitoramento não serão satisfatórios e, se utilizar somente a procura formal, o custo do monitoramento poderá ser elevado. Assim, o sistema ideal de monitoramento de uma organização deve ser estruturado e flexível para que todos os modos de monitoramento possam ser utilizados, aumentando as possibilidades de que as informações realmente estratégicas sejam obtidas do ambiente externo.

Denning (1973) chama a atenção para o fato de esta tipologia representar uma escala com diferentes níveis de esforços, pois, na medida em que se avança pelos tipos propostos na sequência visão não dirigida, visão condicionada, procura informal e procura formal, percebe-se:

a) um aumento do esforço para obter informações;

b) um aumento do foco em algumas áreas ou tipos de informações;

c) um aumento da relevância da informação coletada até que a informação se torne estratégica demandando a procura formal; e

d) uma estruturação das atividades culminando com planejamento, procedimentos e metodologias característicos da procura formal.

Na Figura 1, procura-se ilustrar este aumento gradual de esforços para a obtenção de informação do ambiente. Pressupõe-se a existência de um processo evolutivo no qual a organização vai desenvolvendo formas mais estruturadas e formais de aquisição da informação, mas preservando a capacidade de praticar as formas mais simples. No sentido 
vertical da figura, representam-se os modos de monitoramento e, no sentido horizontal, representa-se o esforço para a aquisição de informação.

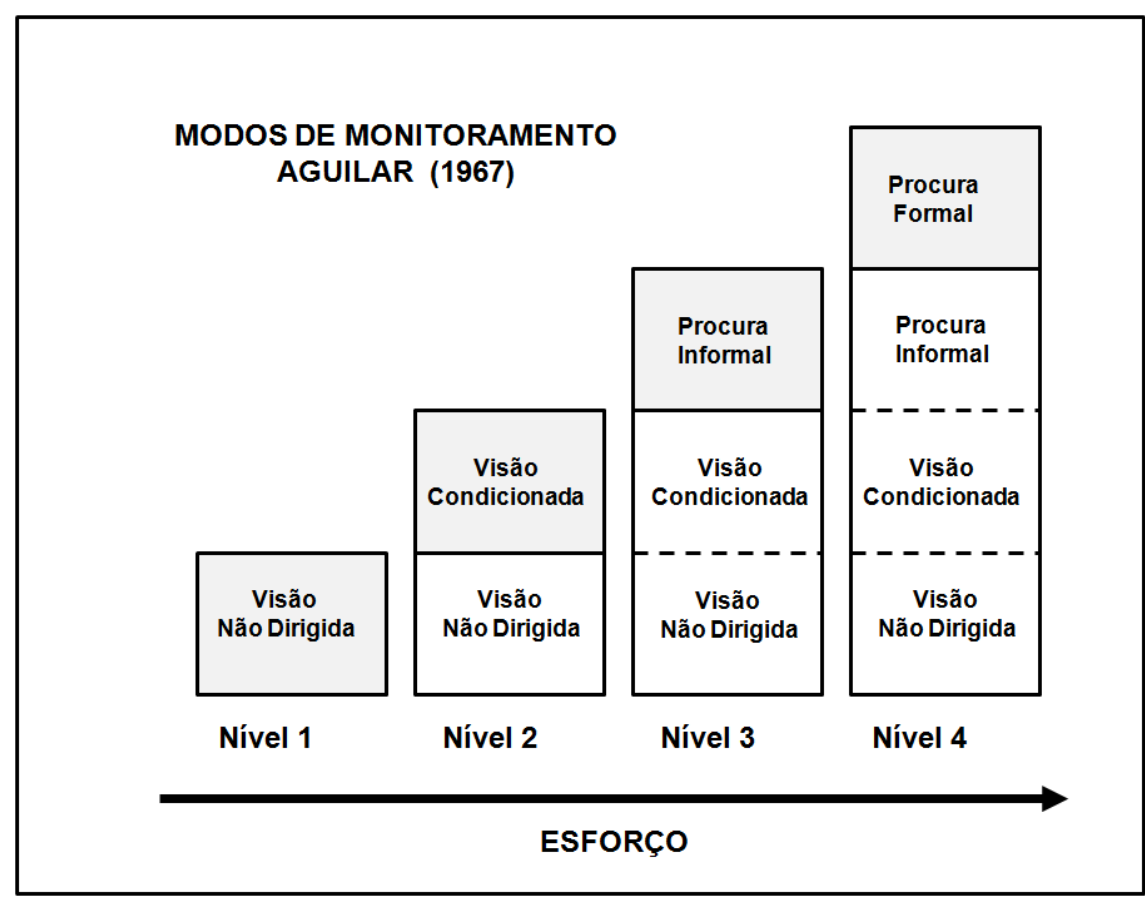

Figura 1 - Modos de monitoramento de Aguilar

Fonte: Elaborado pela autora

A seguir, descrevem-se os níveis mostrados na Figura 1:

a) Nível 1 - tem-se apenas o modo de visão não dirigida, que é totalmente difuso, involuntário, sem esforço e irregularmente pode captar algum alerta do ambiente;

b) Nível 2 - acrescenta-se a visão condicionada, que difere da visão não dirigida por uma sensibilidade maior do observador a certos tipos de dados, estando pronto para avaliar seu significado assim que os encontra;

c) Nível 3 - tem-se a inclusão da procura informal, na qual ocorre a busca intencional por uma informação específica, porém de forma limitada e não estruturada; e

d) Nível 4 - tem-se a procura formal com uma busca estruturada por uma informação específica com o objetivo de amparar uma decisão estratégica. 
A representação na Figura 1 está baseada na proposição de Aguilar (1967) de que a organização é capaz de praticar diferentes modos de monitoramento em dado momento, escolhendo aquele que estiver mais adequado à relação custo versus benefício da informação necessária. Adicionalmente, ilustra-se o conceito de que a organização amadurece em relação às práticas de monitoramento na medida em que é capaz de coordenar níveis mais elevados de esforços para adquirir informação do seu ambiente externo, culminando na prática de um monitoramento formal e estruturado (DENNING, 1973; JAIN, 1984; HERRING; LEAVITT, 2011).

Para finalizar esta seção, apresenta-se o Quadro 3 com um resumo das principais características de cada um dos modos de monitoramento sugeridos por Aguilar (1967). O objetivo deste quadro é facilitar a identificação de dimensões do modo de monitoramento para operacionalizar a pesquisa empírica do presente estudo.

Quadro 3 - Modos de monitoramento de Aguilar

\begin{tabular}{|c|c|c|c|}
\hline \multicolumn{2}{|c|}{ Visão } & \multicolumn{2}{|c|}{ Procura } \\
\hline Não dirigida & Condicionada & Informal & Formal \\
\hline $\begin{array}{l}\text { - Informações obtidas ao } \\
\text { acaso } \\
\text { - Ausência de uma } \\
\text { necessidade específica } \\
\text { de informação } \\
\text { - Exposição geral às } \\
\text { informações do } \\
\text { ambiente } \\
\text { - Fontes e tipos diversos } \\
\text { de informação } \\
\text { - O reconhecimento de } \\
\text { relevância das } \\
\text { informações é vago } \\
\text { - Exploração do ambiente } \\
\text { - Alertas de mudança no } \\
\text { ambiente }\end{array}$ & $\begin{array}{l}\text { - Informações obtidas ao } \\
\text { acaso } \\
\text { - Atenção a um tipo } \\
\text { particular de informação } \\
\text { - Exposição direta às } \\
\text { informações } \\
\text { - Avaliação do } \\
\text { significado assim que } \\
\text { encontra a informação } \\
\text { - Sinalização quando um } \\
\text { monitoramento mais } \\
\text { intenso é necessário }\end{array}$ & $\begin{array}{l}\text { - Esforço intencional para } \\
\text { obter informações } \\
\text { - Procura de informação } \\
\text { específica } \\
\text { - Não se sabe de antemão } \\
\text { como encontrar a } \\
\text { informação } \\
\text { - Procura não estruturada } \\
\text { - Utilização de várias } \\
\text { fontes (leituras, } \\
\text { conversas, etc.) }\end{array}$ & $\begin{array}{l}\text { - Esforço intencional para } \\
\text { obter informações } \\
\text { - Procura de informação } \\
\text { específica } \\
\text { - Planejamento } \\
\text { - Procedimentos } \\
\text { - Metodologias } \\
\text { - Fornece embasamento } \\
\text { para decisões } \\
\text { estratégicas }\end{array}$ \\
\hline
\end{tabular}

Fonte: Adaptado de Aguilar (1967, p. 19-21) 


\subsubsection{A Tipologia de Monitoramento de Fahey e King}

Nesta seção, aborda-se a tipologia de modos de monitoramento proposta por Fahey e King (1977), a qual foi baseada na dimensão da regularidade do monitoramento. No final dos anos de 1970, esses autores concluíram que ainda havia poucos estudos sobre como as organizações monitoravam o ambiente externo. Assim, conduziram uma pesquisa em empresas para investigar este tema e também para estudar a relação entre o monitoramento e o planejamento estratégico.

Para desenvolver este estudo, os autores elaboraram uma classificação composta por três modos de monitoramento que variavam segundo a regularidade das atividades de monitoramento. A seguir, apresentam-se as características de cada uma das modalidades propostas:

a) monitoramento irregular - é um processo reativo que consiste em uma avaliação ambiental ad hoc motivada por um evento inesperado, sendo normalmente uma reação a uma crise. Caracteriza-se pela ênfase no curto prazo, e pouca atenção é dada para a identificação de tendências e eventos futuros do ambiente. O foco é retrospectivo, pois o objetivo é fornecer informações do ambiente para avaliar o que aconteceu para tomar decisões quanto à reação;

b) monitoramento regular - o monitoramento é um processo mais planejado, estruturado e proativo. Consiste em uma revisão regular, muitas vezes anual, do ambiente ou de alguns dos seus setores mais importantes. É proativo, pois questões relevantes ou decisões são elaboradas, e então o ambiente é analisado para o entendimento do impacto futuro. Porém, o foco ainda é retrospectivo, pois a situação atual e o passado recente são utilizados para projetar o futuro. Assim como no modo irregular, seu propósito é fornecer informações do ambiente para decisões; e

c) monitoramento contínuo - consiste no monitoramento com escopo abrangente, orientado ao futuro e de responsabilidade de um grupo especializado da organização ligado aos processos de planejamento estratégico e que emprega coleta 
estruturada de dados e sistemas de processamento dados. O objetivo é prover informações para decisões estratégicas.

Neste modelo, apesar da nomenclatura ser baseada na dimensão da regularidade, outras dimensões foram consideradas em sua elaboração. No Quadro 4, apresenta-se o resumo das demais dimensões abordadas nas alíneas anteriores, com o objetivo de facilitar a identificação de dimensões do modo de monitoramento para a operacionalização da pesquisa empírica do presente estudo.

Quadro 4 - Modos de monitoramento de Fahey e King

\begin{tabular}{|c|c|c|c|}
\hline \multirow{2}{*}{ Dimensões } & \multicolumn{3}{|c|}{ Modos de Monitoramento } \\
\hline & Irregular & Regular & Contínuo \\
\hline Tipo de atividade & Estudos ad hoc & $\begin{array}{l}\text { Estudos de atualização } \\
\text { periódica }\end{array}$ & $\begin{array}{l}\text { Coleta de dados estruturado } \\
\text { e sistemas de processamento }\end{array}$ \\
\hline Escopo do monitoramento & Eventos específicos & Eventos selecionados & $\begin{array}{l}\text { Ampla gama de } \\
\text { sistemas ambientais }\end{array}$ \\
\hline $\begin{array}{l}\text { Motivação para a } \\
\text { atividade }\end{array}$ & Ocorrência de crise & $\begin{array}{l}\text { Orientação a decisões ou } \\
\text { problemas }\end{array}$ & $\begin{array}{l}\text { Orientação ao processo de } \\
\text { planejamento }\end{array}$ \\
\hline $\begin{array}{l}\text { Natureza temporal da } \\
\text { atividade }\end{array}$ & Reativa & Proativa & Proativa \\
\hline $\begin{array}{l}\text { Horizonte de tempo para } \\
\text { os dados }\end{array}$ & Retrospectiva & $\begin{array}{l}\text { Primariamente presente } \mathrm{e} \\
\text { retrospectivo }\end{array}$ & Prospectivo \\
\hline $\begin{array}{l}\text { Horizonte de tempo para a } \\
\text { decisão }\end{array}$ & O presente e o curto prazo & Curto prazo & Longo prazo \\
\hline $\begin{array}{l}\text { Estrutura } \\
\text { organizacional }\end{array}$ & Equipes diversas & Equipes diversas & Departamento especializado \\
\hline
\end{tabular}

Fonte: Adaptado de Fahey e King (1977, p. 63, tradução nossa)

Observa-se que, diferentemente do modelo proposto por Aguilar (1967), esse modelo trata apenas da procura deliberada de informações no ambiente, tendo o monitoramento analisado como função da organização. O monitoramento involuntário, como os modos de visão centrados no indivíduo propostos pelo autor, não são abordados por Fahey e King (1977). 
Não obstante, também se observa nesse modelo um aumento do nível de formalização e estruturação do monitoramento na medida em que se avança de uma modalidade para a outra de maior regularidade. Outro aspecto a ser considerado é que não necessariamente esses modos de monitoramento são mutuamente exclusivos em uma organização, sendo possível sua coexistência. Porém, é razoável supor que a modalidade de monitoramento mais avançada existente na organização é limitada pelo maior nível de regularidade alcançado. Por exemplo, se uma organização pratica o modo de monitoramento contínuo, possivelmente seria capaz de praticar os modos de monitoramento regular e irregular. Na Figura 2, ilustra-se a abordagem evolutiva proposta para os modos de monitoramento de Fahey e King.

MODOS DE MONITORAMENTO

FAHEY E KING (1977)

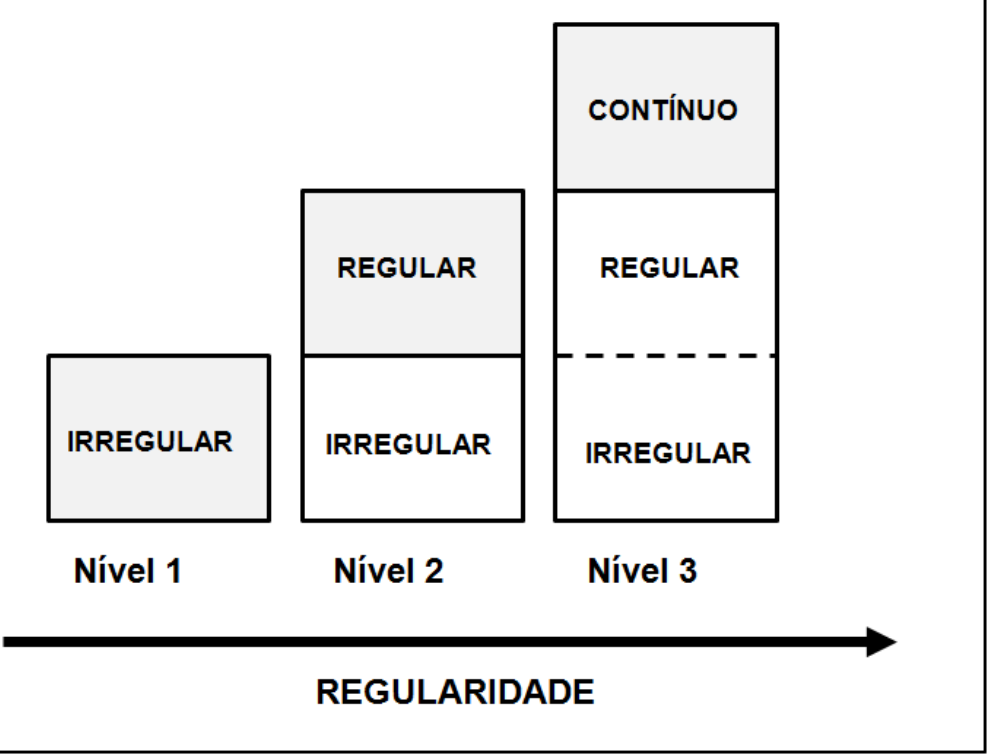

Figura 2 - Modos de monitoramento de Fahey e King

Fonte: Elaborado pela autora

Das doze empresas pesquisadas por Fahey e King (1977), apenas duas haviam alcançado o modo de monitoramento contínuo. Os gestores dessas empresas percebiam que as mudanças estavam ocorrendo com tamanha velocidade que sentiam dificuldades em se manter à frente dos eventos. Por esse motivo, as empresas se estruturavam para analisar continuamente o 
ambiente. Os autores chamam a atenção para o fato de essas empresas não terem conseguido integrar com sucesso o monitoramento ao processo de planejamento estratégico.

As demais empresas pesquisadas reconheciam a necessidade de prever as mudanças do ambiente para evitar consequências desastrosas, mas poucas estavam tentando adotar um modo monitoramento contínuo. Outra constatação interessante foi de que o monitoramento de setores do ambiente que demandavam conhecimento específico, como o tecnológico, era delegado para departamentos, mesmo havendo unidades corporativas sofisticadas de monitoramento.

Fahey e King (1977) consideram que a integração das atividades de monitoramento com o processo de planejamento estratégico é um indicador da institucionalização, aceitação e continuidade do monitoramento. Eles concluíram que existia uma tendência para a formalização e estruturação do monitoramento nas empresas, mas não encontraram evidências de que o monitoramento se tornaria um elemento regular no planejamento corporativo.

Posteriormente, Thomas (1980) fez um estudo com nove empresas, entre elas a Shell e a IBM, que considerava como empresas de porte muito superior ao porte das organizações pesquisadas por Fahey e King (1977). Nesse outro estudo, foram encontradas evidências de que o modo de monitoramento contínuo já era uma prática comum entre as organizações de grande porte, e novas dimensões foram sugeridas para complementar o modelo desses autores.

Primeiramente, Thomas (1980) propôs incluir as dimensões de permanência, periodicidade e difusão. A permanência referia-se ao tempo que o monitoramento vinha sendo praticado na empresa, a periodicidade referia-se à duração de um ciclo de monitoramento visto como um conjunto das fases de coleta, seleção, análise, síntese e comunicação das informações e a difusão referia-se ao aspecto da execução por indivíduos espalhados através de níveis hierárquicos e unidades. $\mathrm{O}$ autor também considerou que o desenvolvimento de competências é uma dimensão crítica do monitoramento. Em relação ao conteúdo do monitoramento, ele sugeriu que deveriam ser consideradas as dimensões de escopo (político, econômico, social e tecnológico), abrangência (cobertura geográfica) e projeção de futuro (5 anos, 10 anos, etc.). 
Thomas (1980) concluiu que o monitoramento deveria ser uma atividade coletiva e estruturada para ser efetivo. $\mathrm{O}$ crescente aumento da complexidade ambiental demandaria a criação de sistemas de monitoramento cada vez mais sofisticados que somente pela aquisição de experiência as empresas conseguiriam implementar. Porém, o apoio dos gestores ao planejamento de longo prazo tornava-se uma condição essencial para institucionalização do monitoramento.

Para finalizar esta seção, listam-se resumidamente as dimensões do monitoramento sugeridas por Thomas (1980):
a) porte da empresa;
b) permanência (tempo que o monitoramento é praticado na organização);
c) duração do ciclo de monitoramento (coleta, seleção, análise, etc.);
d) difusão (em larga escala entre os níveis e unidades);
e) coletividade;
f) experiência da organização em monitoramento;
g) apoio executivo;
h) escopo (político, econômico, social e tecnológico);
i) projeção de futuro (de 5 a 10 anos);
j) abrangência (cobertura geográfica); e
k) desenvolvimento de competências. 


\subsubsection{A Tipologia de Monitoramento de Jain}

Nesta seção, aborda-se a tipologia de modos de monitoramento proposta por Jain (1984), a qual foi empregada por Subramanian et al. (1993) em um estudo sobre a relação entre o monitoramento e a orientação estratégica. Esta tipologia foi baseada no conceito de que as organizações desenvolvem as suas práticas de monitoramento através de estágios evolutivos até que um sistema de monitoramento estruturado e formal seja implantado, o que demanda um certo tempo de amadurecimento.

Para explorar esta questão, o autor conduziu um estudo durante dois anos em 186 empresas, cujo principal resultado foi a proposta de um padrão de evolução das atividades de monitoramento caracterizado pelos estágios sequenciais descritos a seguir:

a) primitivo - o monitoramento ocorre sem qualquer esforço de gestão, pois o ambiente é considerado caótico. Ou seja, os gestores consideram que nada pode ser feito proativamente, exceto aceitar cada impacto que ocorrer. Dessa forma, os gestores não diferenciam informações de natureza estratégica das demais.

b) ad hoc - apesar de não existir nenhum sistema formal de monitoramento, algumas poucas áreas do ambiente são observadas mais cuidadosamente, sem que necessariamente sejam de cunho estratégico. As informações obtidas do ambiente são utilizadas apenas para compreendê-lo, e nenhuma ação proativa é estabelecida.

c) reativo - o monitoramento começa a ser valorizado, e esforços são feitos para buscar informações de diferentes áreas do ambiente, porém de forma não planejada. Ocorre um grande acúmulo de informações, pois todas parecem importantes já que não há critérios de relevância. Muitas informações não são nem olhadas, porém outras são analisadas, entendidas e armazenadas. Nessa fase, os gestores compreendem as ameaças e oportunidades que o ambiente proporciona, porém não assumem postura pioneira, aguardando os líderes de mercado darem o primeiro passo para depois segui-los. 
d) proativo - o monitoramento é estruturado e com foco em áreas consideradas críticas. Dedica-se tempo para estabelecer uma metodologia apropriada para o monitoramento, disseminar a informação coletada e incorporá-la na estratégia. Um diferencial importante dessa fase é a distinção entre o micromonitoramento que ocorre em nível de produto-mercado ou unidade de negócios estratégicos, e o macro monitoramento que foca os interesses comuns a toda a organização. Um sistema corporativo é criado para assegurar que esses dois tipos de monitoramento se complementem, sem que haja redundância de esforços.

Jain (1984) considera que o crescimento das empresas em tamanho e complexidade gera um aumento da dependência da organização de um planejamento estratégico para alcançar seus objetivos. Por esse motivo, o autor propôs que o monitoramento deve se tornar mais estruturado para aumentar as chances de antecipar e interpretar as mudanças significativas do ambiente que possam impactar o planejamento estratégico. $\mathrm{O}$ autor evidenciou uma relação entre a estruturação do monitoramento e o planejamento estratégico, a qual já havia sido identificada no estudo de Thomas (1980) em empresas de grande porte.

Quanto ao escopo de avaliação do ambiente, Jain (1984) sugere que as grandes corporações categorizam o ambiente em quatro áreas para coleta de informações ambientais: econômica, tecnológica, política e social. O foco em cada área depende da sua relevância para a corporação. Normalmente, a área econômica é a mais significativa pela sua importância e provavelmente, pelo fato de ser o estado da arte em projeções de futuro com os modelos econométricos, seguindo-se das áreas tecnológicas, políticas e sociais.

O autor também sugeriu que o monitoramento amadurece com o tempo, não sendo possível copiar o sistema de monitoramento de outra empresa, pois este necessita ser compatível com a cultura organizacional. Assim, deve ocorrer um processo evolutivo até que o monitoramento se torne um sistema formal e estruturado, sendo relevante para o planejamento da organização. O autor chegou a essa conclusão pelos resultados de que a maior parte das organizações com modo de monitoramento proativo havia começado essa atividade há pelo menos cinco anos. Por outro lado, nas organizações com modo de monitoramento primitivo, com necessidades de melhorias, essa prática era bem mais recente. Como qualquer outro processo, o monitoramento aperfeiçoa-se na medida em que novos métodos são concebidos e melhorados ao longo do tempo. 
Jain (1984) argumenta que o monitoramento é uma atividade muito difícil de ser realizada dada a complexidade do ambiente, concordando com as considerações de Aguilar (1967) e Denning (1973). Quando muito, seus resultados serão estimativas com alto grau de incerteza. $\mathrm{O}$ autor comenta que mesmo as análises econômicas do ambiente, apesar do uso de técnicas sofisticadas de modelagem matemática, podem revelar pouco ou nada do ambiente.

Os resultados da pesquisa de Jain (1984) indicaram que as quatro maiores dificuldades na prática do monitoramento são:
a) avaliar o impacto das tendências do ambiente no negócio;
b) relacionar o impacto ambiental com a estratégia corporativa;
c) fazer previsão de tendências para o futuro; e
d) filtrar o que é relevante do ambiente.

Para esses problemas, nenhum modelo teórico ou computacional pode ser implementado, e somente o julgamento e a criatividade humana podem tratá-los. Assim, dada essas dificuldades, é compreensível que o interesse das organizações em monitorar o ambiente possa ser limitado, o que de certa forma corrobora os resultados da pesquisa de Fahey e King (1977).

Jain (1984) considera que dois fatores são críticos para que o monitoramento seja formalmente estabelecido e estruturado. Primeiro, a alta direção deve acreditar na importância do monitoramento. Segundo, deve existir um planejamento estratégico formal, pois seu alinhamento com o ambiente depende dos resultados do monitoramento.

O modelo proposto pelo autor diferencia-se dos modelos apresentados nas seções anteriores do presente estudo por explorar a evolução estagiada dos modos de monitoramento e não apenas descrevê-los isoladamente. $\mathrm{O}$ autor considera que o monitoramento progride em estágios tanto pela incorporação de melhorias na maneira de adquirir e analisar as informações do ambiente quanto pela sua aplicação na elaboração das estratégias, conforme indicaram os resultados da pesquisa que realizou.

Entretanto, é interessante observar que há uma certa correspondência entre os modos de monitoramento propostos por Aguilar (1967) e os sugeridos por Jain (1984). O modo 
primitivo compara-se à visão não dirigida de Aguilar (1967), pois contempla apenas a exposição dos indivíduos às informações aleatórias sem um objetivo de busca. $\mathrm{O}$ modo $a d$ hoc relaciona-se à visão condicionada, pois os gestores continuam expostos às informações, porém começam a prestar atenção em determinados áreas. O modo reativo relaciona-se à procura informal, pois são estabelecidos objetivos de busca de informação, porém de forma não estruturada. $\mathrm{O}$ modo proativo relaciona-se à procura formal, pois o monitoramento passa a ser formal e estruturado, com o uso de métodos e praticado por áreas mais especializadas da organização.

Considera-se que a prática do monitoramento é um processo evolutivo no sentido de que a organização ao longo do tempo pode aumentar suas competências para lidar com a complexidade do ambiente. Nesse processo, destaca-se a dimensão da proatividade em relação às mudanças do ambiente. Entretanto, os modos de monitoramento mais simples e mais sofisticados podem coexistir da forma como Aguilar (1967) sugeriu, sendo o critério de escolha a relação custo versus benefício do esforço para obter a informação.

Um aspecto que chama a atenção no estudo de Jain (1984) é o fato de não estar detalhado o método utilizado para evidenciar o padrão evolutivo do monitoramento, ou seja, para evidenciar como o monitoramento nas organizações progrediu de um estágio para outro. Constata-se a classificação das empresas nos modos de monitoramento, porém não há uma descrição da abordagem de como o padrão evolutivo foi levantado nas organizações pesquisadas.

Na Figura 3, procura-se ilustrar a evolução estagiada do monitoramento proposta por Jain (1984) na medida em que o monitoramento adquire características de maior proatividade. Nesta figura, procura-se representar também a possibilidade de coexistência entre os modos de monitoramento, tomando-se em conta as proposições de Aguilar (1967). Ou seja, considera-se que a organização é capaz de empregar mais de um modo de monitoramento, porém com características limitadas pelo grau de maturidade alcançado pela organização em cada estágio evolutivo. 


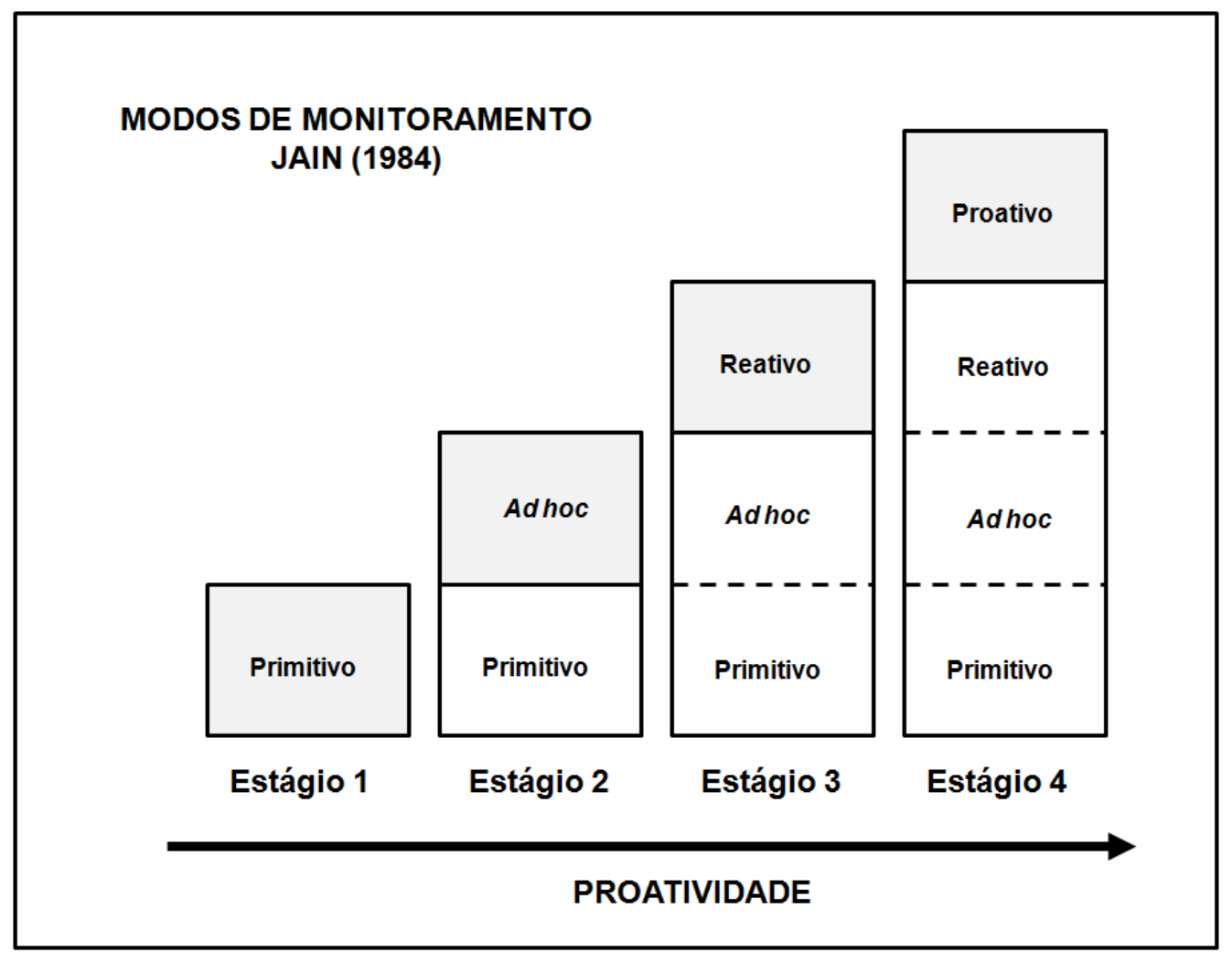

Figura 3 - Modos de monitoramento de Jain

Fonte: Elaborado pela autora

Para finalizar esta seção, apresenta-se, no Quadro 5, um resumo das principais características de cada um dos modos de monitoramento sugeridos por Jain (1984). O objetivo deste quadro é facilitar a identificação de dimensões do modo de monitoramento para operacionalizar a pesquisa empírica do presente estudo. 
Quadro 5 - Modos de monitoramento de Jain

\begin{tabular}{|c|c|c|c|}
\hline Primitivo & Ad Hoc & Reativo & Proativo \\
\hline $\begin{array}{l}\text { - Monitoramento sem } \\
\text { esforço. } \\
\text { - Exposição à informação } \\
\text { sem um propósito. } \\
\text { - Não há diferenciação } \\
\text { entre informação } \\
\text { estratégica e não } \\
\text { estratégica. } \\
\text { - Raramente a informação } \\
\text { está relacionada a uma } \\
\text { decisão estratégica. } \\
\text { - Os gestores consideram o } \\
\text { ambiente aleatório e } \\
\text { inevitável. } \\
\text { - Aceitação dos impactos } \\
\text { do ambiente sem reação. }\end{array}$ & $\begin{array}{l}\text { - Monitoramento para } \\
\text { melhorar o entendimento } \\
\text { sobre eventos } \\
\text { específicos. } \\
\text { - Atenção para um possível } \\
\text { impacto do ambiente. } \\
\text { - Não há sistema formal de } \\
\text { monitoramento. } \\
\text { - As informações não } \\
\text { necessariamente são } \\
\text { utilizadas para o } \\
\text { planejamento estratégico. }\end{array}$ & $\begin{array}{l}\text { - Monitoramento para } \\
\text { elaborar uma reação ao } \\
\text { ambiente ou mercado. } \\
\text { - Analisa o ambiente para } \\
\text { proteger o futuro. } \\
\text { - Esforço não planejado } \\
\text { - Pode ocorrer coleta de } \\
\text { informações em excesso. } \\
\text { - Característico de } \\
\text { empresas que aguardam } \\
\text { os líderes de mercado } \\
\text { reagir às ameaças e } \\
\text { oportunidades do } \\
\text { ambiente. }\end{array}$ & $\begin{array}{l}\text { - Monitoramento } \\
\text { estratégico para aumentar } \\
\text { a vantagem competitiva. } \\
\text { - Analisa o ambiente para } \\
\text { um futuro desejado. } \\
\text { - Foco nas áreas do } \\
\text { ambiente consideradas } \\
\text { críticas. } \\
\text { - Coleta de informações } \\
\text { específicas. } \\
\text { - Esforço estruturado e } \\
\text { intencional. } \\
\text { - Emprego de } \\
\text { metodologias } \\
\text { apropriadas. } \\
\text { - Distribuição da } \\
\text { informação coletada. } \\
\text { - Utilização da informação } \\
\text { para as estratégias. } \\
\text { - Diferenciação e } \\
\text { integração entre } \\
\text { monitoramento macro } \\
\text { (corporativo) e micro } \\
\text { (unidades de negócio). }\end{array}$ \\
\hline
\end{tabular}

Fonte: Adaptado de Jain (1984, p. 118) 


\subsubsection{A Tipologia Organizacional de Daft e Weick}

Nesta seção, aborda-se o estudo de Daft e Weick (1984) no qual as organizações são descritas como sistemas de interpretação que atribuem significado às informações coletadas do ambiente para tomar decisões e gerar ações. Esses autores, de certa forma, ampliaram as fronteiras do estudo de Aguilar (1967, p. 15), cujo "foco era o reconhecimento, a procura e a comunicação de informação externa por indivíduos de uma organização, excluindo-se a análise e interpretação desta informação". O autor reconhecia que a distinção entre procura e interpretação nem sempre poderia ser mantida, pois se tratam de partes de um mesmo sistema.

Em seu estudo teórico, Daft e Weick (1984) modelaram as organizações como um sistema de interpretação do ambiente, composto por três processos dos quais o monitoramento é o primeiro. Na Figura 4, ilustra-se esse sistema, descrevendo-se seus processos logo a seguir.

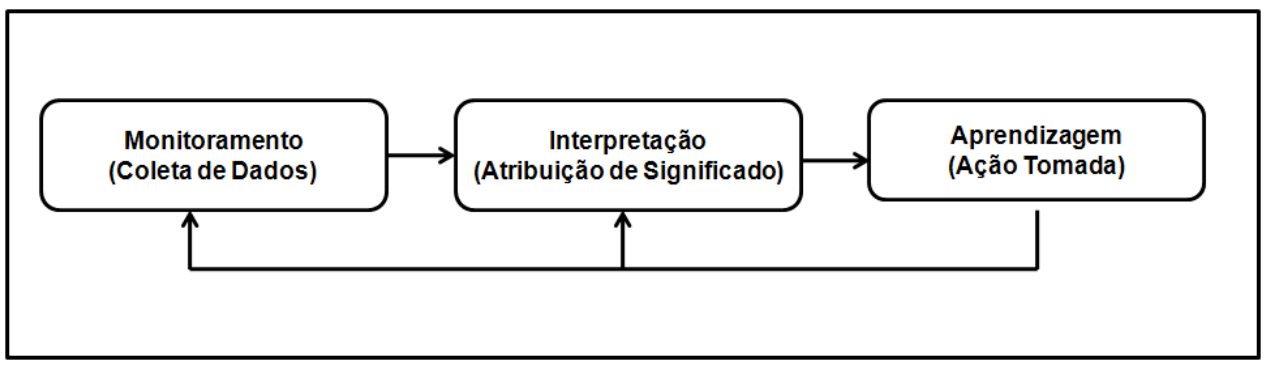

Figura 4 - Sistema de interpretação organizacional

Fonte: Adaptado de Daft e Weick (1984, p. 286, tradução nossa)

a) monitoramento - é a coleta de informações do ambiente através de processos formais e/ou contatos pessoais com o objetivo de prover informações aos gestores;

b) interpretação - ocorre quando os indivíduos atribuem um significado às informações coletadas. A interpretação organizacional é formalmente definida como o processo de traduzir eventos e desenvolver entendimentos compartilhados e esquemas conceituais entre os membros da alta direção; e 
c) aprendizagem: ocorre quando a organização adquire conhecimento a partir das suas ações sobre o ambiente. A aprendizagem pode demandar a coleta de mais informações, bem como novas interpretações podem ser geradas em um loop de feedback, conforme mostrado anteriormente na Figura 4.

Daft e Weick (1984) sugerem que a forma da organização interpretar o ambiente depende de como os gestores percebem o ambiente em relação às seguintes dimensões:

a) analisabilidade do ambiente: é o quanto é possível encontrar respostas no ambiente, percebendo-se o ambiente como analisável ou como não analisável;

b) intromissão da organização: é o quanto as informações podem ser procuradas de forma deliberada no ambiente, diferenciando as organizações entre ativas e passivas.

Com base nessas dimensões, esses autores propuseram uma tipologia de quatro modos de interpretação organizacional do ambiente, e cada um caracterizará uma forma diferenciada de monitoramento do ambiente. A seguir, descrevem-se os perfis de organizações sugeridos pelos autores:

a) atuação - enacting - as organizações percebem o ambiente como não analisável e são ativas. Coletam informações através da experiência e testes de novos comportamentos e avaliação dos resultados. Desenvolvem produtos baseadas no que acreditam que possa ser vendido e, não, em análises e previsões de mercado. Normalmente, são empresas que criam tendências no mercado através da inovação.

b) descoberta - discovering - as organizações consideram o ambiente como analisável e são ativas. Ou seja, entendem que as respostas para perguntas tais como "o que os clientes querem comprar" estão no ambiente e basta procurálas. Há o emprego de pesquisas de mercado, de análise de tendências e de previsões para antecipar problemas e oportunidades. A interpretação organizacional das expectativas e características do ambiente são baseadas em buscas formais de dados. 
c) visão condicionada - conditioned viewing - as organizações percebem o ambiente como analisável, porém são passivas. Ou seja, acreditam que as respostas estão no ambiente, mas esperam que esse as disponibilize. Condicionaram-se a utilizar documentos de rotina, relatórios, publicações e sistemas de informações que em algum momento foram importantes. A visão do ambiente fica limitada a essas fontes tradicionais de informações.

d) visão não dirigida - undirected viewing - as organizações são passivas e assumem o ambiente como sendo não analisável. Portanto, não usam dados quantitativos e objetivos. Para criar a percepção do ambiente, os gestores baseiam-se em informações de natureza soft obtidas através de contatos pessoais e encontradas ao acaso.

Daft e Weick (1984) basearam-se nos modos de monitoramento propostos por Aguilar (1967). A abordagem da visão caracteriza as organizações que interpretam o ambiente de forma passiva e a abordagem da procura, as organizações que interpretam o ambiente de forma ativa. Dessa forma, resulta que as organizações com os modos atuação e descoberta de interpretação do ambiente são as que procuram ativamente por informações no seu ambiente externo. 
Na Figura 5, ilustram-se os modos de interpretação do ambiente propostos pelos autores:

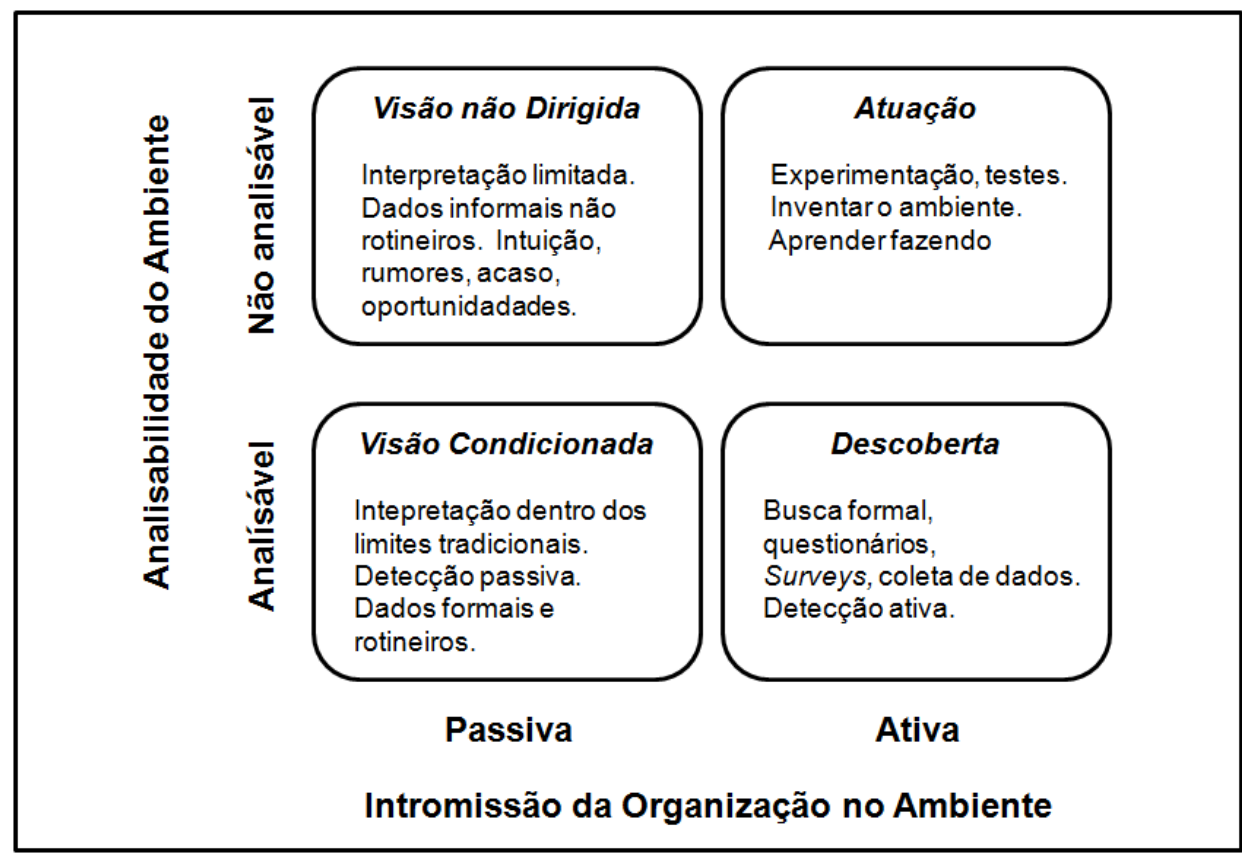

Figura 5 - Modos de interpretação organizacional de Daft e Weick

Fonte: Adaptado de Daft e Weick (1984, p. 289, tradução nossa)

Daft e Weick (1984) previram como seriam os processos de monitoramento, interpretação e tomada de decisão com base em características específicas de cada um desses modos de interpretação. A seguir, listam-se essas características para um melhor entendimento do modelo.

a) Características do Processo de Monitoramento

- Fontes: (1) externas - os gestores obtêm diretamente a informação fora da organização; (2) internas - as informações são coletadas diretamente no ambiente externo por pessoas de dentro da organização e fornecidas aos gestores por outros canais de comunicação; (3) pessoais - as informações são obtidas através do contato direto com outras pessoas; e (4) impessoais - as informações são obtidas a partir de documentos escritos como jornais, revistas, relatórios emitidos por sistemas de informática, etc. 
- Aquisição de dados: é o modo como a organização coleta informações do ambiente externo. Daft e Weick (1984) adotaram a tipologia de Aguilar (1967) associando as organizações com modo de interpretação descoberta ao modo de monitoramento procura formal. As características do modo de monitoramento procura informal foram atribuídas às organizações do tipo atuação. Observa-se que essas duas categorias de organizações são ativas na aquisição de informações do ambiente. Para as organizações passivas do tipo visão não dirigida e visão condicionada, foram associadas as características dos modos de monitoramento de mesmo nome da tipologia de Aguilar (1967).

b) Características do Processo de Interpretação

- Redução da equivocalidade - refere-se às informações que não são claras e podem ser interpretadas de várias maneiras. A redução da equivocalidade requer que se discutam as interpretações até que seja alcançado um entendimento comum e que tenha sentido.

- Regras de montagem - tratam-se dos processos ou diretrizes da organização para gerar uma interpretação coletiva das informações. Em geral, quanto maior a equivocalidade menor o número de regras utilizadas para se montar uma interpretação, pois há maior incerteza quanto ao significado exato da informação. Também, quanto maior a equivocalidade tanto maior é a quantidade de ciclos de interação entre os gestores para estabelecer uma interpretação comum.

c) Características do Processo de Tomada de Decisão e Estratégia

- Tomada de Decisão - na literatura há várias formas das organizações tomarem decisões, entre as quais: (1) pesquisa problemística - resgata-se a solução de problemas anteriores para solucionar um problema novo; (2) formação de coalizão - os gestores investem tempo em analisar o que ocorreu para chegar a um consenso sobre o problema e então tomar uma decisão; e (3) processo incremental de tentativa e erro - o avanço ocorre em etapas, para que se ganhe 
informação sobre o ambiente através de experiências e resultados. Em ambientes analisáveis, as decisões são lógicas e racionais e as simulações com o uso de computadores podem ser empregadas para a tomada de decisão.

- Formulação de estratégias - Miles e Snow (1978, 2003) propuseram quatro tipos de orientações estratégicas: Prospectora, Analítica, Defensiva e Reativa. Daft e Weick (1984) associaram cada modo de interpretação a um desses tipos, considerando que a formulação de estratégia é responsabilidade da alta direção e deve estar relacionada às condições ambientais que influenciam os modos de interpretação.

É interessante observar que Daft e Weick (1984) fixaram as características de monitoramento e orientação estratégica para cada um dos modos de interpretação do ambiente que propuseram. É oportuno lembrar que Aguilar (1967) afirma que uma organização pode praticar mais de um modo de monitoramento, dependendo da relação custo versus benefício para obter a informação necessária. Choo (1999) afirma que o monitoramento não é uma atividade monolítica e que inclui tanto visualizar a informação quanto procurá-la. Nesse caso, pode-se considerar que os modos de monitoramento fixados por Daft e Weick (1984) são modos predominantes e não exclusivos de adquirir informação do ambiente. Ou ainda, refletem o nível de maturidade da função de monitoramento necessário para amparar a orientação estratégica escolhida pela alta direção.

Para finalizar esta seção, apresenta-se o Quadro 6 com um resumo das principais características dos processos de cada um dos modos de interpretação do ambiente sugeridos por Daft e Weick (1984). O objetivo desse quadro é facilitar a identificação de dimensões do modo de monitoramento para operacionalizar a pesquisa empírica do presente estudo. 
Quadro 6 - Modos de interpretação do ambiente propostos por Daft e Weick

\begin{tabular}{|c|c|c|}
\hline & \multicolumn{2}{|c|}{ MODOS DE INTERPRETAÇÃO ORGANIZACIONAL } \\
\hline 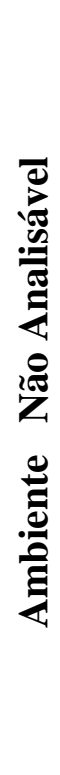 & $\begin{array}{l}\text { VISÃO NÃO DIRIGIDA } \\
\text { 1. Monitoramento } \\
\text { - Fonte: externas, pessoais } \\
\text { - Aquisição de dados: não há depto. de } \\
\text { monitoramento, contatos e relatórios irregulares, } \\
\text { informações casuais } \\
\text { 2. Interpretação } \\
\text { - Muita redução da equivocalidade } \\
\text { - Poucas regras, muitos ciclos } \\
\text { 3. Estratégia e Tomada de Decisão } \\
\text { - Orientação estratégica: Reativa } \\
\text { - Processo de Decisão: formação de coalizão }\end{array}$ & $\begin{array}{l}\text { ATUAÇÃo } \\
\text { 1. Monitoramento } \\
\text { - Fonte: externas, pessoais } \\
\text { - Aquisição de dados: não há depto. de } \\
\text { monitoramento, contatos e relatórios irregulares } \\
\text { e feedbacks do ambiente, informações seletiva } \\
\text { 2. Interpretacão } \\
\text { - Alguma redução da equivocalidade } \\
\text { - Regras e ciclos moderados } \\
\text { 3. Estratégia e Tomada de Decisão } \\
\text { - Orientação estratégica: Prospectora } \\
\text { - Processo de Decisão: tentativa e erro } \\
\text { incremental }\end{array}$ \\
\hline 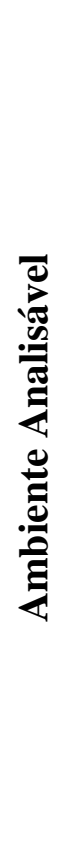 & 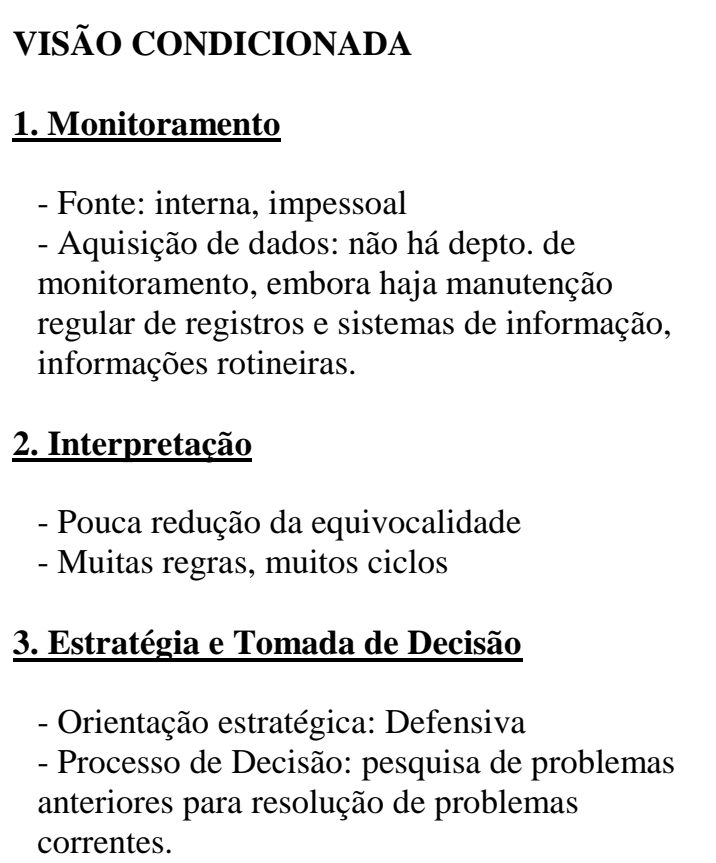 & $\begin{array}{l}\text { DESCOBERTA } \\
\text { 1. Monitoramento } \\
\text { - Fonte: interna, impessoal } \\
\text { - Aquisição de dados: depto. separado, estudos } \\
\text { especiais e relatórios, informação extensiva. } \\
\text { 2. Interpretacão } \\
\text { - Pouca redução da equivocalidade } \\
\text { - Muitas regras e ciclos moderados } \\
\text { 3. Estratégia e Tomada de Decisão } \\
\text { - Orientação estratégica: Analítica } \\
\text { - Processo de Decisão: análises de sistemas, } \\
\text { computação }\end{array}$ \\
\hline & Organização Passiva & Organização Ativa \\
\hline
\end{tabular}

Fonte: Adaptado de Daft e Weick (1984, p. 291, tradução nossa) 


\subsubsection{A Tipologia Organizacional de Choo}

Nesta seção, aborda-se o estudo de Choo (2002) que apresenta uma revisão do modelo proposto por Daft e Weick (1984). Nesse estudo, as organizações são abordadas não apenas como sistemas de interpretação do ambiente, mas também como sistemas de aprendizagem. Choo (2002) comenta que os modelos monitoramento-interpretação encontraram suporte no conhecimento empírico e então sugeriu analisar o monitoramento como um sistema informacional sujeito a influências internas e externas à organização.

Para esta análise, Choo (2002) apresentou um modelo no qual o monitoramento é uma forma de comportamento da organização com o objetivo de analisar o ambiente em três etapas:

a) identificação da necessidade de informação: refere-se ao escopo e foco do monitoramento, em particular dos setores a serem monitorados;

b) procura da informação: refere-se às fontes de informação que são usadas, bem como os métodos e sistemas empregados para monitorar o ambiente. A forma de procurar a informação está relacionada com o tamanho da organização, com a dependência e percepção do ambiente, com a experiência em monitoramento e com o direcionamento da indústria à qual a organização pertence; e

c) uso da informação: refere-se à utilização da informação principalmente para o planejamento estratégico e para a melhoria do aprendizado e desempenho da organização.

$\mathrm{O}$ autor considera que o monitoramento do ambiente é influenciado por vários fatores externos, que chamou de dimensões situacionais, as quais se relacionam principalmente à incerteza do ambiente externo gerada pela complexidade. $\mathrm{O}$ monitoramento também seria influenciado pelos fatores internos como as estratégias organizacionais, pois o monitoramento deve ter a estruturação e o escopo necessário para fornecer informações que suportem o desenvolvimento e busca de estratégias. Ainda, ocorreria a influência das 
características gerenciais como o nível hierárquico, especialização funcional e estilo cognitivo dos tomadores de decisões.

O modelo proposto por Choo (2002) é ilustrado na Figura 6, representando-se a influência das dimensões situacionais, das estratégias organizacionais e do estilo gerencial sobre a análise do ambiente.

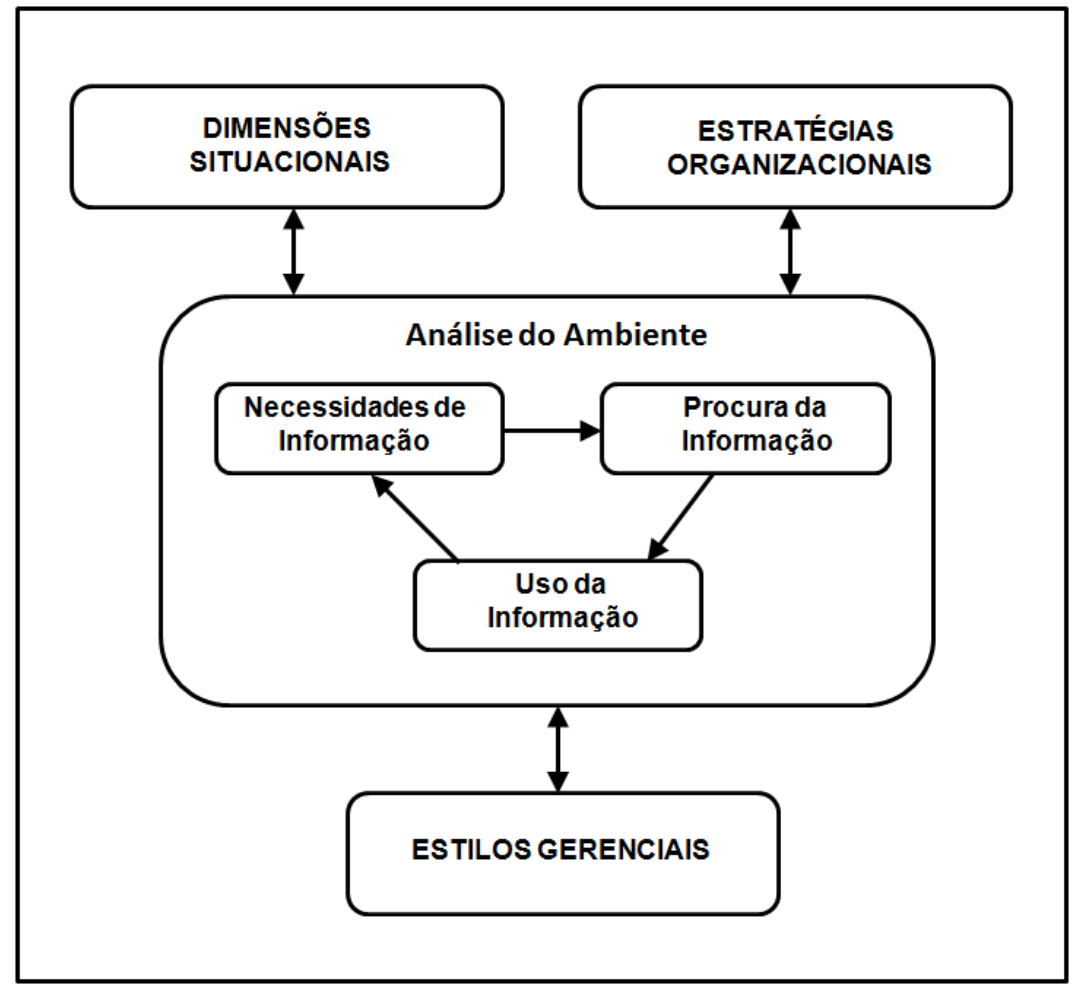

Figura 6 - Modelo conceitual da análise do ambiente

Fonte: Adaptado de Choo (2002, p. 98, tradução nossa) 
No Quadro 7, apresenta-se a revisão proposta por Choo (2002) para o modelo de Daft e Weick (1984). O objetivo deste quadro é mostrar que o tipo da informação a ser coletada está relacionado com a necessidade de informação, que o tipo de fonte de informação é influenciado pelo modo de procura por informação e que a estratégia bem como o processo decisório estão relacionados com o uso da informação. Observa-se que Choo (2002) não alterou a estrutura do modelo proposto por Daft e Weck (1984), apenas sugeriu uma perspectiva diferente para caracterizar as organizações como sistemas de aprendizagem.

Quadro 7- Modos de monitoramento e interpretação de Choo

\begin{tabular}{|c|c|c|c|c|c|}
\hline \multirow{10}{*}{ 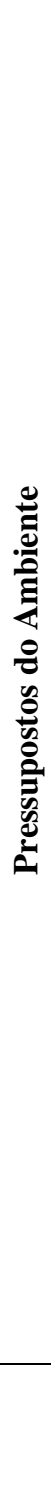 } & \multirow{4}{*}{ 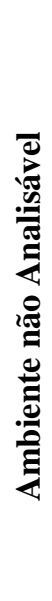 } & \multicolumn{2}{|c|}{ VISÃO NÃO DIRIGIDA } & \multicolumn{2}{|r|}{ ATUAÇÃO } \\
\hline & & $\begin{array}{l}\text { Necessidade de } \\
\text { Informação }\end{array}$ & $\begin{array}{l}\text { Não há rotinas, dados informais. } \\
\text { Intuição, rumor, acaso, } \\
\text { oportunidade. }\end{array}$ & $\begin{array}{l}\text { Necessidade de } \\
\text { Informação }\end{array}$ & $\begin{array}{l}\text { Experimentação, testes. Criação de } \\
\text { ambiente próprio. Aprender } \\
\text { fazendo. }\end{array}$ \\
\hline & & $\begin{array}{l}\text { Procura por } \\
\text { Informação }\end{array}$ & $\begin{array}{l}\text { Fontes pessoais, externas. } \\
\text { Informação casual. Contato } \\
\text { irregular, relatórios. Não há } \\
\text { unidade de monitoramento. }\end{array}$ & $\begin{array}{l}\text { Procura por } \\
\text { Informação }\end{array}$ & $\begin{array}{l}\text { Fontes pessoais, externas. Irregular, } \\
\text { relatórios, feedback. Informação } \\
\text { seletiva. Não há unidade de } \\
\text { monitoramento. }\end{array}$ \\
\hline & & $\begin{array}{c}\text { Uso da } \\
\text { Informação }\end{array}$ & $\begin{array}{l}\text { Muita redução de equivocalidade. } \\
\text { Poucas regras, muitos ciclos. } \\
\text { Estratégia Reativa. Formação de } \\
\text { coalizão. }\end{array}$ & $\begin{array}{c}\text { Uso da } \\
\text { Informação }\end{array}$ & $\begin{array}{l}\text { Alguma redução de equivocalidade. } \\
\text { Regras moderadas e ciclos. } \\
\text { Estratégia Prospectora. Processo } \\
\text { incremental de decisão. }\end{array}$ \\
\hline & & \multicolumn{2}{|c|}{ VISÃO CONDICIONADA } & \multicolumn{2}{|c|}{ DESCOBERTA } \\
\hline & \multirow{3}{*}{ 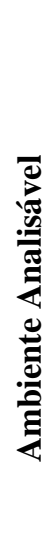 } & $\begin{array}{l}\text { Necessidade de } \\
\text { Informação }\end{array}$ & $\begin{array}{l}\text { Rotinas, dados formais. Dados } \\
\text { formais. Baseada em limites } \\
\text { tradicionais. }\end{array}$ & $\begin{array}{l}\text { Necessidade de } \\
\text { Informação }\end{array}$ & $\begin{array}{l}\text { Informação formal. Questionários, } \\
\text { pesquisas, Descobrir a resposta } \\
\text { correta. }\end{array}$ \\
\hline & & $\begin{array}{l}\text { Procura por } \\
\text { Informação }\end{array}$ & $\begin{array}{l}\text { Detecção passiva. Fontes } \\
\text { impessoais, internas. Regular, } \\
\text { manutenção de registro e sistemas } \\
\text { de informação. }\end{array}$ & $\begin{array}{l}\text { Procura por } \\
\text { Informação }\end{array}$ & $\begin{array}{l}\text { Detecção ativa. Fontes internas, } \\
\text { impessoais. Estudos especiais, } \\
\text { informação extensiva. Existe } \\
\text { unidade de monitoramento. }\end{array}$ \\
\hline & & $\begin{array}{c}\text { Uso da } \\
\text { Informação }\end{array}$ & $\begin{array}{l}\text { Pouca redução de equivocalidade. } \\
\text { Muitas regras, poucos ciclos. } \\
\text { Estratégia Defensiva. Processo } \\
\text { programado de decisão. }\end{array}$ & $\begin{array}{c}\text { Uso da } \\
\text { Informação }\end{array}$ & $\begin{array}{l}\text { Pouca redução de equivocalidade. } \\
\text { Muitas regras, ciclos moderados. } \\
\text { Estratégia Analítica. Processo } \\
\text { analítico de decisão. }\end{array}$ \\
\hline & & \multicolumn{2}{|c|}{ Organização Ativa } & \multicolumn{2}{|c|}{ Organização Passiva } \\
\hline & & \multicolumn{4}{|c|}{ Intrusão da Organização } \\
\hline
\end{tabular}

Fonte: Adaptado de (Choo, 2002, p. 95, tradução nossa) 
Choo (2002) contribuiu também com um estudo da aplicação da tipologia proposta por Aguilar (1967) para o monitoramento na Internet. Nesse estudo, a Internet é tratada como um espaço social de informação, sendo tanto um meio de comunicação quanto de publicação. Como consequência, a Internet disponibiliza uma infinidade de fontes de informação do ambiente externo.

A seguir, apresentam-se as considerações do autor para cada um dos modos de monitoramento de Aguilar (1967), quando aplicados à Internet:

a. visão não dirigida - o imediatismo e a variedade torna a Web um meio útil para captar ao acaso, sinais fracos sobre tendências e fenômenos que podem se tornar relevantes ao longo do tempo. Através de um monitoramento amplo na Internet, os indivíduos são expostos a um grande número de diferentes fontes de informações, as quais podem fornecer informações atualizadas e uma variedade de pontos de vista;

b. visão condicionada - para as áreas de atenção identificadas na visão não dirigida, obtém-se mais informações na Web permitindo criar um sentido inicial para um fenômeno emergente. Choo (2002) observa que muitos acadêmicos, autores, consultores, observadores de indústrias e especialistas usam a Web para compartilhar percepções e previsões. Pode-se fazer uma avaliação com boa relação custo-benefício, sem que se invista tempo e esforço em uma procura formal;

c. procura informal - o autor considera que a importância potencial de um determinado tópico já foi definida e inicia-se uma pesquisa para construir o conhecimento específico e aprofundar o entendimento de suas implicações e consequências. A Web disponibiliza mecanismos de comunicação e busca que permitem localizar informação sem um dispêndio significativo de tempo e custo; e

d. procura formal - há um esforço sistemático e estruturado para coletar informações sobre um tópico com o objetivo de apoiar uma decisão e definir um curso de ação. Essa procura é considerada formal, porque segue procedimentos e 
metodologias pré-estabelecidas. Nesse caso, as informações são preferencialmente obtidas na Web em fontes percebidas como referência ou de sistemas e serviços de informação que asseguram qualidade e precisão nos dados. As fontes primárias são usadas em buscas formais, e a Web permite identificar e contatar especialistas no mundo todo.

Choo (2002) propõe que, na medida em que se avança da visão não dirigida para a procura formal, ocorre uma necessidade maior de informações específicas e acionáveis, cuja confiabilidade possa ser avaliada. Nos modos de monitoramento do tipo visão na Web, captase o maior número possível de sinais em uma varredura ampla e superficial e nos modos do tipo procura, busca-se a profundidade, a especificidade e a precisão das informações.

$\mathrm{Na}$ Figura 7, mostra-se como o autor considera que os quatro modos de monitoramento de Aguilar (1967) podem ser representados por um contínuo de coleta de informação online e métodos de comunicação que variam:

a) da navegação na Web de forma caótica e informal aos serviços formais de bases online;

b) de fontes secundárias às fontes primárias;

c) da comunicação de vários para vários (ex.: newsgroups, listas de discussão) para a comunicação de uma para um (ex.: email); e

d) de um foco vago para um foco refinado. 


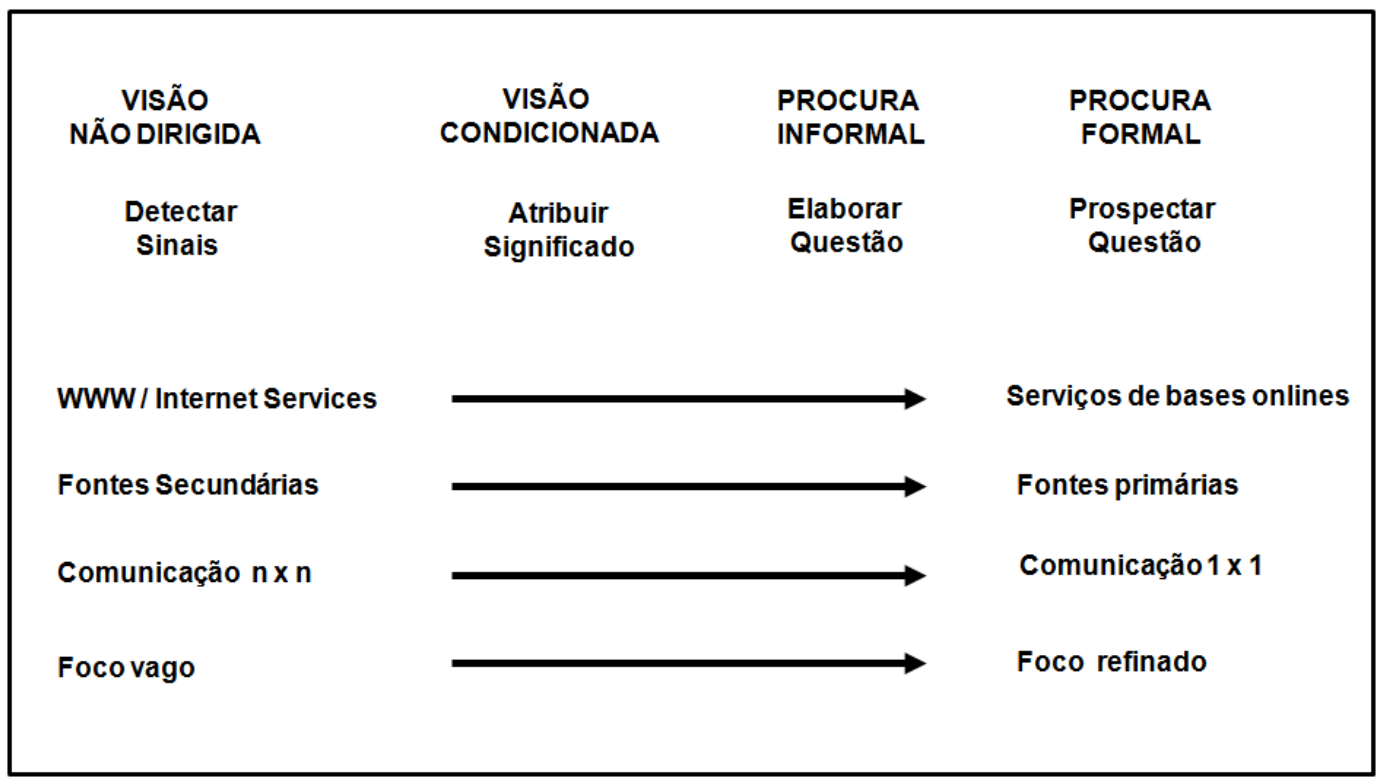

Figura 7 - Modelo de monitoramento de informações na Web

Fonte: Adaptado de Choo (2002, p. 198, tradução nossa)

Choo (2002) descreve quatro categorias de serviços disponíveis na Web para compartilhamento e recuperação da informação: navegação, pushing, busca e comunicação. $\mathrm{O}$ autor considera que esses serviços relacionam-se aos quatro modos de monitoramento de Aguilar (1967) da seguinte forma:

a) serviços de navegação - fornecem o escopo e a cobertura ampla demandada pelo modo de monitoramento de visão não dirigida. A navegação na Web ocorre através do uso de browsers para acesso aos sites;

b) serviços de pushing - consistem na automatização e customização da entrega de informações sobre um tópico específico através da Web, sendo adequados para o modo de monitoramento de visão condicionada;

c) serviços de busca - são apropriados para a procura informal, permitindo procurar por uma informação específica para aumentar o conhecimento e o entendimento a respeito de uma questão. Observa-se que, na atualidade, o Google é um exemplo desses serviços; e 
d) serviços de comunicação - suportam a procura formal permitindo rastrear pessoas que sejam referências em determinadas áreas de conhecimento ou grupo para ação ou tomada de decisão.

Choo (2002) considera que a Web não é apenas uma rede de informação, mas um espaço compartilhado, no qual a informação é acessada, comunicada e manipulada, promovendo o autoaprendizado e a solução de problemas. Para organizações que possuem intranets, essa infraestrutura pode promover o compartilhamento de informações e conhecimento. Comunidades podem emergir através da auto-organização, reunindo indivíduos com interesses comuns na organização para trocar experiências e descobertas, além de estabelecerem conversações online.

O autor também considera que, apesar de a Web ser fácil de usar, algumas questões críticas ainda precisam ser tratadas:
a) Como gerenciar o overload de informação?
b) Como avaliar a qualidade das informações online?
c) Como recuperar as informações mais relevantes?

Choo (2002) conclui que as pessoas nas organizações precisam de treinamento e assistência para fazer uma utilização eficiente e eficaz da Web para o monitoramento. Elas precisam aprender a diagnosticar os resultados das buscas e refinar as estratégias de busca, avaliar a qualidade da informação disponível nas páginas da Web e compreender quando e como complementar o uso da Web com fontes de informação que não estão disponíveis online.

Finaliza-se esta seção destacando-se que a tipologia de modos de monitoramento de Aguilar (1967) foi empregada para descrever o monitoramento na Web, que foi popularizada somente a partir dos anos de 1990. Esse fato indica que essa tipologia adquiriu contornos clássicos, sendo aplicável para temas contemporâneos. 


\subsection{A Tipologia de Orientações Estratégicas de Miles e Snow}

Para atingir os objetivos deste estudo, escolheu-se a tipologia proposta por Miles e Snow $(1978,2003)$ para classificar as organizações quanto à orientação estratégica. Essa tipologia faz parte de um modelo criado para explicar como as organizações se adaptam ao ambiente e foi desenvolvido a partir do estudo da literatura e de uma pesquisa que os autores conduziram em empresas de setores diversos. Os autores também descrevem a estrutura e os processos organizacionais característicos para cada tipo estratégico.

Esse modelo, publicado em 1978 e revisado em 2003, tem sido amplamente utilizado em pesquisas, e sua tipologia tem sido bastante duradoura, testada e aplicada (FISS, 2011). Para verificar sua utilização em trabalhos científicos, realizou-se uma pesquisa na base de publicações Web of Knowledge da Thomsom Reuters, procurando-se pela palavra-chave "Miles and Snow" nos campos título, resumo e palavras-chave nas publicações do período de 1978 a 2012. Como resultado, encontraram-se 164 publicações com 3.538 citações, excluindo-se as autocitações. No Gráfico 5, apresenta-se a distribuição anual de publicações na base $W o K$ nos últimos dez anos, totalizando 90 publicações.

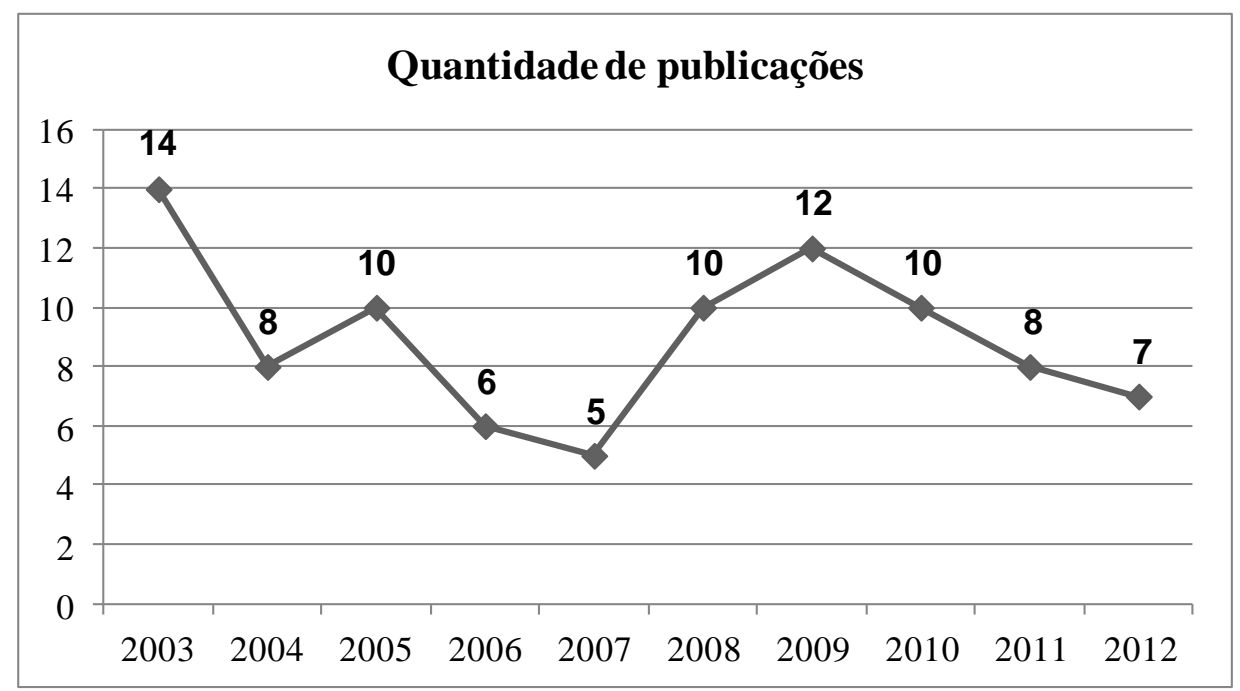

Gráfico 5 - Publicações anuais mencionando o modelo de Miles e Snow Fonte: WEB OF KNOWLEDGE (2013) 
Vieira et al. (2012) realizaram uma revisão bibliográfica na bases dos congressos nacionais de gestão 3E’s - ENANPAD, EGEPE e ENEGEP - abrangendo eventos de 1997 a 2010. Os autores também utilizaram a palavra-chave "Miles e Snow" para busca nos campos título, resumo e palavras-chave dos autores. Como resultado, foram selecionados 235 artigos de um universo de 1.258 artigos na categoria "Estratégia" correspondentes a 18,6\%. Desses artigos, $166(70,6 \%)$ foram apresentados no período de 2003 a 2010. Vieira et al. (2012) concluíram que os estudos de Miles e Snow estão cada vez mais presentes no que tange às pesquisas apresentadas em congressos de gestão no Brasil.

Atribui-se grande parte da validade e duração desse modelo às ideias centrais adotadas por seus autores e sumarizadas a seguir:

a) as organizações, além de se adaptarem às condições do ambiente, também criam seus próprios ambientes através de uma série de escolhas estratégicas relativas a mercados, produtos, tecnologias e etc. Esse conceito foi explorado por Weick (1969, 1977), denominando-se enactment;

b) a estratégia pode ser inferida a partir do comportamento da organização e, conceitualmente, é possível associar estratégia com intenção e estrutura com ação. Os autores atribuem esse conceito a Mintzberg (1976) e consideram que as decisões estratégicas modelam a estrutura e os processos da organização, na medida em que são implementadas; e

c) a estrutura e os processos da organização, apesar de modelados pela estratégia, acabam por delimitá-la (MARCH; SIMON, 1958). Com o tempo, a organização passa a fazer muito bem determinadas coisas, mas acaba ficando com capacidade limitada para outras. Cria-se uma inércia que dificulta buscar atividades fora da operação rotineira. Ainda, a estrutura e os processos acabam por delimitar também a amplitude do monitoramento do ambiente, pois o foco torna-se direcionado.

É oportuno comentar que o conceito apresentado na alínea "c" anterior vincula-se diretamente ao tema central do presente estudo, pois sugere a existência de uma relação entre a orientação estratégica e o modo de monitoramento. Encontram-se na literatura evidências de que, quanto 
mais amplo o foco do monitoramento, mais estruturada se torna essa prática nas organizações (JAIN, 1984; SUBRAMANIAN et al., 1993). Observa-se também a relação do estreitamento do foco do monitoramento, citado na referida alínea, com a criação de pontos cegos (blind spots), os quais limitam a percepção de ameaças e oportunidades no ambiente, reduzindo a eficácia do monitoramento (DAY; SCHOEMAKER, 2005; GILAD, 2011).

Miles e Snow $(1978,2003)$ consideram que os gestores têm a visão holística da organização, conseguindo percebê-la como um todo composto por pessoas, estruturas e processos, o qual deve estar alinhado com o ambiente escolhido pela organização. São os gestores que fazem as escolhas estratégicas, orientados pelas suas crenças no que proporcionará um alinhamento efetivo com o ambiente, e consequentemente modelam o perfil estratégico da organização. Esses autores consideram também que o ambiente é percebido pelos gestores como uma rede de influências e relações, sendo uma composição complexa de fatores como mercado de produtos, mercado de trabalho, costumes e práticas da indústria, regulamentos governamentais, relações com o mercado financeiro, relações com fornecedores de matériaprima, etc.

Choo (2002) consolidou estudos sobre o efeito das incertezas do ambiente (dimensões situacionais), do perfil dos gestores e das estratégias organizacionais sobre o modo de monitorar o ambiente. Esses aspectos estão presentes no modelo de Miles e Snow (1978, 2003), sugerindo uma relação entre o modo de monitoramento e a orientação estratégica. Choo (2002, p. 103) afirma que os estudos que analisou indicavam que a orientação estratégica relaciona-se com a sofisticação, a abrangência do escopo e a intensidade do monitoramento, pois as organizações tentam se ajustar a um modo de monitoramento capaz de prover as informações necessárias para perseguir os objetivos estratégicos.

Miles e Snow (1978, 2003) consideram que a sobrevivência das organizações depende da capacidade de seus gestores em lidar com três fatores principais: o domínio produto-mercado da organização, a tecnologia necessária para poder atuar nesse domínio e a estrutura e processos desenvolvidos para coordenar e controlar essa tecnologia. Porém, o fato do ambiente não ser estático torna complexa a tarefa de alinhamento com esses fatores, pois cada um tem sua própria dinâmica de mudanças, demandando diferentes ações dos gestores. Assim, desenvolveram seu modelo com o objetivo de responder a seguinte indagação: "como ocorre o processo de alinhamento da organização com ambiente?". 
Para responder a essa indagação, primeiramente Miles e Snow resgataram na literatura dois processos de alinhamento com ambiente:

a) seleção natural - algumas organizações desenvolvem ao acaso características mais compatíveis com as condições que surgem no ambiente em dado momento, forçando os concorrentes a copiarem essa estrutura ou desaparecer; e

b) seleção racional - derivado da teoria econômica da firma, propondo que os gestores de uma organização bem-sucedida selecionam, adotam ou descartam eficazmente componentes da estrutura e processos para manter o equilíbrio da organização com o ambiente. Entretanto, a racionalidade das escolhas é apenas pretendida, pois se baseia na percepção dos gestores quanto ao ambiente, podendo não ser precisa.

Miles e Snow $(1978,2003)$ consideraram que nem a seleção natural e nem a seleção racional explicavam como a maioria das organizações se adaptavam às condições ambientais. Entendiam que ambas as abordagens poderiam estar parcialmente corretas, uma vez que os gestores geralmente tentam fazer escolhas racionais baseados nas suas percepções imperfeitas. Algumas destas escolhas estarão casualmente mais alinhadas com a realidade do que outras.

Os autores recorreram à abordagem da escolha-estratégica de Child (1972) para propor uma explicação mais precisa para a adaptação das organizações ao ambiente. Essa abordagem coloca uma ênfase maior no papel dos gestores que tomam decisões e que estabelecem a ligação entre a organização e o ambiente em primeiro plano. Os gestores não apenas ajustam as estruturas e os processos da organização quando necessário, mas também tentam manipular o ambiente a fim de trazê-lo para a conformidade com o que a organização está fazendo. Assim, a estrutura e os processos da organização são apenas parcialmente definidos pelas condições ambientais.

Dessa forma, a abordagem da escolha-estratégica apresenta alguns pressupostos como o da existência de uma "coalizão dominante", ou seja, cada organização tem um grupo de tomadores de decisões que predominantemente influenciam o curso de ação da organização. Esse grupo acaba por exercer a responsabilidade tanto de identificar problemas estratégicos quanto de resolvê-los. Assim, o comportamento da organização é influenciado pela 
"percepção" da coalizão dominante, pois a organização responderá às condições ambientais percebidas pela coalizão dominante e ignorará as demais.

A coalizão dominante, com base na sua percepção, efetuará uma "segmentação" do ambiente de forma a identificar os componentes ambientais relevantes e distribuí-los entre as diversas áreas da organização, alocando os recursos de acordo com a importância estratégica percebida de cada componente. A coalizão dominante possui também a responsabilidade de promover o "monitoramento" dos componentes mais críticos do ambiente. E, com respeito às informações coletadas, poderá optar pela reatividade, esperando que os eventos apresentem um formato claro antes de reagir ou pela proatividade, antecipando o formato dos eventos e agindo rapidamente (ANSOFF, 1975).

Miles e Snow (1978, 2003) ressaltam que a coalizão dominante, por sua vez, tem suas decisões e ações de adaptação ao ambiente delimitadas pela estratégia passada e atual, pela estrutura e pelo desempenho da organização. Essas delimitações podem ser flexibilizadas ou removidas dinamicamente por alterações maiores na estratégia, mas para qualquer direcionamento escolhido, poderá surgir um novo conjunto de "delimitações dinâmicas".

Em síntese, a abordagem da escolha-estratégica sugere que a efetividade do processo de adaptação da organização ao ambiente externo depende da percepção que a coalizão dominante formula sobre as condições do ambiente e das decisões que toma quanto à maneira de lidar com estas condições.

\subsubsection{O Ciclo Adaptativo}

Miles e Snow $(1978,2003)$ propõem que, para lidar com a complexidade e o dinamismo do processo de adaptação da organização ao ambiente, é necessário dividir esse processo em três problemas principais que a coalizão dominante resolverá continuamente através de suas escolhas-estratégicas:

a) o problema de empreendedorismo;

b) o problema de engenharia; e 
c) o problema de administração.

Os autores sugerem que a resolução desses problemas ocorre em etapas que são mais nítidas e destacadas em organizações novas ou em rápido crescimento e também, em organizações que sobreviveram recentemente a uma crise maior. Em organizações maduras, essas etapas ocorrem quase que simultaneamente, mas, para fins didáticos, os autores optaram por apresentá-las como etapas sequenciais que chamaram de "ciclo adaptativo". A seguir, descrevem-se as etapas desse ciclo que constituem os três principais problemas a serem resolvidos para a adaptação ambiental segundo os autores.

\subsubsection{O Problema de Empreendedorismo}

O problema de empreendedorismo consiste em definir quais produtos e serviços serão ofertados e em quais mercados, ou seja, definir o domínio competitivo. Em empresas novas, esse problema tem um grau menor de dificuldade, pois ainda não existe uma "solução" implementada para os demais problemas da adaptação ambiental (engenharia e administração), ou seja, não há uma "inércia" para mudanças internas.

Porém, os autores consideram que, independentemente de ser uma organização nova ou não, a solução do problema de empreendedorismo se torna aparente quando os gestores se comprometem com a alocação de recursos para atingir os objetivos estabelecidos para o domínio escolhido. Nesse momento, a organização começa a desenvolver e projetar sua imagem, como, por exemplo, uma imagem de inovação ou de eficiência.

Observa-se que Qiu (2008) encontrou evidências de relação entre o modo como os gestores resolvem o problema do empreendedorismo e o modo como monitoram o ambiente externo para adquirir inteligência competitiva. Os gestores com uma maior orientação à inovação tendem a monitorar o ambiente com um escopo mais amplo e uma frequência maior. Assim, o monitoramento torna-se mais proativo na detecção das oportunidades e ameaças do ambiente. 


\subsubsection{O Problema de Engenharia}

Uma vez solucionado o problema de empreendedorismo, Miles e Snow (1978, 2003) consideram que é necessário selecionar e implementar uma tecnologia apropriada para produzir e distribuir os produtos e serviços escolhidos. Os autores consideram também que é necessário definir novos fluxos de informações, comunicação e controles para assegurar uma operação apropriada da tecnologia.

A configuração da organização poderá mudar desde a definição do problema de engenharia até sua solução final. Miles e Snow $(1978,2003)$ sugerem que ocorrerá um amadurecimento dos processos para coordenar e controlar as operações internas na medida em que a relação da organização com as condições do ambiente se estabiliza.

\subsubsection{O Problema de Administração}

A solução do problema de administração consiste na definição, racionalização e estabilização das atividades que resolverão os problemas de empreendedorismo e de engenharia. Miles e Snow $(1978,2003)$ consideram que solucionar o problema de administração também envolve os processos de inovação para que a organização continue a evoluir, tornando o problema da administração crítico para o ciclo de adaptação.

Os autores consideram que o sistema administrativo composto pela estrutura e processos da organização deve direcionar e monitorar as atividades sem se tornar tão rígido e enraizado a ponto de comprometer as atividades futuras de inovação. Como fator de liderança, o sistema administrativo deve permitir que a organização persiga as novas áreas de negócio escolhidas pela organização e, como um fator de latência, deve desenvolver a estrutura e os processos para que sejam implementadas as decisões estratégicas feitas em momentos anteriores do processo de adaptação. 
Os autores concluem que, quando os gestores iniciam um programa de mudança da organização sem considerar os problemas de empreendedorismo, de engenharia e de administração como aspectos integrados do processo de adaptação, os resultados serão frequentemente inadequados.

Na Figura 8, representa-se o ciclo adaptativo como uma sequência de processos para definir o produto-mercado (empreendedorismo), a tecnologia para produzir e distribuir o produto (engenharia) e a implementação da estrutura e dos processos para coordenação e controle dessa tecnologia (administrativo). O objetivo dessa figura é mostrar como os três problemas se relacionam no processo de adaptação da organização às condições ambientais.

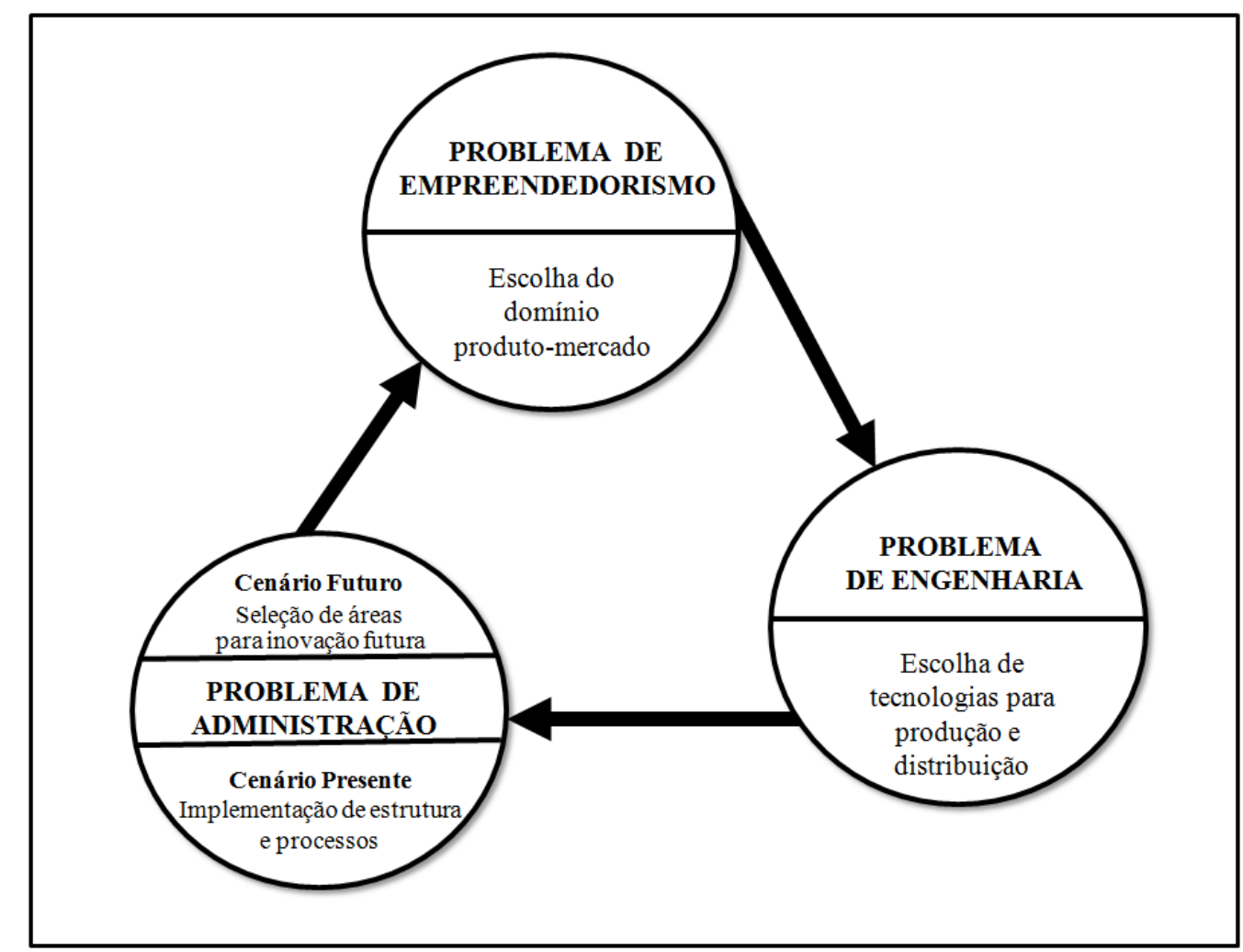

Figura 8 - Ciclo de adaptação da organização ao ambiente externo

Fonte: Adaptado de Miles e Snow (2003, p. 24, tradução nossa) 


\subsubsection{Tipos de Adaptação Organizacional}

Ao observar organizações pertencentes a um mesmo segmento, Miles e Snow (1978, 2003) perceberam que essas poderiam ser reduzidas a uma pequena quantidade de tipos, conforme a estratégia para responder ao ambiente. Cada um dos tipos observados apresentava uma configuração particular de tecnologia, estrutura e processos coerentes com sua estratégia. $\mathrm{Ou}$ seja, apresentavam semelhanças na forma como tratavam os problemas de empreendedorismo, tecnologia e administração, estabelecendo-se padrões para o ciclo adaptativo. Assim, esses autores consideram que uma organização procura criar uma imagem interna coerente com sua imagem produto-mercado, pois sua estrutura e processos devem refletir suas decisões estratégicas. Ou seja, essa coerência interna e externa é que acaba por estabelecer um tipo estratégico de organização.

Miles e Snow $(1978,2003)$ identificaram quatro tipos de organizações que chamaram de Defensiva, Prospectora, Analítica e Reativa. A seguir, apresentam-se as características gerais de cada um desses tipos.

a) Defensivas - são organizações conservadoras que possuem uma variedade limitada de produtos e clientes. Os executivos em geral são experts na área de atuação da organização e não procuram novas oportunidades fora de seu domínio. Consequentemente, sua tecnologia, estrutura e métodos de operação são bastante estáveis e demandam poucos ajustes. Em geral, buscam a melhoria da eficiência operacional.

b) Prospectoras - são organizações inovadoras que buscam constantemente por oportunidades de mercado e respondem às tendências emergentes. Em geral, criam mudanças e incertezas às quais seus competidores são forçados a reagir. Como se preocupam excessivamente com a inovação de produtos e mercados, em geral não são completamente eficientes.

c) Analíticas - essas organizações possuem características dos dois tipos anteriores. No lado estável, operam com eficiência de forma rotineira através de estruturas e 
processos formalizados. No lado mais turbulento, imitam as novas ideias dos líderes de mercado, assim que essas se mostram bem-sucedidas.

d) Reativas - essas organizações não conseguem responder eficientemente às mudanças do ambiente, pois não possuem uma relação consistente de estratégiaestrutura. Somente quando são pressionadas pelo ambiente, efetuam algum tipo de mudança.

Miles e Snow $(1978,2003)$ apresentaram as principais características, pontos fortes e fraquezas das organizações Defensivas, Prospectoras e Analíticas considerando cada um dos problemas do ciclo adaptativo para descrever um padrão de resposta às condições ambientais. De uma maneira geral, consideraram que esse padrão varia do esforço das organizações Defensivas em desenvolver elevada eficiência na operação até o esforço das Prospectoras em criar novas áreas de oportunidade através da inovação. Observam que as organizações Reativas não apresentam um padrão de adaptação às condições externas, sendo forçadas a uma resposta quando não são capazes de apresentar uma das três estratégias estáveis.

Para finalizar, os Quadros 8, 9 e 10 transcritos de Miles e Snow (2003) apresentam as características das organizações Defensivas, Prospectoras e Analíticas respectivamente para cada um dos problemas do ciclo adaptativo. O objetivo da inclusão desses quadros no presente estudo é facilitar a fundamentação da pesquisa empírica do presente estudo. 
Quadro 8 - Características das organizações Defensivas

\begin{tabular}{|c|c|c|}
\hline \multicolumn{3}{|c|}{ Características das Organizações Defensivas } \\
\hline Empreendedorismo & Engenharia & Administração \\
\hline $\begin{array}{l}\text { Problema: } \\
\text { Como "blindar" uma parte do } \\
\text { mercado para criar e estabilizar } \\
\text { produtos e clientes? } \\
\text { Soluções: } \\
\text { 1. Estreitar e estabilizar o } \\
\text { domínio. } \\
\text { 2. Manter o domínio de forma } \\
\text { agressiva (ex. preços } \\
\text { competitivos, excelência de } \\
\text { serviços). } \\
\text { 3. Tendência a ignorar } \\
\text { oportunidades fora do domínio. } \\
\text { 4. Cautela e crescimento } \\
\text { incremental principalmente } \\
\text { através de penetração de } \\
\text { mercado. } \\
\text { 5. Algum desenvolvimento de } \\
\text { produto, mas bastante } \\
\text { relacionado aos bens e serviços } \\
\text { atuais. } \\
\text { Custos e benefícios: } \\
\text { É difícil para os concorrentes } \\
\text { desalocar a organização de seu } \\
\text { pequeno nicho na indústria, mas } \\
\text { uma mudança maior no mercado } \\
\text { pode ameaçar a sobrevivência. }\end{array}$ & $\begin{array}{l}\text { Problema: } \\
\text { Como produzir e distribuir bens e } \\
\text { serviços da forma mais eficiente } \\
\text { possível? } \\
\text { Soluções: } \\
\text { 1. Otimizar relação eficiência } \\
\quad \text { versus tecnologia. } \\
\text { 2. Tecnologia estável. } \\
\text { 3. Tendência à integração } \\
\quad \text { vertical. } \\
\text { 4. Melhoria contínua na } \\
\quad \text { tecnologia para manter a } \\
\quad \text { eficiência. } \\
\text { Custos e benefícios: } \\
\text { A eficiência tecnológica é central } \\
\text { para o desempenho da organização, } \\
\text { mas para grandes investimentos, na } \\
\text { área é necessário que os problemas } \\
\text { tecnológicos permaneçam } \\
\text { familiares e previsíveis por longos } \\
\text { períodos de tempo. }\end{array}$ & 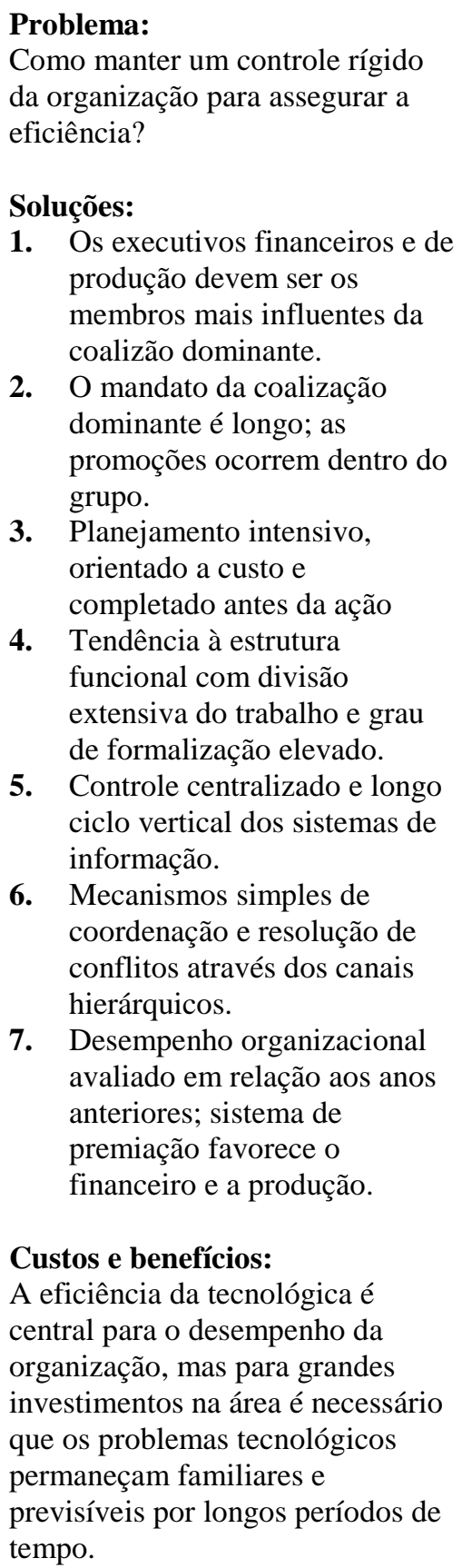 \\
\hline
\end{tabular}

Fonte: Adaptado de Miles e Snow (2003, p. 48, tradução nossa) 
Quadro 9 - Características das organizações Prospectoras

\begin{tabular}{|c|c|c|}
\hline \multicolumn{3}{|c|}{ Características das Organizações Prospectoras } \\
\hline Empreendedorismo & Engenharia & Administração \\
\hline $\begin{array}{l}\text { Problema: } \\
\text { Como localizar e explorar novas } \\
\text { oportunidades de produtos e } \\
\text { mercados? } \\
\text { Soluções: } \\
\text { 1. Desenvolver ampla e } \\
\text { continuamente o domínio. } \\
\text { 2. Monitorar as condições e } \\
\text { eventos do ambiente de forma } \\
\text { vasta. } \\
\text { 3. Criar mudanças na indústria. } \\
\text { 4. Crescimento através do } \\
\quad \text { desenvolvimento de produtos e } \\
\text { mercados. } \\
\text { 5. Crescimento pode acontecer em } \\
\text { "explosões". } \\
\text { Custos e benefícios: } \\
\text { A inovação em produtos e } \\
\text { mercados protege a organização } \\
\text { em um ambiente dinâmico, mas a } \\
\text { organização corre o corre o risco } \\
\text { de baixa lucratividade e sobrecarga } \\
\text { de recursos. }\end{array}$ & $\begin{array}{l}\text { Problema: } \\
\text { Como evitar dependência de longo } \\
\text { prazo de um único processo } \\
\text { tecnológico? } \\
\text { Soluções: } \\
\text { 1. Tecnologias flexíveis e } \\
\text { prototipáveis. } \\
\text { 2. Múltiplas tecnologias. } \\
\text { 3. Baixo grau de rotinização e } \\
\quad \text { mecanização; tecnologia } \\
\text { enraizada na mentalidade das } \\
\text { pessoas. } \\
\text { Custos e benefícios: } \\
\text { A flexibilidade tecnológica permite } \\
\text { uma resposta rápida às mudanças } \\
\text { do domínio, mas a organização não } \\
\text { pode desenvolver eficiência } \\
\text { máxima em seus sistemas de } \\
\text { produção e distribuição devido ao } \\
\text { uso de múltiplas tecnologias. }\end{array}$ & $\begin{array}{l}\text { Problema: } \\
\text { Como facilitar e coordenar } \\
\text { numerosas e diversas operações? } \\
\text { Soluções: } \\
\text { 1. Os executivos de marketing, e } \\
\text { P\&D são os mais influentes na } \\
\text { coalizão dominante. } \\
\text { 2. Coalizão dominante é grande, } \\
\text { diversificada e transitória; } \\
\text { pode incluir uma "panelinha". } \\
\text { Mandato da coalizão } \\
\text { dominante nem sempre é } \\
\text { longo; principais executivos } \\
\text { podem ser contratados de fora } \\
\text { ou podem ser de promoções } \\
\text { internas. } \\
\text { O planejamento é amplo em } \\
\text { vez de intenso; orientado a } \\
\text { problemas e pode não estar } \\
\text { concluído antes do início da } \\
\text { ação. } \\
\text { Tendência ao produto e } \\
\text { estrutura com pouca divisão } \\
\text { do trabalho e baixo nível de } \\
\text { formalização. } \\
\text { para manter a flexibilidade e } \\
\text { os recursos. } \\
\text { Mecanismos complexos de } \\
\text { coordenação e resolução de } \\
\text { conflitos através de } \\
\text { integradores. } \\
\text { Desempenho organizacional } \\
\text { medido contra os principais } \\
\text { competidores; sistema de } \\
\text { recompensas favorece o } \\
\text { marketing e P\&D. } \\
\text { 7. bubutilizar } \\
\text { 7. }\end{array}$ \\
\hline
\end{tabular}

Fonte: Adaptado de Miles e Snow (2003, p. 66, tradução nossa) 
Quadro 10 - Características das organizações Analíticas

\begin{tabular}{|c|c|c|}
\hline \multicolumn{3}{|c|}{ Características das Organizações Analíticas } \\
\hline Empreendedorismo & Engenharia & Administração \\
\hline $\begin{array}{l}\text { Problema: } \\
\text { Como localizar e explorar } \\
\text { oportunidades de novos produtos e } \\
\text { mercados e simultaneamente } \\
\text { manter estável a base de produtos e } \\
\text { clientes tradicionais? } \\
\text { Soluções: } \\
\text { 1. Domínio híbrido, pois é estável } \\
\text { e dinâmico simultaneamente. } \\
\text { 2. Mecanismos de monitoramento } \\
\text { em geral limitado ao marketing; } \\
\text { pode abranger P\&D. } \\
\text { 3. Crescimento estável através de } \\
\text { penetração de mercado e } \\
\text { desenvolvimento de produtos e } \\
\text { mercados. } \\
\text { Custos e benefícios: } \\
\text { Investimento pequeno em P\&D, } \\
\text { combinado com imitação de } \\
\text { produtos bem-sucedidos, minimiza } \\
\text { riscos, mas o domínio deve manter } \\
\text { sempre um equilíbrio ótimo entre } \\
\text { estabilidade e flexibilidade. }\end{array}$ & $\begin{array}{l}\text { Problema: } \\
\text { Como ser eficiente nas partes } \\
\text { estáveis do domínio e flexível nas } \\
\text { partes dinâmicas? } \\
\text { Soluções: } \\
\text { 1. Tecnologia de núcleo dual } \\
\quad \text { (componente estável e } \\
\text { flexível). } \\
\text { 2. Grupo amplo e influente de } \\
\text { pesquisa aplicada. } \\
\text { 3. Grau moderado de eficiência } \\
\text { técnica. } \\
\text { Custos e benefícios: } \\
\text { Tecnologia de núcleo dual capaz } \\
\text { de atender um domínio híbrido } \\
\text { estável-dinâmico, mas a tecnologia } \\
\text { nunca será completamente efetiva } \\
\text { ou eficiente. }\end{array}$ & $\begin{array}{l}\text { Problema: } \\
\text { Como diferenciar a estrutura e } \\
\text { processos da organização para } \\
\text { acomodar as áreas estáveis e } \\
\text { dinâmicas da operação? } \\
\text { Soluções: } \\
\text { 1. Os executivos de marketing e } \\
\text { pesquisa aplicada são os } \\
\text { membros mais influentes da } \\
\text { coalizão dominante, seguido de } \\
\text { perto pelos de produção. } \\
\text { 2. Planejamento intenso entre } \\
\text { marketing e produção para as } \\
\text { partes estáveis do domínio; } \\
\text { planejamento exaustivo entre } \\
\text { marketing, pesquisa aplicada e } \\
\text { produção sobre novos produtos } \\
\text { e mercados. } \\
\text { 3. Estrutura matricial combina } \\
\text { grupos funcionais e grupos de } \\
\text { produtos. } \\
\text { 4. Sistema de controle } \\
\text { moderadamente centralizado } \\
\text { com ciclos de pareceres vertical } \\
\text { e horizontal. } \\
\text { 5. Mecanismos de coordenação } \\
\text { extremamente complexos e } \\
\text { custosos; alguma resolução de } \\
\text { conflito através dos gerentes de } \\
\text { produto, outros através de } \\
\text { canais hierárquicos. } \\
\text { idealizado para equilibrar } \\
\text { estabilidade e flexibilidade, mas se } \\
\text { este equilíbrio é perdido, pode ser } \\
\text { difícil restaurá-lo. } \\
\text { baseadiação de desempenho medidas de eficácia } \\
\text { e eficiência, maiores } \\
\text { recompensas para marketing e } \\
\text { pesquisa aplicada. } \\
\text { intema administrativo é }\end{array}$ \\
\hline
\end{tabular}

Fonte: Adaptado de Miles e Snow (2003, p. 79, tradução nossa) 


\section{METODOLOGIA}

\subsection{Abordagem, Estratégia e Método de Pesquisa}

O objetivo principal deste estudo é investigar a relação entre a orientação estratégica e o modo como as organizações praticam o monitoramento de seu ambiente externo. Para alcançar esse objetivo, fez-se necessário o estabelecimento de uma estratégia de investigação com o emprego de técnicas e métodos específicos, considerando-se que não existem regras exaustivas e infalíveis de investigação (MARTINS; THÉOPHILO, 2009).

A estratégia de investigação pode ser de natureza quantitativa, qualitativa ou uma combinação de ambas, dependendo das premissas, que o pesquisador traz para seu estudo, resultantes de seu modo particular de conceber a realidade, e a abordagem metodológica será uma consequência dessas premissas (MARTINS E THÉOPHILO, 2009; CRESWELL, 2010). Assim, estabeleceram-se duas premissas para o presente estudo. A primeira é que a orientação estratégica e o modo de monitoramento são constructos que podem ser mensurados, e a segunda é que a existência ou não de uma relação causal entre eles pode ser verificada.

Essas premissas traduziram-se em uma abordagem metodológica empírico-positivista com a adoção de uma estratégia de natureza quantitativa. Segundo Martins e Théophilo (2009), o empirismo consagra a observação e a mensuração quantitativa como critérios de cientificidade, e o positivismo caracteriza-se pela busca da explicação dos fenômenos a partir da identificação de suas relações, sendo imprescindível a existência de uma teoria para nortear as observações. Uma característica importante dessa abordagem é o emprego de métodos que utilizam instrumentos como questionários, escalas de atitudes, tipos de amostragem entre outros, privilegiando-se a estatística.

Considerando-se a adoção de uma abordagem empírico-positivista com uma estratégia de natureza quantitativa para o presente estudo, escolheu-se como método de pesquisa a survey (levantamento) que consiste em "entrevistas com um grande número de respondentes por meio de um questionário predeterminado" (MALHOTRA, 2006, p. 135). 
$\mathrm{Na}$ literatura, encontram-se muitas classificações para as surveys, e Lima (2004) sumariza essas classificações de maneira didática, conforme mostrado no Quadro 11:

Quadro 11 - Tipos de surveys

\begin{tabular}{|c|c|}
\hline \multicolumn{1}{|c|}{ Surveys } & \multicolumn{1}{c|}{ Objetivos } \\
\hline a) Exploratória & \begin{tabular}{l}
$-\begin{array}{l}\text { identificar variáveis que interferem no fenômeno investigado e } \\
\text { até que ponto essas variáveis podem ser medidas e como seria } \\
\text { possível realizar esta medição. }\end{array}$ \\
\hline b) Explanatória
\end{tabular} \\
\hline c) Descritiva & $\begin{array}{l}\text { testar uma teoria, explicando fundamentalmente relações } \\
\text { causais possíveis de se estabelecer. }\end{array}$ \\
\hline d) Longitudinal & $\begin{array}{l}\text { identificar quais situações, eventos, atitudes, opiniões estão } \\
\text { ocorrido com a população ou parte dela. }\end{array}$ \\
\hline e) Corte-transversal & $\begin{array}{l}\text { investigar a evolução ou as transformações, ou ainda, as } \\
\text { mudanças ocorridas em determinadas variáveis no curso de } \\
\text { diferentes espaços de tempo. }\end{array}$ \\
\hline $\begin{array}{l}\text { identificar e explicar uma ou mais variáveis no limite de um } \\
\text { determinado espaço de tempo. }\end{array}$ \\
\hline
\end{tabular}

Fonte: Adaptação de Lima (2004, p. 26)

De acordo com esse esquema classificatório, a survey do presente estudo é de natureza:

a) descritiva, pois para atingir os objetivos da pesquisa necessita-se descrever os constructos orientação estratégica e modo de monitoramento;

b) explanatória, pois busca evidências da existência ou não de uma relação causal entre a orientação estratégica e o modo de monitoramento; e

c) corte-tranversal, pois esses constructos serão observados em um limite de tempo bem definido. 


\subsection{Hipóteses de Pesquisa}

Segundo Gil (2010), as hipóteses têm por finalidade oferecer uma solução provisória para o problema de pesquisa, ou seja, uma possível resposta para a indagação formulada. Malhotra (2006) afirma que as hipóteses são afirmações ou proposições não comprovadas, podendo ser testadas empiricamente.

Considerando-se a abordagem positivista do presente estudo, formularam-se duas hipóteses sobre a relação causal entre o modo de monitoramento e a orientação estratégica das organizações. Para esta finalidade, a tipologia de orientações estratégicas sugerida por Miles e Snow (1978, 2003) e os estudos de Daft e Weick (1984) e Choo (2002) sobre o modo de monitoramento foram utilizadas como principais arcabouços teóricos. A seguir, apresentamse as hipóteses formuladas para o presente estudo.

H1: O modo de monitoramento varia de acordo com a orientação estratégica das organizações.

Miles e Snow $(1978,2003)$ sugerem que as atividades de monitoramento variam de acordo a orientação estratégica da organização estabelecida pelos seus gestores. Choo (2002) argumenta que o modo de monitoramento é escolhido de forma a prover as informações necessárias para a organização perseguir as estratégias escolhidas pelos seus gestores. Daft e Weick (1984) propõem que a orientação estratégica da organização é responsabilidade de seus gestores e, portanto, deve estar associada ao modo como as condições ambientais são monitoradas e interpretadas.

H2: As organizações com orientação estratégica Analítica apresentam um modo de monitoramento mais formal do que as organizações com orientação estratégica Prospectora.

Choo (1999) afirma que a procura de informações no ambiente é formal quando é estruturada de acordo com metodologias e procedimentos pré-definidos. Na procura formal, o objetivo é sistematicamente obter informação relevante para uma questão a fim de prover uma base para desenvolver uma decisão ou curso de ação. Portanto, preferem-se informações de fontes 
percebidas como confiáveis ou serviços de informação que fazem esforços para assegurar qualidade e precisão dos dados.

Daft e Weick (1984) sugerem que tanto as organizações com a orientação estratégica Analítica quanto a Prospectora, sugeridas por Miles e Snow (1978, 2003), procuram ativamente por informações no ambiente. Entretanto, as organizações Analíticas consideram o ambiente analisável e previsível, empregando a procura formal de informação com uma coleta sistemática de dados. Como consideram o ambiente mensurável e passível da análise racional, as organizações Analíticas empregam pesquisas de mercado, análise de tendências e projeções estatísticas para a previsão de problemas e oportunidades entre outros métodos e procedimentos.

Em contrapartida, Daft e Weick (1984) sugerem que as organizações Prospectoras consideram o ambiente pouco analisável e priorizam os dados obtidos de maneira mais informal, empregando o julgamento e a intuição para influenciar o ambiente e se manterem à frente no lançamento de inovações no mercado. Essa abordagem é adotada, pois não consideram que o ambiente possa ser mensurado ou avaliado através da lógica.

\subsection{População-Alvo e Amostra}

A população-alvo deste estudo são os profissionais que atuam no monitoramento em organizações. Através da percepção desses, serão avaliados os constructos orientação estratégica e modo de monitoramento das organizações para as quais trabalham. Considera-se que esses profissionais estão envolvidos com as atividades de coleta e uso de informações do ambiente externo à organização. $\mathrm{O}$ resultado esperado de sua atuação consiste na identificação de ameaças e oportunidades, no aumento da vantagem competitiva e na melhoraria do planejamento de curto e longo prazo (CHOO, 2002).

O mapeamento da população desses profissionais para a extração de uma amostra não é uma tarefa imediata, pois não há uma função padronizada de monitoramento ou mesmo um perfil bem definido para esses profissionais no mercado. As atividades de monitoramento podem ser realizadas por profissionais em departamentos como Inteligência, Marketing, Estratégia, 
Vendas, $\mathrm{P} \& \mathrm{D}$ entre outros ou até mesmo podem ser executadas de uma maneira informal nas organizações (JAIN, 1984; CALOF; WRIGHT, 2008; LESCA; CARON-FASAN, 2008; QIU, 2008). Tomando-se em conta essa dificuldade, utilizou-se uma rede social de cunho profissional mediada por computadores na Internet denominada LinkedIn para viabilizar o processo de amostragem.

O LinkedIn é uma plataforma Web lançada em 2003 e que atualmente reúne mais de 250 milhões de profissionais distribuídos em mais de 200 países, sendo mantida por uma empresa americana de capital aberto de mesmo nome (LINKEDIN, 2013). No Brasil, em janeiro de 2013, o LinkedIn contabilizava mais de 11 milhões de usuários (WIKIPEDIA, 2013).

O LinkedIn possibilita que cada usuário crie um perfil para expor sua formação escolar e acadêmica, experiência profissional, competências e currículo. O principal propósito dessa plataforma é permitir que os usuários cadastrados mantenham uma lista de contatos com detalhes profissionais de pessoas com quem tem algum nível de relacionamento denominada "Connections". O LinkedIn tornou-se, ao longo do tempo, uma ferramenta bastante empregada para o recrutamento e a seleção de profissionais pelas organizações (WIKIPEDIA, 2013), característica essa que permitiu qualificá-lo como uma ferramenta para identificar e acessar os profissionais para a amostra deste trabalho de investigação.

No presente estudo, o recurso da plataforma LinkedIn utilizado foi o de formação de grupos de interesse, o qual disponibiliza formas de discussão entre os membros em torno de um tema de interesse comum. Em 2012, já havia mais de 1,2 milhões de grupos com uma quantidade de membros variando de 1 a 750 mil cada, além de mais de 128 mil grupos de alunos acadêmicos e corporativos (WIKIPEDIA, 2013).

O LinkedIn mantém os membros dos grupos informados através do envio de emails com as atualizações dos grupos, incluindo as postagens de discussões. Os membros do grupo também podem enviar mensagens para outros membros que pertençam ou não à sua lista de conexões, desde que o grupo esteja configurado para permitir tal comunicação. Esses mecanismos viabilizaram o acesso aos profissionais que compuseram a amostra do presente estudo.

Considerando-se a utilização do LinkedIn, a amostragem ocorreu por conveniência, pois a escolha dos indivíduos não dependeu de que todos tivessem a mesma probabilidade de serem 
escolhidos, mas, sim, das decisões tomadas pelos pesquisadores. Esse tipo de amostragem é útil para estudos de natureza quantitativa que requerem uma cuidadosa e controlada escolha de indivíduos com características especificas (SAMPIERI et al., 2012).

\subsection{Instrumento de Coleta de Dados}

Considerando-se que a pesquisa survey (levantamento) foi escolhida como método de coleta de dados para o presente estudo, desenvolveu-se um questionário estruturado, padronizado e sem a identificação do respondente (anônimo). Como o acesso ao público-alvo deste estudo ocorreu através da plataforma Web LinkedIn, fez-se necessário o uso de uma ferramenta online de questionários. O software escolhido foi o Surveymonkey, cujos principais recursos são:

a) a construção de questões customizadas para a pesquisa;

b) o acesso ao questionário pelos respondentes via Web;

c) o armazenamento das respostas em base ubíqua e segura;

d) a geração de relatórios com os sumários das respostas; e

e) a exportação das respostas para a ferramenta SPSS $^{2}$.

O questionário é composto por 53 questões divididas em sete blocos, cujos conteúdos são mostrados a seguir no Quadro 12:

\footnotetext{
${ }^{2}$ SPSS - Statistical Package for Social Sciences - software da IBM utilizado para análise estatística dos dados coletados no presente estudo.
} 
Quadro 12 - Conteúdo dos blocos de questões

\begin{tabular}{|c|l|c|}
\hline Bloco & \multicolumn{1}{|c|}{ Conteúdo } & $\begin{array}{c}\text { Qtde. de } \\
\text { questões }\end{array}$ \\
\hline 1 & Modo de monitoramento & 15 \\
\hline 2 & Fontes de informação & 4 \\
\hline 3 & Escopo de monitoramento & 8 \\
\hline 4 & Dificuldades do monitoramento & 9 \\
\hline 5 & Orientação estratégica & 5 \\
\hline 6 & Dados da organização & 6 \\
\hline 7 & Dados do respondente & 6 \\
\hline
\end{tabular}

Segundo Marconi e Lakatos (1982), um questionário precisa ser testado antes de sua utilização definitiva para a verificação de possíveis falhas. Assim, realizou-se uma fase de pré-teste com o envio para sete profissionais de monitoramento com o objetivo de validar o entendimento das questões e a facilidade para responder. As principais alterações sugeridas pelos respondentes foram:

a) substituição do termo "Ambiente Externo" por "Ambiente de Negócios";

b) inclusão de um pequeno texto apresentando os conceitos de "Ambiente de Negócios" e "Monitoramento do Ambiente de Negócios";

c) reformulação dos enunciados das questões do primeiro bloco para tornar os textos mais sintéticos; e

d) alteração das escalas Likert de sete pontos para cinco pontos.

A seguir, apresentam-se os blocos de questões da versão final do questionário.

\subsubsection{Bloco de Questões 01 - Modo de Monitoramento}

O primeiro bloco do questionário é composto por questões cuja finalidade é verificar o modo de monitoramento das organizações para as quais os respondentes trabalham. Essas questões foram formuladas com base no modelo proposto por Daft e Weick (1984), que foi revisado 
posteriormente por Choo (2002), tomando-se em conta que esse modelo foi baseado nos modos de monitoramento sugeridos por Aguilar (1967).

Observa-se que, dos quatro tipos de organizações propostos por esse modelo, apenas os tipos discovering e enacting se caracterizam pela procura ativa de informação no ambiente. Como o universo de pesquisa do presente estudo são os profissionais de monitoramento cujas atividades relacionam-se à procura deliberada de informação no ambiente, pressupôs-se que as organizações dos respondentes pertencem a esses tipos de organizações.

Nos estudos de Daft e Weick (1984) e Choo (2002), as organizações do tipo discovering interpretam o ambiente através da análise racional e da mensuração precisa, praticando o modo de monitoramento procura formal proposto por Aguilar (1967). Para as organizações do tipo enacting, que interpretam o ambiente de maneira mais pessoal, menos linear, mais ad hoc e improvisada, os autores descrevem um modo de monitoramento com características da procura informal proposta por Aguilar (1967).

Para verificar o modo de monitoramento das organizações dos respondentes, definiram-se 15 indicadores em escala Likert de cinco pontos apresentados em questões para avaliação do grau de concordância com características sugeridas da procura formal e da procura informal. Observa-se que houve uma redução da quantidade de pontos da escala Likert de sete para cinco pontos na fase de pré-teste. Mcdonald (2004), citado por Trevisani (2006), desenvolveu um estudo empírico para identificar a quantidade ideal de pontos e concluiu que cinco é o número adequado com base em aspectos psicométricos e estatísticos. Dessa forma, o resultado do pré-teste apresentou coerência com este estudo.

Na escala Likert utilizada, o extremo inferior corresponde a "1 - discordo totalmente" e o extremo superior a "5 - concordo totalmente". Os pontos intermediários 2, 3 e 4 não foram rotulados e quanto mais elevados, maior o grau de concordância do respondente com a questão.

No questionário, apresenta-se para o respondente a sentença: "Em sua empresa, o monitoramento do Ambiente de Negócios é uma atividade:", seguida das questões mostradas no Quadro 13. Observa-se que quanto maior o grau de concordância com a questão, maior é a 
proximidade com o modo de monitoramento da coluna "Modo de monitoramento" do referido quadro, e quanto menor a concordância, maior é o distanciamento.

"Em sua empresa, o monitoramento do Ambiente de Negócios é uma atividade:"

Quadro 13 - Questões para avaliação do modo de monitoramento

\begin{tabular}{|c|c|c|}
\hline Indicadores & Questões em escala Likert de concordância & $\begin{array}{c}\text { Modo de } \\
\text { monitoramento }\end{array}$ \\
\hline V01 & - caráter ocasional; & Procura Informal \\
\hline V02 & - exploratória, pois busca hipóteses mais do que confirmações; & Procura Informal \\
\hline V03 & - focada em informações qualitativas (ex.: percepções, motivações, etc.); & Procura Informal \\
\hline V04 & $\begin{array}{l}\text { - não direcionada a informações específicas, sendo análoga a um radar; } \\
\text { (como ir pescar - jogo o anzol, mas não sei que peixe vem). }\end{array}$ & Procura Informal \\
\hline V05 & - que busca sinais antecipativos de oportunidades e ameaças; & Procura Formal \\
\hline V06 & - formal e gerenciada por departamento(s) específico(s); & Procura Formal \\
\hline V07 & - planejada e sistemática; & Procura Formal \\
\hline V08 & $\begin{array}{l}\text { - direcionada a informações específicas, colocando questões objetivas; } \\
\text { (como um tiro certo - miro em um alvo claro). }\end{array}$ & Procura Formal \\
\hline V09 & $\begin{array}{l}\text { - focada em informações quantitativas } \\
\text { (ex.: consumo, demanda, frequências, preços, etc.); }\end{array}$ & Procura Formal \\
\hline V10 & - que utiliza dados gerados por sistemas de gestão da informação; & Procura Formal \\
\hline V11 & - regular (periodicidade seja anual, mensal, etc.); & Procura Formal \\
\hline V12 & $\begin{array}{l}\text { - focada em fontes de informação claramente determinadas } \\
\text { (clientes, concorrentes, etc.); }\end{array}$ & Procura Formal \\
\hline V13 & - que busca tendências e projeções estatísticas; & Procura Formal \\
\hline V14 & $\begin{array}{l}\text { - que tem caráter de levantamento de dados } \\
\text { (usa questionários, formulários, etc.); }\end{array}$ & Procura Formal \\
\hline V15 & - que gera estudos e relatórios especiais não rotineiros. & Procura Formal \\
\hline
\end{tabular}


Para finalizar esta seção, salienta-se que as questões deste bloco são autoexplicativas. Entretanto, na fase do pré-teste, alguns respondentes ficaram com dúvidas sobre o significado dos termos monitoramento e ambiente. Por esse motivo, incluíram-se, antes do bloco de questões, esses conceitos traduzidos e adaptados de Choo (2002). Adicionalmente, substituise o termo "Ambiente Externo" por "Ambiente de Negócios". A seguir, listam-se os conceitos como foram apresentados para os respondentes:

a) Ambiente de Negócios: é o conjunto de todos os fatores externos a uma empresa que podem afetar seu desempenho e até mesmo sua sobrevivência como clientes, fornecedores concorrentes, aspectos econômicos, tecnológicos, regulatórios, políticos e socioculturais.

b) Monitoramento do Ambiente de Negócios: é a coleta e uso de informações sobre o Ambiente de Negócios para identificar ameaças e oportunidades, ganhar vantagem competitiva e melhorar o planejamento de curto e longo prazo.

\subsubsection{Bloco de Questões 02 - Fontes de Informação}

O segundo bloco do questionário apresenta quatro questões para descrever a frequência de utilização das fontes de informação do ambiente externo à organização. Na prática, encontrase uma infinidade de tipos de fontes de informação. Assim, procurou-se estruturá-los em poucas categorias para uma descrição parcimoniosa na presente investigação.

$\mathrm{Na}$ literatura, as fontes de informação do monitoramento são usualmente classificadas entre pessoais e impessoais, e internas e externas (AGUILAR, 1967; CULNAN, 1983; DAFT et al., 1988). As fontes pessoais se referem ao contato humano direto seja face a face ou por meios de comunicação como o telefone (CHOO, 2002). As fontes impessoais são escritas e incluem jornais, relatórios gerados por sistemas, revistas especializadas, etc. As fontes internas referem-se a dados, relatórios ou mesmo discussões entre gerentes sobre as condições externas à organização. As fontes externas referem-se a pessoas de outras organizações, revistas, jornais, conferências e etc. (DAFT et al., 1988). 
Assim, definiram-se quatro indicadores em escala Likert de cinco pontos apresentados em questões para avaliação da frequência de utilização das fontes pessoais e impessoais e das fontes internas e externas. Nessa escala, o extremo inferior corresponde a "1 - nunca" e o extremo superior corresponde a "5 - sempre". Os pontos intermediários 2, 3 e 4 não foram rotulados, e quanto mais elevados, mais frequente é a utilização da fonte de informação avaliada. Para as análises posteriores no presente estudo, considerou-se a seguinte equivalência: "2 - quase nunca", "3 - às vezes" e "4 - quase sempre".

No questionário, apresenta-se para o respondente a pergunta: "Em sua empresa, qual a frequência com que são utilizadas as fontes de informação do Ambiente de Negócios listadas a seguir?", conforme listadas no Quadro 14.

Quadro 14 - Questões para avaliação das fontes de informação

\begin{tabular}{|c|l|}
\hline Indicadores & Questões em escala Likert de fequência \\
\hline V16 & - Pessoais externas - ex.: clientes, fornecedores, consultores,contatos, etc. \\
\hline V17 & - Pessoais internas - ex.: pares, subordinados, vendedores, etc \\
\hline V18 & - Impessoais externas - ex.: jornais, revistas, exposições, sites na Internet, etc. \\
\hline V19 & - Impessoais internas - ex.: relatórios, memorandos, newsletters, portais na Intranet, etc. \\
\hline
\end{tabular}

\subsubsection{Bloco de Questões 03 - Escopo do Monitoramento}

O terceiro bloco do questionário apresenta oito questões para descrever a frequência com que são monitoradas as grandes áreas de interesse do ambiente externo às organizações. Jain (1984) comenta que "na teoria o ambiente é tão amplo quanto o próprio mundo, mas na prática, as organizações costumam categorizar o ambiente em grandes áreas como econômica, tecnológica, política (incluindo a regulatória) e social".

Aguilar (1967) sugere que as organizações, para identificar tendências de impacto, devem ampliar o escopo do monitoramento das áreas imediatas nas quais competem para englobar a 
indústria como um todo e, somente então, ampliar para as esferas econômicas, tecnológicas, políticas e sociais. Choo (2002) observa que as informações relacionadas aos setores de mercado como clientes, concorrentes e fornecedores parecem ser as mais importantes para as organizações, porém os aspectos tecnológicos e demográficos do ambiente são priorizados quando apresentam impacto nas estruturas e dinâmicas das organizações.

De uma maneira geral, os autores parecem destacar áreas comuns de interesse para o monitoramento relacionadas a setores ambientais de mercado como clientes, concorrentes e fornecedores e a setores macroambientais como econômico, tecnológico, regulatório, socioculturais e políticos (AGUILAR, 1967; DENNING, 1973; KEFALAS; SCHODERBEK, 1973; FAHEY; KING, 1977; JAIN, 1984; DAFT et al., 1988; CHOO, 2002; CALOF; WRIGHT, 2008).

Essas áreas podem ser visualizadas em duas camadas do ambiente externo, sendo uma próxima da organização que inclui os setores que conduzem transações diárias e influenciam diretamente as operações básicas da organização e uma segunda camada mais distante e dispersa, afetando igualmente todas as organizações de uma maneira indireta (DAFT, 2005). No presente estudo, a primeira camada será referenciada como "mercado", e a segunda, como "macroambiental".

Com base nessas duas camadas do ambiente externo, definiram-se oito indicadores em escala Likert de cinco pontos apresentados em questões para avaliar a frequência de monitoramento dos principais aspectos do ambiente. Nessa escala, o extremo inferior corresponde a "1 nunca", e o extremo superior corresponde a "5 - sempre". Os pontos intermediários 2, 3 e 4 não foram rotulados, e quanto mais elevado o ponto, maior e mais frequente é o monitoramento do aspecto avaliado do ambiente. 
No questionário, apresenta-se para o respondente a pergunta: "Em sua empresa, qual a frequência com que são coletadas informações dos aspectos listados a seguir do Ambiente de Negócios?", seguida das questões mostradas no Quadro 15. Na coluna "Tipo", consta a camada do ambiente externo ao qual o aspecto se refere.

Quadro 15 - Questões para avaliação do escopo do monitoramento

\begin{tabular}{|c|c|c|}
\hline Indicadores & Questões em escala Likert de fequência & Tipo \\
\hline V20 & Clientes - ex.: necessidades, perfil, uso dado aos produtos, novos clientes, etc. & \multirow{3}{*}{ Mercado } \\
\hline $\mathrm{V} 21$ & Concorrentes - ex.: preços, mudanças em produtos, novos produtos, custos e finanças, etc. & \\
\hline V22 & Fornecedores - ex.: preços, novos fornecedores, inovação em insumo, etc. & \\
\hline V23 & Aspectos Econômicos - ex: - variação do PIB, inflação, variação das taxas cambiais, etc. & \multirow{5}{*}{ Macroambiental } \\
\hline V24 & Aspectos Tecnológicos - ex.: novas tecnologias, novos processos, novos materiais, etc. & \\
\hline V25 & Aspectros Regulatórios - ex.: leis e normas do governo, de agências regulatórias, etc. & \\
\hline V26 & Aspectos Socioculturais - ex.: mudanças de coportamento, valores, normas sociais, etc. & \\
\hline V27 & Aspectos Políticos - ex.: eleições, relações internacionais, etc. & \\
\hline
\end{tabular}

\subsubsection{Bloco de Questões 04 - Dificuldades do Monitoramento}

O quarto bloco do questionário apresenta nove questões para descrever as dificuldades das atividades de monitoramento, sendo oito questões fechadas e uma aberta. Muitas das dificuldades técnicas do monitoramento estão relacionadas à finalidade dessa atividade que é fornecer dados para a formulação de estratégias corporativas (DENNING, 1973). Aguilar (1967) afirma que planejar um curso futuro para a organização implica na complexidade de lidar com um grande número de variáveis que podem influenciar eventos futuros, tornando-se difícil identificar as variáveis que de fato são relevantes. Esse autor também comenta que outra dificuldade técnica característica do monitoramento é o grande volume de informações disponíveis, que é um fator limitante do processo de procura de informações no ambiente. 
Observa-se que as dificuldades de natureza organizacional aparecem mais frequentemente do que as dificuldades técnicas, transformando-se em fatores de falha ou de abandono das atividades de monitoramento (LESCA; CARON-FASAN, 2008; FONSECA, 2012). Se o envolvimento dos gestores for inadequado, ou seja, se perderem o interesse pela atividade ou não prestarem o suporte necessário, bem como se o monitoramento não estiver alinhado com a estratégia da organização, aumentam-se as chances de insucesso. A falta de objetivos claros e consequentemente de um escopo bem definido para o monitoramento também é um fator de risco para essa atividade nas organizações.

Para avaliar as dificuldades do monitoramento no presente estudo, adaptou-se a escala proposta por Jain (1984) que mede o grau de importância de um conjunto de áreas de problemas do monitoramento. Essas questões utilizam indicadores em escala Likert de cinco pontos, sendo o extremo inferior correspondente a "1 - nada importante" e o extremo superior correspondente a "5 - muito importante". Os pontos intermediários 2, 3 e 4 não foram rotulados, e quanto mais elevado o ponto, mais importante é o problema para o desempenho das atividades de monitoramento.

No questionário, apresenta-se para o respondente a pergunta:

"Qual a importância dos problemas listados a seguir para as atividades de monitoramento do Ambiente de Negócios em empresas de modo geral?".

Após essa indagação, apresentam-se as questões mostradas no Quadro 16, observando-se que, na coluna "Tipo" do quadro, consta se o problema é de natureza técnica ou organizacional. 
Quadro 16 - Questões para avaliação dos problemas do monitoramento

\begin{tabular}{|c|l|c|}
\hline Indicadores & \multicolumn{1}{|c|}{ Questões em escala Likert de importância } & Tipo \\
\hline V28 & Falta de apoio dos gestores & \multirow{2}{*}{ Organizacional } \\
\hline V29 & Falta de recursos & \\
\hline V30 & Falta de atribuição de responsabilidades & \\
\hline V31 & Dificuldade para definir o escopo do monitoramento & \\
\hline V32 & Dificuldade para disseminar informações entre departamentos & \multirow{2}{*}{ Técnico } \\
\hline V33 & Dificuldade para avaliar o impacto do ambiente sobre as estratégias corporativas & \\
\hline V34 & Dificuldade para filtrar as informações realmente relevantes para a estratégia & \\
\hline V35 & Dificuldade para elaborar previsões sobre tendências futuras & \\
\hline
\end{tabular}

Ao final deste bloco, apresenta-se uma questão opcional de resposta aberta para o respondente citar outros problemas que considere relevante. O objetivo dessa questão foi permitir ao respondente expressar suas dificuldades na prática do monitoramento para posteriormente compartilhar os resultados em retribuição à participação na pesquisa. As respostas encontramse listadas no Apêndice 07, mas não serão objeto de análise no presente estudo.

\subsubsection{Bloco de Questões 05 - Orientação Estratégica}

Este bloco é composto por cinco questões de escolha múltipla e tem o objetivo de verificar o constructo orientação estratégica das organizações dos respondentes. Adotou-se o modelo sugerido por Miles e Snow (1978, 2003), o qual propõe quatro tipos de orientação estratégica:
a) Prospectora $(\mathrm{P})$;
b) Analítica (A);
c) Defensiva (D); e
d) Reativa (R). 
Estas questões foram extraídas e adaptadas de uma escala de onze questões elaborada por Conant et al. (1990). Segundo esses autores, as cinco questões selecionadas para o presente estudo se referem às dimensões dos problemas do ciclo adaptativo das organizações do modelo de Miles e Snow (1978, 2003), conforme mostrado no Quadro17 a seguir.

Quadro 17 - Dimensões das questões de orientação estratégica

\begin{tabular}{|l|l|l|}
\hline \multirow{2}{*}{} & \multicolumn{2}{|c|}{ Ciclo Adaptativo das Organi zações } \\
\cline { 2 - 3 } & Problema do Empreendedorismo & Problema Administrativo \\
\hline \multirow{4}{*}{ Dimensões } & $\begin{array}{l}\text { 1. Domínio produto/mercado } \\
\text { 2. Postura de sucesso }\end{array}$ & 5. Planejamento futuro \\
& $\begin{array}{l}\text { 3. Crescimento } \\
\text { 4. Monitoramento }\end{array}$ & \\
\hline
\end{tabular}

Fonte: Adaptado de Conant et al. (1990)

Em cada questão, o respondente deve escolher a alternativa que melhor caracteriza sua organização, e cada uma das quatro alternativas corresponde a um dos tipos de orientação estratégica P, A, D ou R propostos por Miles e Snow (1978, 2003).

No Quadro18, são mostradas as questões, observando-se que foi incluída em cada alternativa de resposta uma letra indicativa da orientação estratégica correspondente. Essas letras não constam no questionário apresentado aos respondentes, bem como os nomes das dimensões incluídas no referido quadro. 
Quadro 18 - Questões para avaliar a orientação estratégica

\begin{tabular}{|c|c|}
\hline Indicador & Questões do Problema do Empreendedorismo do Ciclo Adaptativo \\
\hline V37 & $\begin{array}{l}\text { 1. Os produtos ofertados pela nossa empresa são melhor caracterizados como: } \\
\text { P ( ) produtos mais inovadores e que mudam constantemente. } \\
\text { A ( ) produtos estáveis em certos mercados e inovadores em outros. } \\
\text { D ( ) produtos bem estáveis e bem definidos através do mercado. } \\
\text { R ( ) produtos transitórios para responder às oportunidades e ameaças do mercado. } \\
\text { Dimensão: domínio produto mercado }\end{array}$ \\
\hline V38 & $\begin{array}{l}\text { 2. A nossa imagem no mercado é principalmente de uma empresa que: } \\
\text { D ( ) oferece poucos produtos, mas de melhor qualidade, serviços superiores e/ou preços } \\
\text { menores. } \\
\text { A ( ) adota novas ideias e inovações, mas somente após uma análise muito cuidadosa. } \\
\text { R ( ) somente se arrisca em novos produtos quando pressionada pelos concorrentes. } \\
\text { P ( ) tem uma reputação de ser criativa e inovadora. } \\
\text { Dimensão: postura de sucesso }\end{array}$ \\
\hline V39 & $\begin{array}{l}\text { 3. Os aumentos ou reduções na demanda de nossos produtos se devem principalmente à } \\
\text { nossa prática de: } \\
\text { D ( ) concentrar no crescimento dos mercados aos quais já servimos. } \\
\text { P ( ) entrar agressivamente em novos mercados com novos tipos de produtos. } \\
\text { R ( ) de responder às pressões do mercado, correndo poucos riscos. } \\
\text { A ( ) crescer nos mercados que já servimos, enquanto adotamos novos produtos após uma } \\
\text { revisão criteriosa do seu potencial. } \\
\text { Dimensão: crescimento }\end{array}$ \\
\hline
\end{tabular}


Conclusão

\begin{tabular}{|c|c|}
\hline V40 & $\begin{array}{l}\text { 4. A quantidade de tempo que investimos no monitoramento de mudanças e tendências do } \\
\text { mercado é: } \\
\text { P ( ) elevada, pois nós estamos continuamente monitorando o mercado. } \\
\text { D ( ) mínima, pois nós realmente não investimos muito tempo no monitoramento do mercado. } \\
\text { A ( ) média, pois nós investimos um tempo razoável no monitoramento do mercado. } \\
\text { R ( ) irregular, pois às vezes investimos muito tempo no monitoramento do mercado e às vezes } \\
\text { pouco. } \\
\text { Dimensão: monitoramento }\end{array}$ \\
\hline Indicador & Questão do Problema Administrativo do Ciclo Adaptativo \\
\hline V41 & $\begin{array}{l}\text { 5. Em nossa empresa, procuramos nos preparar para o futuro identificando: } \\
\text { R ( ) a melhor solução possível para os problemas que requerem atenção imediata. } \\
\text { P ( ) tendências e oportunidades no mercado que possam resultar na criação de novos produtos } \\
\text { ou alcançar novos mercados. } \\
\text { D ( ) aqueles que, quando resolvidos, manterão ou melhorarão nossa oferta de produtos e } \\
\text { posição de mercado. } \\
\text { A ( ) as tendências da indústria que mostram potencial de longo prazo, enquanto resolvemos } \\
\text { problemas de produtos ou necessidades de clientes. } \\
\text { Dimensão: planejamento do futuro }\end{array}$ \\
\hline
\end{tabular}

Fonte: Adaptado de Conant et al. (1990, tradução nossa)

Os critérios para a escolha dessas cinco questões dentre as 11 da escala proposta por Conant et al. (1990) foram:

a) Miles e Snow $(1978,2003)$ associam o monitoramento com o problema do empreendedorismo;

b) na escala de Conant et al. (1990), essa associação é evidenciada pela dimensão "monitoramento" nas questões relativas ao problema do empreendedorismo; 
c) a dimensão de planejamento futuro relativa ao problema administrativo está associada ao monitoramento, pois requer a coleta de informações para a elaboração de estratégias (MILES; SNOW, 1978, 2003);

d) na literatura há evidências da influência da atitude empreendedora da organização sobre seu modo de monitoramento (QIU, 2008);

e) as dimensões escolhidas podem ser percebidas pelos respondentes; e

f) essas questões estão próximas do desdobramento da escala de parágrafo único proposta por Snow e Hrebiniak (1980) com o benefício de ser possível analisar as dimensões separadamente.

Para definir a orientação estratégica da organização do respondente a partir das cinco questões, utilizou-se a "regra da maioria" proposta pelos autores da escala, cujo algoritmo é mostrado a seguir.

a) Algoritmo da "Regra da Maioria"

Existe alguma orientação estratégica predominante dentre as cinco respostas, como por exemplo, três respostas de orientação estratégica Prospectora $(\mathrm{P})$, uma resposta Defensiva (D) e outra resposta Analítica (A)?

Sim: A orientação estratégica é a que apresentou predominância.

No exemplo anterior, a orientação estratégica seria Prospectora (P).

Não: Existe algum empate entre as respostas das cinco questões envolvendo a orientação estratégica Reativa (R)?

Sim: A orientação estratégica resultante é Reativa (R).

Não: A orientação estratégica resultante é Analítica (A). 
b) Exemplo de aplicação da "Regra da Maioria"

No Quadro 19, apresentam-se as respostas de quatro respondentes para as cinco questões e a orientação estratégica resultante para cada respondente na última linha.

Quadro 19 - Exemplos da aplicação da "Regra da Maioria"

\begin{tabular}{|c|c|c|c|c|}
\hline \multirow{2}{*}{ Questões } & \multicolumn{4}{|c|}{ Respondentes } \\
\cline { 2 - 5 } & $\mathbf{1}$ & $\mathbf{2}$ & $\mathbf{3}$ & $\mathbf{4}$ \\
\hline $\mathbf{1}$ & $\mathrm{R}$ & $\mathrm{P}$ & $\mathrm{A}$ & $\mathrm{P}$ \\
\hline $\mathbf{2}$ & $\mathrm{R}$ & $\mathrm{P}$ & $\mathrm{P}$ & $\mathrm{P}$ \\
\hline $\mathbf{3}$ & $\mathrm{D}$ & $\mathrm{R}$ & $\mathrm{P}$ & $\mathrm{P}$ \\
\hline $\mathbf{4}$ & $\mathrm{D}$ & $\mathrm{D}$ & $\mathrm{A}$ & $\mathrm{A}$ \\
\hline $\mathbf{5}$ & $\mathrm{A}$ & $\mathrm{D}$ & $\mathrm{D}$ & $\mathrm{R}$ \\
\hline Resultado & R & A & A & P \\
\hline
\end{tabular}

Fonte: Elaborado pela autora 


\subsubsection{Bloco de Questões 06 - Dados da Organização}

Este bloco do questionário apresenta seis questões de múltipla escolha para delinear o perfil das organizações dos respondentes, avaliando-se as características mostradas no Quadro 20.

Quadro 20 - Variáveis para delinear o perfil da organização

\begin{tabular}{|c|c|c|c|}
\hline & Variável & Alternativas de respostas & Observações \\
\hline V42 & Setor & $\begin{array}{l}\text { - Indústria de bens de consumo } \\
\text { - Indústria de bens de produção } \\
\text { - Construção civil } \\
\text { - Outros tipos de indústria } \\
\text { - Comércio atacadista } \\
\text { - Comérico varejista } \\
\text { - Serviços de engenharia } \\
\text { - Serviços financeiros } \\
\text { - Serviços de TI } \\
\text { - Outros tipos de serviços }\end{array}$ & $\begin{array}{l}\text { Adaptação da escala utilizada por } \\
\text { Trevisani (2006) em seu estudo } \\
\text { com organizações fornecedoras } \\
\text { do Serviço Público. } \\
\text { Incluiu-se um campo de resposta } \\
\text { aberta para complementar as } \\
\text { respostas "Outros tipos [...]" }\end{array}$ \\
\hline V43 & Capital & $\begin{array}{l}\text { - Privado } \\
\text { - Público } \\
\text { - Misto }\end{array}$ & \\
\hline V44 & Nacionalidade & $\begin{array}{l}\text { - Nacional } \\
\text { - Multinacional }\end{array}$ & $\begin{array}{l}\text { Nacional: empresas brasileiras que } \\
\text { desenvolvem negócios dentro e } \\
\text { fora do país } \\
\text { Multinacional: empresas que } \\
\text { possuem matriz em outro país e } \\
\text { subsidiária(s) local(is) }\end{array}$ \\
\hline V45 & Funcionários & $\begin{array}{l}\text { - } 500 \text { ou mais } \\
\text { - de } 100 \text { a } 499 \\
\text { - de } 50 \text { a } 99 \\
\text { - de } 20 \text { a } 49 \\
\text { - de } 10 \text { a } 19 \\
\text { - até } 9 \text { funcionários }\end{array}$ & $\begin{array}{l}\text { Combinação das faixas das } \\
\text { escalas do SEBRAE para a } \\
\text { indústria e comércio/serviço }\end{array}$ \\
\hline V46 & $\begin{array}{l}\text { Faturamento anual } \\
\text { (em milhões de R\$) }\end{array}$ & $\begin{array}{l}\text { - Microempresa : até } 2,4 \\
\text { - Pequena empresa: de } 2,4 \text { a } 16 \\
\text { - Média empresa: de } 16 \text { a } 90 \\
\text { - Média-grande empresa: de } 90 \text { a } 300 \\
\text { - Grande empresa: acima de } 300\end{array}$ & Critério do BNDES \\
\hline V47 & Tempo de existência & $\begin{array}{l}\text { - mais de } 20 \text { anos } \\
\text { - de } 10 \text { a } 20 \text { anos } \\
\text { - de } 5 \text { a } 10 \text { anos } \\
\text { - de } 1 \text { a } 5 \text { anos } \\
\text { - menos de } 1 \text { ano }\end{array}$ & \\
\hline
\end{tabular}




\subsubsection{Bloco de Questões 07 - Dados do Respondente}

Este bloco do questionário apresenta seis questões de múltipla escolha para delinear o perfil do respondente, avaliando-se suas características pessoais e funcionais mostradas nos Quadros 21 e 22 respectivamente.

Quadro 21 - Características pessoais do respondente

\begin{tabular}{|c|c|c|}
\hline \multicolumn{2}{|c|}{ Variável } & Alternativas de respostas \\
\hline V48 & Gênero & $\begin{array}{l}\text { - Feminino } \\
\text { - Masculino }\end{array}$ \\
\hline V49 & Idade & $\begin{array}{l}\text { - menos de } 20 \text { anos } \\
\text { - de } 20 \text { a } 24 \text { anos } \\
\text { - de } 25 \text { a } 29 \text { anos } \\
\text { - de } 30 \text { a } 34 \text { anos } \\
\text { - de } 35 \text { a } 39 \text { anos } \\
\text { - de } 40 \text { a } 49 \text { anos } \\
\text { - de } 50 \text { a } 60 \text { anos } \\
\text { - acima de } 60 \text { anos }\end{array}$ \\
\hline V50 & Escolaridade & $\begin{array}{l}\text { - Pós-doutorado } \\
\text { - Doutorado } \\
\text { - Mestrado } \\
\text { - Especialização } \\
\text { - Superior completo } \\
\text { - Superior incompleto } \\
\text { - Segundo grau completo } \\
\text { - Segundo grau incompleto } \\
\text { - Primeiro grau completo } \\
\text { - Primeiro grau incompleto }\end{array}$ \\
\hline
\end{tabular}


Quadro 22 - Características funcionais do respondente

\begin{tabular}{|c|c|c|}
\hline \multicolumn{2}{|r|}{ Variável } & Alternativas de respostas \\
\hline V51 & Cargo & $\begin{array}{l}\text { - CEO } \\
\text { - Diretor } \\
\text { - Gerente } \\
\text { - Supervisor } \\
\text { - Analista } \\
\text { - Técnico } \\
\text { - Outro }\end{array}$ \\
\hline V52 & Área da empresa & $\begin{array}{l}\text { - Administração } \\
\text { - Estratégia } \\
\text { - Inteligência } \\
\text { - Marketing } \\
\text { - P\&D } \\
\text { - Produção } \\
\text { - Vendas } \\
\text { - TI } \\
\text { - Outra }\end{array}$ \\
\hline V53 & Tempo na empresa & $\begin{array}{l}\text { - menos de } 1 \text { ano } \\
\text { - de } 1 \text { a menos de } 2 \text { anos } \\
\text { - de } 2 \text { a menos de } 5 \text { anos } \\
\text { - de } 5 \text { a menos de } 10 \text { anos } \\
\text { - } 10 \text { ou mais anos }\end{array}$ \\
\hline
\end{tabular}

Observações:

a) Para as questões V51 e V52 que possuem a alternativa "Outro", incluiu-se um campo de resposta aberta para complementação pelo respondente.

b) $\mathrm{Na}$ finalização do questionário, foi incluso um campo opcional para o respondente informar seu email para receber os resultados da pesquisa caso assim o desejasse. 


\subsection{Estratégia de Coleta}

A captação de indivíduos representativos para responder o questionário (coleta) ocorreu em duas etapas, sendo a primeira baseada em convites coletivos e a segunda, em convites individuais. Em ambas as etapas, utilizaram-se os recursos de comunicação dos grupos do LinkedIn. Adicionalmente, houve a captação de profissionais de monitoramento em dois eventos presenciais, utilizando-se formulários impressos do questionário da pesquisa.

A seguir, essas etapas de captação de respondentes são descritas, bem como a amostra resultante.

\subsubsection{Primeira Etapa da Coleta}

Nesta etapa, considerou-se que a amostra seria formada apenas pela adesão voluntária dos membros em atendimento a convites coletivos para participação postados nos fóruns de discussão dos grupos do LinkedIn. Nesses convites, cujos modelos encontram-se no Apêndice 01, informavam-se os objetivos da pesquisa, o perfil procurado dos respondentes e o link para acessar o questionário da pesquisa via Web.

Para escolher os grupos, utilizou-se o conhecimento prévio dos pesquisadores sobre os grupos de Inteligência Competitiva disponíveis no LinkedIn. Foram escolhidos três grupos, incluindo-se o grupo criado em 2010 pelo capítulo brasileiro da Strategic and Competitive Intelligence Professionals (SCIP). A SCIP é a maior organização sem fins lucrativos de profissionais de Inteligência Competitiva, fundada em 1986 nos EUA, e que conta atualmente com mais de 3.000 associados distribuídos entre 70 países (SCIP, 2013).

A esses três grupos, adicionou-se o grupo do LinkedIn formado por alunos e egressos da FEA USP, pois muitos seguiram carreira nas áreas prospectadas por este estudo e, por afinidade, poderia haver uma predisposição de participação voluntária na pesquisa. Na Tabela 2, apresentam-se os grupos escolhidos para a coleta, sendo que os nomes dos grupos foram substituídos por letras para preservar as informações LinkedIn. 
Tabela 2 - Coleta através de convites coletivos do LinkedIn

\begin{tabular}{cccc}
\hline Grupo & $\begin{array}{c}\text { Qtde. de membros } \\
\text { do grupo }\end{array}$ & $\begin{array}{c}\text { Ano de criação } \\
\text { do grupo }\end{array}$ & $\begin{array}{c}\text { Data de postagem } \\
\text { dos convites }\end{array}$ \\
\hline A & 89 & 2010 & $08 / 05 / 2013$ \\
B & 777 & 2010 & $10 / 05 / 2013$ \\
C & 3.271 & 2008 & $12 / 05 / 2013$ \\
D & 3.768 & 2010 & $12 / 05 / 2013$ \\
\hline Total & $\mathbf{7 . 9 0 5}$ & & \\
\hline
\end{tabular}

Fonte: Dados extraídos de LinkedIn Groups (2013)

É importante observar que nem todos os membros dos grupos selecionados são profissionais de monitoramento, pois também ocorre a adesão de outros simpatizantes pelo tema. Observase também que no grupo da FEA USP há profissionais de diversas disciplinas da Administração, sendo os profissionais de monitoramento apenas uma parcela. Outro aspecto relevante é que ocorre repetição dos membros entre os grupos, ou seja, um mesmo membro pode estar filiado a mais de um grupo. Consequentemente, o tamanho do universo pesquisado não corresponde à somatória dos membros dos grupos selecionados.

No período de 08 a 21 de maio de 2013 coletaram-se 28 questionários e ao término da coleta em 08 de julho de 2013, totalizavam-se 36 questionários obtidos por esse procedimento. Observa-se que os convites expirariam em 02 de junho de 2013, mas permaneceram disponíveis online sem novas chamadas até o término da coleta.

\subsubsection{Segunda Etapa da Coleta}

Nesta etapa, enviaram-se convites individuais e nominais para os membros dos grupos com o objetivo de aumentar a adesão de respondentes. A escolha dos profissionais para o envio dos convites ocorreu através da inspeção dos seus cargos e perfis no LinkedIn para verificar se realizavam atividades de monitoramento em organizações. Observa-se que o LinkedIn permite a visualização apenas dos 500 membros mais relevantes de cada grupo, os quais são 
exibidos em uma sequência de 25 telas com 20 membros cada, não sendo possível inspecionar todos os membros de um grupo.

Nessa etapa também, selecionou-se mais um grupo de profissionais de monitoramento para aumentar a quantidade de respondentes em potencial. Para escolher esse grupo, utilizou-se o mecanismo de procura de grupos no LinkedIn informando-se a palavra-chave "Inteligência" e filtrando-se os grupos com mais de 50 membros. Identificaram-se 11 grupos, excluindo-se os já selecionados, e escolheu-se o "Grupo E" com base nas informações de seu perfil e pelo fato de ser um grupo fechado e seleto de Inteligência Competitiva. Após a autorização do moderador do grupo para entrada, constatou-se por inspeção parcial que o grupo de fato estava adequado aos propósitos do estudo e continha 1.198 membros. No Apêndice 02, encontra-se a relação dos 11 grupos adicionais identificados pela busca por palavra-chave.

Para o envio dos convites individuais, analisou-se o perfil de cada um dos membros mais relevantes dos Grupos A, C, B e E, nessa ordem. Para o Grupo D, não foram enviados convites individuais, pois em uma inspeção inicial constatou-se que a maior parte de seus profissionais de monitoramento, dentre os 500 mais relevantes, já havia sido inclusa nos quatro grupos anteriormente inspecionados. Na Tabela 3, apresenta-se a quantidade de convites individuais enviados no período de 22 de maio a 14 de junho de 2013.

Tabela 3 - Coleta através de convites individuais no LinkedIn

\begin{tabular}{cccc}
\hline \multirow{2}{*}{ Grupo } & $\begin{array}{c}\text { Qtde. de membros } \\
\text { analisados }\end{array}$ & \multicolumn{2}{c}{$\begin{array}{c}\text { Qtde. de membros } \\
\text { selecionados }\end{array}$} \\
\cline { 3 - 4 } & 89 & $\mathbf{n}$ & $\%$ \\
\hline A & 500 & 25 & $28,1 \%$ \\
B & 500 & 37 & $7,4 \%$ \\
C & 500 & 279 & $55,8 \%$ \\
E & $\mathbf{1 . 5 8 9}$ & 137 & $27,4 \%$ \\
\hline Total & & $\mathbf{4 7 8}$ & $\mathbf{3 0 , 1 \%}$ \\
\hline
\end{tabular}

Fonte: Dados extraídos de LinkedIn Groups (2013) 
Para os 478 convites enviados, que corresponderam a $30 \%$ do total de membros inspecionados, obtiveram-se 169 questionários respondidos no período de 22 de maio a 08 de julho de 2013 com uma taxa de retorno de 35\%. Entretanto, 11 questionários foram descartados por estarem incompletos, resultando em 158 questionários aproveitados, correspondendo a $33 \%$ do total de convites enviados.

\subsubsection{Coleta em Formulário Impresso}

Além da coleta online, houve duas coletas de questionários em formulário impresso. A primeira foi em um evento gratuito promovido pela SCIP Brasil no dia 24 de maio de 2013 na Fundação Instituto de Pesquisas Econômicas (FIPE), na cidade de São Paulo, intitulado "Para onde a Inteligência Competitiva caminha?", no qual se fez uma breve apresentação da pesquisa, e obtiveram-se 22 questionários preenchidos de uma plateia de aproximadamente 50 participantes. A segunda ocorreu em duas turmas do curso MBA - Inteligência Estratégica, Competitiva e Econômica da FIPE em 24 de maio e 07 de junho de 2013, obtendo-se 16 questionários preenchidos, dos quais um foi descartado por preenchimento não consistente. 


\subsubsection{Amostra Resultante}

$\mathrm{Na}$ coleta de questionários realizada no período de 08 de maio a 08 de julho de 2013 , obtevese uma amostra de 195 profissionais de monitoramentos. No LinkedIn, identificou-se a modalidade da coleta - convite coletivo ou individual - por meio de uma pergunta específica ao final do questionário.

Na Tabela 4, apresenta-se a amostra estratificada por tipo de coleta. Observa-se que os questionários considerados incompletos são os que não apresentaram as questões sobre o perfil do respondente e/ou da organização preenchidas. Para esses questionários, não foi possível identificar sua modalidade e foram classificados apenas como "incompletos" em uma linha específica na referida tabela.

Tabela 4 - Amostra resultante

\begin{tabular}{cccc}
\hline \multirow{2}{*}{ Tipo de coleta } & \multicolumn{2}{c}{ Questionários } & $\begin{array}{c}\text { \% } \\
\text { Utilização }\end{array}$ \\
\cline { 2 - 3 } & Preenchidos & Utilizados & \\
\hline Online pelo LinkedIn & & & \\
Convites coletivos & 36 & 36 & $100,00 \%$ \\
Convites individuais & 122 & 122 & $100,00 \%$ \\
Incompletos & 11 & 0 & $0,00 \%$ \\
Subtotal & 169 & 158 & $93,49 \%$ \\
Formulário impresso & & & \\
Evento SCIP & 22 & 22 & $100,00 \%$ \\
MBA FIPE & 16 & 15 & $93,75 \%$ \\
Subtotal & 38 & 37 & $97,37 \%$ \\
\hline \multicolumn{1}{c}{ Total } & $\mathbf{2 0 7}$ & $\mathbf{1 9 5}$ & $\mathbf{9 4 , 2 0 \%}$ \\
\hline
\end{tabular}




\subsection{Caracterização da Amostra}

\subsubsection{Porte das Organizações dos Respondentes}

Para o presente estudo, o porte das organizações dos respondentes foi classificado pelo critério de faturamento anual do BNDES - Banco Nacional de Desenvolvimento Econômico e Social (BNDES, 2013). Por esse critério, observa-se o predomínio de organizações de grande porte $(66,2 \%)$, conforme os dados apresentados na Tabela 5.

Tabela 5 - Porte das organizações dos respondentes

\begin{tabular}{llccc}
\hline \multicolumn{1}{c}{ Porte } & $\begin{array}{c}\text { Faturamento anual } \\
\text { (R\$ milhões) }\end{array}$ & n & \% & \% Acumulado \\
\hline Grande & acima de 300 & 129 & $66,2 \%$ & $66,2 \%$ \\
Média-Grande & de 90 a 300 & 19 & $9,7 \%$ & $75,9 \%$ \\
Média & de 16 a 90 & 25 & $12,8 \%$ & $88,7 \%$ \\
Pequena & de 2,4 a 16 & 16 & $8,2 \%$ & $96,9 \%$ \\
Micro & até 2,4 & 6 & $3,1 \%$ & $100,0 \%$ \\
\hline \multicolumn{1}{c}{ Total } & $\mathbf{1 9 5}$ & $\mathbf{1 0 0 , 0 \%}$ & \\
\hline
\end{tabular}

O número de funcionários é um outro indicativo usual do porte das organizações. Na Tabela 6, utilizou-se a combinação das faixas de número de funcionários para a indústria e para o comércio/serviço sugeridas pelo Serviço de Apoio às pequenas e Médias Empresas (SEBRAE). Verifica-se que há um predomínio (72,3\%) de organizações com mais de 500 funcionários, sendo um indicativo de organizações de grande porte, tanto para a indústria quanto para o comércio e serviços pelos critérios do SEBRAE. 
Tabela 6 - Número de funcionários das organizações dos respondentes

\begin{tabular}{lccc}
\hline Funcionários & n & \% & \% Acumulado \\
\hline 500 ou mais & 141 & $72,3 \%$ & $72,3 \%$ \\
de 100 a 499 & 26 & $13,3 \%$ & $85,6 \%$ \\
de 50 a 99 & 9 & $4,6 \%$ & $90,3 \%$ \\
de 20 a 49 & 9 & $4,6 \%$ & $94,9 \%$ \\
de 10 a 19 & 4 & $2,1 \%$ & $96,9 \%$ \\
até 9 & 6 & $3,1 \%$ & $100,0 \%$ \\
\hline \multicolumn{1}{c}{ Total } & $\mathbf{1 9 5}$ & $\mathbf{1 0 0 , 0 \%}$ & \\
\hline
\end{tabular}

Na Tabela 7, apresenta-se a classificação das organizações pelo tempo de existência, que é um indicativo de maturidade organizacional. Observa-se um forte predomínio de empresas maduras com pelo menos 10 anos de existência $(89,2 \%)$.

Tabela 7 - Maturidade das organizações dos respondentes

\begin{tabular}{rccc}
\hline Tempo & n & \% & \% Acumulado \\
\hline mais de 20 anos & 134 & $68,7 \%$ & $68,7 \%$ \\
de 10 a 20 anos & 40 & $20,5 \%$ & $89,2 \%$ \\
de 5 a 10 anos & 8 & $4,1 \%$ & $93,3 \%$ \\
de 1 a 5 anos & 11 & $5,6 \%$ & $99,0 \%$ \\
menos de 1 ano & 2 & $1,0 \%$ & $100,0 \%$ \\
\hline Total & $\mathbf{1 9 5}$ & $\mathbf{1 0 0 , 0 \%}$ & \\
\hline
\end{tabular}

Considerando-se que o porte e a maturidade são fatores que podem influenciar o modo de monitoramento das organizações (THOMAS, 1980; CHOO, 2002), optou-se por analisar os questionários cujas organizações dos respondentes atendiam aos seguintes requisitos:

- faturamento anual acima de $\mathrm{R} \$ 300$ milhões;

- mínimo de 100 funcionários; e

- mínimo de 10 anos de existência. 
Escolheu-se esse segmento para se alcançar maior homogeneidade das organizações na amostra, mantendo-se uma quantidade razoável de 120 observações. Esse estrato da amostra ficou estabelecido como objeto de análise do presente estudo, ou seja, como a amostra efetiva.

\subsubsection{Características das Organizações na Amostra Efetiva}

Nesta seção, limitou-se a apresentação dos dados às 120 observações da amostra efetiva e que correspondem a 61,5\% do total de 195 questionários válidos. No Apêndice 04, podem ser consultadas as tabulações para a amostra completa.

$\mathrm{Na}$ Tabela 8, apresenta-se novamente a distribuição das organizações pela quantidade de funcionários considerando a amostra efetiva. Verifica-se o predomínio de organizações de grande porte, quase que na totalidade, com mais de 500 funcionários $(96,7 \%)$. As quatro organizações com menos de 500 funcionários na referida tabela pertencem ao setor de serviços e, portanto, podem ser consideradas empresas de grande porte pelos critérios do SEBRAE.

Tabela 8 - Número de funcionários das organizações dos respondentes

\begin{tabular}{cccc}
\hline Funcionários & $\mathbf{n}$ & $\mathbf{\%}$ & \% Acumulado \\
\hline 500 ou mais & 116 & $96,7 \%$ & $96,7 \%$ \\
de 100 a 499 & 4 & $3,3 \%$ & $100,0 \%$ \\
\hline Total & $\mathbf{1 2 0}$ & $\mathbf{1 0 0 , 0 \%}$ & \\
\hline
\end{tabular}

Na Tabela 9, apresenta-se uma nova distribuição das organizações pela maturidade, considerando-se apenas a amostra efetiva. Verifica-se o predomínio de organizações bastante maduras com mais de 20 anos de existência (83,3\%). 
Tabela 9 - Maturidade das organizações dos respondentes

\begin{tabular}{cccc}
\hline Tempo de existência & $\mathbf{n}$ & $\boldsymbol{\%}$ & \% Acumulado \\
\hline mais de 20 anos & 100 & $83,3 \%$ & $83,3 \%$ \\
de 10 a 20 anos & 20 & $16,7 \%$ & $100,0 \%$ \\
\hline Total & $\mathbf{1 2 0}$ & $\mathbf{1 0 0 , 0 \%}$ & \\
\hline
\end{tabular}

$\mathrm{Na}$ Tabela 10, apresentam-se as organizações classificadas pela origem de seu capital. Verifica-se que há uma forte predominância de empresas de capital privado $(90,8 \%)$.

Tabela 10 - Origem do capital das organizações dos respondentes

\begin{tabular}{lcc}
\hline Capital & n & \% \\
\hline Privado & 109 & $90,8 \%$ \\
Público & 8 & $6,7 \%$ \\
Misto & 3 & $2,5 \%$ \\
\hline Total & $\mathbf{1 2 0}$ & $\mathbf{1 0 0 , 0 \%}$ \\
\hline
\end{tabular}

Na Tabela 11, apresentam-se as organizações classificadas segundo a nacionalidade ${ }^{3}$, com uma moderada predominância de empresas multinacionais $(58,3 \%)$.

Tabela 11 - Nacionalidade das organizações dos respondentes

\begin{tabular}{lcc}
\hline \multicolumn{1}{c}{ Tipo } & $\mathbf{n}$ & $\boldsymbol{\%}$ \\
\hline Nacional & 50 & $41,7 \%$ \\
Multinacional & 70 & $58,3 \%$ \\
\hline Total & $\mathbf{1 2 0}$ & $\mathbf{1 0 0 , 0 \%}$ \\
\hline
\end{tabular}

\footnotetext{
${ }^{3}$ A categoria de empresas nacionais engloba tanto as empresas brasileiras que desenvolvem negócios apenas em território nacional quanto as que desenvolvem negócios com outros países (transnacionais). A categoria de empresas multinacionais engloba as que possuem matriz em outro país e subsidiária(s) local(is).
} 
Na Tabela 12, as organizações são classificadas pelo grupo setorial ao qual pertencem. No geral, há um predomínio de organizações dos setores da indústria $(45,8 \%)$ e de serviços (50,0\%), sendo a participação do setor de serviços superior. O setor do comércio apresenta uma participação pequena $(4,2 \%)$, e as suas organizações serão analisadas com as do setor de serviços, considerando-se que o SEBRAE atribui a mesma classificação de porte pela quantidade de funcionários para esses dois setores.

Tabela 12 - Grupos setoriais das organizações dos respondentes

\begin{tabular}{lcc}
\hline Grupo Setorial & $\mathbf{n}$ & $\mathbf{\%}$ \\
\hline Indústria & 55 & $45,8 \%$ \\
Comércio & 5 & $4,2 \%$ \\
Serviços & 60 & $50,0 \%$ \\
\hline \multicolumn{1}{c}{ Total } & $\mathbf{1 2 0}$ & $\mathbf{1 0 0 , 0 \%}$ \\
\hline
\end{tabular}

Na Tabela 13, apresenta-se um detalhamento dos setores das organizações, utilizando-se uma adaptação da classificação sugerida por Trevisani (2006) em seu estudo com empresas fornecedoras do setor público. Observa-se uma concentração de organizações na categoria "Outro" tanto para serviços $(26,7 \%)$ quanto para a indústria (17,5\%). No Apêndice 05, mostra-se um desdobramento dessa categoria, listando-se todos os setores informados no campo complementar de resposta aberta para essa categoria. 
Tabela 13 - Setores das organizações dos respondentes

\begin{tabular}{lcc}
\hline \multicolumn{1}{c}{ Setor } & n & \% \\
\hline Indústria de bens de consumo & 16 & $13,3 \%$ \\
Indústria de bens de produção & 14 & $11,7 \%$ \\
Construção civil & 4 & $3,3 \%$ \\
Outros tipos de indústria & 21 & $17,5 \%$ \\
Comércio atacadista & 1 & $0,8 \%$ \\
Comércio varejista & 4 & $3,3 \%$ \\
Serviços de engenharia & 1 & $0,8 \%$ \\
Serviços financeiros & 16 & $13,3 \%$ \\
Serviços de TI & 11 & $9,2 \%$ \\
Outros tipos de serviços & 32 & $26,7 \%$ \\
\hline \multicolumn{1}{c}{ Total } & $\mathbf{1 2 0}$ & $\mathbf{1 0 0 , 0 \%}$ \\
\hline
\end{tabular}

\subsubsection{Características dos Respondentes na Amostra Efetiva}

Na Tabela 14, mostra-se a distribuição dos respondentes por gênero. É possível evidenciar uma predominância do gênero masculino (60\%) sobre o gênero feminino (40\%).

Tabela 14 - Gênero dos respondentes

\begin{tabular}{ccc}
\hline Gênero & $\mathbf{n}$ & $\mathbf{\%}$ \\
\hline Feminino & 48 & $40,0 \%$ \\
Masculino & 72 & $60,0 \%$ \\
\hline Total & $\mathbf{1 2 0}$ & $\mathbf{1 0 0 , 0 \%}$ \\
\hline
\end{tabular}

Na Tabela 15, mostra-se a distribuição dos respondentes por faixa etária. Verifica-se uma predominância dos respondentes que possuem no mínimo 30 anos de idade $(65,8 \%)$, podendo ser esse um indicativo de maturidade dos respondentes. 
Tabela 15 - Idade dos respondentes

\begin{tabular}{cccc}
\hline Faixa etária & $\mathbf{n}$ & $\mathbf{\%}$ & \% Acumulado \\
\hline de 50 a 60 anos & 4 & $3,3 \%$ & $3,3 \%$ \\
de 40 a 49 anos & 18 & $15,0 \%$ & $18,3 \%$ \\
de 35 a 39 anos & 21 & $17,5 \%$ & $35,8 \%$ \\
de 30 a 34 anos & 36 & $30,0 \%$ & $65,8 \%$ \\
de 25 a 29 anos & 33 & $27,5 \%$ & $93,3 \%$ \\
de 20 a 24 anos & 8 & $6,7 \%$ & $100,0 \%$ \\
\hline Total & $\mathbf{1 2 0}$ & $\mathbf{1 0 0 , 0 \%}$ & \\
\hline
\end{tabular}

Na Tabela 16, mostra-se a distribuição dos respondentes por nível de escolaridade. Observase que os respondentes apresentam um nível elevado de escolaridade, pois 97,5\% possuem no mínimo o curso superior completo e 79,2\% são pós-graduados.

Tabela 16 - Escolaridade dos respondentes

\begin{tabular}{lccc}
\hline \multicolumn{1}{c}{ Escolaridade } & n & \% & \% Acumulado \\
\hline Pós-doutorado & 1 & $0,8 \%$ & $0,8 \%$ \\
Doutorado & 2 & $1,7 \%$ & $2,5 \%$ \\
Mestrado & 19 & $15,8 \%$ & $18,3 \%$ \\
Especialização (Lato Sensu) & 73 & $60,8 \%$ & $79,2 \%$ \\
Superior completo & 22 & $18,3 \%$ & $97,5 \%$ \\
Superior incompleto & 3 & $2,5 \%$ & $100,0 \%$ \\
\multicolumn{1}{c}{ Total } & $\mathbf{1 2 0}$ & $\mathbf{1 0 0 , 0 \%}$ & \\
\hline
\end{tabular}

$\mathrm{Na}$ Tabela 17, apresentam-se faixas para a classificação dos respondentes segundo a quantidade de anos que trabalham na organização. Verifica-se que há uma predominância com $35,0 \%$ de respondentes que trabalham na organização entre dois e cinco anos, e 36,7\% apresentam tempo superior a cinco anos. 
Tabela 17 - Tempo de atuação dos respondentes nas organizações

\begin{tabular}{lccc}
\hline Tempo na empresa & n & \% & \% Acumulado \\
\hline 10 anos ou mais & 17 & $14,2 \%$ & $14,2 \%$ \\
de 5 a 10 anos & 27 & $22,5 \%$ & $36,7 \%$ \\
de 2 a 5 anos & 42 & $35,0 \%$ & $71,7 \%$ \\
de 1 a 2 anos & 17 & $14,2 \%$ & $85,8 \%$ \\
menos de 1 ano & 17 & $14,2 \%$ & $100,0 \%$ \\
\hline \multicolumn{1}{c}{ Total } & $\mathbf{1 2 0}$ & $\mathbf{1 0 0 , 0 \%}$ & \\
\hline
\end{tabular}

Na Tabela 18, mostra-se a distribuição dos respondentes por área de atuação na organização. Observa-se uma concentração na área de Inteligência que engloba quase a metade dos respondentes com $49,2 \%$.

Tabela 18 - Áreas de atuação dos respondentes nas organizações

\begin{tabular}{lcc}
\hline \multicolumn{1}{c}{ Área } & $\mathbf{n}$ & $\mathbf{\%}$ \\
\hline Administração & 1 & $0,8 \%$ \\
Estratégia & 20 & $16,7 \%$ \\
Inteligência & 59 & $49,2 \%$ \\
Marketing & 23 & $19,2 \%$ \\
P\&D & 3 & $2,5 \%$ \\
Produção & 2 & $1,7 \%$ \\
Vendas & 7 & $5,8 \%$ \\
TI & 1 & $0,8 \%$ \\
Outra & 4 & $3,3 \%$ \\
\hline \multicolumn{1}{c}{ Total } & $\mathbf{1 2 0}$ & $\mathbf{1 0 0 , 0 \%}$ \\
\hline
\end{tabular}

$\mathrm{Na}$ Tabela 19, apresenta-se a distribuição dos respondentes pelo cargo ocupado na organização. Observa-se que 55,8\% dos respondentes possuem o cargo mínimo de Supervisor, considerando-se uma hierarquia para os cargos da tabela. Os respondentes que escolheram a categoria "Outro" e descreveram seu cargo na questão de resposta aberta "Complemente para a opção Outro" foram reclassificados em categorias já existentes ou em 
novas criadas a partir dessas respostas. Por esse motivo, a categoria "Outro" não consta na referida tabela.

Tabela 19 - Cargos dos respondentes nas organizações

\begin{tabular}{lccc}
\hline Cargo & $\mathbf{n}$ & $\mathbf{\%}$ & \% Acumulado \\
\hline Diretor & 9 & $7,5 \%$ & $7,5 \%$ \\
Gerente & 36 & $30,0 \%$ & $37,5 \%$ \\
Coordenador & 2 & $1,7 \%$ & $39,2 \%$ \\
Supervisor & 20 & $16,7 \%$ & $55,8 \%$ \\
Analista / Especialista / Consultor & 49 & $40,8 \%$ & $96,7 \%$ \\
Assistente / Técnico / Trainee & 4 & $3,3 \%$ & $100,0 \%$ \\
\multicolumn{2}{c}{ Total } & $\mathbf{1 2 0}$ & $\mathbf{1 0 0 , 0 \%}$ \\
\hline
\end{tabular}




\subsection{Análise e Tratamento dos Dados}

A análise dos dados coletados foi subdividida em três etapas para atingir os objetivos deste estudo e formular a resposta para a indagação de pesquisa: "Existe relação entre o modo de monitoramento e a orientação estratégica das organizações?".

Na primeira etapa, as organizações dos respondentes foram classificadas segundo os tipos de orientação estratégica Prospectora, Analítica, Defensiva e Reativa da tipologia proposta por Miles e Snow (1978, 2003). Investigou-se também a existência de relação entre a orientação estratégica e as características das organizações com base nas questões do último bloco do questionário. Nessa etapa, procurou-se alcançar o primeiro objetivo específico do presente estudo: "identificar a orientação estratégica das organizações pesquisadas".

$\mathrm{Na}$ segunda etapa, classificou-se o modo de monitoramento das organizações dos respondentes entre as modalidades procura formal e procura informal propostas por Aguilar (1967), obtendo-se dois grupos. Adicionalmente, descreveram-se esses grupos com base nas fontes de informação, escopo e dificuldades do monitoramento. Assim, buscou-se atingir o segundo objetivo específico do presente estudo: "identificar o modo como as organizações monitoram o ambiente externo".

Na terceira e última etapa, verificou-se a existência de relação entre a orientação estratégica e o modo de monitoramento das organizações dos respondentes, sendo esse o objetivo principal do presente estudo.

Considerando-se que este estudo é de natureza quantitativa, os procedimentos em cada etapa envolveram a escolha de técnicas estatísticas adequadas ao nível de medição das variáveis e aos objetivos a serem alcançados (SAMPIERI et al., 2012). A estratégia para a análise dos dados está sumarizada no Quadro 23, mostrando-se os procedimentos, as variáveis e as técnicas em cada etapa da análise. Observa-se que o procedimento de maior importância em cada etapa está destacado com um círculo. 
Quadro 23 - Estratégia para a análise dos dados

\begin{tabular}{|c|c|c|c|}
\hline \multicolumn{2}{|r|}{$1^{\text {a }}$ etapa - Identificação da Orientação Estratégica (OE) } & Variáveis & Técnica \\
\hline & $\begin{array}{l}\text { Classificação das organizações segundo os tipos de orientação estratégica A, } \\
\text { P, D e R }\end{array}$ & V37 a V41 & - "Regra da Maioria" - escala de Conant et al. (1990) \\
\hline 2 & $\begin{array}{l}\text { Investigação da existência de relação entre a orientação estratégica e o setor } \\
\text { e a nacionalidade das organizações }\end{array}$ & V42 e V44 & - Estatística não paramétrica: teste qui-quadrado \\
\hline \multicolumn{2}{|r|}{$2^{\text {a }}$ etapa - Identificação do Modo de Monitoramento (MM) } & Variáveis & Técnica \\
\hline \multirow[t]{2}{*}{1} & $\begin{array}{l}\text { Análise descritiva das variáveis do primeiro bloco do questionário relativo ao } \\
\text { modo de monitoramento das organizações }\end{array}$ & V01 a V15 & - Estatística descritiva: posição e dispersão \\
\hline & $\begin{array}{l}\text { Subdivisão da amostra em dois grupos diferenciados segundo o modo de } \\
\text { monitoramento (Procura Formal ou Procura Informal) }\end{array}$ & V01 a V15 & $\begin{array}{l}\text { - Estatística multivariada: Análise de Conglomerados e } \\
\text { Análise Discriminante }\end{array}$ \\
\hline 3 & $\begin{array}{l}\text { Sumarização das variáveis significativas na divisão da amostra nos dois } \\
\text { grupos (identificação de fatores) }\end{array}$ & $\begin{array}{l}\text { V01 e } \\
\text { V03 a V15 }\end{array}$ & - Estatística multivariada: Análise Fatorial \\
\hline 4 & Descrição dos dois grupos pelos critérios: & & \\
\hline & - fatores do modo de monitoramento & F01 a F03 & - Estatística paramétrica: teste $\mathrm{t}$ de Student \\
\hline & - fontes de informação & V16 a V19 & \multirow{3}{*}{$\begin{array}{l}\text { - Estatística não paramétrica: teste de Mann-Whitney } \\
\text { teste de Friedman }\end{array}$} \\
\hline & - escopo de monitoramento & V20 a V27 & \\
\hline & - dificuldades de monitoramento & V28 a V35 & \\
\hline \multicolumn{2}{|r|}{$3^{a}$ etapa - Verificação da existência de relação entre OE e MM } & Variáveis & Técnica \\
\hline & $\begin{array}{l}\text { Análise cruzada da orientação estratégica e do modo de monitoramento das } \\
\text { organizações }\end{array}$ & OE e MM & - Estatística não paramétrica: teste qui-quadrado \\
\hline
\end{tabular}


Sampieri et al. (2012) comentam que atualmente a análise quantitativa de dados emprega softwares estatísticos, e quase todos os centros de pesquisa possuem essas ferramentas para arquivar e analisar dados. Dessa forma, o foco passa ser a avaliação da adequação do método estatístico e a interpretação de seus resultados. Para o presente estudo, escolheu-se o software SPSS $^{4}$ para o processamento de todas as rotinas estatísticas.

Com relação à escala de medida das variáveis do presente estudo, observa-se que predominam as escalas ordinais do tipo Likert, que devem preferencialmente ser tratadas por métodos estatísticos não paramétricos. Entretanto, é comum considerar as escalas Likert como medidas intervalares. Malhotra (2006), por exemplo, considera as variáveis em escala Likert como intervalares no seu exemplo de aplicação da técnica estatística multivariada da Análise Discriminante. Carifio e Perla (2008) afirmam que existem muitos estudos que evidenciam que as escalas Likert produzem dados intervalares com a robustez necessária para a utilização de testes paramétricos. Assim, optou-se por tratar as variáveis em escala Likert como intervalares por aproximação com o cálculo de estatísticas descritivas, como a média e o desvio padrão, bem como no uso técnicas estatísticas multivariadas.

Hair Jr. et al. (2006) sugerem que o primeiro passo na análise dos dados é o exame para avaliar:

a) o impacto dos dados não informados pelos respondentes (missings);

b) a existência de valores atípicos na amostra (outliers), ou seja, dados com grande distanciamento dos demais; e

c) as premissas das principais técnicas estatísticas, como a distribuição normal.

Para o presente estudo, o exame dos dados da amostra revelou uma quantidade ínfima de missings sem qualquer padrão de ocorrência. Optou-se por substituir esses missings pelo valor três da escala Likert (ponto neutro). Para identificação de outliers, utilizou-se a técnica multivariada baseada na medida $\mathrm{D}^{2}$ de Mahalanobis e não foram detectados valores atípicos. Finalmente, empregou-se o teste de Kolmogorov Smirnov, não sendo evidenciada a distribuição normal para qualquer uma das variáveis do questionário. No Apêndice 08, encontram-se mais detalhes dessas três análises.

\footnotetext{
${ }^{4}$ SPSS - Statistical Package for Social Sciences da IBM - versão 17.
} 
Nas próximas seções, apresentam-se os procedimentos e detalhes de cada uma das três etapas que compõem a estratégia de análise dos dados do presente estudo.

\subsubsection{Identificação da Orientação Estratégica}

Nesta etapa da análise dos dados, a orientação estratégica da organização de cada respondente foi classificada em um dos quatro tipos propostos por Miles e Snow (1978, 2003):
a) Prospectora $(\mathrm{P})$;
b) Analítica (A);
c) Defensiva (D); e
d) Reativa (R).

O procedimento empregado para essa classificação encontra-se descrito na seção 3.4.5 desta dissertação - "Bloco 05 de Questões - Orientação Estratégica". Porém, é oportuno lembrar que essa classificação foi realizada com base nas respostas das cinco questões de múltipla escolha extraídas da escala de Conant et al. (1990). Cada questão apresenta quatro alternativas de resposta, e cada alternativa corresponde a um dos tipos estratégicos P, A, D ou R. Para consolidar o tipo estratégico da organização de cada respondente a partir destas cinco questões, aplicou-se a "regra da maioria" sugerida pelos autores da escala.

Na Tabela 20, mostra-se a classificação resultante das organizações dos respondentes:

Tabela 20 - Orientação estratégica das organizações dos respondentes

\begin{tabular}{lcc}
\hline \multicolumn{1}{c}{ Tipo } & n & \% \\
\hline A - Analítica & 53 & $44,2 \%$ \\
D - Defensiva & 27 & $22,5 \%$ \\
P - Prospectora & 21 & $17,5 \%$ \\
R - Reativa & 19 & $15,8 \%$ \\
\hline Total & & \\
\hline
\end{tabular}


Observa-se na Tabela 20, o predomínio da orientação estratégica do tipo Analítica (44,2\%), ou seja, de organizações híbridas com características Defensivas e Prospectoras. As organizações que aparecem com a menor frequência são as Reativas correspondendo a 15,8\%, porém com participação muito próxima das Prospectoras com 17,5\%.

É interessante observar que Gimenez et al. (1999) em um estudo com 107 pequenas empresas brasileiras de setores diversificados, encontraram a seguinte distribuição das organizações:

a) $44,8 \%$ de Analíticas;

b) $14,9 \%$ de Defensivas;

c) $22,4 \%$ de Prospectoras; e

d) $17,7 \%$ de Reativas.

Nesse estudo, os autores utilizaram a escala completa de 11 questões proposta por Conant et al. (1990). Destaca-se principalmente a semelhança do percentual de empresas Analíticas $(44,8 \%)$ com o encontrado no presente estudo (44,2\%), apesar do foco da investigação atual ser grandes e não pequenas empresas. A participação de empresas Reativas foi relativamente semelhante entre os dois estudos, com $15,8 \%$ no estudo atual versus $17,7 \%$ no estudo anterior. Entretanto, as pequenas empresas no estudo anterior, apresentaram um perfil mais Prospector $(22,4 \%$ versus $17,5 \%)$ do que Defensivo (14,9\% versus $22,5 \%)$ em relação às organizações do presente estudo.

É interessante citar também os resultados encontrados por Yap et al. (2012) em um estudo com 93 empresas de vários portes e setores na Malásia utilizando a escala completa de Conant et al. (1990). Estes resultados listados a seguir, assemelham-se aos do presente estudo:
a) $45,1 \%$ de Analíticas;
b) $25,8 \%$ de Defensivas;
c) $15,1 \%$ de Prospectoras; e
d) $14,0 \%$ de Reativas.

Cada contexto pode apresentar fatores particulares que influenciam a distribuição dos perfis de orientação estratégica. Por exemplo, o pequeno porte das organizações pode torná-las mais flexíveis e ágeis para a inovação do que muitas das grandes organizações, o que explicaria, 
por exemplo, a maior presença de empresas Prospectoras nos resultados de Gimenez et al. (1999).

Para complementar a análise da orientação estratégica, avaliou-se a influência de dois fatores: o setor e a nacionalidade. As características relativas à maturidade e porte das organizações não foram avaliadas, pois na amostra efetiva foram selecionadas apenas as empresas maduras e de grande porte. O tipo de capital das organizações também não foi avaliado, pois é predominantemente privado.

A seguir, apresentam-se os resultados da análise da relação do setor e da nacionalidade com a orientação estratégica nesta amostra. Observa-se que os setores foram consolidados em dois grupos: indústria e comércio/serviços. No Quadro 24, apresenta-se a distribuição cruzada de frequências das variáveis orientação estratégica e grupo setorial, que, em cada célula, há quatro linhas que correspondem à contagem obtida, à contagem esperada, ao percentual na coluna e ao percentual na linha respectivamente.

Por exemplo, na primeira célula que cruza a orientação estratégica Analítica (A) com o setor Indústria, tem-se uma contagem de 19 observações do total de 120. Se as variáveis forem independentes, a contagem esperada será de 16,3, sendo menor do que a observada. A contagem esperada é o produto do total das 120 observações pelas probabilidades estimadas da observação ser Analítica (53/120) e ser do setor Indústria (37/120). Das 53 organizações Analíticas, 35,8\% (percentual da coluna) são do setor Indústria, e 51,4\% (percentual da linha) das 37 organizações do setor Indústria são Analíticas. Essa é a interpretação dos números de cada uma das quatro linhas das células do referido quadro.

Observa-se que, se as variáveis forem independentes, os percentuais dentro das colunas devem ser próximos dos percentuais da coluna Total. Por exemplo, na coluna total tem-se 30,8\% das organizações no setor Indústria e 69,2\% no setor Comércio/Serviço. Se não houver relação entre as variáveis, esperam-se percentuais próximos para cada orientação estratégica nas colunas. Por exemplo, na coluna Analítica, tem-se 35,8\% de organizações da Indústria e 64,2\% do Comércio/Serviços, sendo esses percentuais relativamente próximos dos percentuais da coluna Total. 
Quadro 24 - Orientação Estratégica versus Grupo Setorial

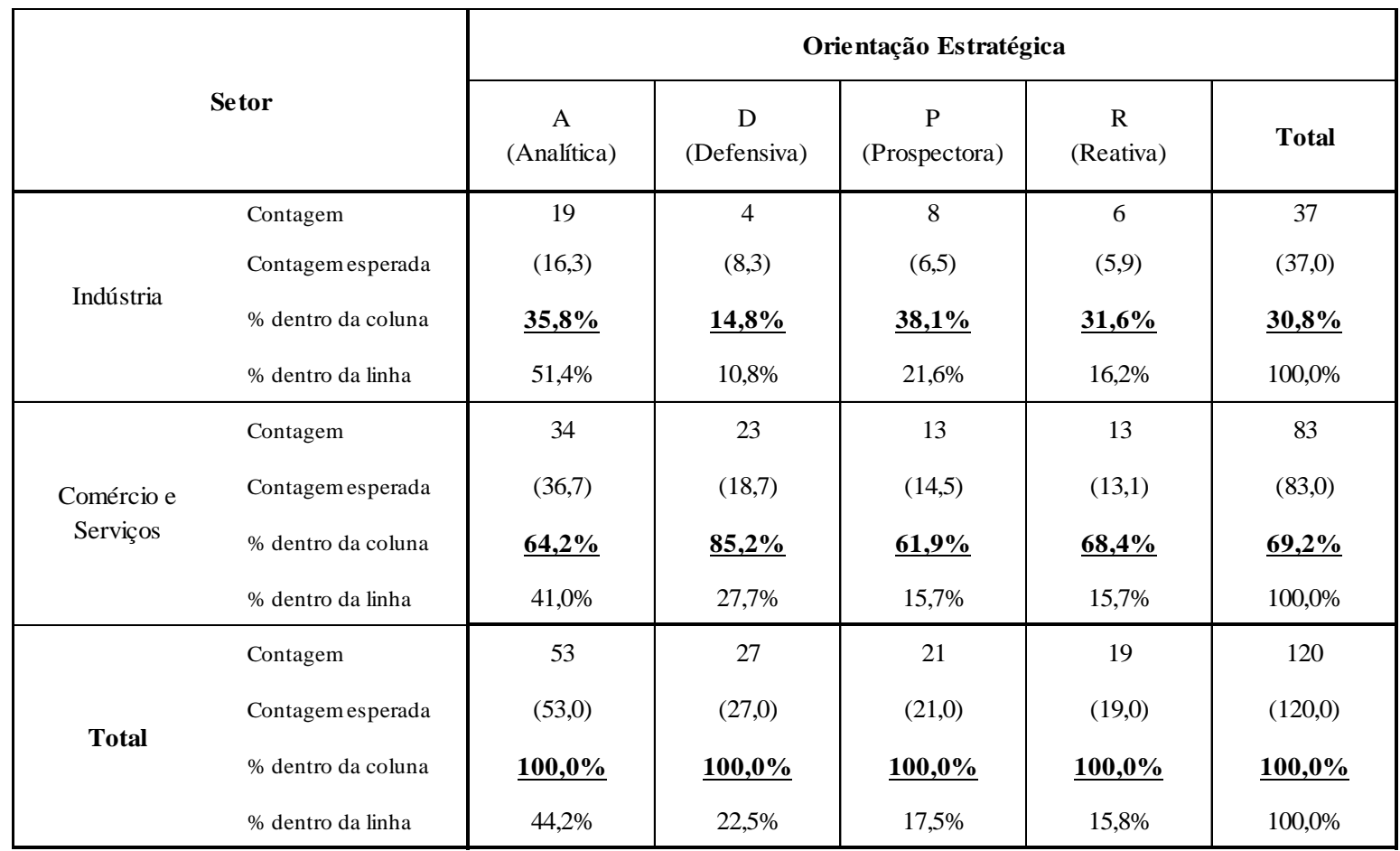

Para a verificação da independência da orientação estratégica em relação ao setor, aplicou-se a prova $\chi^{2}$ (qui-quadrado). Escolheu-se essa prova por ser um teste não paramétrico adequado para escalas nominais e cuja hipótese nula é de que as variáveis são independentes (SIEGEL, 1975). Obteve-se um valor de 4,398 para a estatística Pearson Chi-Square do teste com significância (p-value) 0,222 para três graus de liberdade, aceitando-se a hipótese de independência entre as variáveis com nível crítico de significância 0,05. Ou seja, o setor parece não influenciar a orientação estratégica, o que está em conformidade com a teoria de Miles e Snow $(1978,2003)$.

Agora, analisa-se a influência da nacionalidade sobre a orientação estratégica. No Quadro 25, mostra-se a distribuição de frequências cruzando-se as variáveis nacionalidade e orientação estratégica. Em cada célula, tem-se também, nas quatro linhas respectivamente, a contagem obtida, a contagem esperada, o percentual na coluna e o percentual na linha. É interessante observar nas colunas que os percentuais (valores destacados) de organizações nacionais e multinacionais para cada orientação estratégica parecem um pouco distantes dos percentuais da coluna Total, exceto para as organizações Analíticas. Esse pode ser um indicativo de relação entre essas duas variáveis. 
As organizações Prospectoras apresentam um predomínio de organizações multinacionais $(85,7 \%)$ e as Analíticas também, porém mais moderado (60,4\%). As Defensivas apresentam um predomínio discreto de empresas nacionais (59,3\%), e as Reativas estão mais próximas do equilíbrio com $52,6 \%$ de nacionais versus $47,4 \%$ de multinacionais.

Quadro 25 - Orientação Estratégica versus Nacionalidade

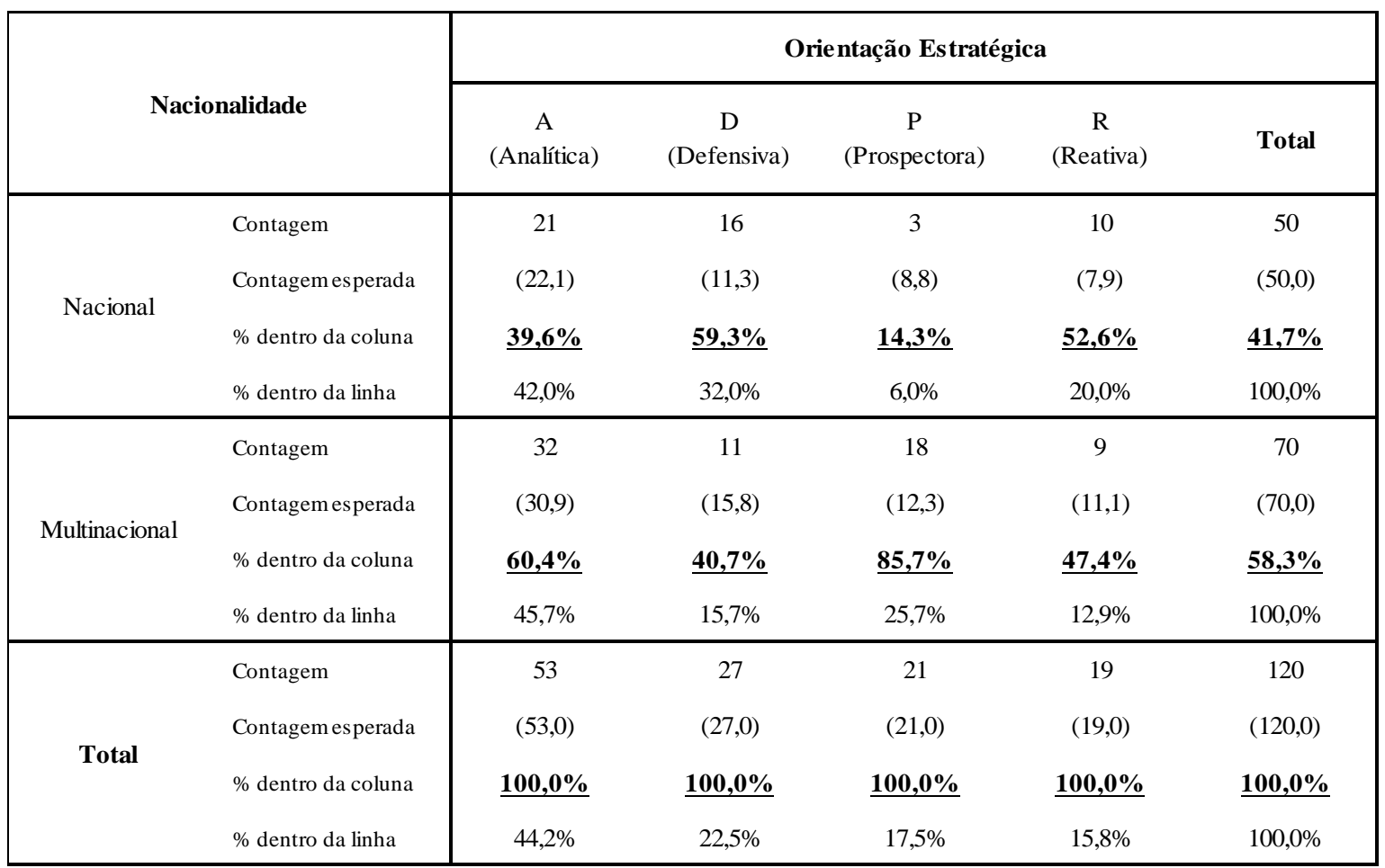

Para verificar se a orientação estratégica é independente da nacionalidade, aplicou-se a prova $\chi^{2}$ (qui-quadrado). Obteve-se um valor de 10,947 para a estatística Pearson Chi-Square do teste com significância ( $p$-value) 0,012 para três graus de liberdade, rejeitando-se a independência entre essas variáveis com nível crítico de significância 0,05. Destaca-se que esse resultado está coerente com a análise feita anteriormente das contagens e percentuais do Quadro 25.

Conclui-se então que, nas observações do presente estudo, o setor e a orientação estratégica não estão relacionados. Entretanto, a orientação estratégica apresenta alguma relação com a nacionalidade, havendo uma tendência para organizações multinacionais entre as Prospectoras. 


\subsubsection{Identificação do Modo de Monitoramento}

Nesta etapa da análise dos dados, classificou-se o modo de monitoramento das organizações, considerando-se que esse pode ser formal ou informal, conforme abordado na revisão da literatura desta dissertação (AGUILAR, 1967; DAFT; WEICK, 1984; CHOO, 2002). A procura formal de informações caracteriza-se pelo fato de ser estruturada de acordo com procedimentos e metodologias, com o objetivo de sistematicamente levantar informações relevantes sobre uma questão para tomar uma decisão ou definir um curso de ação (CHOO, 1999). A granularidade da informação é fina, pois a procura é relativamente focada em encontrar informação detalhada.

As 15 questões do primeiro bloco foram elaboradas com o objetivo de avaliar as características do tipo de procura de informação no ambiente. No Apêndice 06, encontram-se as distribuições de frequências e estatísticas descritivas de cada variável.

Na Tabela 21, apresenta-se a análise descritiva com as estatísticas média, desvio padrão e coeficiente de variação (CV). Nas três colunas finais da referida tabela, tem-se o percentual de respondentes que concordaram total ou parcialmente (graus 5 e 4), respondentes neutros (grau 3) e respondentes que discordaram total ou parcialmente (graus 1 e 2) com a questão. É oportuno lembrar que essas variáveis foram medidas através de uma escala Likert de cinco pontos, com extremos "1 - discordo totalmente" e "5 - concordo totalmente", e pontos centrais 2,3 e 4 não rotulados.

Observa-se que as variáveis com maior percentual de concordância são a V09 (monitoramento focado em informações quantitativas) com $72 \%$ e a V12 (monitoramento focado em fontes de informação claramente determinadas) com $70 \%$, estando destacadas na Tabela 21. Essas variáveis também foram as mais homogêneas considerando-se seus coeficientes de variação de $27 \%$ e $28 \%$ respectivamente. Esse coeficiente expressa o desvio padrão como um percentual da média, permitindo comparar a homogeneidade entre as variáveis. 
Tabela 21 - Resumo das respostas das questões do primeiro bloco

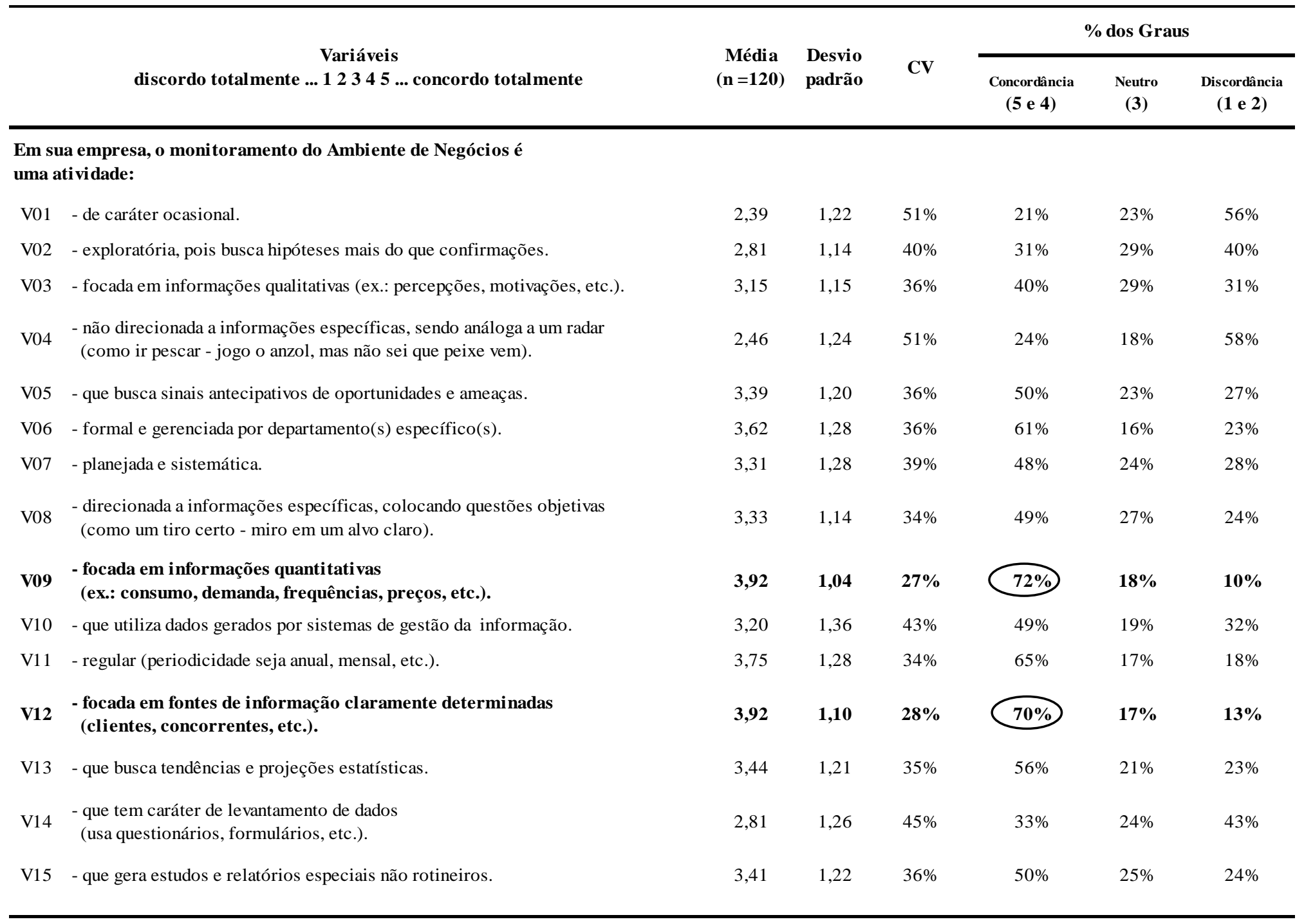


No Quadro 26, mostra-se o ranking das variáveis pelo percentual de graus de concordância (5 e 4) dos respondentes. Destacam-se, no final deste quadro, as quatro únicas variáveis que apresentaram média inferior a três indicando discordância. Essas variáveis também foram as únicas que apresentaram percentual de graus de discordância (1 e 2) maiores do que o percentual de graus de concordância (5 e 4), conforme pode ser observado na Tabela 21 mostrada na página anterior. Esse resultado indica que, no geral, as organizações são mais orientadas à procura formal, o que parece coerente com o grande porte das organizações (THOMAS, 1980).

Quadro 26 - Ranking das variáveis pelo grau de concordância

\begin{tabular}{|c|c|c|c|c|c|}
\hline $\begin{array}{l}\text { Posição no } \\
\text { Ranking }\end{array}$ & & $\begin{array}{c}\text { Variáveis } \\
\text { discordo totalmente } \ldots 12345 \ldots \text { concordo totalmente }\end{array}$ & $\begin{array}{c}\% \text { dos } \\
\text { graus } 5 \text { e } 4\end{array}$ & Média & $\begin{array}{l}\text { Tipo da } \\
\text { Procura }\end{array}$ \\
\hline \multicolumn{6}{|c|}{ Médias superiores a três } \\
\hline $1^{\circ}$ & V09 & $\begin{array}{l}\text { - focada em informações quantitativas } \\
\text { (ex.: consumo, demanda, frequências, preços, etc.). }\end{array}$ & $72 \%$ & 3,92 & Formal \\
\hline $2^{\circ}$ & V12 & $\begin{array}{l}\text { - focada em fontes de informação claramente determinadas } \\
\text { (clientes, concorrentes, etc.). }\end{array}$ & $70 \%$ & 3,92 & Formal \\
\hline $3^{\circ}$ & V11 & - regular (periodicidade seja anual, mensal, etc.). & $65 \%$ & 3,75 & Formal \\
\hline $4^{\circ}$ & V06 & - formal e gerenciada por departamento(s) específico(s). & $61 \%$ & 3,62 & Formal \\
\hline $5^{\circ}$ & V13 & - que busca tendências e projeções estatísticas. & $56 \%$ & 3,44 & Formal \\
\hline $6^{\circ}$ & V05 & - que busca sinais antecipativos de oportunidades e ameaças. & $50 \%$ & 3,39 & Formal \\
\hline $7^{\circ}$ & V15 & - que gera estudos e relatórios especiais não rotineiros. & $50 \%$ & 3,41 & Formal \\
\hline $8^{\circ}$ & V08 & $\begin{array}{l}\text { - direcionada a informações específicas, colocando questões objetivas } \\
\text { (como um tiro certo - miro em um alvo claro). }\end{array}$ & $49 \%$ & 3,33 & Formal \\
\hline $9^{\circ}$ & V10 & - que utiliza dados gerados por sistemas de gestão da informação. & $49 \%$ & 3,20 & Formal \\
\hline $10^{\circ}$ & V07 & - planejada e sistemática. & $48 \%$ & 3,31 & Formal \\
\hline $11^{\circ}$ & V03 & - focada em informações qualitativas (ex.: percepções, motivações, etc.). & $40 \%$ & 3,15 & Informal \\
\hline \multicolumn{6}{|c|}{ Médias inferiores a três } \\
\hline $12^{\circ}$ & V14 & $\begin{array}{l}\text { - que tem caráter de levantamento de dados } \\
\text { (usa questionários, formulários, etc.). }\end{array}$ & $33 \%$ & 2,81 & Formal \\
\hline $13^{\circ}$ & V02 & - exploratória, pois busca hipóteses mais do que confirmações. & $31 \%$ & 2,81 & Informal \\
\hline $14^{\circ}$ & V04 & $\begin{array}{l}\text { - não direcionada a informações específicas, sendo análoga a um radar } \\
\text { (como ir pescar - jogo o anzol, mas não sei que peixe vem). }\end{array}$ & $24 \%$ & 2,46 & Informal \\
\hline $15^{\circ}$ & V01 & - caráter ocasional. & $21 \%$ & 2,39 & Informal \\
\hline
\end{tabular}


Ainda, a maior parte das variáveis apresenta coeficientes de variação acima de $30 \%$ indicando uma dispersão razoável em torno da média, conforme mostrado na Tabela 21. Esse pode ser um indicativo da possibilidade de subdividir as observações em grupos mais homogêneos quanto ao modo de monitoramento, considerando-se que o tamanho da amostra é suficientemente grande para essa subdivisão. Optou-se pela utilização da técnica estatística multivariada da Análise de Conglomerados para essa finalidade, apresentando-se os resultados obtidos na seção a seguir.

\subsubsection{Análise de Conglomerados}

A Análise de Conglomerados é uma técnica estatística de interdependência empregada para reunir elementos (por exemplo, respondentes, produtos ou outras entidades) em grupos, tais que os elementos de um mesmo grupo sejam mais parecidos uns com os outros do que com os elementos de outros grupos. A ideia é maximizar a homogeneidade de elementos dentro dos grupos, ao mesmo tempo em que se maximiza a heterogeneidade entre os grupos. Essa técnica é útil quando se deseja examinar hipóteses previamente estabelecidas em relação à natureza dos dados, sendo uma prerrogativa do pesquisador estabelecer de antemão a quantidade de grupos a serem formados com base em um modelo teórico utilizado como referência (HAIR JR. et al., 2006; FÁVERO et al., 2009).

É oportuno ressaltar que as organizações do presente estudo foram consideradas do tipo que procuram ativamente por informação no ambiente externo pelo fato de empregarem profissionais de monitoramento. Segundo os modelos teóricos de Daft e Weick (1984) e Choo (2002), tais organizações classificam-se nas categorias discovering ou enacting, dependendo se consideram o ambiente analisável ou não. Para esses dois tipos de organizações, os autores associaram respectivamente os modos de monitoramento procura formal e procura informal descritos por Aguilar (1967). As 15 variáveis do primeiro bloco do questionário foram definidas com a finalidade de medir as características dessas modalidades.

Para dividir as observações em dois grupos com base nessas variáveis, sendo um mais orientado à procura formal e outro mais orientado à procura informal, utilizou-se a Análise de 
Conglomerados com o método de agrupamento não hierárquico $k$-means. Esse método é adequado quando o pesquisador especifica previamente a quantidade de grupos (FÁVERO et al., 2009). Como resultado, as 120 observações foram subdivididas em dois grupos, ficando o primeiro grupo com 81 observações e o segundo com 39.

Na Tabela 22, apresentam-se as médias (centros dos conglomerados) das variáveis para cada grupo. Observa-se que um maior nível de concordância com uma variável específica indica uma proximidade maior com o tipo de procura ao qual ela está associada, bem como um distanciamento maior com o tipo oposto.

Tabela 22 - Médias das variáveis nos grupos

\begin{tabular}{|c|c|c|c|c|}
\hline \multirow{2}{*}{\multicolumn{2}{|c|}{$\begin{array}{c}\text { Variáveis } \\
\text { discordo totalmente } \ldots 12345 \ldots \text { concordo totalmente }\end{array}$}} & \multicolumn{2}{|c|}{ Médias } & \multirow{2}{*}{$\begin{array}{l}\text { Tipo da } \\
\text { Procura }\end{array}$} \\
\hline & & \multicolumn{2}{|c|}{ Grupo 1 Grupo 2} & \\
\hline $\begin{array}{l}\text { Em st } \\
\text { uma }\end{array}$ & $\begin{array}{l}\text { la empresa, o monitoramento do Ambiente de Negócios é } \\
\text { tividade: }\end{array}$ & $(\mathbf{n}=\mathbf{8 1})$ & $(\mathbf{n}=39)$ & \\
\hline V01 & - de caráter ocasional. & 2,04 & 3,15 & Informal \\
\hline V02 & - exploratória, pois busca hipóteses mais do que confirmações. & 2,93 & 2,59 & Informal \\
\hline V03 & - focada em informações qualitativas (ex.: percepções, motivações, etc.). & 3,43 & 2,56 & Informal \\
\hline V04 & $\begin{array}{l}\text { - não direcionada a informações específicas, sendo análoga a um radar } \\
\text { (como ir pescar - jogo o anzol, mas não sei que peixe vem). }\end{array}$ & 2,20 & 3,00 & Informal \\
\hline V05 & - que busca sinais antecipativos de oportunidades e ameaças. & 3,86 & 2,41 & Formal \\
\hline V06 & - formal e gerenciada por departamento(s) específico(s). & 4,17 & 2,46 & Formal \\
\hline V07 & - planejada e sistemática. & 3,95 & 1,97 & Formal \\
\hline V08 & $\begin{array}{l}\text { - direcionada a informações específicas, colocando questões objetivas } \\
\text { (como um tiro certo - miro em um alvo claro). }\end{array}$ & 3,73 & 2,49 & Formal \\
\hline V09 & $\begin{array}{l}\text { - focada em informações quantitativas } \\
\text { (ex.: consumo, demanda, frequências, preços, etc.). }\end{array}$ & 4,19 & 3,33 & Formal \\
\hline V10 & - que utiliza dados gerados por sistemas de gestão da informação. & 3,72 & 2,13 & Formal \\
\hline V11 & - regular (periodicidade seja anual, mensal, etc.), & 4,28 & 2,62 & Formal \\
\hline V12 & $\begin{array}{l}\text { - focada em fontes de informação claramente determinadas } \\
\text { (clientes, concorrentes, etc.). }\end{array}$ & 4,36 & 3,00 & Formal \\
\hline V13 & - que busca tendências e projeções estatísticas. & 3,99 & 2,31 & Formal \\
\hline V14 & $\begin{array}{l}\text { - que tem caráter de levantamento de dados } \\
\text { (usa questionários, formulários, etc.). }\end{array}$ & 3,21 & 1,97 & Formal \\
\hline V15 & - que gera estudos e relatórios especiais não rotineiros. & 3,77 & 2,67 & Formal \\
\hline
\end{tabular}


No primeiro grupo $(\mathrm{n}=81)$, todas as 11 variáveis associadas à procura formal apresentaram médias acima de três indicando concordância, e três das quatro variáveis associadas à procura informal apresentaram médias abaixo de três indicando discordância. No geral, esse grupo apresenta características mais próximas da procura formal. No segundo grupo $(n=39)$, nove das onze variáveis associadas à procura formal apresentaram médias abaixo de três indicando discordância, e duas das quatro variáveis associadas à procura informal ficaram com médias iguais ou superiores a três indicando neutralidade ou concordância. No geral, esse grupo apresenta características mais próximas da procura informal.

A variável V03 (informações qualitativas) associada à procura informal apresentou um comportamento contrário ao esperado quando da elaboração do questionário, apresentando um nível de concordância no primeiro grupo $(3,43)$ e de discordância no segundo $(2,56)$. A justificativa pode ser o fato de, no geral, os respondentes não terem associado essa variável a informações mais pessoais (soft) e, sim, à condução de pesquisas de campo utilizando métodos qualitativos para a coleta de informações sobre as percepções e motivações de maneira planejada. Assim, tomou-se a decisão de pesquisa de alterar a associação dessa variável para a procura formal.

A variável V02 também apresentou um comportamento diferente do esperado com quase neutralidade no grupo um com média 2,93 e com discordância para o grupo dois com média 2,56. Esperava-se discordância no primeiro grupo e concordância no segundo grupo. Uma possível justificativa é o fato de a descrição da variável no questionário não ter apresentado clareza suficiente para a avaliação dos respondentes: "a atividade de monitoramento é exploratória, pois busca hipóteses mais do que confirmações”. Pelos resultados obtidos para essa variável, a procura de informações no ambiente parece estar mais associada à confirmação de hipóteses, independentemente do grau de formalidade dessa atividade na organização. Essa variável parece diferenciar muito pouco grupos.

Na Tabela 23.a, apresenta-se o primeiro grupo $(\mathrm{n}=81)$ com ordenação descendente pelas médias das variáveis, e na Tabela 23.b, o segundo grupo $(n=39)$ com ordenação ascendente também pelas médias das variáveis. O objetivo dessas tabelas é destacar as variáveis que mais caracterizam cada grupo, considerando-se que o primeiro grupo tem um quadro mais generalizado de concordância com as 15 questões em análise, e o segundo, de discordância. 
Tabela 23.a - Médias ordenados pelo Grupo 1 (ordem descendente)

\begin{tabular}{|c|c|c|}
\hline \multirow{2}{*}{$\begin{array}{l}\text { Variáveis } \\
\text { discordo totalmente ... } 12345 \ldots \text { concordo totalmente }\end{array}$} & \multicolumn{2}{|c|}{ Médias } \\
\hline & Grupo 1 & Grupo 2 \\
\hline $\begin{array}{l}\text { Em sua empresa, o monitoramento do Ambiente de Negócios é } \\
\text { uma atividade: }\end{array}$ & $(\mathbf{n}=\mathbf{8 1})$ & $(\mathbf{n}=39)$ \\
\hline $\begin{array}{l}\text { V12 - focada em fontes de informação claramente determinadas } \\
\text { (clientes, concorrentes, etc.). }\end{array}$ & 4,36 & 3,00 \\
\hline V11 - regular (periodicidade seja anual, mensal, etc.). & 4,28 & 2,62 \\
\hline $\begin{array}{l}\text { V09 - focada em informações quantitativas } \\
\text { (ex.: consumo, demanda, frequências, preços, etc.). }\end{array}$ & 4,19 & 3,33 \\
\hline V06 - formal e gerenciada por departamento(s) específico(s). & 4,17 & 2,46 \\
\hline V13 - que busca tendências e projeções estatísticas. & 3,99 & 2,31 \\
\hline V07 - planejada e sistemática. & 3,95 & 1,97 \\
\hline V05 - que busca sinais antecipativos de oportunidades e ameaças. & 3,86 & 2,41 \\
\hline V15 - que gera estudos e relatórios especiais não rotineiros. & 3,77 & 2,67 \\
\hline $\begin{array}{l}\text { v08 - direcionada a informaç̃oses específicas, colocando questões objetivas } \\
\text { (como um tiro certo - miro em um alvo claro). }\end{array}$ & 3,73 & 2,49 \\
\hline V10 - que utiliza dados gerados por sistemas de gestão da informação. & 3,72 & 2,13 \\
\hline - focada em informações qualitativas (ex.: percepções, motivações, etc.). & 3,43 & 2,56 \\
\hline $\begin{array}{l}\text { - que tem caráter de levantamento de dados } \\
\text { (usa questionários, formulários, etc.). }\end{array}$ & 3,21 & 1,97 \\
\hline exploratớria, pois busca hipóteses mais do que confirmações. & 2,93 & 2,59 \\
\hline $\begin{array}{l}\text { - não direcionada a informações específicas, sendo análoga a um radar. } \\
\text { (como ir pescar - jogo o anzol, mas não sei que peixe vem). }\end{array}$ & 2,20 & 3,00 \\
\hline - de caráter ocasional. & 2,04 & 3,15 \\
\hline
\end{tabular}

Tabela 23.b - Médias ordenados pelo do Grupo 2 (ordem ascendente)

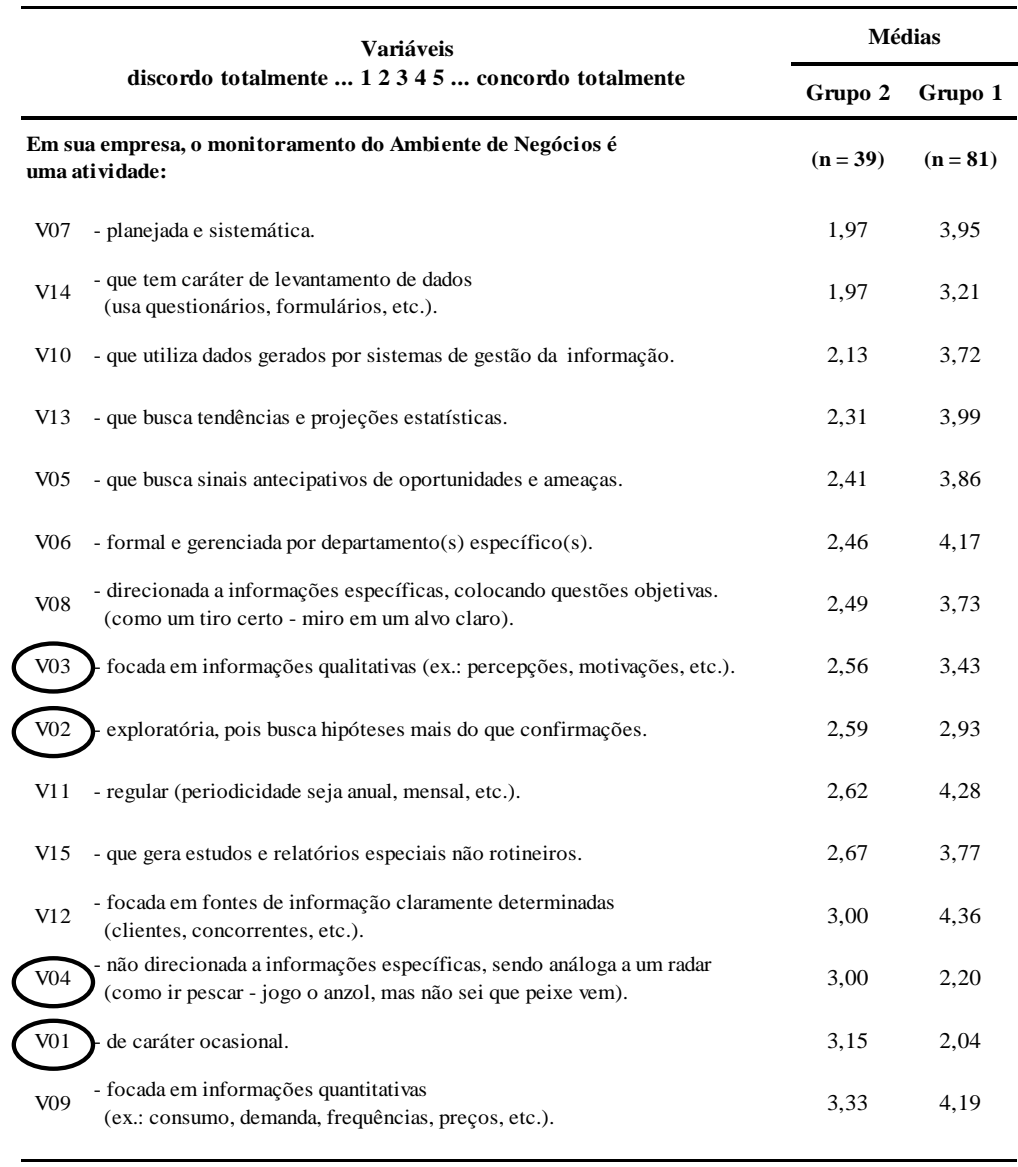

Nota: as variáveis destacadas com um círculo são as que foram originalmente associadas à procura informal na elaboração do questionário. 
A rotina de Análise de Conglomerados do software SPSS processa uma ANOVA (análise de variância) para identificar as variáveis que mais contribuíram para a separação dos grupos. Se uma variável consegue distinguir bem os grupos, espera-se que sua variabilidade entre grupos (cluster mean square) seja elevada e que sua variabilidade interna (error mean square) seja mínima. Assim, as variáveis que mais discriminam os grupos são as que apresentaram maior valor da estatística F na ANOVA (FÁVERO et al., 2009). Na Tabela 24, apresentam-se as variáveis ordenadas de forma descendente pela influência na separação dos grupos de acordo com os valores da estatística F.

Tabela 24 - Análise de Variância (ANOVA)

\begin{tabular}{|c|c|c|c|c|c|c|c|}
\hline & \multirow{2}{*}{ VARIÁVEIS } & \multicolumn{2}{|c|}{ Cluster } & \multicolumn{2}{|c|}{ Error } & \multirow[b]{2}{*}{$\mathbf{F}$} & \multirow[b]{2}{*}{ Sig. } \\
\hline & & $\begin{array}{r}\text { Mean } \\
\text { Square }\end{array}$ & gl & $\begin{array}{r}\text { Mean } \\
\text { Square }\end{array}$ & gl & & \\
\hline \multicolumn{8}{|c|}{$\begin{array}{l}\text { Em sua empresa, o monitoramento do Ambiente de Negócios é } \\
\text { uma atividade: }\end{array}$} \\
\hline V07 & - planejada e sistemática. & 102,815 & 1 & 0,769 & 118 & 133,648 & 0,000 \\
\hline V13 & - que busca tendências e projeções estatísticas. & 74,296 & 1 & 0,841 & 118 & 88,292 & 0,000 \\
\hline V06 & - formal e gerenciada por departamento(s) específico(s). & 77,094 & 1 & 1,011 & 118 & 76,272 & 0,000 \\
\hline V11 & - regular (periodicidade seja anual, mensal, etc.). & 73,292 & 1 & 1,031 & 118 & 71,064 & 0,000 \\
\hline V12 & $\begin{array}{l}\text { - focada em fontes de informação claramente determinadas } \\
\text { (clientes, concorrentes, etc.). }\end{array}$ & 48,549 & 1 & 0,802 & 118 & 60,547 & 0,000 \\
\hline V05 & - que busca sinais antecipativos de oportunidades e ameaças. & 55,650 & 1 & 0,991 & 118 & 56,153 & 0,000 \\
\hline V10 & - que utiliza dados gerados por sistemas de gestão da informação. & 66,372 & 1 & 1,278 & 118 & 51,926 & 0,000 \\
\hline V08 & $\begin{array}{l}\text { - direcionada a informações específicas, colocando questões objetivas. } \\
\text { (como um tiro certo - miro em um alvo claro). }\end{array}$ & 40,557 & 1 & 0,947 & 118 & 42,818 & 0,000 \\
\hline V14 & $\begin{array}{l}\text { - que tem caráter de levantamento de dados } \\
\text { (usa questionários, formulários, etc.). }\end{array}$ & 40,185 & 1 & 1,258 & 118 & 31,952 & 0,000 \\
\hline V01 & - de caráter ocasional. & 32,834 & 1 & 1,203 & 118 & 27,291 & 0,000 \\
\hline V15 & - que gera estudos e relatórios especiais não rotineiros. & 31,782 & 1 & 1,231 & 118 & 25,826 & 0,000 \\
\hline V09 & $\begin{array}{l}\text { - focada em informações quantitativas } \\
\text { (ex.: consumo, demanda, frequências, preços, etc.). }\end{array}$ & 19,103 & 1 & 0,923 & 118 & 20,701 & 0,000 \\
\hline V03 & - focada em informações qualitativas (ex.: percepções, motivações, etc.). & 19,834 & 1 & 1,165 & 118 & 17,025 & 0,000 \\
\hline V04 & $\begin{array}{l}\text { - não direcionada a informações específicas, sendo análoga a um radar } \\
\text { (como ir pescar - jogo o anzol, mas não sei que peixe vem). }\end{array}$ & 16,952 & 1 & 1,414 & 118 & 11,990 & 0,001 \\
\hline V02 & - exploratória, pois busca hipóteses mais do que confirmações. & 2,975 & 1 & 1,263 & 118 & 2,356 & 0,127 \\
\hline
\end{tabular}

Observa-se, na Tabela 24, que apenas a variável V02 não apresentou evidências estatísticas com nível crítico de significância 0,05 de influenciar na separação dos grupos, além de ter apresentado o menor valor para a estatística F $(2,356)$, o que já era esperado. As quatro variáveis que mais contribuíram para essa separação foram: 
a) V07 (planejada e sistemática);

b) V13 (que busca tendências e projeções estatísticas);

c) V06 (formal e gerenciada por departamentos específicos); e

d) V11 (regular, com periodicidade seja anual, mensal, etc.).

Considera-se que um nível mais elevado de concordância com essas variáveis indica um modo de monitoramento mais próximo da procura formal, e, por outro lado, um nível maior de discordância com essas variáveis aumenta a proximidade com a procura informal (AGUILAR, 1967; DAFT; WEICK, 1984; CHOO, 2002).

Tomando-se em conta que a distribuição normal é um dos pressupostos da ANOVA, repetiuse essa análise com o teste não paramétrico correspondente de Mann-Whitney, obtendo-se resultado semelhante quanto à significância estatística das variáveis para a separação dos grupos. Os detalhes dessa análise podem ser consultados no Apêndice 09.

Considerando-se que 14 das 15 variáveis foram significativas para separar as organizações dos respondentes nos dois grupos, procurou-se representar esse conjunto de variáveis por outro menor, de forma a se obter parcimônia, identificando-se as dimensões latentes da estrutura de correlação dessas variáveis. Para tanto, utilizou-se a técnica estatística Análise Fatorial, e a variável V02 não foi considerada nesse procedimento, dado que não apresentou significância para a formação dos grupos. Esse procedimento encontra-se descrito mais adiante na seção 4.7.2.3 desta dissertação.

Na próxima seção, será aplicada uma técnica estatística multivariada adicional para confirmar a separação dos grupos com base nas 15 variáveis utilizadas.

\subsubsection{Análise Discriminante}

A Análise Discriminante é uma técnica da estatística multivariada que pode ser empregada como um procedimento confirmatório da Análise de Conglomerados, pois permite avaliar o grau de separação entre dois grupos (FÁVERO et al., 2009). Sua característica básica é a 
utilização de um conjunto de variáveis independentes para obter um valor para uma variável dependente categórica que possibilite uma classificação desejada (CORRAR et al., 2007). No presente estudo, a variável dependente é o modo de monitoramento a ser classificado em procura formal (PF) ou procura informal (PI), e as variáveis independentes são as 15 variáveis do primeiro bloco do questionário.

É importante destacar que a variável dependente deve ser de natureza qualitativa (não métrica), ou seja, categórica ou discreta. Com relação às variáveis independentes, pressupõese que sejam quantitativas (métricas) com uma unidade constante de medida (HAIR JR. et al., 2006). Em muitas pesquisas, as variáveis em escala Likert são tratadas como métricas por aproximação, apesar de sua natureza ordinal. Malhotra (2006, p. 524) inclusive cita a escala Likert como intervalar na aplicação da Análise Discriminante, e essa abordagem foi a adotada para o presente estudo.

Ressalta-se também que o principal pressuposto para a Análise Discriminante é de que os grupos apresentem igualdade de matrizes de covariância para as variáveis independentes (HAIR JR. et al., 2006). Esse pressuposto foi validado pela estatística Box’s M que apresentou valor 147,362 com significância estatística ( $p$-value) 0,397 , levando à aceitação da hipótese nula de igualdade das matrizes de covariância com nível crítico de significância de 0,05 .

Na Análise Discriminante, uma medida importante para a comparação dos grupos é o centróide que é uma espécie de média geral de todas as variáveis independentes que mostra o quanto os grupos se distanciam (HAIR JR. et al., 2006). Para o presente estudo, o grupo PF apresentou um centróide com valor positivo de 1,15, e o grupo PI, um centróide com valor negativo de -2,39, sinalizando que os dois grupos apresentam uma separação razoável.

Como resultado final da Análise Discriminante, obtém-se uma função discriminante que mostra a variável dependente como uma combinação linear das variáveis independentes. Para o presente estudo, os coeficientes calculados para as variáveis da função discriminante encontram-se no Apêndice 11. Segundo Hair Jr. et al. (2006), a importância de cada variável para a separação dos grupos pode ser avaliada por meio dos coeficientes de correlação entre as variáveis independentes e a função discriminante denominados cargas discriminantes, sendo mostrados com ordenação decrescente no Quadro 27. 
Quadro 27 - Cargas Discriminantes

\begin{tabular}{|c|c|}
\hline Variáveis & Correlação \\
\hline V07 - planejada e sistemática. & 0,638 \\
\hline V13 - que busca tendências e projeções estatísticas. & 0,518 \\
\hline V06 - formal e gerenciada por departamento(s) específico(s). & 0,482 \\
\hline V11 - regular (periodicidade seja anual, mensal, etc.). & 0,465 \\
\hline V12 - focada em fontes de informação claramente determinadas (clientes, concorrentes, etc.). & 0,429 \\
\hline V05 - que busca sinais antecipativos de oportunidades e ameaças. & 0,413 \\
\hline V10 - que utiliza dados gerados por sistemas de gestão da informação. & 0,397 \\
\hline V08 - direcionada a informações específicas, colocando questões objetivas. & 0,361 \\
\hline V14 - que tem caráter de levantamento de dados (usa questionários, formulários, etc.). & 0,312 \\
\hline V01 - de caráter ocasional. & $-0,288$ \\
\hline V15 - que gera estudos e relatórios especiais não rotineiros. & 0,280 \\
\hline V09 - focada em informações quantitativas (ex.: consumo, demanda, frequências, preços, etc.). & 0,251 \\
\hline V03 - focada em informações qualitativas (ex.: percepções, motivações, etc.). & 0,228 \\
\hline V04 - não direcionada a informações específicas, sendo análoga a um radar. & $-0,191$ \\
\hline V02 - exploratória, pois busca hipóteses mais do que confirmações. & 0,085 \\
\hline
\end{tabular}

É interessante observar que, assim como na Análise de Conglomerados, a variável V07 que avalia o planejamento e a sistematização do monitoramento é a mais destacada na separação das observações com coeficiente de correlação 0,638. A variável V02 apresenta correlação quase nula, confirmando sua pouca importância na separação dos grupos. Validou-se a associação das variáveis V01 e V04 com a procura informal, sendo as únicas variáveis com correlação negativa com a função discriminante. Confirmou-se, também, a associação da variável V03 com a PF, dada a correlação positiva com a função discriminante, lembrando-se que essa variável foi associada originalmente com a PI na elaboração do questionário.

Na técnica da Análise Discriminante, aplica-se a função discriminante sobre os dados da própria amostra do estudo e verifica-se, para cada observação, qual o valor da variável dependente (escore discriminante Z) obtido. Com todos os escores apurados, calcula-se a média de cada grupo, que servirá de base para o cálculo do ponto de corte (cut off point) ou escore crítico que servirá para discriminar a qual grupo pertence um elemento. $\mathrm{O}$ valor do 
ponto de corte para os dados do presente estudo foi calculado em -0,62. Assim, todos os escores calculados pela função discriminante que forem maiores do que esse valor serão classificados no grupo procura formal e os demais, no grupo procura informal.

Comparando-se a classificação das 120 observações da amostra pela função discriminante com a obtida pela Análise de Conglomerados, tem-se que no grupo procura formal ocorreu um grau de acerto da função discriminante de 98,8\% das classificações (80 em 81) e no grupo procura informal de 94,9\% (37 em 39). Esse resultado, sumarizado no Quadro 28, evidencia que existe uma clara separação entre os dois grupos, pois a função discriminante os separa de forma excepcional, o que evidencia que eles têm características bastante diferentes. Nos Gráficos 6 e 7, mostram-se os histogramas da função discriminante para cada um dos grupos, nos quais a separação dos grupos pode ser percebida devido à quase ausência de sobreposição dos gráficos.

Quadro 28 - Classificação prevista pela Análise Discriminante

\begin{tabular}{|c|c|c|c|c|c|}
\hline \multicolumn{2}{|c|}{} & \multicolumn{3}{|c|}{$\begin{array}{c}\text { Classificação prevista } \\
\text { pela Análise Discriminante }\end{array}$} \\
\cline { 3 - 6 } & \multirow{2}{*}{ Contagem } & PF & $\mathbf{8 0}$ & 1 & 81 \\
\cline { 3 - 6 } & & PI & 2 & $\mathbf{3 7}$ & 39 \\
\hline \multirow{3}{*}{$\begin{array}{c}\text { Classificação original pela } \\
\text { Análise de Conglomerados }\end{array}$} & \multirow{3}{*}{ Percentagem } & PF & $\mathbf{9 8 , 8 \%}$ & $1,2 \%$ & $100,0 \%$ \\
\cline { 3 - 7 } & & PI & $5,1 \%$ & $\mathbf{9 4 , 9 \%}$ & $100,0 \%$ \\
\cline { 3 - 7 } & & & & &
\end{tabular}

Considerando-se que a separação dos grupos foi validada nesta seção, será dado prosseguimento à sumarização das 14 variáveis que se mostraram significativas para a formação dos grupos na Análise de Conglomerados com o objetivo de descrever e comparar os grupos de forma parcimoniosa. 


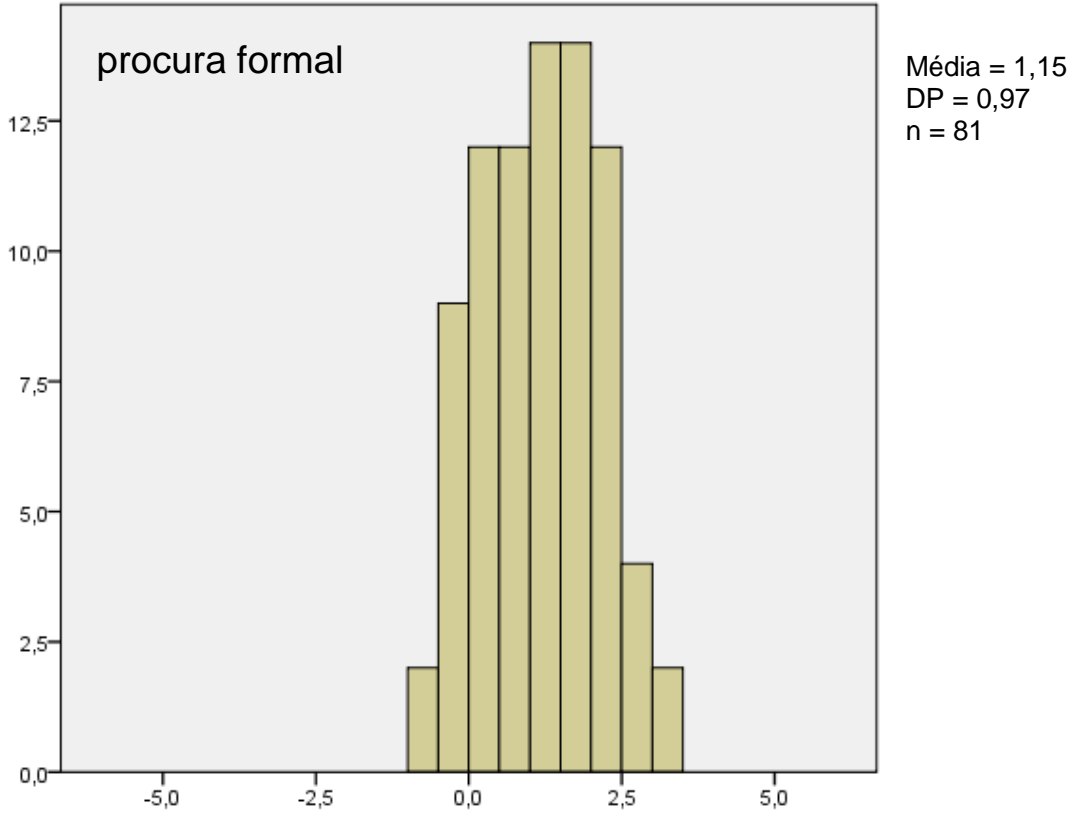

Gráfico 6 - Função discriminante para o grupo procura formal

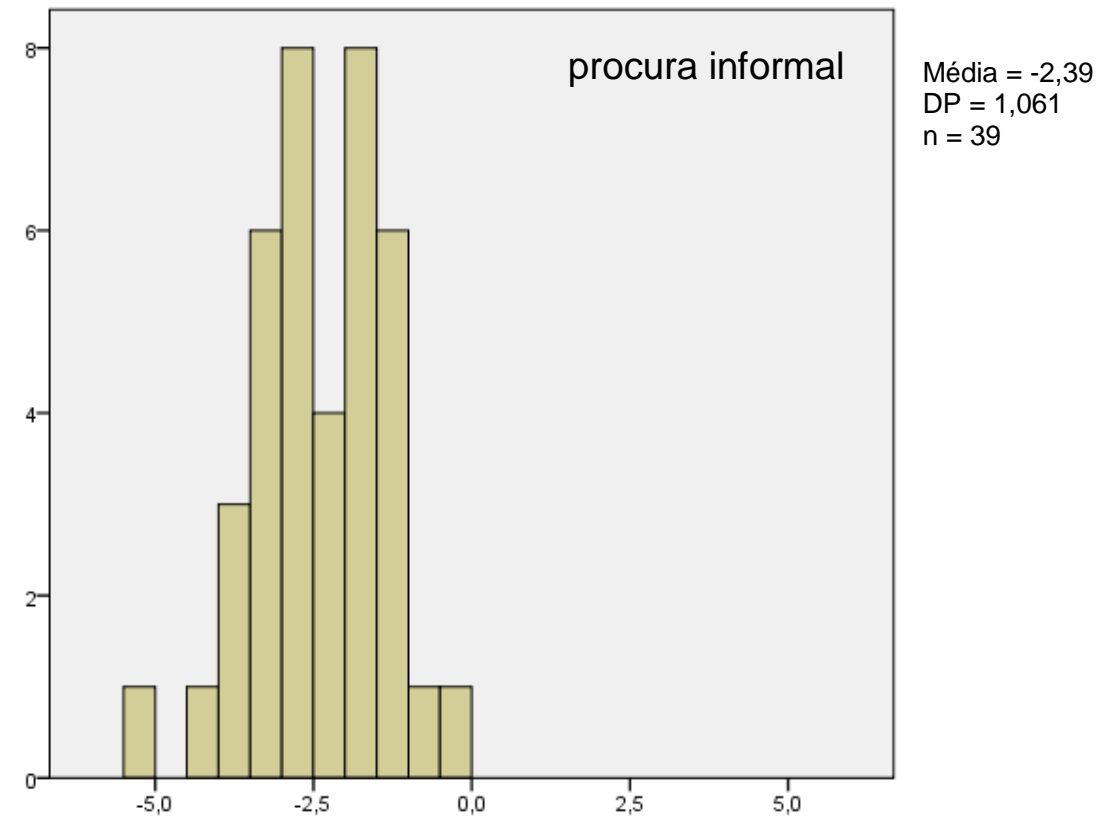

Gráfico 7 - Função discriminante para o grupo procura informal 


\subsubsection{Análise Fatorial}

A Análise Fatorial é uma técnica da estatística multivariada, cuja ideia básica reside na premissa de que é possível representar um conjunto de variáveis originais inter-relacionadas por um conjunto menor de fatores da estrutura latente dos dados (FÁVERO et al., 2009). Procura-se identificar estes fatores (dimensões) com a menor perda possível de informação das variáveis originais e, para tal, considera-se que a quantidade de observações na amostra deve ser no mínimo cinco vezes a quantidade de variáveis, não sendo inferior a 100 (HAIR JR. et al. 2006). No presente estudo, atendeu-se a esse requisito, pois há 120 observações para 14 variáveis, excedendo os mínimos recomendados.

Essa técnica deve ser aplicada quando existem correlações significativas com índices superiores a 0,3 entre as variáveis. No Apêndice 10, encontra-se a matriz de coeficientes de correlação de Pearson entre os pares de variáveis, na qual se percebe uma quantidade considerável de correlações significativas superiores a 0,3 .

Para assegurar que a correlação existente entre as variáveis é suficiente, aplicou-se o teste de significância da esfericidade de Bartlett's com nível crítico de significância 0,05. Adicionalmente, calculou-se a estatística KMO que avalia a adequação da amostra quanto ao grau de correlação parcial entre as variáveis e que deve ser superior a 0,6 (FÁVERO et al., 2009). No Quadro 29, mostram-se os resultados obtidos, indicando que a Análise Fatorial é adequada para o presente estudo.

Quadro 29 - KMO e Teste de Esfericidade de Bartlett

\begin{tabular}{|c|c|c|}
\hline KMO & & 0,881 \\
\hline \multirow{3}{*}{ Teste de Bartlett } & Qui-quadrado & 631,081 \\
\hline & g.l. & 91 \\
\hline & Sig. & 0,000 \\
\hline
\end{tabular}


Na Tabela 25, mostra-se o resultado da Análise Fatorial obtido pelo método das componentes principais. Optou-se pelo método oblíquo Promax de rotação dos fatores por se considerar a existência de correlação entre os fatores. $\mathrm{O}$ processamento resultou em três fatores com autovalores (eigenvalue) maiores do que a unidade e que explicam 57\% da variância total. Em estudos de ciências sociais, nos quais a informação é menos precisa, percentuais dessa ordem de grandeza podem ser aceitos (HAIR JR. et al., 2006, p. 120).

Tabela 25 - Autovalores e \% de variância explicada pelos fatores

\begin{tabular}{cccc}
\hline \multirow{2}{*}{ Componentes } & \multicolumn{3}{c}{ Autovalores } \\
\cline { 2 - 4 } & Total & \% da variância & \% acumulado \\
\hline $\mathbf{2}$ & $\mathbf{5 , 7 6 8}$ & $\mathbf{4 1 , 2 0}$ & $\mathbf{4 1 , 2 0}$ \\
$\mathbf{3}$ & $\mathbf{1 , 1 6 8}$ & $\mathbf{8 , 3 4}$ & $\mathbf{4 9 , 5 4}$ \\
\hline 4 & $\mathbf{1 , 0 4 9}$ & $\mathbf{7 , 4 9}$ & $\mathbf{5 7 , 0 4}$ \\
\hline 5 & 0,938 & 6,70 & 63,74 \\
6 & 0,769 & 5,49 & 69,23 \\
7 & 0,732 & 5,23 & 74,46 \\
8 & 0,665 & 4,75 & 79,21 \\
9 & 0,604 & 4,31 & 83,52 \\
10 & 0,524 & 3,74 & 87,26 \\
11 & 0,511 & 3,65 & 90,91 \\
12 & 0,382 & 2,73 & 93,64 \\
13 & 0,359 & 2,56 & 96,21 \\
14 & 0,290 & 2,07 & 98,28 \\
\hline
\end{tabular}

$\mathrm{Na}$ análise das comunalidades, ou seja, do total da variância que uma variável original compartilha com as demais, deve-se levar em conta o seguinte critério:
a) inferior a 50\%: muito prejudicado;
b) de $50 \%$ a $60 \%$ : prejudicado;
c) de $60 \%$ a $70 \%$ : impacto moderado;
d) de $70 \%$ a $80 \%$ : favorecido; e
e) acima de $80 \%$ : muito favorecido. 
Na Tabela 26, apresentam-se as comunalidades calculadas para as variáveis. Observa-se que a variável V11 ("monitoramento regular, com periodicidade seja anual, mensal, etc.") apresentou comunalidade de 0,470 sendo a única inferior a 0,5 (muito prejudicada). Entretanto, essa variável foi mantida, pois a maioria das variáveis apresentou comunalidade acima de 0,6 (HAIR JR. et al., 2006, p. 122). A variável V07 ("monitoramento planejado e sistemático") por sua vez apresentou a mais alta comunalidade $(0,710)$ com um ótimo nível de explicação de sua variância pelos novos fatores.

Tabela 26 - Comunalidades das variáveis

\begin{tabular}{|c|c|}
\hline Variáveis & Comunalidades \\
\hline \multicolumn{2}{|l|}{$\begin{array}{l}\text { Em sua empresa, o monitoramento do Ambiente de Negócios é } \\
\text { uma atividade: }\end{array}$} \\
\hline V01 - de caráter ocasional. & 0,519 \\
\hline V03 - focada em informações qualitativas (ex.: percepções, motivações, etc.). & 0,627 \\
\hline V04 - não direcionada a informações específicas sendo análoga a um radar (pesca). & 0,617 \\
\hline V05 - que busca sinais antecipativos de oportunidades e ameaças. & 0,516 \\
\hline V06 - formal e gerenciada por departamento(s) específico(s). & 0,518 \\
\hline V07 - planejada e sistemática. & \\
\hline V08 - direcionada a informações específicas, colocando questões objetivas (mira no alvo). & 0,573 \\
\hline V09 - focada em informações quantitativas (ex.: consumo, demanda, frequências, preços, etc.). & 0,598 \\
\hline V10 - que utiliza dados gerados por sistemas de gestão da informação. & 0,507 \\
\hline V11 - regular (periodicidade seja anual, mensal, etc.). & \\
\hline V12 - focada em fontes de informação claramente determinadas (clientes, concorrentes, etc.). & 0,624 \\
\hline V13 - que busca tendências e projeções estatísticas. & 0,665 \\
\hline V14 - que tem caráter de levantamento de dados (usa questionários, formulários, etc.). & 0,533 \\
\hline V15 - que gera estudos e relatórios especiais não rotineiros. & 0,509 \\
\hline
\end{tabular}

Para interpretar os fatores com o objetivo de identificar as dimensões da estrutura latente das variáveis, analisaram-se as cargas fatoriais (correlações entre as variáveis e os fatores), considerando-se o critério sugerido por (HAIR JR. et al., 2006, p. 128):

a) de \pm 0,3 a \pm 0,4 - atendem ao requisito mínimo para interpretar a estrutura;

b) maior ou igual a $\pm 0,5$ - são consideradas praticamente significantes; e

c) acima de $\pm 0,7$ - são consideradas indicativas de uma estrutura muito bem definida, sendo o objetivo de qualquer Análise Fatorial. 
Na Tabela 27, mostra-se o resultado dessa análise, destacando-se a maior carga fatorial para cada variável.

Tabela 27- Estrutura fatorial (correlações entre variáveis $\boldsymbol{e}$ fatores)

\begin{tabular}{|c|c|c|c|}
\hline Variáveis & Fator1 & Fator2 & Fator3 \\
\hline \multicolumn{4}{|l|}{$\begin{array}{l}\text { Em sua empresa, o monitoramento do Ambiente de Negócios é } \\
\text { uma atividade: }\end{array}$} \\
\hline V01 - de caráter ocasional. & $-0,378$ & & $-0,525$ \\
\hline V03 - focada em informações qualitativas (ex.: percepções, motivações, etc.). & 0,260 & 0,320 & \\
\hline V04 - não direcionada a informações específicas sendo análoga a um radar (pesca). & $-0,413$ & & 0,090 \\
\hline V05 - que busca sinais antecipativos de oportunidades e ameaças. & & 0,407 & 0,520 \\
\hline V06 - formal e gerenciada por departamento(s) específico(s). & & 0,529 & 0,469 \\
\hline V07 - planejada e sistemática. & & 0,661 & 0,592 \\
\hline V08 - direcionada a informações específicas, colocando questões objetivas (mira no alvo). & 0,629 & & 0,253 \\
\hline V09 - focada em informações quantitativas (ex.: consumo, demanda, frequências, preços, etc.). & & 0,276 & 0,070 \\
\hline V10 - que utiliza dados gerados por sistemas de gestão da informação. & 0,441 & & 0,345 \\
\hline V11 - regular (periodicidade seja anual, mensal, etc.). & & 0,390 & 0,293 \\
\hline V12 - focada em fontes de informação claramente determinadas (clientes, concorrentes, etc.). & & 0,516 & 0,305 \\
\hline V13 - que busca tendências e projeções estatísticas. & & 0,514 & 0,398 \\
\hline V14 - que tem caráter de levantamento de dados (usa questionários, formulários, etc.). & 0,286 & & 0,380 \\
\hline V15 - que gera estudos e relatórios especiais não rotineiros. & 0,549 & 0,195 & \\
\hline
\end{tabular}

$\mathrm{Na}$ Tabela 28, apresentam-se os fatores em outro formato de maior facilidade para interpretação, listando-se as variáveis com maiores cargas fatoriais para cada fator. 
Tabela 28 - Variáveis associadas a cada fator

\begin{tabular}{|c|c|c|}
\hline Fatores & $\begin{array}{c}\text { Carga } \\
\text { Fatorial }\end{array}$ & Comunalidade \\
\hline \multicolumn{3}{|l|}{ Fator 1} \\
\hline V13 - que busca tendências e projeções estatísticas. & 0,811 & 0,665 \\
\hline V12 - focada em fontes de informação claramente determinadas (clientes, concorrentes, etc.). & 0,785 & 0,624 \\
\hline V07 - planejada e sistemática. & 0,744 & 0,710 \\
\hline V09 - focada em informações quantitativas (ex.: consumo, demanda, frequências, preços, etc.). & 0,722 & 0,598 \\
\hline V11 - regular (periodicidade seja anual, mensal, etc.), & 0,686 & 0,470 \\
\hline V06 - formal e gerenciada por departamento(s) específico(s). & 0,672 & 0,518 \\
\hline V05 - que busca sinais antecipativos de oportunidades e ameaças. & 0,665 & 0,516 \\
\hline \multicolumn{3}{|l|}{ Fator 2} \\
\hline V10 - que utiliza dados gerados por sistemas de gestão da informação. & 0,705 & 0,507 \\
\hline V08 - direcionada a informações específicas, colocando questões objetivas (mira no alvo). & 0,699 & 0,573 \\
\hline V14 - que tem caráter de levantamento de dados (usa questionários, formulários, etc.). & 0,694 & 0,533 \\
\hline V01 - de caráter ocasional. & $-0,644$ & 0,519 \\
\hline V04 - não direcionada a informações específicas sendo análoga a um radar (pesca) & $-0,686$ & 0,617 \\
\hline \multicolumn{3}{|l|}{ Fator 3} \\
\hline V03 - focada em informações qualitativas (ex.: percepções, motivações, etc.). & 0,784 & 0,627 \\
\hline V15 - que gera estudos e relatórios especiais não rotineiros. & 0,592 & 0,509 \\
\hline
\end{tabular}

A interpretação dos fatores é uma tarefa que deve considerar o significado prático dos fatores, requerendo um mínimo de teoria para supor esse significado (ARANHA e ZAMBALDI, 2008). Trata-se muito mais de um exercício de sensibilidade do pesquisador do que uma mera aplicação de regras matemáticas. O resultado dessa interpretação é um nome para cada fator que o represente da melhor maneira possível, sugerido com base nas cargas fatoriais e na intuição do pesquisador (HAIR JR. et al., 2006).

Dessa forma, com base nos dados do Tabela 28 e na abordagem teórica deste estudo, definiram-se os seguintes nomes para os fatores:

a) Fator 1 - Estruturação da atividade

b) Fator 2 - Estruturação da informação coletada

c) Fator 3 - Ocasionalidade da pesquisa qualitativa 
Finalmente, para a substituição das 14 variáveis originais pelo conjunto dos três fatores, foram calculados os escores fatoriais que, segundo Hair Jr. et al. (2006, p. 139), "consistem em medidas compostas de cada fator computadas para cada observação da amostra. Conceitualmente, o escore fatorial representa o grau em que cada observação apresenta escores elevados no grupo de variáveis que têm cargas elevadas em um fator. Assim, valores mais altos nas variáveis com cargas elevadas em um fator resultam em um escore fatorial mais elevado". Observa-se que os escores fatoriais são variáveis padronizadas com média zero e desvio padrão igual a unidade. Para o presente estudo, escores fatoriais mais elevados são característicos do modo de monitoramento procura formal e escores mais baixos, da procura informal.

Para comparar os dois grupos em relação aos escores fatoriais, optou-se pelo teste paramétrico t de Student para a verificação da igualdade das médias, obtendo-se os resultados mostrados na Tabela 29:

Tabela 29 - Teste da diferença das médias dos escores fatoriais

\begin{tabular}{cccccccc}
\hline \multirow{2}{*}{$\begin{array}{c}\text { Escores } \\
\text { fatoriais }\end{array}$} & \multicolumn{2}{c}{ Médias dos grupos } & & & & \\
\cline { 2 - 3 } & $\mathrm{n}=81$ & $\mathrm{n}=39$ & $\begin{array}{c}\text { Diferenças } \\
\text { das médias }\end{array}$ & $\begin{array}{c}\text { Estatística } \\
\mathrm{t}\end{array}$ & $\mathrm{gl}$ & sig. \\
\hline F1 & 0,411 & $-0,854$ & 1,266 & 8,051 & 118 & 0,000 \\
F2 & 0,301 & $-0,625$ & 0,926 & 5,257 & 118 & 0,000 \\
F3 & 0,250 & $-0,519$ & 0,769 & 4,270 & 118 & 0,000 \\
\hline
\end{tabular}

No primeiro grupo $(\mathrm{n}=81)$, todos os escores fatoriais apresentaram valores médios positivos indicativos da procura formal, caracterizando-se pela alta estruturação da atividade (Fator 1), estruturação da informação coletada (Fator 2) e tendência de realização de pesquisas qualitativas ocasionais (Fator 3).

No segundo grupo $(n=39)$, encontra-se um cenário oposto, com todos os escores fatoriais apresentando médias negativas, indicando maior similaridade com o modo de monitoramento 
procura informal. Destaca-se a tendência à pouca estruturação da atividade (Fator 1) que apresentou a média de menor valor relativo $(-0,854)$ entre os escores fatoriais. Esse resultado é bastante coerente com a variável V07 que avalia o planejamento e a sistematização das atividades e apresentou a menor média neste grupo com 1,97, indicando a discordância dos respondentes com estes atributos do monitoramento.

Com base nestes resultados, confirma-se a denominação procura formal para o primeiro grupo $(\mathrm{n}=81)$ e procura informal para o segundo grupo $(\mathrm{n}=39)$ em relação às características do modo de monitoramento. A seguir, nas próximas seções, esses grupos serão descritos e comparados em relação às fontes de informação utilizadas, o escopo do monitoramento e as dificuldades dessa atividade.

\subsubsection{Análise dos Grupos pelas Fontes de Informação}

O segundo bloco do questionário é composto por quatro questões que avaliam a frequência com que as fontes de informação são utilizadas no monitoramento. As respostas destas questões foram analisadas com o objetivo de descrever e comparar os grupos procura formal (PF) e procura informal (PI).

As fontes de informação estudadas encontram-se detalhadas na seção 4.4.2 "Bloco 01 de Questões - Fontes de Informação" desta dissertação e estão listadas a seguir com o código das variáveis às quais estão associadas:

a) V16 - fontes pessoais internas;

b) V17 - fontes pessoais externas;

c) V18 - fontes impessoais internas; e

d) V19 - fontes impessoais externas.

A frequência de utilização das fontes de informação foi mensurada em escala Likert com extremos " 1 = nunca" e "5 = sempre" e pontos intermediários 2, 3 e 4. Quanto mais elevado o grau atribuído pelo respondente, mais frequente é a utilização da fonte avaliada. Apesar de 
não rotulados no questionário, será considerado que os pontos intermediários correspondem a "2 - quase nunca", "3 - às vezes" e "4 - quase sempre" para a análise dos resultados.

No Quadro 30, apresentam-se as estatísticas descritivas média, desvio padrão (DP) e coeficiente de variação $(\mathrm{CV})$ para as quatro variáveis relativas às fontes de informação nos grupos PF e PI. Na última linha do referido quadro, apresentam-se as diferenças das médias entre os grupos.

Quadro 30 - Estatísticas descritivas dos tipos de fontes de informação

\begin{tabular}{|cc|c|c|c|c|}
\hline \multirow{2}{*}{} & \multirow{2}{*}{ Estatísticas } & \multicolumn{4}{|c|}{ Fontes de Informação } \\
\cline { 3 - 6 } & & \multicolumn{2}{|c|}{ Pessoais } & \multicolumn{2}{c|}{ Impessoais } \\
\cline { 3 - 6 } & & $\begin{array}{c}\text { Externas } \\
\text { (V16) }\end{array}$ & $\begin{array}{c}\text { Internas } \\
\text { (V17) }\end{array}$ & $\begin{array}{c}\text { Externas } \\
\text { (V18) }\end{array}$ & $\begin{array}{c}\text { Internas } \\
\text { (V19) }\end{array}$ \\
\hline \multirow{2}{*}{$\begin{array}{c}\text { Procura Formal (PF) } \\
(\mathrm{n}=81)\end{array}$} & Média & 4,07 & 3,99 & 4,23 & 4,14 \\
\cline { 2 - 6 } & $\mathrm{DP}$ & 0,89 & 1,02 & 1,03 & 1,06 \\
\hline \multirow{2}{*}{$\begin{array}{c}\text { Procura Informal (PI) } \\
(\mathrm{n}=39)\end{array}$} & $\mathrm{CV}$ & $21,9 \%$ & $25,5 \%$ & $24,3 \%$ & $25,6 \%$ \\
\cline { 2 - 6 } & $\mathrm{Média}$ & 2,67 & 2,90 & 3,33 & 3,13 \\
\hline & $\mathrm{DP}$ & 1,06 & 1,17 & 1,15 & 1,15 \\
\hline \multicolumn{2}{|c|}{ Diferença entre as médias } & $39,7 \%$ & $40,2 \%$ & $34,6 \%$ & $36,8 \%$ \\
\hline
\end{tabular}

Para comparar as quatro fontes de informação dentro de cada um dos grupos, utilizou-se a prova estatística não paramétrica de Friedman, considerando-se que as variáveis não são normais e estão em escala ordinal (SIEGEL, 1975). Observa-se que essa prova é análoga à prova paramétrica ANOVA. Quando o teste detecta diferença significativa no grupo de variáveis, reaplica-se a prova de Friedman para cada par de variáveis para localizar as diferenças significativas.

Com nível crítico de significância 0,05 , obtiveram-se os seguintes resultados para cada grupo:

- PF: não há diferença significativa entre a frequência de utilização das quatro fontes de informação pesquisadas, e todas são utilizadas com frequência média elevada próxima de 4 ("quase sempre"). 
- PI: há diferença significativa apenas entre a frequência de utilização das fontes pessoais externas com média 2,67 e as fontes impessoais externas (escritas) com média 3,33.

Para comparar cada uma das quatro fontes de informação entre os grupos PF e PI, utilizou-se a prova não paramétrica de Mann-Whitney, considerando-se que as variáveis não são normais e estão em escala ordinal (SIEGEL, 1975). Essa prova é análoga à prova paramétrica t de Student para comparação de médias entre grupos. Para o nível crítico de significância 0,05 , obtiverem-se os seguintes resultados:

- o grupo PF apresenta frequência de monitoramento significativamente superior para todas as quatro fontes de informação em comparação ao grupo PI;

- a frequência de utilização das fontes pessoais externas é a que mais diferencia os grupos, com média 4,07 para o grupo PF e 2,67 para o grupo PI.

As informações obtidas no contato com pessoas de fora da organização parecem privilegiadas no grupo PF em oposição ao grupo PI, o que pode ser resultado da realização de esforços estruturados de pesquisas de campo tanto quantitativas quanto qualitativas.

Nos Apêndices 12 e 13, encontram-se os detalhes das provas estatísticas de Mann-Whitney e de Friedman aplicados não apenas para esta análise, mas também para as análises subsequentes do escopo e das dificuldades do monitoramento.

\subsubsection{Análise dos Grupos pelo Escopo do Monitoramento}

O terceiro bloco do questionário é composto por oito questões que avaliam a frequência com que são monitorados os aspectos críticos do ambiente externo à organização. As respostas destas questões foram analisadas com o objetivo de descrever e comparar os grupos PF e PI. 
Os aspectos críticos do ambiente para este estudo foram abordados na seção 4.4.3 "Bloco 02 de Questões - Escopo do Monitoramento" desta dissertação e estão listados a seguir no Quadro 31 com o código das variáveis às quais estão associados:

Quadro 31 - Aspectos do ambiente externo para monitoramento

\begin{tabular}{|c|c|c|}
\hline & Aspectos ambientais de mercado & Aspectos macroambientais \\
\hline a) & V20 - Clientes & a) V23 - Aspectos econômicos \\
\hline b) & V21 - Concorrentes & b) V24 - Inovações tecnológicas \\
\hline \multirow[t]{3}{*}{ c) } & V22 - Fornecedores & c) V25 - Aspectos regulatórios \\
\hline & & d) V26 - Aspectos socioculturais \\
\hline & & e) V27 - Aspectos políticos \\
\hline
\end{tabular}

A análise será realizada separadamente para cada categoria de aspecto ambiental, de forma a tornar mais coerente e didática a apresentação dos resultados.

\subsection{Aspectos Ambientais de Mercado do Escopo do Monitoramento}

No Quadro 32, apresentam-se as estatísticas descritivas média, desvio padrão (DP) e coeficiente de variação (CV) para as três variáveis relativas aos aspectos ambientais de mercado nos grupos PF e PI. Na última linha do referido quadro, apresentam-se as diferenças das médias entre os grupos. 
Quadro 32 - Estatísticas descritivas dos aspectos ambientais de mercado

\begin{tabular}{|c|c|c|c|c|}
\hline \multirow{2}{*}{\multicolumn{2}{|c|}{ Estatísticas descritivas }} & \multicolumn{3}{|c|}{ Aspectos ambientais de mercado } \\
\hline & & $\begin{array}{l}\text { Clientes } \\
\text { (V20) }\end{array}$ & $\begin{array}{l}\text { Concorrentes } \\
\text { (V21) }\end{array}$ & $\begin{array}{c}\text { Fornecedores } \\
\text { (V22) }\end{array}$ \\
\hline \multirow{3}{*}{$\begin{array}{l}\text { Procura Formal (PF) } \\
\qquad(\mathrm{n}=81)\end{array}$} & Média & 4,26 & 4,54 & 3,57 \\
\hline & DP & 0,79 & 0,74 & 1,12 \\
\hline & $\mathrm{CV}$ & $18,5 \%$ & $16,3 \%$ & $31,3 \%$ \\
\hline \multirow{3}{*}{$\begin{array}{l}\text { Procura Informal (PI) } \\
\qquad(\mathrm{n}=39)\end{array}$} & Média & 3,10 & 3,26 & 2,59 \\
\hline & DP & 1,06 & 1,17 & 1,15 \\
\hline & $\mathrm{CV}$ & $34,2 \%$ & $35,8 \%$ & $44,6 \%$ \\
\hline \multicolumn{2}{|l|}{ Diferença entre as médias } & 1,16 & 1,29 & 0,98 \\
\hline
\end{tabular}

Para comparar a frequência de monitoramento entre os três aspectos de mercado dentro de cada um dos grupos, aplicou-se a prova não paramétrica de Friedman, obtendo-se os seguintes resultados com nível crítico de significância 0,05 :

- PF: a frequência de monitoramento dos concorrentes é significativamente superior à dos clientes, e a frequência de monitoramento dos fornecedores é significativamente inferior à de ambos.

- PI: não há diferença significativa entre a frequência de monitoramento dos concorrentes e dos clientes, porém a frequência de monitoramento dos fornecedores é significativamente inferior à de ambos.

Para comparar cada um dos três aspectos de mercado entre os grupos PF e PI, utilizou-se a prova não paramétrica Mann-Whitney, obtendo-se os seguintes resultados com nível crítico de significância 0,05 :

- a frequência de monitoramento de todos os aspectos de mercado é significativamente superior para o grupo PF, quando comparado ao grupo PI;

- os concorrentes constituem o aspecto de mercado de maior diferenciação entre os grupos com média 4,54 para o grupo PF e 3,26 para o grupo PI. 


\subsection{Aspectos Macroambientais do Escopo de Monitoramento}

A seguir, são analisadas as diferenças entre os grupos PF e PI quanto à frequência média de monitoramento dos aspectos macroambientais. No Quadro 33, apresentam-se as estatísticas descritivas média, desvio padrão (DP) e coeficiente de variação (CV) dessas variáveis para cada um dos grupos. Na última linha do referido quadro, apresentam-se as diferenças das médias entre os grupos PF e PI.

Quadro 33 - Estatísticas descritivas dos aspectos macroambientais

\begin{tabular}{|c|c|c|c|c|c|c|}
\hline \multirow{2}{*}{\multicolumn{2}{|c|}{ Estatísticas }} & \multicolumn{5}{|c|}{ Aspectos macroambientais } \\
\hline & & $\begin{array}{l}\text { Econômicos } \\
\text { (V23) }\end{array}$ & $\begin{array}{l}\text { Tecnológicos } \\
\text { (V24) }\end{array}$ & $\begin{array}{l}\text { Regulatórios } \\
\text { (v25) }\end{array}$ & $\begin{array}{l}\text { Socioculturais } \\
\text { (V26) }\end{array}$ & $\begin{array}{l}\text { Políticos } \\
\text { (V27) }\end{array}$ \\
\hline \multirow{3}{*}{$\begin{array}{l}\text { Procura Formal (PF) } \\
\qquad(\mathrm{n}=81)\end{array}$} & Média & 4,06 & 3,86 & 3,99 & 3,16 & 3,02 \\
\hline & DP & 1,12 & 1,10 & 1,09 & 1,10 & 1,15 \\
\hline & $\mathrm{CV}$ & $27,6 \%$ & $28,6 \%$ & $27,3 \%$ & $34,8 \%$ & $38,0 \%$ \\
\hline \multirow{3}{*}{$\begin{array}{l}\text { Procura Informal (PI) } \\
\qquad(\mathrm{n}=39)\end{array}$} & Média & 3,05 & 2,74 & 3,03 & 2,33 & 2,34 \\
\hline & DP & 1,06 & 1,17 & 1,15 & 1,17 & 1,15 \\
\hline & $\mathrm{CV}$ & $34,7 \%$ & $42,5 \%$ & $38,2 \%$ & $49,9 \%$ & $49,3 \%$ \\
\hline \multicolumn{2}{|c|}{ Diferença entre as médias } & 1,01 & 1,12 & 0,96 & 0,83 & 0,68 \\
\hline
\end{tabular}

Para comparar a frequência de monitoramento entre os cinco aspectos macroambientais dentro de cada um dos grupos, aplicou-se a prova não paramétrica de Friedman, obtendo-se os seguintes resultados com nível crítico de significância 0,05 :

- PF: identificaram-se dois grupos de aspectos macroambientais quanto às diferenças significativas na frequência de monitoramento. O primeiro grupo é composto pelos aspectos econômicos, tecnológicos e regulatórios, e o segundo, pelos aspectos socioculturais e políticos. Não há diferença significativa entre os aspectos dentro de cada grupo, porém os aspectos do primeiro grupo são monitorados com frequência significativamente superior à do segundo. 
- PI: obteve-se resultado análogo ao do grupo procura formal quanto à significância da diferença entre a frequência de monitoramento dos aspectos macroambientais.

Para comparar cada um dos cinco aspectos macroambientais entre os grupos PF e PI, utilizouse a prova não paramétrica Mann-Whitney, obtendo-se os seguintes resultados com nível crítico de significância 0,05 :

- a frequência de monitoramento de todos os aspectos macroambientais é significativamente superior para o grupo PF, quando comparado ao grupo PI;

- a frequência de monitoramento dos aspectos de inovação tecnológica é a que mais diferencia os grupos com média 3,86 para o grupo PF e 2,74 para o grupo PI.

\subsection{Considerações sobre o Escopo de Monitoramento}

Após a análise dos aspectos ambientais de mercado e macroambientais, concluiu-se que as organizações do grupo PF são mais ativas do que as organizações do grupo PI no monitoramento do ambiente para todos os aspectos críticos ambientais, analisando o ambiente com maior constância.

Os concorrentes constituem o aspecto ambiental de mercado de maior atenção para o grupo $\mathrm{PF}$, o que pode contribuir para a estruturação das atividades de monitoramento com a implementação de técnicas de IC como o "business war games" (GILAD, 2009), por exemplo. A frequência média de monitoramento dos concorrentes nesse grupo é 4,54, estando mais próxima de 5 ("sempre"). Destaca-se o baixo coeficiente de variação de 16,3\% para esse quesito no grupo PF, o que é indicativo de um certo consenso entre os respondentes desse grupo quanto à frequência da observação dos concorrentes. 
Em ambos os grupos, os fornecedores constituem o aspecto de mercado de menor atenção, e no grupo PI os fornecedores estão pouco presentes no escopo de monitoramento com frequência média de monitoramento 2,59, sendo inferior a 3 ("às vezes"). Entretanto, observase que, no grupo PF, os fornecedores são monitorados com frequência média 3,57, estando mais próxima de 4 ("quase sempre), apesar de menos frequente do que a observação dos concorrentes e clientes.

Os aspectos econômicos, regulatórios e tecnológicos são os aspectos macroambientais de maior atenção para ambos os grupos em oposição aos aspectos políticos e socioculturais. No grupo PI, os aspectos políticos e socioculturais encontram-se pouco presentes no escopo do monitoramento com frequências médias de 2,33 e 2,34 respectivamente, estando mais próxima de 2 ("quase nunca"). Uma possível explicação para a diferença de atenção entre os aspectos macroambientais seja a disponibilidade e facilidade de acesso a informações econômicas, regulatórias e tecnológicas, considerando fontes de informação como eventos, entidades de classe, patentes e etc.

\subsubsection{Análise dos Grupos pelas Dificuldades de Monitoramento}

O quarto bloco do questionário é composto por oito questões que avaliam a importância atribuída pelos respondentes às dificuldades técnicas e organizacionais do monitoramento. As respostas dessas questões foram analisadas com o objetivo de descrever e comparar os grupos PF e PI.

As dificuldades do monitoramento pesquisadas foram abordadas na seção 4.4.4 "Bloco 03 de Questões - Dificuldades do Monitoramento" desta dissertação e estão listadas no Quadro 34 com o código das variáveis às quais estão associadas: 
1. Dificuldades organizacionais do monitoramento:

a) V28 - falta de apoio dos gestores;

b) V29 - falta de recursos;

c) V30 - falta de atribuição de responsabilidades

d) V31 - dificuldade para definir o escopo de monitoramento; e

e) V32 - dificuldade para disseminar informações entre departamentos.

2. Dificuldades técnicas do monitoramento:

f) V33 - dificuldade para avaliar o impacto do ambiente sobre as estratégias corporativas;

g) V34 - dificuldade para filtrar as informações realmente relevantes para a estratégia; e

h) V35 - dificuldade para elaborar previsões sobre tendências futuras.

A subdivisão das dificuldades do monitoramento nas categorias organizacional e técnica foi proposta pela autora da dissertação com o objetivo de tornar a apresentação dos resultados mais coerente e didática, analisando-se cada categoria separadamente nas seções a seguir.

\subsection{Dificuldades Organizacionais do Monitoramento}

No Quadro 35, apresentam-se as estatísticas descritivas média, desvio padrão (DP) e coeficiente de variação $(\mathrm{CV})$ para as cinco variáveis relativas às dificuldades de natureza organizacional nos grupos PF e PI. Na última linha do referido quadro, apresentam-se as diferenças entre as médias entre os grupos. 
É oportuno lembrar que essas variáveis foram mensuradas em escala Likert de importância com os extremos " 1 = nada importante" e "5 = muito importante", com pontos intermediários não rotulados.

A seguir, são analisadas as diferenças entre os grupos PF e PI quanto ao grau médio de importância das dificuldades organizacionais do monitoramento. No Quadro 35, apresentamse as estatísticas descritivas média, desvio padrão (DP) e coeficiente de variação (CV) dessas variáveis para cada um dos grupos. Na última linha do referido quadro, apresentam-se as diferenças das médias entre os grupos PF e PI.

Quadro 35 - Estatísticas descritivas das dificuldades organizacionais

\begin{tabular}{|c|c|c|c|c|c|c|}
\hline \multirow{2}{*}{\multicolumn{2}{|c|}{ Estatísticas Descritivas }} & \multicolumn{5}{|c|}{ Dificuldades organizacionais } \\
\hline & & $\begin{array}{l}\text { Apoio } \\
\text { (V28) }\end{array}$ & $\begin{array}{l}\text { Recursos } \\
\quad \text { (V29) }\end{array}$ & $\begin{array}{l}\text { Responsab. } \\
\text { (V30) }\end{array}$ & $\begin{array}{l}\text { Escopo } \\
\text { (V31) }\end{array}$ & $\begin{array}{l}\text { Deptos. } \\
\text { (V32) }\end{array}$ \\
\hline \multirow{3}{*}{$\begin{array}{l}\text { Procura Formal (PF) } \\
\qquad(\mathrm{n}=81)\end{array}$} & Média & 3,83 & 3,73 & 3,44 & 3,77 & 3,73 \\
\hline & DP & 1,21 & 1,12 & 1,16 & 1,10 & 1,01 \\
\hline & $\mathrm{CV}$ & $31,7 \%$ & $30,0 \%$ & $33,7 \%$ & $29,2 \%$ & $27,2 \%$ \\
\hline \multirow{3}{*}{$\begin{array}{l}\text { Procura Informal (PI) } \\
\qquad(\mathrm{n}=39)\end{array}$} & Média & 4,03 & 3,46 & 3,79 & 3,62 & 3,62 \\
\hline & DP & 1,14 & 1,12 & 1,06 & 1,18 & 1,14 \\
\hline & $\mathrm{CV}$ & $28,2 \%$ & $32,4 \%$ & $27,8 \%$ & $32,7 \%$ & $31,5 \%$ \\
\hline \multicolumn{2}{|l|}{ Diferença entre as médias } & $-0,20$ & 0,27 & $-0,35$ & 0,15 & 0,11 \\
\hline
\end{tabular}

Para comparar o grau de importância entre as cinco dificuldades organizacionais dentro de cada um dos grupos, aplicou-se a prova não paramétrica de Friedman, obtendo-se os seguintes resultados com nível crítico de significância 0,05 :

- PF: a falta de apoio dos gestores e a falta de recursos, com médias 3,83 e 3,73 respectivamente, são significativamente mais importantes do que a falta de atribuição de responsabilidades com média 3,44.

- PI: a falta de apoio dos gestores é significativamente mais importante do que a falta de recursos, e a primeira apresentou média 4,03 e a segunda, 3,46. 
No grupo PF, pode-se inferir que, pelo fato de o monitoramento ser uma atividade de maior formalidade, apresenta papéis e responsabilidades bem definidos sob a gestão de um departamento, podendo até existir uma estrutura de cargos específicos. Entretanto, se a Alta Direção não der o apoio por meio dos investimentos necessários para a área, podem faltar recursos para o desempenho das atividades planejadas para o monitoramento. Essa é uma possível interpretação para os resultados encontrados para esse grupo, assumindo-se que a falta de recursos é uma consequência da falta de apoio dos gestores no grupo PF.

No caso do grupo PI, pode-se supor que o apoio dos gestores é fator crítico para que ocorra a formalização e a estruturação das atividades de monitoramento, e somente então haverá o planejamento e a sistematização das atividades com a identificação dos recursos necessários para executá-las. Infere-se que, por esse motivo, o apoio dos gestores se mostrou mais importante do que a falta de recursos na percepção dos respondentes desse grupo.

Para comparar cada uma das cinco dificuldades entre os grupos PF e PI, utilizou-se a prova não paramétrica Mann-Whitney, não se identificando diferenças significativas para essas variáveis entre os grupos.

\subsection{Dificuldades Técnicas do Monitoramento}

No presente estudo, foram analisadas as seguintes dificuldades técnicas do monitoramento:

a) avaliação do impacto do ambiente sobre as estratégias corporativas;

b) seleção das informações realmente relevantes para a estratégia; e

c) elaboração de previsões sobre tendências futuras.

A seguir, são analisadas as diferenças entre os grupos PF e PI quanto ao grau médio de importância atribuída às dificuldades técnicas do monitoramento. No Quadro 36, apresentamse as estatísticas descritivas média, desvio padrão (DP) e coeficiente de variação (CV) dessas variáveis para cada um dos grupos. Na última linha do referido quadro, apresentam-se as diferenças das médias entre os grupos PF e PI. 
Quadro 36 - Estatísticas descritivas das dificuldades técnicas

\begin{tabular}{|c|c|c|c|c|}
\hline \multicolumn{2}{|c|}{} & \multicolumn{3}{c|}{ Dificuldades técnicas } \\
\cline { 3 - 5 } \multicolumn{2}{|c|}{} & $\begin{array}{c}\text { Avaliação } \\
\text { (V33) }\end{array}$ & $\begin{array}{c}\text { Seleção } \\
\text { (V34) }\end{array}$ & $\begin{array}{c}\text { Previsão } \\
\text { (V35) }\end{array}$ \\
\hline \multirow{2}{*}{$\begin{array}{c}\text { Procura Formal (PF) } \\
(\mathrm{n}=81)\end{array}$} & Média & 3,65 & 3,75 & 3,68 \\
\cline { 2 - 5 } & DP & 1,12 & 1,12 & 1,08 \\
\cline { 2 - 5 } & CV & $30,6 \%$ & $29,9 \%$ & $29,4 \%$ \\
\hline \multirow{2}{*}{$\begin{array}{c}\text { Procura Informal (PI) } \\
(\mathrm{n}=39)\end{array}$} & Média & 3,44 & 3,59 & 3,62 \\
\cline { 2 - 5 } & DP & 1,23 & 1,09 & 1,14 \\
\cline { 2 - 5 } & CV & $35,8 \%$ & $30,5 \%$ & $31,5 \%$ \\
\hline Diferença entre as médias & & 0,22 & 0,16 & 0,06 \\
\hline
\end{tabular}

Novamente, aplicaram-se os testes não paramétricos de Friedman para identificar diferenças significativas intragrupos e o teste não paramétrico de Mann-Whitney para as diferenças significativas intergrupos com nível crítico de significância 0,05. Para ambos os testes, não foram encontradas diferenças significativas.

Observa-se que os graus médios de importância para as três dificuldades técnicas analisadas, em ambos os grupos, são superiores a 3, sendo um indicativo de que essas dificuldades apresentam alguma importância para os respondentes.

\subsubsection{Síntese da Identificação do Modo de Monitoramento}

Nesta etapa da análise dos dados, considerou-se que as organizações dos respondentes fazem procura ativa de informação no ambiente externo à organização pelo fato de utilizarem profissionais de monitoramento. Empregou-se a Análise de Conglomerados para classificar as organizações dos respondentes em dois grupos diferenciados pelo nível de formalidade de procura de informação denominados procura formal e procura informal, com 81 e 39 observações respectivamente. Essa formação foi validada pela aplicação da técnica da Análise Discriminante, cujos resultados evidenciaram uma excepcional separação dos grupos pelas 15 variáveis do primeiro bloco do questionário. 
Após, empregou-se a Análise Fatorial para sumarizar as 14 variáveis que se mostraram significativas para a formação dos grupos, obtendo-se três fatores correlatos denominados estruturação da atividade (Fator 1), estruturação da informação coletada (Fator 2) e ocasionalidade da pesquisa qualitativa (Fator 3). Segundo o arcabouço teórico do presente estudo, esses fatores estão associados a um nível maior de formalidade do modo de monitoramento. Considerando-se que as organizações que apresentam essas características praticam um modo de monitoramento do tipo procura formal.

Para complementar a descrição e a comparação dos grupos, investigaram-se três variáveis adicionais: as fontes de informação, o escopo do monitoramento e as dificuldades do monitoramento. Obteve-se que o grupo PF monitora o ambiente de forma mais abrangente e constante do que o grupo PI, com foco prioritário sobre os concorrentes seguidos dos clientes, além de privilegiar as informações obtidas por meio do contato com pessoas de fora da organização (fontes pessoais externas). O grupo PI apresenta um monitoramento menos intenso do ambiente e utiliza mais as informações escritas geradas fora da organização (fontes impessoais externas), como as obtidas em jornais, revistas e sites da Internet. O apoio da alta direção às atividades de monitoramento parece ser a dificuldade de maior importância em ambos os grupos, uma vez que se trata de um fator fundamental para o amadurecimento da prática nas organizações. 


\subsubsection{Relação do Modo de Monitoramento e Orientação Estratégica}

Nesta etapa final da análise dos dados, verifica-se a existência ou não de relação entre modo de monitoramento e a orientação estratégica. A abordagem da análise será a aplicação do teste estatístico não paramétrico $\chi^{2}$ (qui-quadrado) para a verificação da independência destes constructos. A operacionalização desse teste consiste no uso das variáveis em escalas nominais definidas nas etapas anteriores.

Considera-se que a orientação estratégica é uma variável em escala nominal que pode assumir os valores Analítica (A), Defensiva (D), Prospectora (P) e Reativa (R), segundo a tipologia proposta pelo modelo de Miles e Snow (1978, 2003). Na primeira etapa da análise dos dados, cada observação da amostra foi classificada em uma dessas categorias, conforme os resultados das questões da escala de Conant et al. (1990) inclusas no questionário do presente estudo.

Com base nos resultados da segunda etapa da análise dos dados, considera-se que o modo de monitoramento é uma variável em escala nominal que pode assumir os valores procura formal (PF) e procura informal (PI). A classificação de cada observação da amostra em uma dessas categorias ocorreu conforme o grupo no qual a observação foi inclusa na Análise de Conglomerados. É oportuno lembrar que os dois grupos formados diferenciam-se de forma parcimoniosa pelos fatores: estruturação das atividades, estruturação da informação coletada e ocasionalidade da pesquisa qualitativa.

A seguir, serão apresentados os resultados da análise da relação entre o modo de monitoramento e a orientação estratégica. No Quadro 37, apresenta-se a distribuição cruzada de frequências dessas variáveis, que, em cada célula, há quatro linhas que correspondem à contagem obtida, à contagem esperada, ao percentual na coluna e ao percentual na linha respectivamente. 
Quadro 37 - Orientação Estratégica versus Modo de Monitoramento

\begin{tabular}{|c|c|c|c|c|c|c|}
\hline \multirow{2}{*}{\multicolumn{2}{|c|}{ Modo de Monitoramento (MM) }} & \multicolumn{5}{|c|}{ Orientação Estratégica (OE) } \\
\hline & & $\begin{array}{c}\text { A } \\
\text { (Analítica) }\end{array}$ & $\begin{array}{c}\mathrm{D} \\
\text { (Defensiva) }\end{array}$ & $\begin{array}{c}\text { P } \\
\text { (Prospectora) }\end{array}$ & $\begin{array}{c}\mathrm{R} \\
\text { (Reativa) }\end{array}$ & Total \\
\hline \multirow{4}{*}{$\begin{array}{c}\text { PF } \\
\text { (Procura Formal) }\end{array}$} & Contagem & 41 & 16 & 16 & 8 & 81 \\
\hline & Contagem esperada & $(35,8)$ & $(18,2)$ & $(14,2)$ & $(12,8)$ & $(81,0)$ \\
\hline & $\%$ dentro da coluna & $\underline{77,4 \%}$ & $\underline{\mathbf{5 9}, 3 \%}$ & $\underline{76,2 \%}$ & $\underline{42,1 \%}$ & $67,5 \%$ \\
\hline & $\%$ dentro da linha & $50,6 \%$ & $19,8 \%$ & $19,8 \%$ & $9,9 \%$ & $100,0 \%$ \\
\hline \multirow{4}{*}{$\begin{array}{c}\text { PI } \\
\text { (Procura Informal) }\end{array}$} & Contagem & 12 & 11 & 5 & 11 & 39 \\
\hline & Contagem esperada & $(17,2)$ & $(8,8)$ & $(6,8)$ & $(6,2)$ & $(39,0)$ \\
\hline & $\%$ dentro da coluna & $\underline{22,6 \%}$ & $\underline{40,7 \%}$ & $\underline{23,8 \%}$ & $\underline{\mathbf{5 7 , 9 \%}}$ & $\underline{32,5 \%}$ \\
\hline & $\%$ dentro da linha & $30,8 \%$ & $28,2 \%$ & $12,8 \%$ & $28,2 \%$ & $100,0 \%$ \\
\hline \multirow{4}{*}{ Total } & Contagem & 53 & 27 & 21 & 19 & 120 \\
\hline & Contagem esperada & $(53,0)$ & $(27,0)$ & $(21,0)$ & $(19,0)$ & $(120,0)$ \\
\hline & $\%$ dentro da coluna & $100,0 \%$ & $100,0 \%$ & $100,0 \%$ & $100,0 \%$ & $100,0 \%$ \\
\hline & $\%$ dentro da linha & $44,2 \%$ & $22,5 \%$ & $17,5 \%$ & $15,8 \%$ & $100,0 \%$ \\
\hline
\end{tabular}

Por exemplo, na primeira célula do Quadro 37, que cruza o modo de monitoramento procura formal (PF) com a orientação estratégica Analítica (A), foram contadas 41 observações do total de 120. Caso as duas variáveis sejam independentes, a contagem esperada será de 38,5, sendo menor do que a contagem observada. A contagem esperada é o produto do tamanho da amostra (120) pelas probabilidades estimadas de uma observação ser Analítica (53/120) e ser PF (81/120). Das 53 organizações Analíticas, 77,4\% (percentual da coluna) são PF e 50,6\% (percentual da linha) das organizações PF são Analíticas. Essa interpretação aplica-se a todas as células do quadro.

Se as duas variáveis fossem independentes, os percentuais esperados para qualquer orientação estratégica seriam os da coluna Total, ou seja, 67,5\% para o modo de monitoramento PF e 32,5\% para PI. Assim, infere-se a existência de uma tendência de as organizações Analíticas da amostra adotarem um modo de monitoramento do tipo procura formal com $77,4 \%$ das observações nesta categoria. Empregando-se a mesma análise para a célula que cruza o modo de monitoramento PF com a orientação estratégica Prospectora (P), tem-se que 76,2\% das 21 
organizações com essa orientação estratégica adotam o modo de monitoramento PF, indicando também uma tendência nesse sentido na amostra.

Em contrapartida, para as orientações estratégicas Defensiva (D) e Reativa (R), observa-se uma tendência contrária, pois os percentuais de observações para o modo de monitoramento procura informal foram 40,7\% e 57,9\%, respectivamente, superiores ao esperado de 32,5\%, caso as variáveis fossem independentes. Assim, infere-se que as organizações com essas orientações estratégicas apresentam uma tendência para a procura informal (PI) na amostra.

Aplicando-se a prova estatística não paramétrica $\chi^{2}$ (qui-quadrado), obteve-se um valor de 9,492 para a estatística Pearson Chi-Square com significância de 0,023 para 3 graus de liberdade. Dessa forma, rejeita-se com nível crítico de significância 0,05 a hipótese nula do teste $\chi^{2}$ de independência entre as variáveis modo de monitoramento e orientação estratégica.

Assim, se aceita a primeira hipótese (H1) proposta na seção "4.2 - Hipóteses de Pesquisa" desta dissertação e ilustrada na Figura 9:

H1: O modo de monitoramento varia de acordo com a orientação estratégica das organizações.

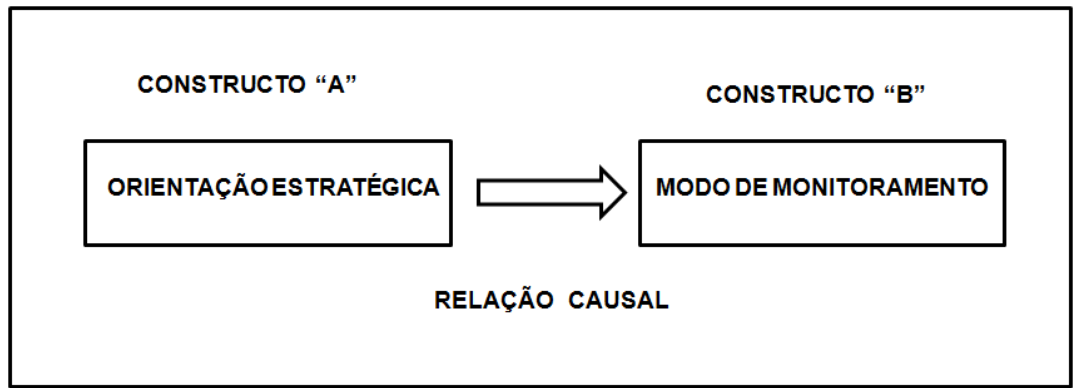

Figura 9 - Relação entre modo de monitoramento e orientação estratégica 
Com base nos resultados obtidos, considera-se que as organizações com orientação estratégica Analítica e Prospectora da amostra do presente estudo tendem a empregar o modo de monitoramento procura formal e as organizações Defensivas e Reativas, a procura informal.

Agora, será testada a segunda hipótese (H2) proposta para o presente estudo:

\section{H2: As organizações com orientação estratégica Analítica apresentam um modo de} monitoramento mais formal do que as organizações Prospectoras.

No Quadro 38, apresenta-se novamente a distribuição cruzada das variáveis modo de monitoramento e orientação estratégica, porém limitando-se às organizações Analíticas e Prospectoras.

Quadro 38 - Modo de monitoramento e orientações estratégicas A e P

\begin{tabular}{|c|c|c|c|c|}
\hline \multirow{2}{*}{\multicolumn{2}{|c|}{ Modo de Monitoramento (MM) }} & \multicolumn{3}{|c|}{ Orientação Estratégica (OE) } \\
\hline & & $\begin{array}{c}\text { A } \\
\text { (Analítica) }\end{array}$ & $\begin{array}{c}\mathrm{P} \\
\text { (Prospectora) }\end{array}$ & Total \\
\hline \multirow{4}{*}{$\begin{array}{c}\text { PF } \\
\text { (Procura Formal) }\end{array}$} & Contagem & 41 & 16 & 57 \\
\hline & Contagem esperada & $(40,8)$ & $(16,2)$ & $(57,0)$ \\
\hline & $\%$ dentro da coluna & $\mathbf{7 7 , 4 \%}$ & $76,2 \%$ & $\mathbf{7 7 , 0 \%}$ \\
\hline & $\%$ dentro da linha & $71,9 \%$ & $28,1 \%$ & $100,0 \%$ \\
\hline \multirow{4}{*}{$\begin{array}{c}\text { PI } \\
\text { (Procura Informal) }\end{array}$} & Contagem & 12 & 5 & 17 \\
\hline & Contagem esperada & $(12,2)$ & $(4,8)$ & $(17,0)$ \\
\hline & $\%$ dentro da coluna & $\underline{22,6 \%}$ & $\underline{23,8 \%}$ & $\underline{23,0 \%}$ \\
\hline & $\%$ dentro da linha & $70,6 \%$ & $29,4 \%$ & $100,0 \%$ \\
\hline \multirow{4}{*}{ Total } & Contagem & 53 & 21 & 74 \\
\hline & Contagem esperada & $(53,0)$ & $(21,0)$ & $(74,0)$ \\
\hline & $\%$ dentro da coluna & $100,0 \%$ & $100,0 \%$ & $100,0 \%$ \\
\hline & $\%$ dentro da linha & $71,6 \%$ & $28,4 \%$ & $100,0 \%$ \\
\hline
\end{tabular}

Em uma inspeção visual no Quadro 41, percebe-se que tanto a orientação estratégica Analítica quanto a Prospectora possuem percentuais muito próximos de $77 \%$ para o modo de 
monitoramento procura formal e $23 \%$ para a procura informal, à semelhança da coluna Total. Esses percentuais não indicam a existência de uma maior tendência à procura formal das Prospectoras em relação às Analíticas.

Aplicando-se a prova estatística não paramétrica $\chi^{2}$ (qui-quadrado), obteve-se um valor de 0,012 para a estatística Pearson Chi-Square com significância de 0,914 para 1 grau de liberdade. Dessa forma, aceita-se com nível crítico de significância 0,05 a hipótese nula do teste $\chi^{2}$ de que não há diferença entre as organizações Analíticas e Prospectoras quanto à proporção de organizações com modo de monitoramento PF.

Dessa forma, a segunda hipótese (H2) do presente estudo que sugere que as organizações Analíticas apresentam um modo de monitoramento mais formal do que as Prospectoras foi rejeitada, pois não foram encontradas diferenças significativas entre as organizações Analíticas e Prospectoras quanto à proporção das organizações que praticam a procura formal. 


\section{CONSIDERAÇÕES FINAIS}

Esse estudo teve como objeto de análise 120 organizações de grande porte descritas por seus profissionais de monitoramento em relação ao modo como ocorre a procura de informações no ambiente externo e à maneira escolhida pelos seus gestores para competir no mercado. A simples contribuição deste estudo, considerando-se a importância e a abrangência do tema escolhido, é justamente trazer a perspectiva das pessoas que de fato estão envolvidas com as atividades de monitoramento e que podem oferecer uma visão mais próxima do que ocorre na prática organizações.

Do ponto de vista teórico, buscou-se contribuir com o resgate e a verificação de modelos teóricos que foram apenas parcialmente testados em estudos anteriores e que se propõem a descrever e explicar o modo como as organizações monitoram seu ambiente externo. Esses modelos forneceram subsídios para a construção de uma escala para operacionalizar a verificação da existência de relação entre o modo de monitoramento e a orientação estratégica das organizações, sendo esse o objetivo principal da investigação. Assim, espera-se que o estabelecimento de uma relação entre o modo de monitoramento e a orientação estratégica contribua para relacionar o monitoramento com seu principal propósito, reforçando sua importância estratégica.

O primeiro objetivo específico deste estudo foi identificar o modo como as organizações monitoram o ambiente externo. Com base no modelo teórico de Daft e Weick (1984), no qual as organizações que procuram ativamente por informações no ambiente adotam a procura formal ou a procura informal para esta finalidade (AGUILAR, 1967), construiu-se um questionário para essa classificação. Considera-se que esse objetivo foi atingido, pois foi possível classificar as organizações dos respondentes nessas duas modalidades.

É interessante observar que a maioria das organizações investigadas adota a procura formal para monitorar o ambiente, correspondendo a $66 \%$ das observações. Esse resultado está alinhado com Thomas (1980) que argumenta que as organizações de grande porte, como as selecionadas para a análise, tendem a implementar sistemas de monitoramento mais estruturados, sendo compatíveis com as necessidades de planejamento estratégico. 
$\mathrm{Na}$ análise das variáveis pesquisadas, identificaram-se três fatores que contribuem para a implementação da procura formal nas organizações. O primeiro fator é a estruturação das atividades que, segundo Choo (1999), é decorrente da adoção de procedimentos e metodologias que conduzem a um modo de monitoramento planejado, contínuo, sustentado e coordenado, pois:

a) o planejamento assegura que a informação procurada seja crítica para os objetivos da organização;

b) o monitoramento contínuo permite detectar proativamente os indícios de mudanças no ambiente;

c) o monitoramento sustentado permite que a organização construa uma rede de informações e cresça sua base de conhecimento; e

d) a coordenação minimiza duplicidades e maximiza o escopo e a eficiência da coleta de informação.

É oportuno mencionar que, na literatura, encontra-se uma preocupação quanto à estruturação excessiva das atividades de monitoramento, que pode levar à redução da criatividade que é um elemento crucial para a interpretação de sinais fracos e para a geração de perspectivas de futuro. Jain (1984, p. 107) comenta que "o monitoramento não é uma ciência exata. Na verdade, está mais para arte do que para ciência". Thomas (1980) argumenta que as abordagens sistematizadas do monitoramento devem ser projetadas de tal forma a desenvolver a criatividade dos executivos para que possam lidar com as mudanças futuras do ambiente.

O segundo fator da procura formal é a estruturação da informação que, de certa forma, está associado ao "monitoramento sustentado" mencionado por Choo (1999). O monitoramento sustentado tem por finalidade a construção de bases informatizadas de conhecimento nas quais a informação é estruturada para que possa ser armazenada e recuperada quando necessário, bem como relacionada a outras informações. Potter et al. (2010) afirmam que o uso de sistemas de tecnologia da informação para armazenar e distribuir informação reduz o tempo para tomada de decisões estratégicas.

Kahaner (1997), por sua vez, comenta que uma das tarefas mais difíceis do monitoramento é prever o que irá acontecer no futuro e que as informações estruturadas (hard), principalmente as de natureza quantitativa, mostram o passado. $\mathrm{O}$ autor afirma que as informações não 
estruturadas (soft) como rumores e comentários também devem fazer parte do escopo do monitoramento. Os resultados do presente estudo levam ao questionamento do quanto a procura formal é eficaz na previsão do futuro, pois observou-se sua forte associação com as análises e previsões estatísticas que podem desviar a atenção das surpresas estratégicas ou rupturas (ANSOFF, 1975).

$\mathrm{O}$ terceiro fator da procura formal refere-se ao desenvolvimento de pesquisas qualitativas ocasionais. Esse fator apresenta uma certa associação com a o monitoramento baseado em projeto mencionado por Cartwright et al. (1995). Nessa abordagem, a análise é delineada para requisitos únicos da informação necessária para uma decisão específica. $\mathrm{O}$ desenvolvimento de pesquisas qualitativas demanda metodologias e estratégias de coleta e análise de dados que requerem planejamento e sistematização. Por esse motivo, conclui-se que essa modalidade de coleta de informações esteja associada à procura formal.

Os resultados da análise das questões relativas às fontes de informação e aos aspectos monitorados do ambiente levam a sugerir que a procura formal permite que a organização realize um monitoramento mais abrangente e contínuo, caracterizando uma espécie de estado de alerta. É interessante destacar a utilização mais intensa de fontes pessoais externas, o que pode estar associado com a realização de pesquisas de campo que implicam o contato direto com pessoas. Para a condução dessas pesquisas, faz-se necessário o emprego de planejamento e metodologias para que a coleta seja eficiente e eficaz para a obtenção das informações procuradas.

Os resultados do presente estudo também mostram que a procura formal foca principalmente nos concorrentes. Calof e Wright (2008) comentam que o trabalho seminal de Porter (1980) sobre gestão estratégica e análise competitiva, que aborda a observação do comportamento dos concorrentes e a análise dos concorrentes para elaborar a estratégia competitiva, desencadeou uma onda de publicações sobre a Inteligência Competitiva. É possível que os concorrentes sejam um alvo destacado do monitoramento na procura formal, pela influência do trabalho de Porter (1980) e toda a cultura que se criou a partir dele a respeito de estratégias e vantagens competitivas. Observa-se que o foco excessivo sobre um aspecto do ambiente pode provocar uma certa cegueira para outros aspectos relevantes, sendo um risco para a organização (DAY; SCHOEMAKER, 2005). 
O segundo objetivo específico deste estudo foi identificar a orientação estratégica das organizações dos respondentes utilizando-se os tipos estratégicos de Miles e Snow (2003). Considera-se que esse objetivo foi alcançado pela utilização de uma adaptação da escala de Conant et al. (1990). Os resultados mostraram uma predominância de organizações Analíticas, havendo um alinhamento com o modelo de Daft e Weick (1984) que associa esse perfil de organização à existência de uma estrutura formal de monitoramento. Identificou-se também uma tendência das organizações Prospectoras serem multinacionais, o que apresenta uma certa coerência com o modelo de Miles e Snow (2003), dado que as multinacionais procuram ampliar a abrangência de seus mercados, o que é uma características das organizações Prospectoras.

O objetivo principal deste estudo foi verificar a existência ou não de relação entre o modo de monitoramento e a orientação estratégica das organizações dos respondentes. Considera-se que esse objetivo foi alcançado, pois se conseguiu operacionalizar as variáveis modo de monitoramento e orientação estratégica e testar a relação entre elas através de métodos estatísticos.

Como resultado dos testes, verificou-se que o modo de monitoramento pode variar de acordo com a orientação estratégica, e as organizações Analíticas e Prospectoras tendem à procura formal e as Defensivas e Reativas, à procura informal. Ou seja, identificou-se uma relação entre o modo de monitoramento e a orientação estratégica na amostra analisada. Observa-se que essa relação foi investigada somente em organizações que procuram ativamente por informações no ambiente, encontrando-se organizações Defensivas e Reativas que, pelo modelo de Daft e Weick (1984), seriam passivas. Dessa forma, considera-se que podem existir outras dimensões além da percepção dos executivos quanto à analisabilidade do ambiente e à intromissão no ambiente como determinantes do modo de monitoramento das organizações. Observa-se que essas duas dimensões são as propostas por esses autores para explicar o modo de monitoramento adotado pelas organizações.

Miles e Snow (2003) sugerem que as organizações Prospectoras monitoram as condições e eventos do ambiente de forma vasta, pois buscam oportunidades de inovação. Os resultados da presente investigação mostraram que a procura formal é um modo de monitoramento abrangente em relação aos aspectos analisados do ambiente. Portanto, é bastante razoável 
encontrar uma tendência das organizações Prospectoras para o modo de monitoramento procura formal.

Com relação às organizações Analíticas, Miles e Snow (2003) propõem que os executivos de marketing são bastante influentes, e os mecanismos de monitoramento estão muito relacionados a esta área. Pode-se então, associar o monitoramento do ambiente com os aspectos de mercado como concorrentes, clientes e fornecedores e à realização de pesquisas. Dessa forma, também é razoável encontrar uma tendência desse tipo de organização a adotar um modo de monitoramento como a procura formal que apresenta estruturação para a realização de estudos de mercado.

Para finalizar, destaca-se como principal limitação do presente estudo a utilização de uma amostra que não é suficientemente grande e representativa para a generalização dos resultados encontrados. Entretanto, sugere-se para a continuidade deste estudo o desenvolvimento de pesquisas comparativas dos modos de monitoramento procura formal e procura informal quanto à sua contribuição para o desempenho das organizações. 


\section{REFERÊNCIAS}

AGUILAR, F. J. Scanning the business environment. Nova York: The Macmillan Company, 1967. 239 p.

ANSOFF, H. I. Managing strategic surprise by response to weak signals. California Management Review, v. 18, n. 2, p. 21-33, 1975.

ANTIA, K. D.; HERSOFORD, J. W. A process-oriented view of Competitive Inteligence and its impact on organizational performance. Journal of Competitive Intelligence and Management, v. 4, n. 1, p. 3-31, 2007.

ARANHA, F.; ZAMBALDI, F. Análise fatorial em administração. São Paulo: Cengage learning, 2008. $152 \mathrm{p}$.

BNDES. Disponível em:

<http://www.bndes.gov.br/SiteBNDES/bndes/bndes_pt/Institucional/Apoio_Financeiro/porte. html >. Acesso em: 08-04-2013.

BOULDING, K. E. General system theory: the skeleton of a science. Management Science, v. 2, p. 197-208, 1956.

CALOF, J. L.; WRIGHT, S. Competitive intelligence - A practitioner, academic and interdisciplinary perspective. European Journal of Marketing, v. 42, n. 7-8, p. 717-730, 2008.

CAPES. Disponível em: < http://www-periodicos-capes-govbr.ez67.periodicos.capes.gov.br/index.php?option=com_pcollection \&mn=70\&smn=79>. Acesso em: 23/03/2013.

CARIFIO, J.; PERLA, R. Resolving the 50-year debate around using and misusing Likert scales. Medical Education, v. 42, n. 12, p. 1150-1152, dec. 2008.

CARTWRIGHT, D. L.; BOUGHTON, P. D.; MILLER, S. W. Competitive intelligence systems: relationships to strategic orientation and perceived usefulness. Journal of Managerial Issues, v. 7, n. 4, p. 420-434, 1995.

CHILD, J. Organizational structure, environment, and performance - the role of strategic choice. Sociology, v. 6, p. 1-22, jan. 1972.

CHOO, C. W. The art of scanning the environment. Bulletin of the American Society for Information Science, v. 25, n. 3, p. 21-24, feb./mar. 1999.

Information management for the inteligent organization: the art of scanning the environment. 6. ed. Medford, Nova Jersey: Information Today, Inc., 2002. 325 p.

CONANT, J. S.; MOKWA, M. P.; VARADARAJAN, P. R. Strategic types, distintictive marketing competences and organizational performance: a multiple mearuses-based study. Strategic Management Journal, v. 11, n. 5, p. 365-383, set. 1990. 
CORRAR, L. J.; PAULO, E.; DIAS FILHO, J. M. Análise Multivariada. São Paulo: FIPECAFI - Fundação Instituto de Pesquisas Contábeis, Atuariais e Financeiras, 2007. 541 p.

CRESWELL, J. W. Projeto de pesquisa métodos qualitativo, quantitativo e misto. Porto Alegre: SAGE, 2010. 296 p.

CULNAN, M. J. Environmental scanning: the effects of task complexity and source accessibility on information gathering behavior. Decision Sciences, v. 14, p. 194-206, 1983.

DAFT, R. L. Admninistração. 6 ed. São Paulo: Pioneira Thomson Learning, 2005. 581 p.

DAFT, R. L.; SORMUNEN, J.; PARKS, D. Chief executive scanning, environmental characteristics, and company performance: na empirical study. Strategic Management Journal, v. 9, n. 2, p. 123-139, mar-abr 1988.

DAFT, R. L.; WEICK, K. E. Toward a model of organizatins as interpretation systems. Academy of Management Review, v. 9, n. 2, p. 284-295, 1984.

DAY, G. S.; SCHOEMAKER, P. J. H. Scanning the Periphery. Harvard Business Review, nov. 2005.

DENNING, B. W. Strategic environmental appraisal. Long Range Planning, v. 6, n. 1, p. 22$27,1973$.

DOTY, D. H.; GLICK, W. H. Typologies as a unique form of theory building: toward improve understanding and modeling. Academy of Management Review, v. 19, n. 2, p. 230251, abr 1994.

FAHEY, L.; KING, W. R. Environmental scanning for corporate-planning. Business Horizons, v. 20, n. 4, p. 61-71, 1977.

FISS, P. C. Building better causal theories: a fuzzy set approach to typologies in organization research. Academy of Management Journal, v. 54, n. 2, p. 393-420, abr 2011.

FONSECA, F. Fatores de abandono de iniciativas de inteligência competitiva. São Paulo. 2012. 168 p. Dissertação (Mestrado em Administração) - Programa de Pós-Graduação em Administração, Departamento de Administração, Faculdade de Administração e Contabilidade da Universidade de São Paulo. 2012.

FÁVERO, L. P.; BELFIORE, P.; SILVA, F. L.; CHAN, B. L. Análise de dados: modelagem multivariada para tomada de decisões. Rio de Janeiro: Elsevier, 2009. 646 p.

GIL, A. C. Como elaborar projetos de pesquisa. 5 ed. São Paulo: Editora Atlas, 2010.

GILAD, B. Business war games. Franklin Lakes, NJ: Career Press, 2009. . Strategy without intelligence, intelligence without strategy. Business Strategy

Series, v. 12, p. 4-11, 2011.

GIMENEZ, F. A. P. et al. Estratégia em pequenas empresas: uma aplicação do modelo de Miles e Snow. RAC, v. 3, n. 2, p. 53-74, 1999. 
HAIR JR., J. F.; BLACK;W. C., BABIN, B. J.; ANDERSON, R. E.; TATHAM, R. L. Multivariate Data Analysis. EUA: Pearson Prentice Hall: 2006. 889 p.

HAMBRICK, D. C. Environmental scanning and organizational strategy. Strategic Management Journal, v. 3, n. 2, p. 159-174, 19821982.

An empirical typology of mature industrial-product environments. Academy of Management Journal, v. 26, n. 2, p. 213-230, 1983.

HERBERT, T. T.; DERESKY, H. Generic strategies - na empirical investigation of typology validity and strategy content. Strategic Management Journal, v. 8, n. 2, p. 135-147, mar-apr 1987.

HERRING, P. J.; LEAVITT, J. A. The roadmap to a world-class Competitive Intelligence program. Competitive Intelligence, v. 14, p. 9-28, jan-mar 2011.

HREBINIAK, L. G.; JOYCE, W. F. Organizational adaptation: strategic choice and environmental determinism. Administrative Science Quarterly, v. 30, n. 3, p. 336-349, 1985.

JAIN, S. C. Environmental Scanning in U.S.Corporations. Long Range Planning, v. 17, n. 2, p. 117-128, 1984.

JENNINGS, D. F.; LUMPKIN, J. R. Insights between environmental scanning activities and Porter's generic strategies: na empirical analysis. Journal of Management, v. 18, n. 4, p. 791-803, dec 1992.

KAHANER, L. Competitive Intelligence. Nova York: 1997. 300 p.

KEFALAS, A.; SCHODERBEK, P. P. Scanning the business environment - some emprirical aspects. Decision Sciences, v. 4, p. 63-74, 1973.

KOBASHI, N. Y.; SANTOS, R. N. M. D. Institucionalização da pesquisa científica no Brasil: cartografia temática e de redes sociais por meio de técnicas bibliométricas.

TransInformação, v. 18, n. 1, p. 27-36, jan-abr 2006.

KRAKAUER, Patrícia Viveiros de Castro. A utililização das informações do ambiente no processo de decisão estratégica: estudo com empresários brasileiros e americanos de pequenas empresas. São Paulo, 2010. 137 p. Dissertação (Mestrado em Administração) Programa de Pós-Graduação em Economia, Faculdade de Economia, Administração e Contabilidade da Universidade de São Paulo. 2010.

KRAKAUER, P. V. D. C.; ALMEIDA, F. C. D.; AMEIDA, M. I. R. Competitive intelligence: bibliometric research on early signals. Journal of Modern Accounting and Auditing, v. 9, n. 4, p. 547, abr. 2013.

KUMAR, K.; SUBRAMANIAN, R.; STRANDHOLM, K. Competitive strategy, environmental scanning and performance: a context specific analysis of their relationship. International Journal of Commerce and Management, v. 11, n. 2, p. 1-33, 2001. 
LESCA, N.; CARON-FASAN, M. L. Strategic scanning project failure and abandonment factors: lessons learned. European Journal of Information Systems, v. 17, n. 4, p. 371-386, ago. 2008.

LIMA, M. C. Monografia: a engenharia da produção acadêmica. São Paulo: Saraiva, 2004. xiii, 210 p.

LINKEDIN GROUPS. Disponível em: <

http://www.linkedin.com/vsearch/g?keywords=Intelig\%C3\%AAncia\&orig=GLHD\&pageKey =voltron_group_search_internal_jsp >. Acesso em: 06/04/2013.

LINKEDIN. Disponível em: < http://www.linkedin.com/about-us >. Acesso em: 03/06/2013.

MALHOTRA, N. Pesquisa de Marketing. 4 ed. Bookman, 2006. 720 p.

MANU, F. A.; SRIRAM, V. Innovation, marketing strategy, environment, and performance. Journal of Business Research, v. 35, n. 1, p. 79-91, jan. 1996.

MARCH, J. G.; SIMON, H. Organizations. Nova York: Wiley, 1958.

MARCONI, M. D. A.; LAKATOS, E. M. Técnicas de pesquisa. São Paulo: Editora Atlas S.A., 1982. 205 p.

MARTINS, G. D. A.; THÉOPHILO, C. R. Metodologia da investigação científica para ciências sociais aplicadas. São Paulo: Atlas, 2009. 274 p.

MCDONALD, J.-A. L. The optimal number of categories for numerical rating scales. 2004. Denver. Tese (Doutorado em Filosofia). College of Education, University of Denver. 2004.

MCKINNEY, J. C. Typification, typologies, and sociological theory. Social Forces, v. 48, p. $1-12,1969$.

MCPHEE, R. D.; POOLE, M. S. S. Organizational structures and configurations. In: JABLIN, F. M. e PUTNAM, L. L. (Ed.). The new handbook of organizational communication: advances in theory, research, and methods. Thousand Oaks, CA: SAGE, 2001. cap. III, p.503-543.

MILES, R. E.; SNOW, C. C. Organizational Strategy, Structure and Process. Nova York: McGraw Hill 1978.

Organizational strategy, structure, and process. 2 ed. Palo Alto, CA: Standford University Press, 2003. 274 p..

MINTZBERG, H. Patterns in strategy formation. Montreal: McGill University, 1976.

MORGAN, R. E.; STRONG, C. A. Market orientation and dimensions of strategic orientation. European Journal of Marketing, Bradford, v. 32, n. 11/12, p. 1051-1073, 1998. 
PERSSON, O. D.; DANELL, R.; SCHNEIDER, J. W. How to use Bibexcel for various types of bibliometric analysis. In: ASTRÖM, F.;DANELL, R., et al. (Ed.). Celebrating scholarly communication studies: A Festschrift for Olle Persson at his 60th Birthday. Leuven, Belgium: International Society for Scientometrics and Informetrics, 2009. p. 9-24.

PONDY, L. R.; MITROFF, I. I. Beyond open systems models of organization. In: STAW, B. M. (Ed.). Research in organizational behavior. Greenwich, Conn: JAI, 1979. p. 3-39.

PORTER, M. E. Competitive strategy: techniques for analysing industries and competitors. Nova York: Mac Millan Publishing Co., 1980. 396 p.

. Competitive advantage: creating and sustaining superior performance. Nova York: The Free Press, 1985.

POTTER, J. A.; MINUTOLO, M.; LIPINSKI, J. Key fators for shortening response time in the strategic issues diagnosis proccess. Journal of Behavioral \& Applied Management, v. 12 , n. 1 , p. 69-87, set. 2010.

QIU, T. Scanning for competitive intelligence: a managerial perspective. European Journal of Marketing, v. 42, n. 7-8, p. 814-835, 20082008.

THOMSON REUTERS. Disponível em: < http://ip-science.thomsonreuters.com/mjl/ >. Acesso em: 23/03/2013.

Web of Science. 2013. Disponível em: < http://thomsonreuters.com/web-of-science/ >. Acesso em: 23/03/2013.

SAAYMAN, A. et al. Competitive intelligence: construct exploration, validation and equivalence. Aslib Proceedings, v. 60, n. 4, p. 383-411, 20082008.

SAMPIERI, R. H.; COLLADO, C. F.; LUCIO, P. B. Metodologia de Pesquisa. 3 ed. São Paulo: McGraw-Hill, 2012. 583 p.

SANTOS, J. L. S.; MALDONADO, M. U.; SANTOS, R. N. M. D. Mapeamento das publicações acadêmico-científicas sobre memória organizacional. In: XXXV Encontro da ANPAD, Rio de Janeiro, 2011.

SANTOS, R. N. M.; KOBASHI, N. Y. Bibliometria, cientometria, infometria: conceitos e aplicações. Pesq. bras. Ci. Inf., Brasília, v. 2, n. 1, p. 155-172, set.-dez, 2003.

SCIP. Disponível em: <

http://www.scip.org/Membership/content.cfm?itemnumber=600\&navItemNumber=517 >. Acesso em: 06/04/2013.

SIEGEL, S. Estatística não-paramétrica. São Paulo: McGraw-Hill, Inc., 1975. 350 p.

SNOW, C. C.; HREBINIAK, L. G. Strategy, distinctive competence, and organizational performance. Administrative Science Quarterly, v. 25, n. 2, p. 317-336, 1980. 
SUBRAMANIAN, R.; FERNANDES, N.; HARPER, E. An empirical examination of the relationship between strategy and scanning. The Mid-Atlantic Journal of Business, v. 29, n. 3, p. 315-300, dec. 1993.

THOMAS, P. S. Environmental scanning - State of the art. Long Range Planning, v. 13, n. 1, p. 20-28, 1980.

THOMSON REUTERS. Disponível em: <http://ip-science.thomsonreuters.com/mjl/>. Acesso em: 23/03/2013.

TREVISANI, A. T. Inteligência Competitiva e interpretação do ambiente: um estudo com fornecedores do serviço público federal. São Paulo, 2006. 164 p. Tese (Doutorado em Administração) - Programa de Pós-Graduação em Administração, Departamento de Administração, Faculdade de Administração e Contabilidade da Universidade de São Paulo. 2006.

VIEIRA, V. et al. Evidências das pesquisas que abordam a tipologia de Miles e Snow no Brasil. Revista Ibero-Americana de Estratégia, v. 11, n. 2, p. 70-90, 2012.

WALTERS, B. A.; PRIEM, R. L.; SHOOK, C. L. Small business manager scanning ênfases and the dominant logic of the business-level strategy. Journal of Small Business Strategy, Peoria, v. 15, n. 2, p. 19-32, 2004.

WEB OF KNOWLEDGE. Disponível em:

$<$ http://apps.webofknowledge.com/UA_GeneralSearch_input.do?product=UA\&search_mode $=$ GeneralSearch $\&$ SID=4DjMTrWyAeAvRELZv8i\&preferencesSaved= $>$. Acesso em: 23/03/2013.

WEB OF SCIENCE. Disponível em: <http://thomsonreuters.com/web-of-science/>. Acesso em: 23/03/2013.

WEBSTER, J.; WATSON, R. T. Analyzing the past to prepare for the futuer: writing a literature review. MIS Quaterly, v. 26, n. 2, p. xxiii-xxiii, jun. 2002.

WEICK, K. E. The social psicologyof organizing. Mass: Wesley, 1969.

Enactment process in organizations. In: STAW, B. M. e SALANCIK, G. R. (Ed.). New directions in organizations behavior. Chicago: St. Clair Press, 1977. p. 267-300.

WIKIPEDIA. Disponível em: < http://en.wikipedia.org/wiki/LinkedIn >. Acesso em: 06/04/2013.

YAP, C. S.; RASHID, M. Z. A.; SAPUAN, D. A. Organizational strategy and competitive intelligence practices in Malaysian public listed companies. Information Research-an International Electronic Journal, v. 17, n. 4, dec. 2012.

ZHANG, X.; MAJID, S.; FOO, S. Environmental scanning: an application of information literacy skills at the workplace. Journal of Information Science, v. 36, n. 6, p. 719-732, dec 2010 . 


\section{APÊNDICES}

APÊNDICE 01: CONVITES UTILIZADOS NO LINKEDIN

APÊNDICE 02: GRUPOS DE INTELIGÊNCIA COMPETITIVA DO LINKEDIN

APÊNDICE 03: QUESTIONÁRIO DA PESQUISA

APÊNDICE 04: PERFIL DA AMOSTRA COMPLETA

APÊNDICE 05: DETALHES DOS SETORES INFORMADOS COMO OUTROS

APÊNDICE 06: ESTATÍSTICAS DESCRITIVAS DAS VARIÁVEIS

APÊNDICE 07: DIFICULDADES ADICIONAIS DO MONITORAMENTO

APÊNDICE 08: NORMALIDADE, MISSINGS E OUTLIERS

APÊNDICE 09: TESTE MANN-WHITNEY (ANÁLISE DE CONGLOMERADOS)

APÊNDICE 10: MATRIZ DE CORRELAÇÕES DE PEARSON (ANÁLISE FATORIAL)

APÊNDICE 11: COEFICIENTES DA FUNÇÃO DISCRIMINANTE

APÊNDICE 12: TESTES DE MANN-WHITNEY (VARIÁVEIS V16 A V35)

APÊNDICE 13: TESTES DE FRIEDMAN (VARIÁVEIS V16 A V35) 


\section{APÊNDICE 01: CONVITES UTILIZADOS NO LINKEDIN}

Convite coletivo postado nos Grupos A e B do LinkedIn em 08 e 10 de maio de 2013 respectivamente.

\section{Relação entre modelo de inteligência competitiva e estratégia - pesquisa Prezado(a),}

Gostaríamos de convidá-lo(a) a participar de uma pesquisa de fins acadêmicos do Curso de Mestrado em Administração da FEA USP, a qual tem por finalidade:

- descrever o modo como as empresas monitoram o Ambiente de Negócios,

- descrever as principais dificuldades desta atividade, e

- avaliar a respectiva influência do comportamento estratégico.

Este questionário destina-se a profissionais envolvidos com a coleta e/ou uso de informações do Ambiente de Negócios de suas empresas para apoio a decisões, sendo o nosso público-alvo composto pelos profissionais de Inteligência Competitiva, Estratégia, Marketing, etc.

Através deste estudo, pretendemos obter um melhor entendimento do panorama atual da atividade de monitoramento do Ambiente de Negócios nas empresas.

Esta pesquisa não requer identificação e tem duração aproximada de 10 minutos.

Para acessar o questionário, utilize o link:

https://pt.surveymonkey.com/s/pesquisa-monitoramento-v1

Caso você tenha interesse em conhecer os resultados alcançados por este estudo, informe seu email no fechamento do questionário.

Contamos com sua participação e antecipamos os nossos agradecimentos.

Atenciosamente,

Maria Cristina Pereira Pimentel

Mestranda em Administração - FEA USP

email: mcpimentel@usp.br

Prof. Dr. Fernando Carvalho de Almeida

Orientador - FEA USP

email: fcalmeida@usp.br 
Convite postado nos Grupos C e D em 12 de maio de 2013.

\section{Colaboração - Pesquisa de Mestrado em Administração da FEA-USP}

Sou Maria Cristina Pimentel e gostaria de pedir sua colaboração para a minha pesquisa de Mestrado desenvolvida sob a orientação do Prof. Dr. Fernando Carvalho de Almeida.

A pesquisa é direcionada aos profissionais que atuam em empresas e estejam envolvidos com a coleta e/ou uso de informações de negócios para a tomada de decisões, como os profissionais das áreas de Inteligência, Estratégia, Marketing, Vendas, etc.

Se você for um destes profissionais, por favor, dedique em torno de 10 minutos de seu tempo para responder o questionário, que não requer identificação e estará acessível até 02 de junho de 2013 no link:

https://pt.surveymonkey.com/s/pesquisa-monitoramento-v1

O objetivo deste estudo é entender melhor a relação entre estratégia e monitoramento do ambiente de negócios, bem como as dificuldades desta atividade.

Caso você tenha interesse em receber os resultados, informe seu email ao final da pesquisa.

Por favor, repassem este link aos seus contatos que tenham o perfil da pesquisa.

O meu contato é mcpimentel@usp.br

Muito obrigada! 
Modelo dos convites individuais enviados no período de 22 de maio a 08 de julho de 2013.

Olá Nicolas,

Estou na etapa final do curso de mestrado em Administração na FEA USP e desenvolvo a minha dissertação sob a orientação do Prof. Dr. Fernando C. de Almeida.

O tema é a Inteligência Competitiva, focando o modo como as empresas monitoram o ambiente de negócios, as dificuldades desta prática e a influência da estratégia da empresa.

Gostaria de convidá-lo a participar da pesquisa online deste estudo.

Agradeceria muito se pudesse dispor de 10 minutos para preencher o questionário disponível no link:

https://pt.surveymonkey.com/s/pesquisa-monitoramento-v1

Este questionário não requer identificação e todos os dados serão apresentados de forma consolidada.

Para conhecer os resultados alcançados por esta pesquisa, basta informar o seu email no campo disponível no final do questionário.

Agradeço muito pela atenção e conto com sua participação!

Maria Cristina Pimentel

mcpimentel@usp.br 


\section{APÊNDICE 02: GRUPOS DE INTELIGÊNCIA COMPETITIVA NO LINKEDIN}

\section{Continua}

\begin{tabular}{|c|c|c|c|}
\hline Grupo & Criação & Membros & Descrição do Grupo no LinkedIn \\
\hline 1 & 2011 & 568 & $\begin{array}{l}\text { O objetivo deste grupo é reunir profissionais da atividade de Inteligência de } \\
\text { vários focos. Explorar a doutrina de Inteligência, estudos de processos e } \\
\text { métodos e relatos de casos com a finalidade didática podem ser vertentes a } \\
\text { serem exploradas. Outra vertente seria a abordagem de autores das atividades } \\
\text { de Inteligência de estado, de segurança pública, das organizações em geral, } \\
\text { competitiva, etc. }\end{array}$ \\
\hline 2 & 2010 & 1.948 & $\begin{array}{l}\text { This LinkedIn group provides information and alerts concerning the Brazil } \\
\text { affiliate activities. All intelligence professionals in this area, both current and } \\
\text { potential members, are welcome to join. }\end{array}$ \\
\hline 3 & 2010 & 202 & $\begin{array}{l}\text { Intercâmbio de conhecimentos e experiências em CI - Competitive } \\
\text { Intelligence, BI - Business Intelligence, MI - Market Intelligence e Gestão do } \\
\text { Conhecimento. }\end{array}$ \\
\hline 4 & 2010 & 616 & Site em português do Competitive Intelligence Group. \\
\hline 5 & 2010 & 983 & $\begin{array}{l}\text { O objetivo deste grupo é debater práticas, acompanhar a evolução de mercado, } \\
\text { trocar sugestões, networking e indicação de vagas nas áreas de Inteligência } \\
\text { Competitiva/ de mercado. }\end{array}$ \\
\hline 6 & 2010 & 332 & $\begin{array}{l}\text { FICB - Fórum de Inteligência Competitiva Brasileiro: criado pela GIA } \\
\text { (www.globalintelligence.com), uma consultoria líder de mercado em IC, com } \\
\text { o auxílio de empresas de diversas indústrias tais como Philips, Dow, e } \\
\text { Siemens. O fórum reúne profissionais de IC de diversas empresas, e visa } \\
\text { compartilhar melhores práticas, proporcionar networking e fortalecer o } \\
\text { profissional de IC. Publicamos em média um post por semana e realizamos } \\
\text { eventos/palestras duas ou três vezes por ano, sempre gratuitos. Se você é um } \\
\text { profissional de inteligência competitiva, marketing estratégico e/ou } \\
\text { planejamento estratégico, participe do FICB. Seja bem-vindo! Natan } \\
\text { Rodeguero natan.rodeguero@ globalintelligence.com }\end{array}$ \\
\hline
\end{tabular}




\section{Conclusão}

\begin{tabular}{|c|c|c|c|}
\hline Grupo & Criação & Membros & Descrição do Grupo no LinkedIn \\
\hline 7 & 2010 & 1.198 & $\begin{array}{l}\text { Surgida há poucos anos, a função de Inteligência Competitiva busca coletar } \\
\text { dados, analisar distorções e informar tendências. Num mundo onde o } \\
\text { problema não é mais obter informações, mas digeri-las, cabe ao profissional } \\
\text { de Inteligência Competitiva ir além das pesquisas de mercado e prover } \\
\text { informações que posicionarão sua empresa/produto/serviço à frente da } \\
\text { concorrência. } \\
\text { "A gestão estratégica da informação pode e precisa ser utilizada como o } \\
\text { diferencial competitivo das organizações. Isso requer saber usar a inteligência } \\
\text { competitiva. E o que é inteligência competitiva senão a maneira inteligente de } \\
\text { lidar com a informação e utilizá-la de maneira pronta e rentável antes que os } \\
\text { concorrentes o façam? Partir na frente dos outros, criar novas soluções e } \\
\text { produtos, inovar e ultrapassar depende de saber lidar com a informação." - } \\
\text { Idalberto Chiavenato }\end{array}$ \\
\hline 8 & 2009 & 566 & $\begin{array}{l}\text { Este grupo tem como objetivo reunir participantes, palestrantes, apoiadores, } \\
\text { patrocinadores e colaboradores das conferências e treinamentos de Inovação } \\
\text { Estratégica e Inteligência de Mercado. }\end{array}$ \\
\hline 9 & 2009 & 268 & $\begin{array}{l}\text { A ideia é reunir profissionais atuantes em BI, DW, CRM analítico, Database } \\
\text { Marketing, enfim, aqueles que apoiam suas empresas, usando processos, } \\
\text { métodos e tecnologias, na criação de diferencial competitivo na Região } \\
\text { Metropolitana de Curitiba, PR, Brasil. Também queremos ser um ponto de } \\
\text { apoio para os Executivos que queiram mais informações sobre o assunto e } \\
\text { tenham aqui uma fonte próxima e confiável de informação. }\end{array}$ \\
\hline 10 & 2008 & 435 & $\begin{array}{l}\text { Este grupo tem como objetivo reunir participantes, palestrantes, apoiadores, } \\
\text { patrocinadores e colaboradores das conferências e treinamentos de } \\
\text { Inteligência Competitiva e de Mercado organizados pelo Informa Group (IBC } \\
\text { e IIR) nestes últimos dez anos. }\end{array}$ \\
\hline 11 & 2008 & 344 & $\begin{array}{l}\text { Compreensão do conceito de BI, o qual fornece a arquitetura necessária para } \\
\text { diferentes aplicações de inteligência voltadas à transformação estratégica do } \\
\text { negócio, capacitando o gestor a melhor aplicar conceitos como BI, } \\
\text { Inteligência Competitiva, Gestão do Conhecimento e CRM. }\end{array}$ \\
\hline
\end{tabular}

Fonte: Elaborado com informações de LINKEDIN (2013)

\section{Observações:}

a) Grupos com a palavra "Inteligência" em seus nomes e com mais de 50 membros.

b) Grupos ordenados pelo ano de criação do mais recente para o mais antigo. 


\section{APÊNDICE 03: QUESTIONÁRIO DA PESQUISA}

\section{FEA USP - PESQUISA PARA FINS ACADÉMICOS MONITORAMENTO DO AMBIENTE DE NEgócIOS}

AMgIENTE DE NEOCCIOS: 0 conlunto de todos os fatores extemos a uma empresa que podem afetar o seu desempenho e ate meemo, a sus sobrevivốncla como clientes, fornecedores, concorrentes, aspectos economicos, tecnologicos, regulasorios, politicos e socioculturals.

MONITORAMENTO DO AMEIENTE DE NEG DCIOS: ta coleta e uso de informaçbes sobre o Ambiente Competitivo para lidentificar ameaças e oportunidades, ganhar vantagem competitiva e meihorar o planejamento de curto e longo prazo.

\section{*1. Considere "1 - discordo totalmente" e " 5 - concordo totalmente" e avalie os itens da questão a seguir.}

Em sua empresa, o monitoramento do Ambiente de Negócios é uma atividade:

\section{- de cardter ocasions.}

- exploratoris, pols busca hipoteses mals do que conflimaçbes.

- focada em informaçbes qualtativas (ex.: percep̧̨les, mothaçbes, etc.).

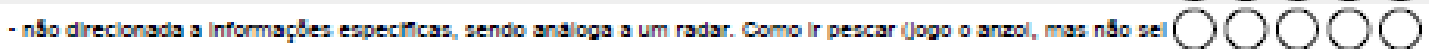
que peire vem).

- que busca sinals antecipativos de oportunidades e ameaças.

- formal e gerenciada por departamento(a) especifico(a).

- planejads e slatematica.

- direcionsda a informaçbes especif cas, colocando questbes objetivas. Como um tro certo imiro em um alvo

claro).

- focads em informaçbes quantiasvas (ex.: conaumo, demanda, freqounclas, preços, etc.).

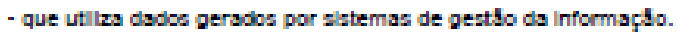

- regular (periodicldade seja anus), menaal, etc.),

- focads em fontea de informaçblo claramente determinadas (clientes, concomentes, etc.).

- que busca tendinclas e projeçbes estasisticas.

- que tem carditer de levantamento de dados (usa queationarios, formularios, etc.).

- que gera eetudioa e relatorios especiala n5o rotineiros.

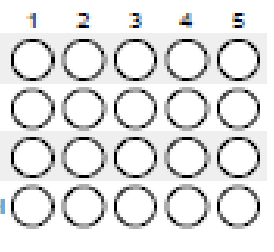

\section{*2. Em sua empresa, qual a frequência com que são utilizadas as fontes de} informação do Ambiente de Negócios listadas a seguir? (considere "1 - nunca" e "5 sempre")

Pessosis extemsa - ex.: cllentes, fornecedores, consubores, contatos, etc.

Fessosis intemsa-ex: gerentes, pares, subordinados, vendedores, etc.

Impessoals entemas - ex: Jomals, revistas, exposiçles, conferónclas, sites na intemet, ebc.

Impessoala Intemas - ex.: relatorios, memorandos, newalesters, portals na intranet, etc.

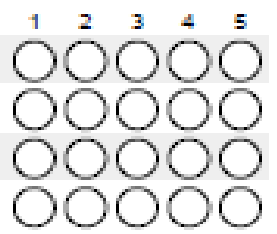

Fonte: Imagem gerada pelo Surveymonkey em formato para impressão do tipo pdf. 


\section{FEA USP - PESQUISA PARA FINS ACADÉMICOS}

3. Em sua empresa, qual a frequência com que são coletadas informaçôes dos aspectos listados a seguir do Ambiente de Negócios? (considere "1 - nunca" e "5 sempre")

Clientes - ex: necesaldades, pernl, uso dsdo aos produtos, novos clentes, etc.

Concorrentes - ex.: preços, mudanças em produtos, novos produtos, custos e finanças, etc.

Fomecedores - ex: preços, novos fomecedores, inovoçమోo em insumo, etc.

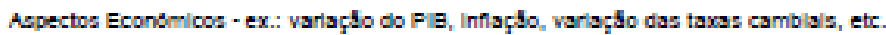

Inovaçbes Tecnologicas - ex.: noves tecnologlas, novos processos, novoe materials, etc.

Aspectos Regulatorios - ex.: leis e normas do govemo, de aponclas regulatorias, etc.

Aspectos Socioculturala - ex.: mudanças de comportamento, valores, normas soclals, etc.

Aopectos Foliticos - ex.: eielçbes, relaçbes Internacionais, etc.

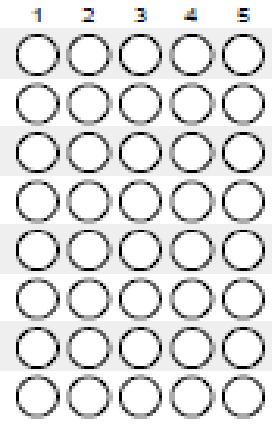

\section{MONITORAMENTO DO AMBIENTE DE NEGÓCIOS - DIFICULDADES}

AMaIENTE DE NEOCCIOS: 0 conlunto de todoa oa fatores externoa a uma empresa que podem afetar o seu desempenho e ate mesmo, a sua sobrevivoncla como clientes, fomecedores, concorrentes, aspectos economicos, tecnologicos, regulatorica, poilticos e sociocuturais.

MONITORAMENTO DO AMEIENTE DE NEGOCIOS: t a coleta e uso de informaçbes sobre o Ambiente Competitivo para identificar ameaças e oportunidades, ganhar vantagem competitiva e meihorar o planejamento de curto e longo prazo.

*1. Considere uma escala na qual "1 - nada importante" e "5 - muito importante" para responder a questäo a seguir.

Qual a importância dos problemas listados a seguir para as atividades de monitoramento do Ambiente de Negócios em empresas de modo geral?

Fats de apolo dos gestores

Fata de recursos

Falta de atribulç5o de responasallidades

Dificuldade para de"inir o eacopo do monitoramento

Difculdade para dlsaeminar informsg̨les entre departamentos

Difculdade para avalar o impacto do ambiente sobre as estrategicas corporativas

Difculdsde para filtrar as informaçbes reaimente reievantes para a estrattgla

Difculdade para elaborar previsbes sobre tendonclas futuras

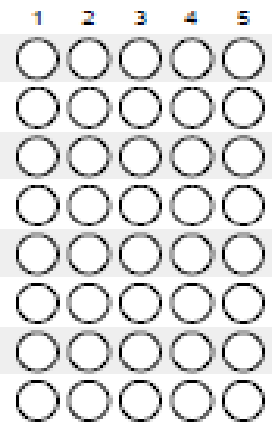

2. Caso você deseje citar outros problemas relevantes, utilize o espaço a seguir.

Fonte: Imagem gerada pelo Surveymonkey em formato para impressão do tipo pdf. 


\section{FEA USP - PESQUISA PARA FINS ACADÊMICOS}

\section{PERFIL ESTRATÉGICO DA EMPRESA}

Nas questöes a seguir, escolha a alternativa que melhor caracteriza o perfil estratégico da sua empresa.

*1. Os produtos ofertados pela nossa empresa sâo melhor caracterizados como:

produboa mals inovadores e que mudam constantemente.

produtos bem eatavels e bem deinidos atraves do mercado.

produtos eatsvels em certos mercados e inovadores em outroa.

produtos transitorica para responder as oportunidades e ameaças do mercado.

*2. A nossa imagem no mercado é principalmente de uma empresa que:

adota novas ldelas e inovaçbes, mas somente apos ums anslise muto culdadoss.

oferece poucos produtos, mas de meihor qualdade, serviços superiores slou preços menores.

- somente ve amisca em novos produtos quando presslonada peloa concomentes.

tem a reputaçlo de ser criativa e inovadora.

*3. Os aumentos ou reduções na demanda de nossos produtos se devem principalmente à nossa prática de:

concentrar no crescimento doa mercados acs quals ja servimos.

de responder as presabes do mercado, correndo poucos recos.

Creacer nos mercadoa que ja servimos, enquanto adotamos novos produtos apoa uma reviabo crituriosa do seu potencial.

entrar agresalvamente em novos mercados com novos tpos de produtos.

* 4. A quantidade de tempo que investimos no monitoramento de mudanças e tendências do mercado é:

(irregular, pola as vezes investimoa muto tempo no monitoramento do mercado e as vezes pouco.

medis, pols noa investimos um tempo razodvei no monitoramento do mercado.

minima, pols nos reaimente nio investimos multo tempo no monitoramento do mercado.

(eievads, pola nos estamos continuamente monitoramento o mercado.

*5. Em nossa empresa, procuramos nos preparar para o futuro identificando:

a meinor soluçblo possivel para os probiemas que requerem atençblo imedlata.

as tendthclas da Industria que mostram potencial de iongo prazo, enquanto resolvemos probiemas de produtos ou necessidades de clentes.

tendonclas e oportunidades no mercado que possam resultar na criaç5o de novos produtos ou aicançar novos mercados.

aqueies probiemsa que, quando resolvidoa, manterbo ou meinorarbo a noass oferta de produtoa e posiç5o de mercado.

Fonte: Imagem gerada pelo Surveymonkey em formato para impressão do tipo pdf. 


\section{FEA USP - PESQUISA PARA FINS ACADÊMICOS}

DADOS DA EMPRESA

\section{Setor}

Indústria de bens de consumo

Indústria de bens de produção

Construção civil

Outros tipos de indústria

Comérico atacadistra

Comérico varejista

Serviços de engenharia

Serviços financeiros

Serviços de TI

Outros tipos de serviços

Complemente para "Outros tipos":

\section{Tipo de Empresa}
Privada
Pública
Mista

\section{Tipo de Empresa \\ Nacional \\ Multinacional}

\section{Número de funcionários}

500 ou mais

$\bigcirc$ de 100 a 499

de 50 a 99

de 20 a 49

de 10 a 19

até 9 funcionários

\section{Faturamento}

Microempresa - até $\mathrm{R} \$ 2,4$ milhões

Pequena empresa - de $\mathrm{R} \$ 2,4$ milhões a $\mathrm{R} \$ 16$ milhões

Média empresa - de $\mathrm{R} \$ 16$ milhões a $\mathrm{R} \$ 90$ milhões

Média-grande empresa - de $\mathrm{R} \$ 90$ milhões a $\mathrm{R} \$ 300$ milhões

$\bigcirc$ Grande empresa - acima de 300 milhões

\section{Tempo de existência da empresa}

mais de 20 anos

de 10 a 20 anos

$\bigcirc$ de 5 a 10 anos

$\bigcirc$ de 1 a 5 anos

menos de 1 ano

Fonte: Transcrição do Surveymonkey para o MS-Excel para apresentar as opções que estão em formato "tipo lista" na ferramenta 


\section{FEA USP - PESQUISA PARA FINS ACADÊMICOS}

\section{DADOS DO RESPONDENTE}

\section{Gênero}

\section{Feminio}

Masculino

\section{Idade}

menos de 20 anos

de 20 a 24 anos

de 25 a 29 anos

de 30 a 34 anos

de 35 a 39 anos

de 40 a 49 anos

de 50 a 60 anos

acima de 60 anos

\section{Escolaridade}

Pós-doutorado

Doutorado

Mestrado

Especialização

Superior Completo

Superior Incompleto

Segundo Grau Completo

Segundo Grau Incompleto

Primeiro Grau Completo

$\bigcirc$ Primeiro Grau Incompleto

\section{Cargo}

CEO

Diretor

Gerente

Supervisor

Analista

Técnico

Outro

Complemente para a opçäo "Outro":

Email para receber resultado da pesquisa:

\section{5. Área da Empresa}

Administração

Estratégia

Inteligência

Marketing

P\&D

Produção

$\bigcirc$ Vendas

$\bigcirc \mathrm{TI}$

Outro

Complemente para a opção "Outro":

\section{Tempo que trabalha na empresa}

menos de 1 ano

de 1 a menos de 2 anos

de 2 a menos de 5 anos

de 5 a menos de 10 anos

10 ou mais anos

Fonte: Transcrição do Surveymonkey para o MS-Excel para apresentar as opções que estão em formato tipo lista na ferramenta 


\section{APÊNDICE 04: PERFIL DA AMOSTRA COMPLETA}

Neste apêndice, apresentam-se tabelas com as distribuições de frequências das variáveis dos blocos 3 e 4 do questionário, que caracterizam o perfil das empresas e dos respondentes para os 195 questionários, cujo preenchimento foi considerado válido.

\section{a) Dados das organizações}

Tabela 1- Nacionalidade das organizações dos respondentes

\begin{tabular}{ccc}
\hline Tipo & $\mathrm{n}$ & $\%$ \\
\hline Nacional & 103 & $52,8 \%$ \\
Multinacional & 92 & $47,2 \%$ \\
\hline Total & 195 & $100,0 \%$ \\
\hline
\end{tabular}

Tabela 2 - Origem do capital das organizações dos respondentes

\begin{tabular}{ccc}
\hline Capital & $\mathrm{n}$ & $\%$ \\
\hline Privado & 177 & $90,8 \%$ \\
Público & 11 & $5,6 \%$ \\
Misto & 7 & $3,6 \%$ \\
\hline Total & 195 & $100,0 \%$ \\
\hline
\end{tabular}

Tabela 3 - Grupo setorial das organizações dos respondentes

\begin{tabular}{lcc}
\hline Grupo Setorial & n & \% \\
\hline & 73 & $37,4 \%$ \\
Indústria & 7 & $3,6 \%$ \\
Comércio & 115 & $59,0 \%$ \\
Serviços & & \\
\hline Total & $\mathbf{1 9 5}$ & $\mathbf{1 0 0 , 0 \%}$ \\
\hline
\end{tabular}


Tabela 4 - Setores das organizações dos respondentes

\begin{tabular}{lcc}
\hline \multicolumn{1}{c}{ Setor } & $\mathbf{n}$ & $\mathbf{\%}$ \\
\hline & 20 & $10,3 \%$ \\
Indústria de bens de consumo & 19 & $9,7 \%$ \\
Indústria de bens de produção & 9 & $4,6 \%$ \\
Construção civil & 25 & $12,8 \%$ \\
Outros tipos de indústria & 2 & $1,0 \%$ \\
Comércio atacadista & 5 & $2,6 \%$ \\
Comércio varejista & 2 & $1,0 \%$ \\
Serviços de engenharia & 19 & $9,7 \%$ \\
Serviços financeiros & 21 & $10,8 \%$ \\
Serviços de TI & 73 & $37,4 \%$ \\
Outros tipos de serviços & & \\
\multicolumn{1}{c}{ Total } & $\mathbf{1 9 5}$ & $\mathbf{1 0 0 , 0 \%}$ \\
\hline
\end{tabular}

b) Dados dos respondentes

Tabela 5 - Gênero dos respondentes

\begin{tabular}{ccc}
\hline Gênero & n & $\%$ \\
\hline Feminio & 76 & $39,0 \%$ \\
Masculino & 119 & $61,0 \%$ \\
\hline Total & $\mathbf{1 9 5}$ & $\mathbf{1 0 0 , 0 \%}$ \\
\hline
\end{tabular}

Tabela 6 - Idade dos respondentes

\begin{tabular}{cccc}
\hline Faixa etária & n & \% & \% Acumulado \\
\hline acima de 60 anos & 1 & $0,5 \%$ & $0,5 \%$ \\
de 50 a 60 anos & 8 & $4,1 \%$ & $4,6 \%$ \\
de 40 a 49 anos & 27 & $13,8 \%$ & $18,5 \%$ \\
de 35 a 39 anos & 33 & $16,9 \%$ & $35,4 \%$ \\
de 30 a 34 anos & 58 & $29,7 \%$ & $65,1 \%$ \\
de 25 a 29 anos & 51 & $26,2 \%$ & $91,3 \%$ \\
de 20 a 24 anos & 17 & $8,7 \%$ & $100,0 \%$ \\
\hline Total & $\mathbf{1 9 5}$ & $\mathbf{1 0 0 , 0 \%}$ & \\
\hline
\end{tabular}


Tabela 7 - Escolaridade dos respondentes

\begin{tabular}{lccc}
\hline \multicolumn{1}{c}{ Escolaridade } & $\mathbf{n}$ & $\mathbf{\%}$ & $\mathbf{\%}$ Acumulado \\
\hline Pós-doutorado & 1 & $1 \%$ & $1 \%$ \\
Doutorado & 4 & $2,1 \%$ & $2,6 \%$ \\
Mestrado & 35 & $17,9 \%$ & $20,5 \%$ \\
Especialização (Lato Sensu) & 109 & $55,9 \%$ & $76,4 \%$ \\
Superior completo & 41 & $21,0 \%$ & $97,4 \%$ \\
Superior incompleto & 5 & $2,6 \%$ & $100,0 \%$ \\
\multicolumn{1}{c}{ Total } & $\mathbf{1 9 5}$ & $\mathbf{1 0 0 , 0 \%}$ & \\
\hline \multicolumn{2}{c}{} \\
\hline
\end{tabular}

Tabela 8 - Tempo de atuação dos respondentes nas organizações

\begin{tabular}{lccc}
\hline \multicolumn{1}{c}{ Tempo } & n & \% & \% Acumulado \\
\hline & & & \\
10 anos ou mais & 23 & $11,8 \%$ & $11,8 \%$ \\
de 5 a 10 anos & 40 & $20,5 \%$ & $32,3 \%$ \\
de 2 a 5 anos & 63 & $32,3 \%$ & $64,6 \%$ \\
de 1 a 2 anos & 37 & $19,0 \%$ & $83,6 \%$ \\
menos de 1 ano & 32 & $16,4 \%$ & $100,0 \%$ \\
& & & \\
\hline \multicolumn{1}{c}{ Total } & $\mathbf{1 9 5}$ & $\mathbf{1 0 0 , 0 \%}$ & \\
\hline
\end{tabular}

Tabela 9 - Áreas de atuação dos respondentes

\begin{tabular}{lcc}
\hline \multicolumn{1}{c}{ Área } & $\mathbf{n}$ & $\mathbf{\%}$ \\
\hline Administração & 9 & $4,6 \%$ \\
Estratégia & 26 & $13,3 \%$ \\
Inteligência & 89 & $45,6 \%$ \\
Marketing & 39 & $20,0 \%$ \\
P\&D & 4 & $2,1 \%$ \\
Produção & 3 & $1,5 \%$ \\
Vendas & 12 & $6,2 \%$ \\
TI & 2 & $1,0 \%$ \\
Outra & 11 & $5,6 \%$ \\
\hline \multicolumn{1}{c}{ Total } & $\mathbf{1 9 5}$ & $\mathbf{1 0 0 , 0 \%}$ \\
\hline
\end{tabular}


Tabela 10 - Cargos dos respondentes

\begin{tabular}{lccc}
\hline Cargo & $\mathbf{n}$ & $\mathbf{\%}$ & \% Acumulado \\
\hline CEO & 3 & $1,5 \%$ & $1,5 \%$ \\
Diretor & 17 & $8,7 \%$ & $10,3 \%$ \\
Gerente & 52 & $26,7 \%$ & $36,9 \%$ \\
Supervisor & 26 & $13,3 \%$ & $50,3 \%$ \\
Analista & 67 & $34,4 \%$ & $84,6 \%$ \\
Técnico & 1 & $0,5 \%$ & $85,1 \%$ \\
Outro & 29 & $14,9 \%$ & $100,0 \%$ \\
\hline \multicolumn{1}{c}{ Total } & $\mathbf{1 9 5}$ & $\mathbf{1 0 0 , 0} \%$ & \\
\hline
\end{tabular}


APÊNDICE 05: DETALHES DOS SETORES INFORMADOS COMO OUTROS

Tabela 11 - Conteúdo da questão "outros setores"

\begin{tabular}{|c|c|}
\hline Setores & $\mathbf{n}$ \\
\hline \multicolumn{2}{|l|}{ Indústria } \\
\hline Aeronáutica & 2 \\
\hline Agroquímica & 1 \\
\hline Auto Peças & 1 \\
\hline Bebidas & 1 \\
\hline Embalagens & 1 \\
\hline Equipamentos eletrônicos & 1 \\
\hline Equipamentos médicos & 1 \\
\hline Farmacêutica & 3 \\
\hline Metalúrgica & 1 \\
\hline Montadora & 1 \\
\hline Química & 2 \\
\hline Química de fragrâncias & 1 \\
\hline Siderurgia & 1 \\
\hline Telecomunicações & 1 \\
\hline Não informada & 3 \\
\hline Subtotal & 21 \\
\hline \multicolumn{2}{|l|}{ Serviços } \\
\hline Aviação civil & 1 \\
\hline BPO contact center & 1 \\
\hline Call center & 1 \\
\hline Crédito imobiliário & 1 \\
\hline Conservação do ambiente & 1 \\
\hline Defesa - forças armadas & 1 \\
\hline Distribuição de combustíveis & 1 \\
\hline Empresa de conservação do ambiente & 1 \\
\hline Farmacêuticos & 1 \\
\hline Logística & 1 \\
\hline Manutenção aeronáutica & 1 \\
\hline Mídia & 1 \\
\hline Mineração e metalurgia & 1 \\
\hline Relacionamento com clientes & 1 \\
\hline Seguros & 1 \\
\hline Serviços de lançamento & 1 \\
\hline Serviços de saúde & 2 \\
\hline Serviços sociais & 1 \\
\hline Telecomunicações & 4 \\
\hline Transporte e logística & 1 \\
\hline Transporte público & 1 \\
\hline Não informado & 7 \\
\hline Subtotal & 32 \\
\hline Total & 53 \\
\hline
\end{tabular}




\section{APÊNDICE 06: ESTATÍSTICAS DESCRITIVAS DAS VARIÁVEIS}

a) Bloco 01 de Questões

Neste bloco do questionário, apresentou-se a questão: "Em sua empresa, o monitoramento do Ambiente de Negócios é uma atividade:". Considerando-se "1 - discordo totalmente" e "5 concordo totalmente", para o conjunto de 120 observações obtiveram-se as seguintes estatísticas descritivas para as variáveis V01 a V15:

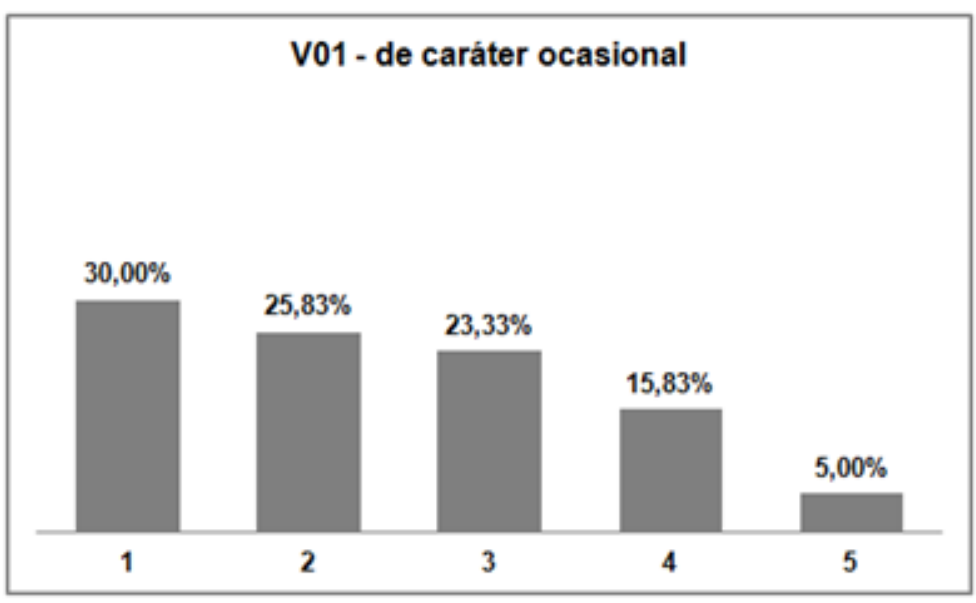

$\begin{array}{lr}\text { Média } & 2,40 \\ \text { Mediana } & 2,00 \\ \text { Moda } & 1,00 \\ \text { Desvio padrão } & 1,21 \\ \text { Assimetria } & 0,43 \\ \text { Curtose } & -0,86 \\ \text { Coef. de variação } & 50,5 \%\end{array}$

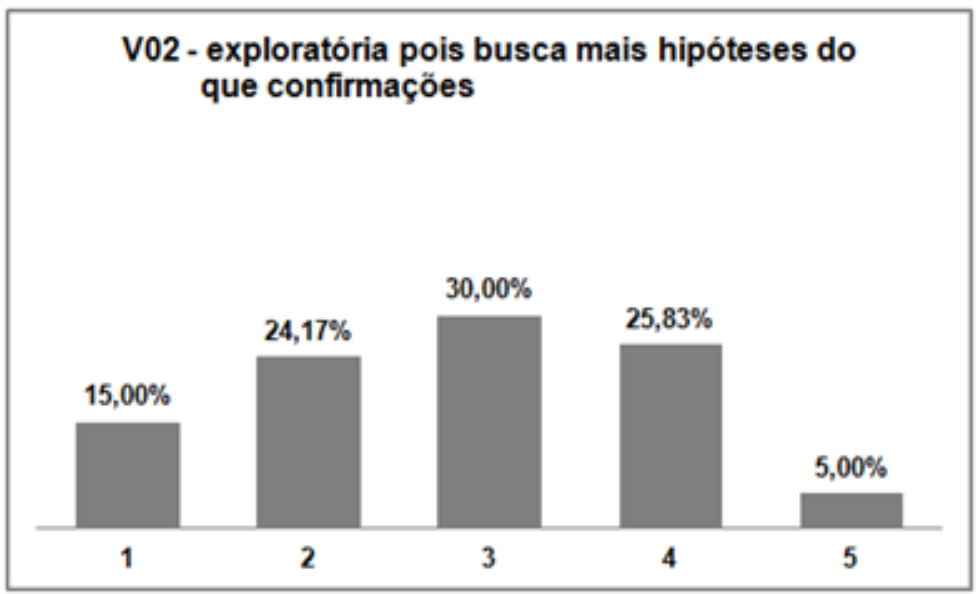

$\begin{array}{lr}\text { Média } & 2,82 \\ \text { Mediana } & 3,00 \\ \text { Moda } & 3,00 \\ \text { Desvio padrão } & 1,13 \\ \text { Assimetria } & -0,06 \\ \text { Curtose } & -0,88 \\ \text { Coef. de variação } & 40,1 \%\end{array}$




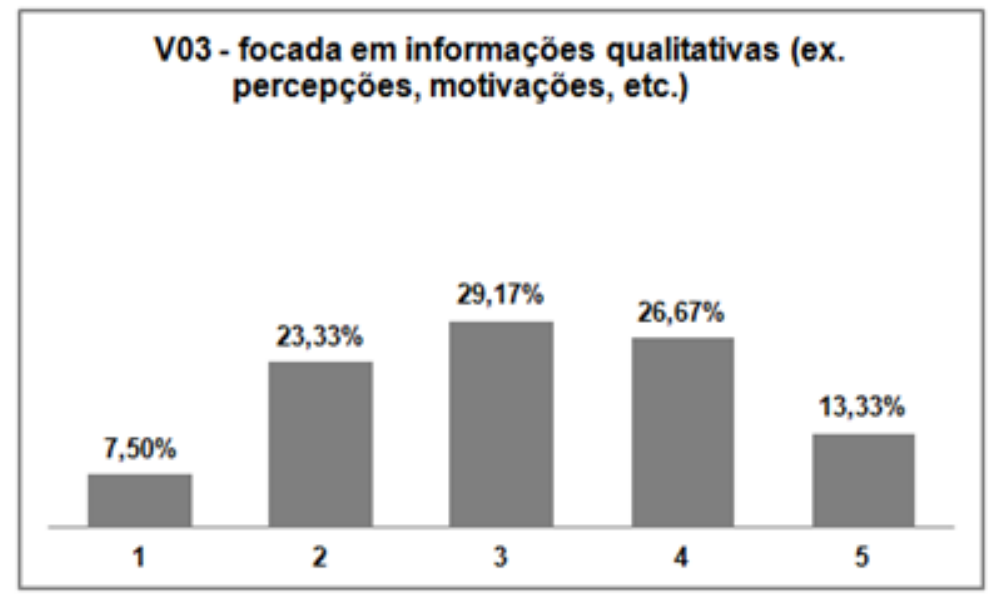

Média

3,15

Mediana

3,00

Moda

3,00

Desvio padrão

1,15

Assimetria

$-0,06$

Curtose

$-0,82$

Coef. de variação

$36,5 \%$

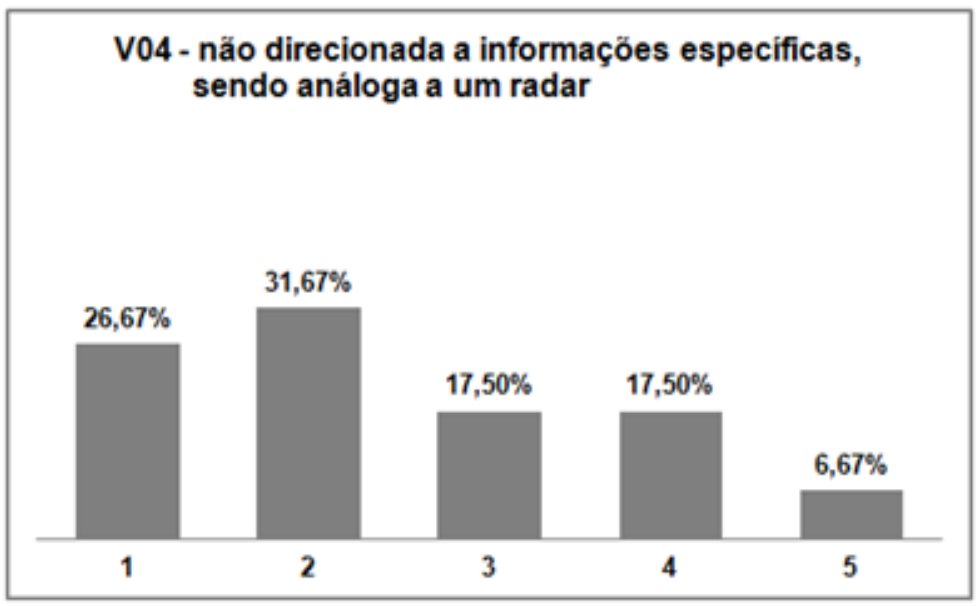

Média

2,46

Mediana

2,00

Moda

2,00

Desvio padrão

1,24

Assimetria

0,48

Curtose

$-0,85$

Coef. de variação

$50,6 \%$

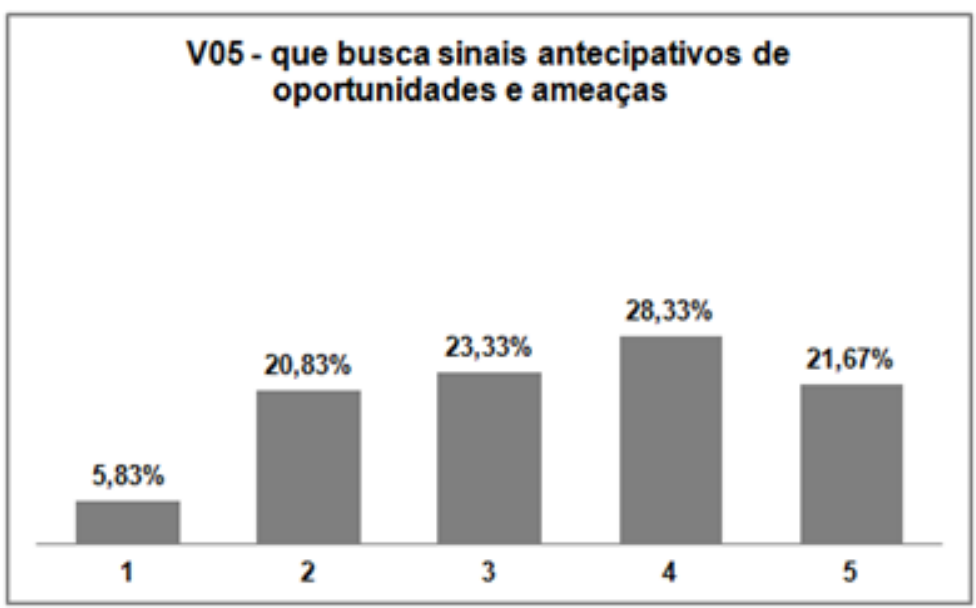

Média

3,39

Mediana

3,50

Moda

4,00

Desvio padrão

1,20

Assimetria

$-0,24$

Curtose

$-0,97$

Coef. de variação

$35,5 \%$ 


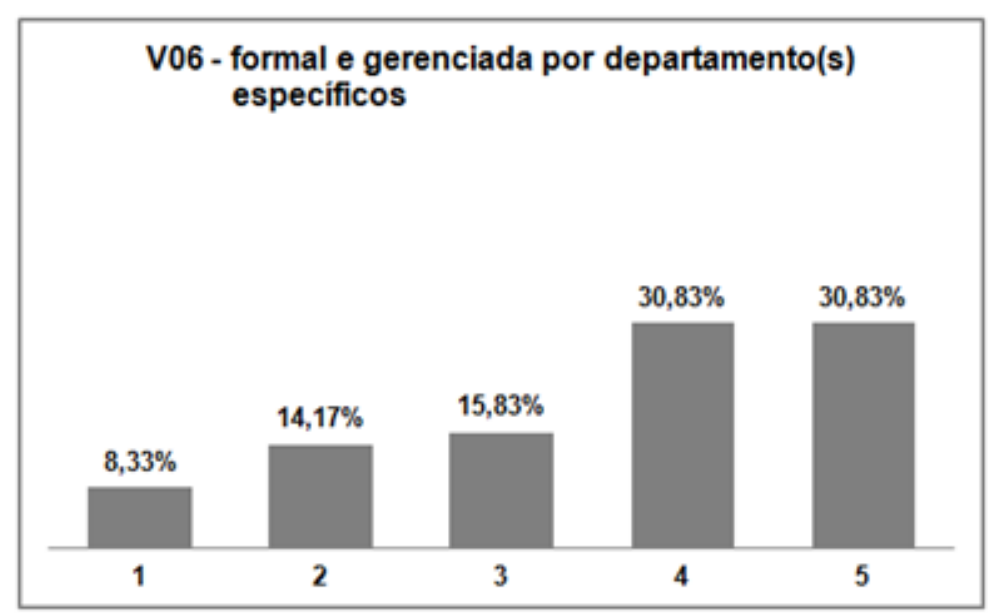

Média

3,62

Mediana

4,00

Moda

4 e 5

Desvio padrão

1,28

Assimetria

$-0,63$

Curtose

$-0,73$

Coef. de variação $\quad 35,5 \%$

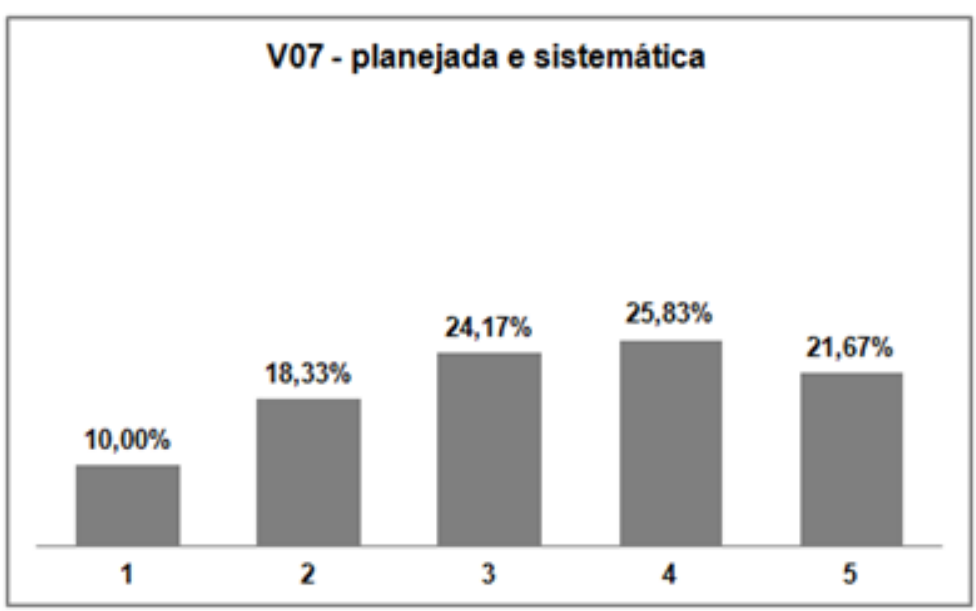

Média

3,31

Mediana

3,00

Moda

4,00

Desvio padrão

1,28

Assimetria

$-0,25$

Curtose

$-0,99$

Coef. de variação

$38,6 \%$

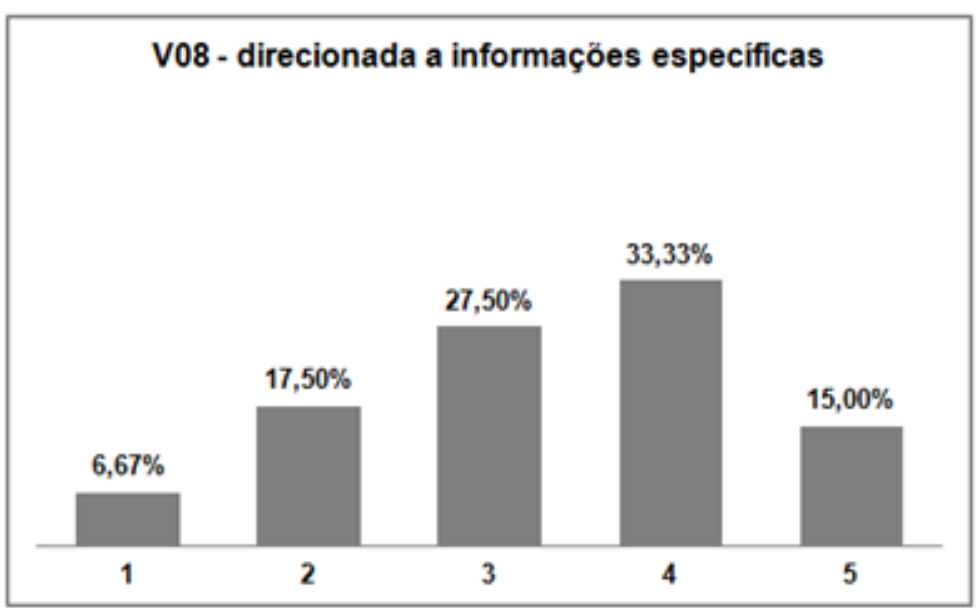

Média

3,33

Mediana

3,00

Moda

4,00

Desvio padrão

1,13

Assimetria

$-0,32$

Curtose

$-0,66$

Coef. de variação

$34,0 \%$ 


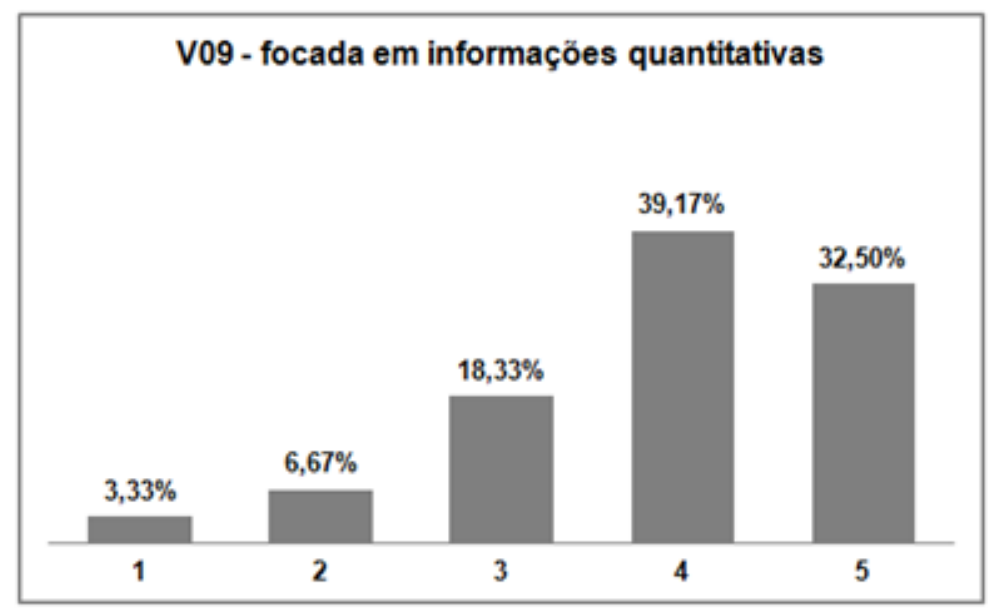

Média

3,91

Mediana

4,00

Moda

4,00

Desvio padrão

1,04

Assimetria

$-0,92$

Curtose

0,46

Coef. de variação

$26,5 \%$

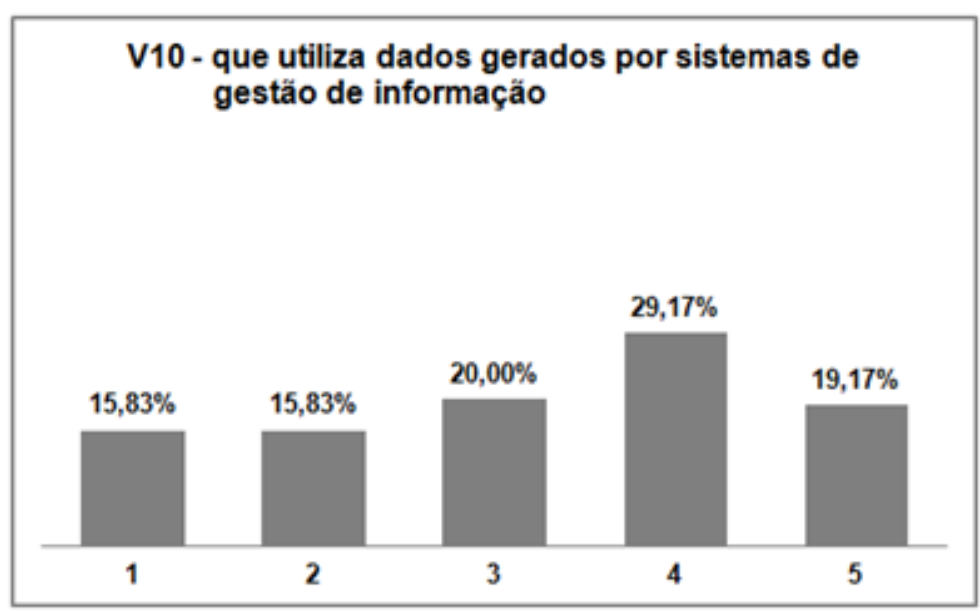

Média

3,20

Mediana

3,00

Moda

4,00

Desvio padrão

1,35

Assimetria

$-0,29$

Curtose

$-1,11$

Coef. de variação

$42,2 \%$

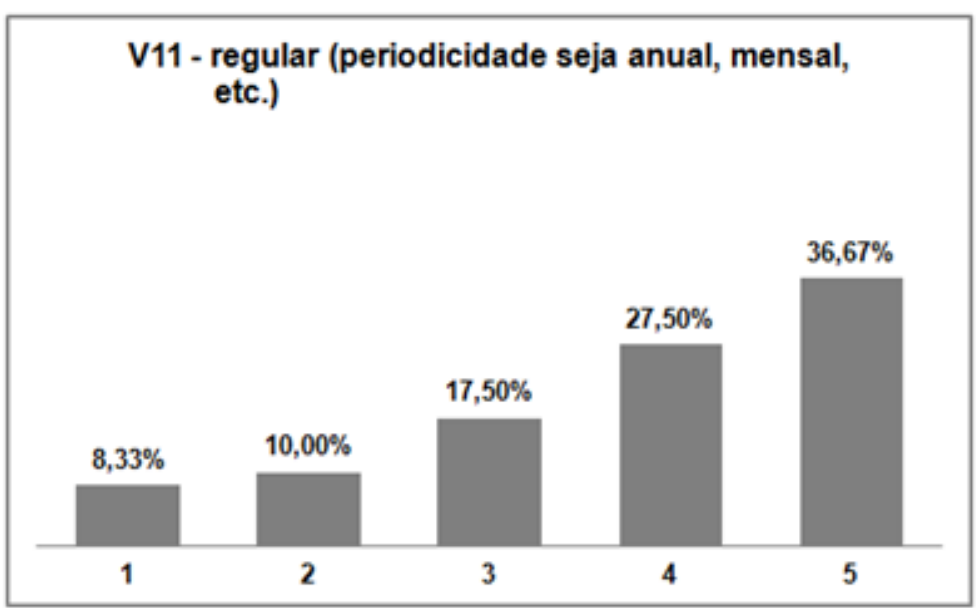

Média

3,74

Mediana

4,00

Moda

5,00

Desvio padrão

1,28

Assimetria

$-0,77$

Curtose

$-0,47$

Coef. de variação

$34,2 \%$ 


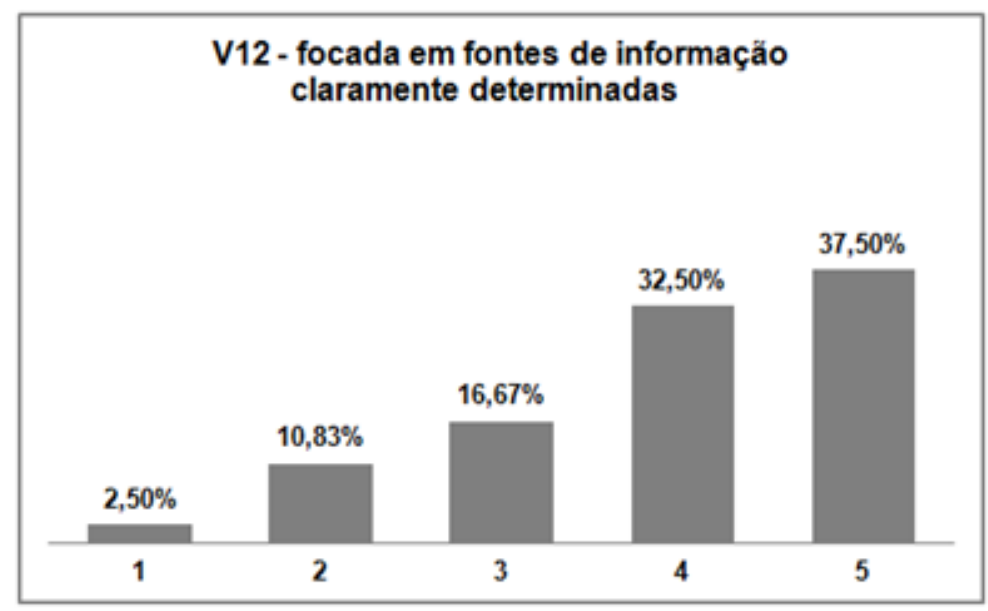

Média

3,92

Mediana

4,00

Moda

5,00

Desvio padrão

1,10

Assimetria

$-0,80$

Curtose

$-0,22$

Coef. de variação $\quad 28,0 \%$

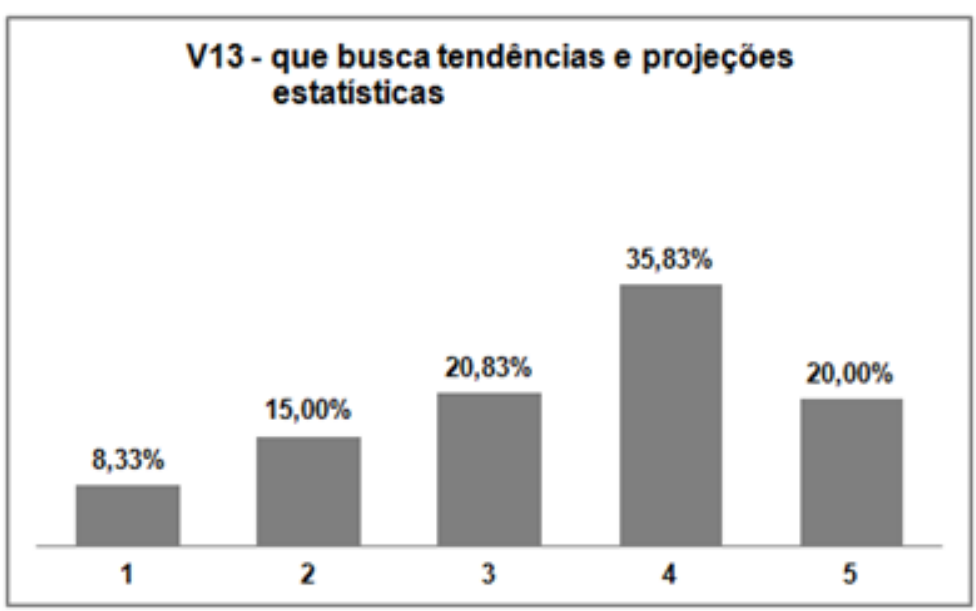

Média

3,44

Mediana

4,00

Moda

4,00

Desvio padrão

1,21

Assimetria

$-0,50$

Curtose

$-0,67$

Coef. de variação

$35,1 \%$

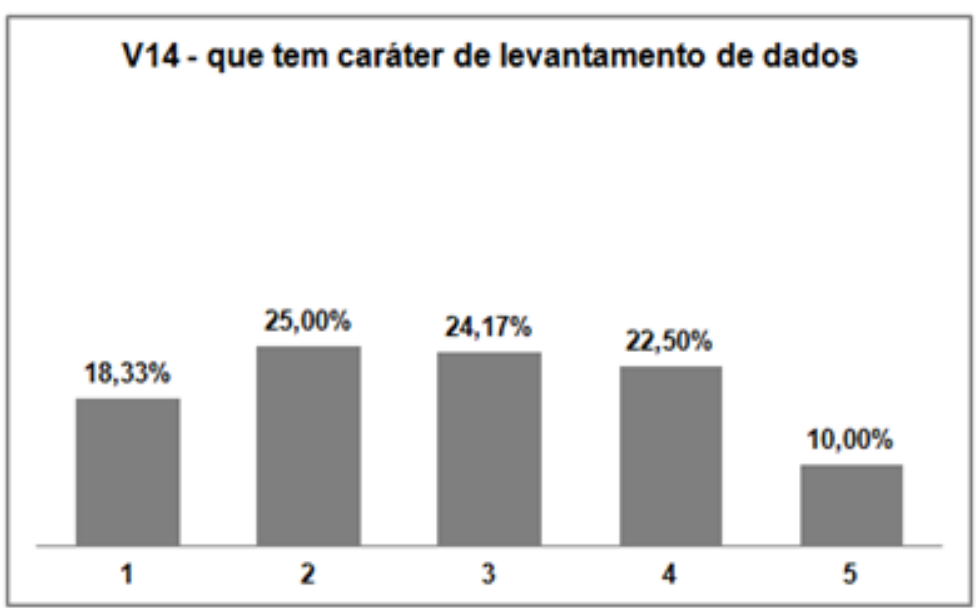

Média

2,81

Mediana

3,00

Moda

2,00

Desvio padrão

1,26

Assimetria

0,11

Curtose

$-1,04$

Coef. de variação

$44,8 \%$ 


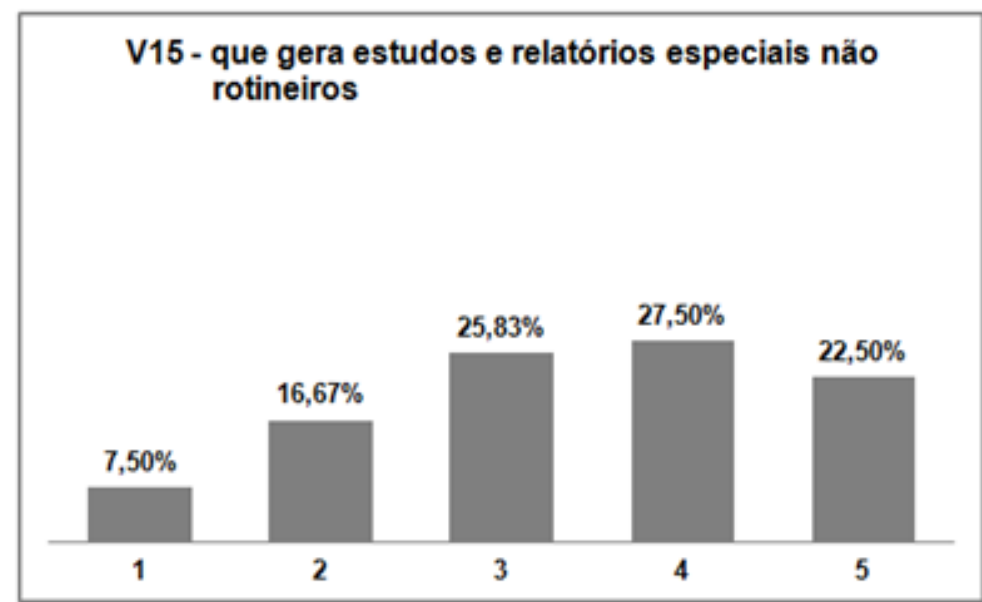

Média

Desvio padrão

1,22

Assimetria

$-0,32$

Curtose

$-0,84$

Coef. de variação $\quad 35,8 \%$

b) Bloco 02 de Questões

Neste bloco do questionário, apresentou-se a questão: "Em sua empresa, qual a frequência com que são utilizadas as fontes de informação do Ambiente de Negócios listadas a seguir?". Considerando-se "1 - sempre" e "5 - concordo totalmente", para o conjunto de 120 observações obtiveram-se as seguintes estatísticas descritivas para as variáveis V16 a V19:

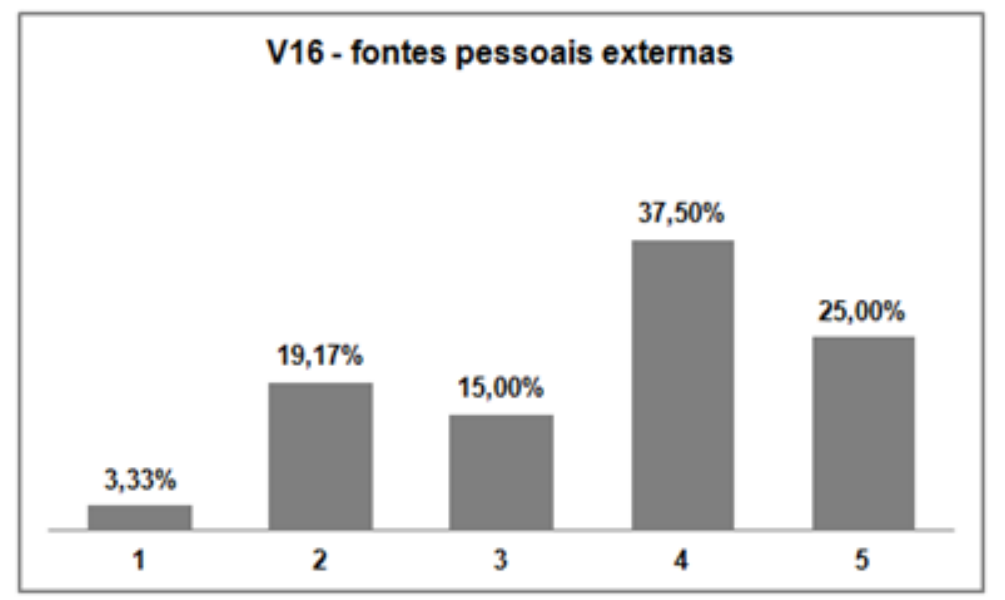

\section{Média}

Mediana

Moda

Desvio padrão

Assimetria

Curtose

Coef. de variação
3,62

4,00

4,00

1,15

$-0,51$

$-0,79$

$31,9 \%$ 


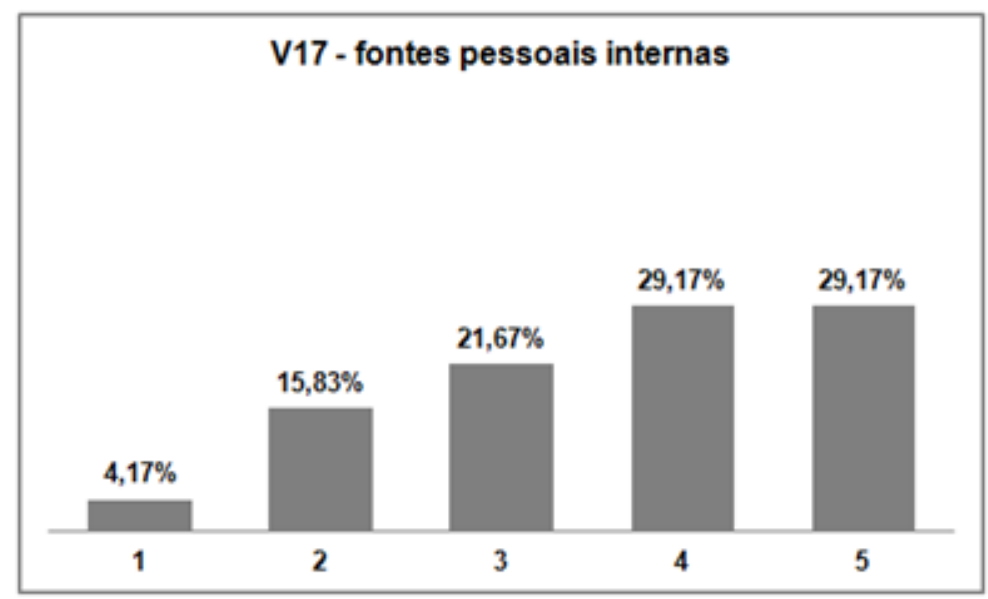

Média

3,63

Mediana

4,00

Moda

4 e 5

Desvio padrão

1,18

Assimetria

$-0,47$

Curtose

$-0,79$

Coef. de variação

$32,5 \%$

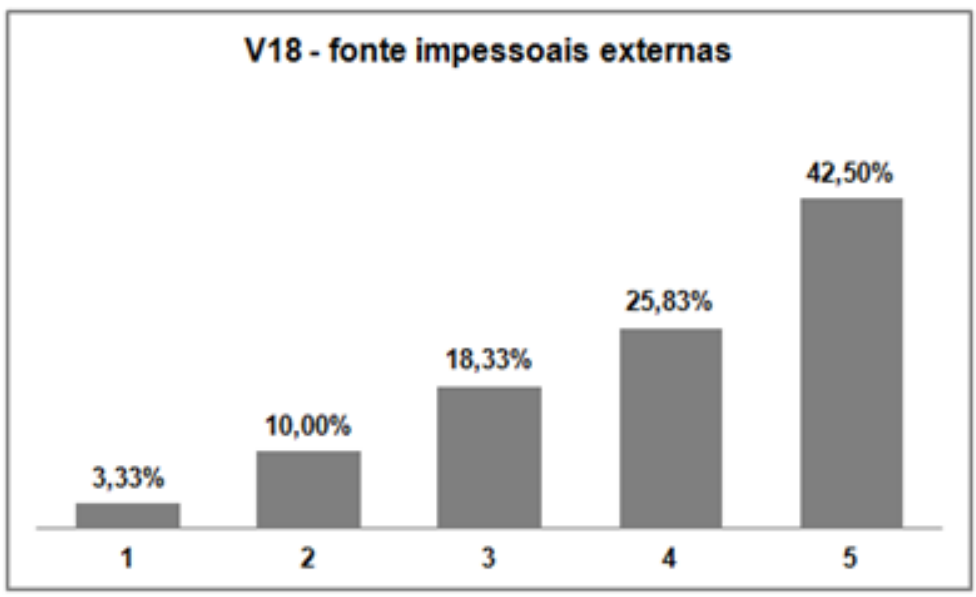

Média

3,94

Mediana

4,00

Moda

5,00

Desvio padrão

1,15

Assimetria

$-0,84$

Curtose

$-0,26$

Coef. de variação

$29,1 \%$

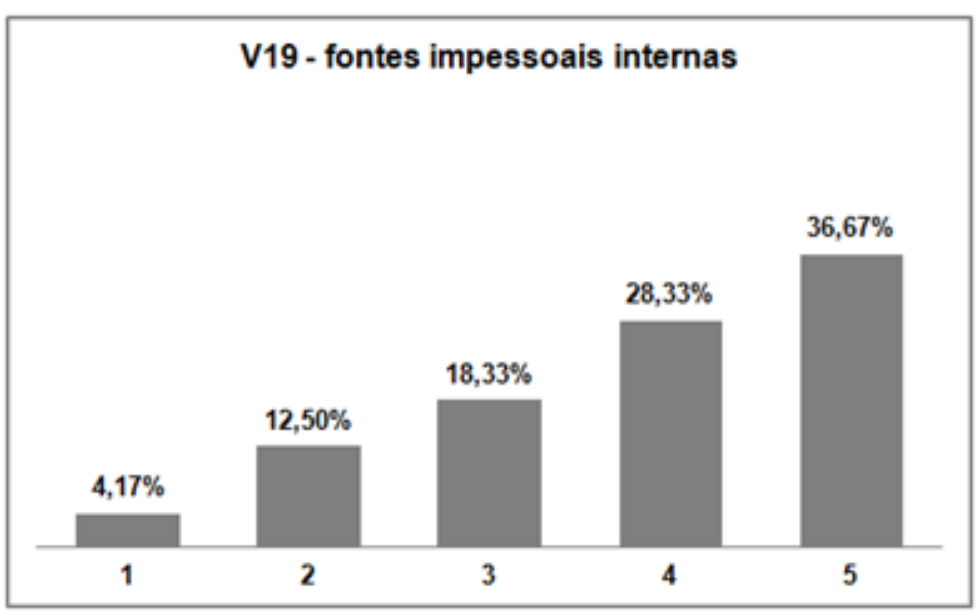

Média

3,81

Mediana

4,00

Moda

5,00

Desvio padrão

1,18

Assimetria

$-0,70$

Curtose

$-0,51$

Coef. de variação

$31,1 \%$ 
c) Bloco 03 de Questões

Neste bloco do questionário, apresentou-se a questão: "Em sua empresa, qual a frequência com que são coletadas informações dos aspectos listados a seguir do Ambiente de negócios?". Considerando-se "1 - sempre" e "5 - concordo totalmente", para o conjunto de 120 observações analisadas obtiveram-se as seguintes estatísticas descritivas para as variáveis V20 a V27:

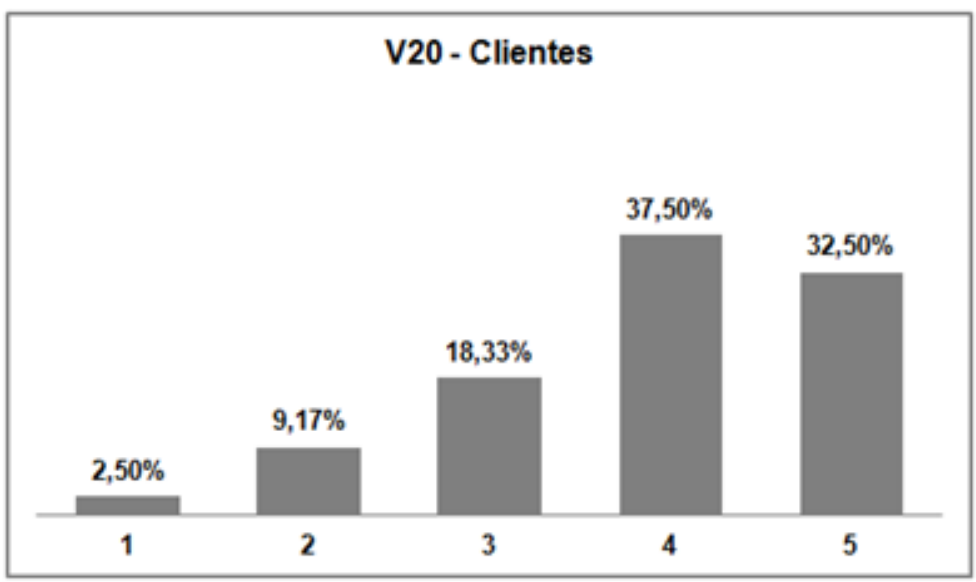

Média

Mediana

Moda

Desvio padrão

Assimetria

Curtose

Coef. de variação
3,88

4,00

4,00

1,05

$-0,79$

0,01

$27,0 \%$

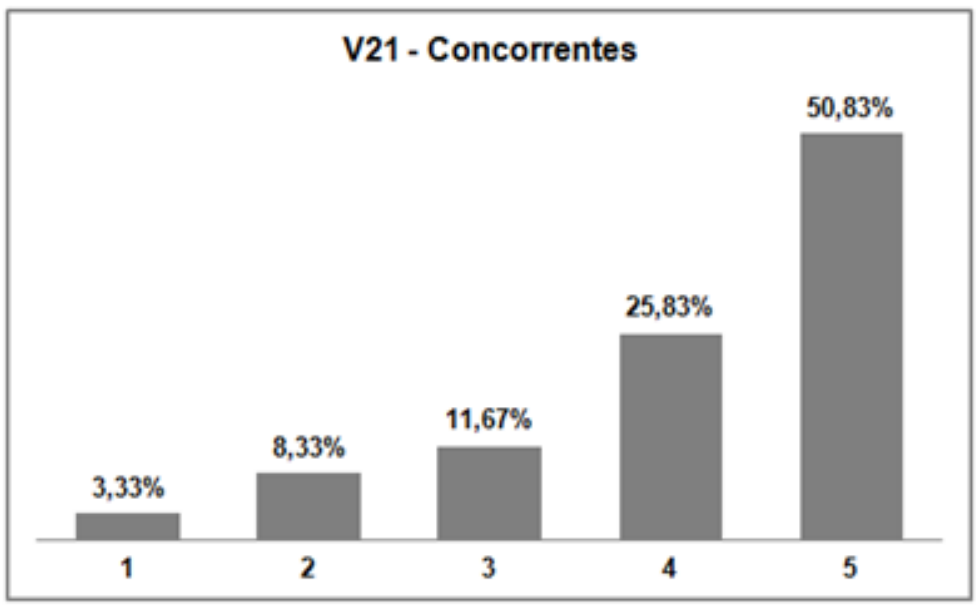

Média

Mediana

Moda

Desvio padrão

Assimetria

Curtose

Coef. de variação
4,13

5,00

5,00

1,12

$-1,20$

0,54

$27,1 \%$ 


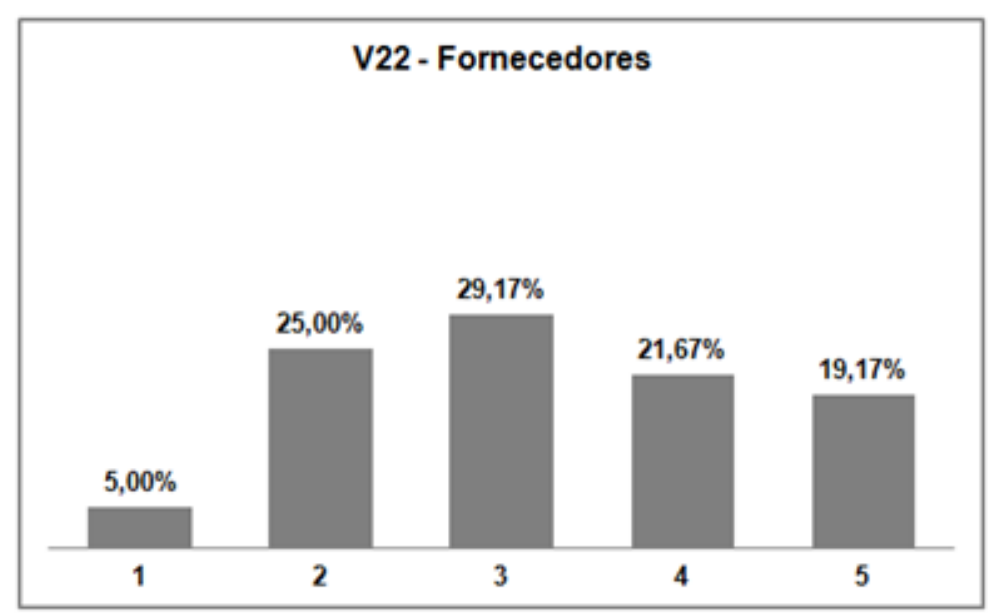

Média

3,25

Mediana

3,00

Moda

3,00

Desvio padrão

1,18

Assimetria

0,04

Curtose

$-0,99$

Coef. de variação $\quad 36,2 \%$

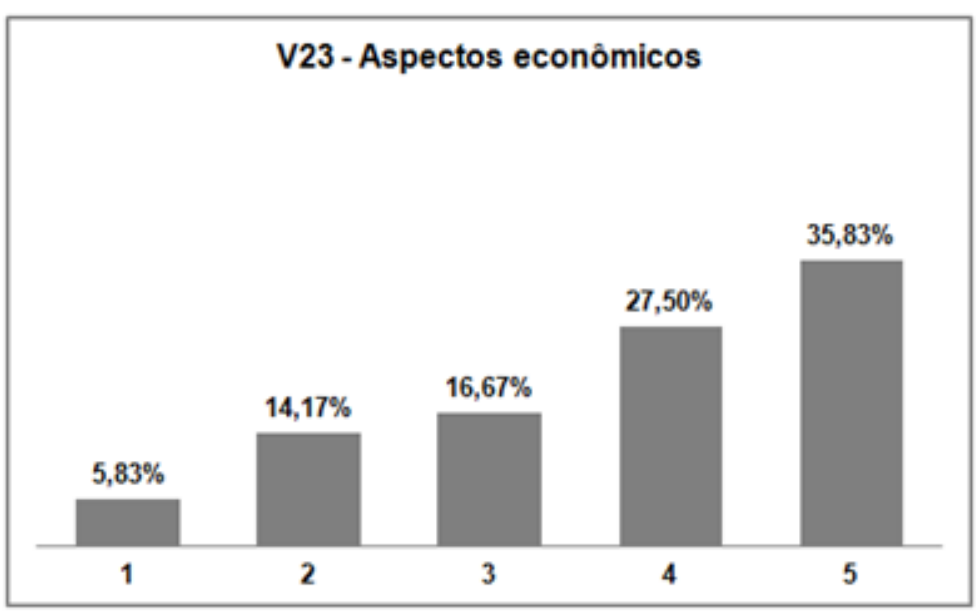

Média

3,73

Mediana

4,00

Moda

5,00

Desvio padrão

1,25

Assimetria

$-0,66$

Curtose

$-0,67$

Coef. de variação

$33,4 \%$

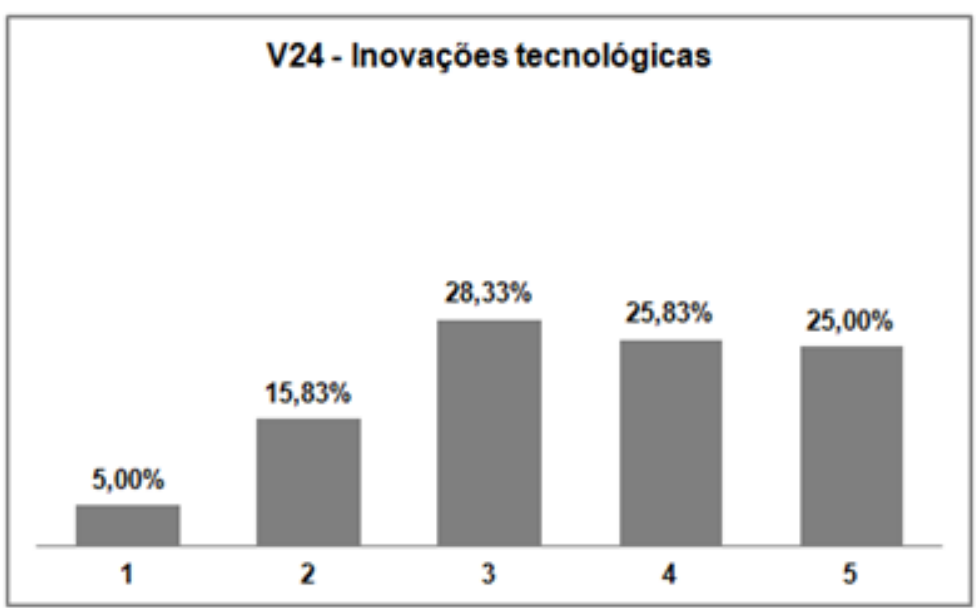

Média

3,50

Mediana

4,00

Moda

3,00

Desvio padrão

1,17

Assimetria

$-0,30$

Curtose

$-0,81$

Coef. de variação

$33,5 \%$ 


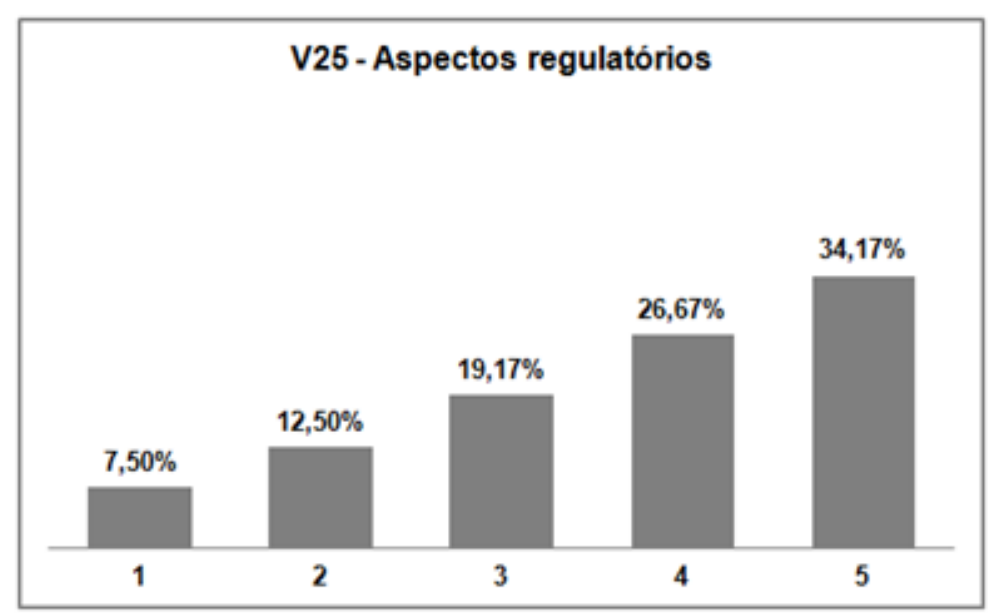

Média

3,68

Mediana

4,00

Moda

5,00

Desvio padrão

1,27

Assimetria

$-0,64$

Curtose

$-0,67$

Coef. de variação

$34,6 \%$

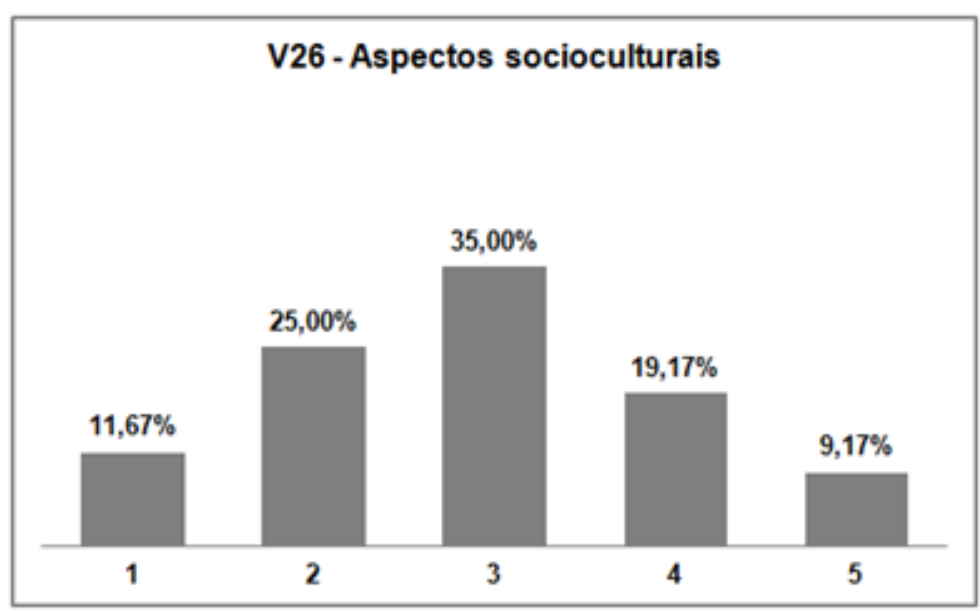

Média

2,89

Mediana

3,00

Moda

3,00

Desvio padrão

1,13

Assimetria

0,11

Curtose

$-0,62$

Coef. de variação

$39,0 \%$

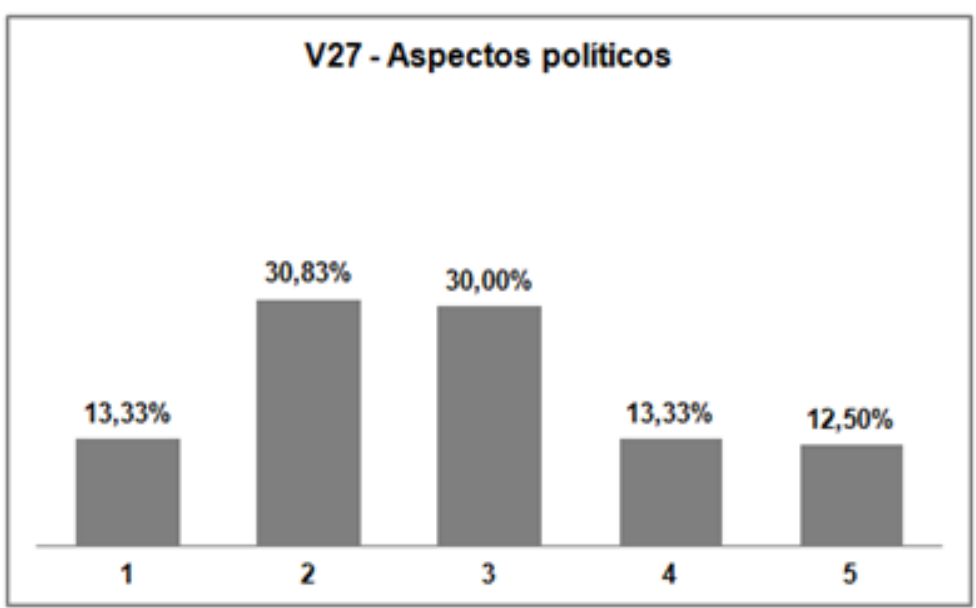

Média

2,81

Mediana

3,00

Moda

2,00

Desvio padrão

1,20

Assimetria

0,35

Curtose

$-0,70$

Coef. de variação

$42,9 \%$ 
d) Bloco 04 de Questões

Neste bloco do questionário, apresentou-se a questão: "Qual a importância dos problemas listados a seguir para as atividades de monitoramento?". Considerando-se "1 - nada importante" e "5 - muito importante", para o conjunto de 120 observações obtiveram-se as seguintes estatísticas descritivas para as variáveis V28 a V35:

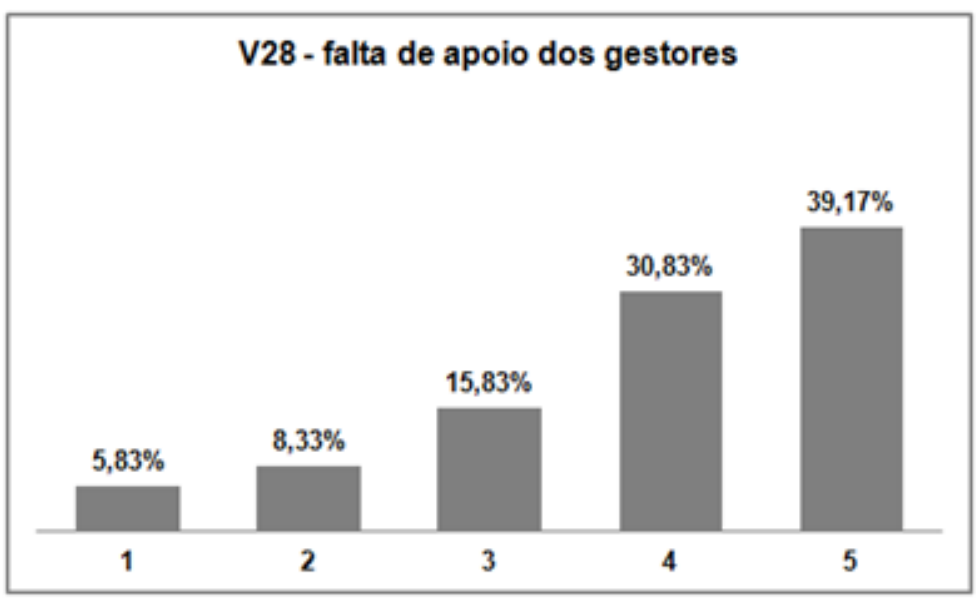

Média

3,89

Mediana

4,00

Moda

5,00

Desvio padrão

1,19

Assimetria

$-0,95$

Curtose

0,04

Coef. de variação

$30,5 \%$

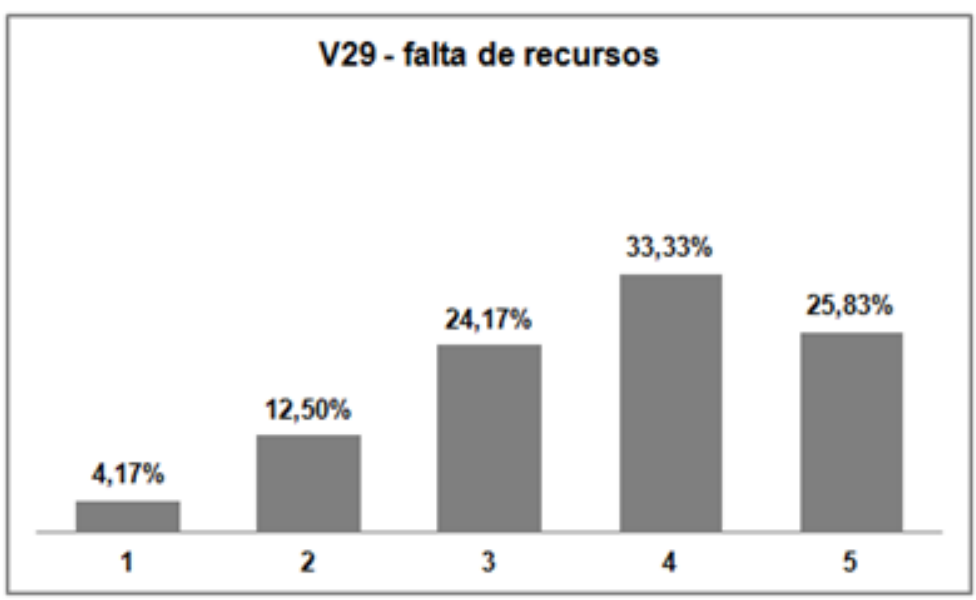

Média

3,64

Mediana

4,00

Moda

4

Desvio padrão

1,12

Assimetria

$-0,53$

Curtose

$-0,48$

Coef. de variação

$30,8 \%$ 


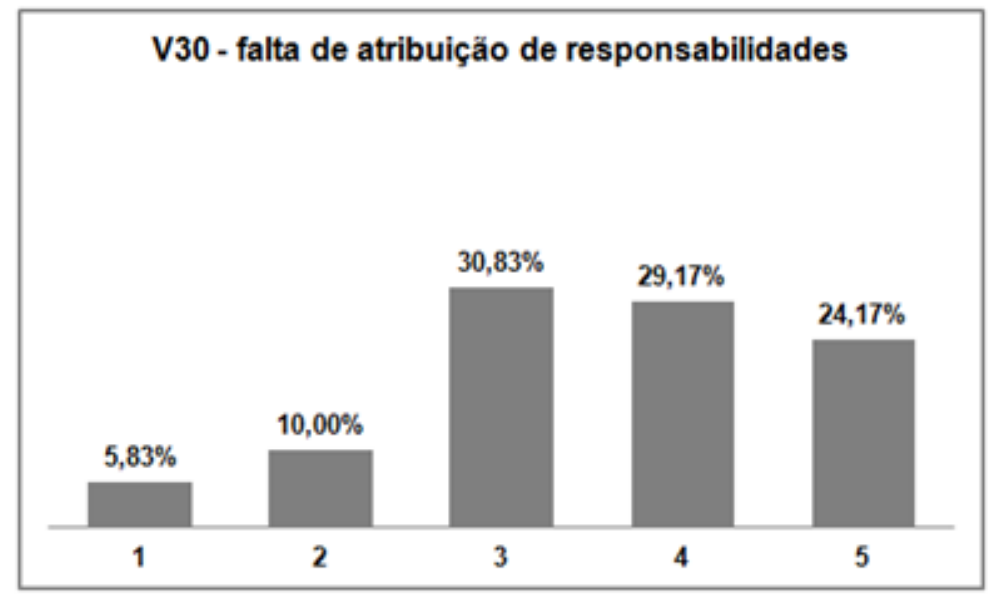

Média

3,56

Mediana

4,00

Moda

3,00

Desvio padrão

1,14

Assimetria

$-0,46$

Curtose

$-0,42$

Coef. de variação

$31,9 \%$

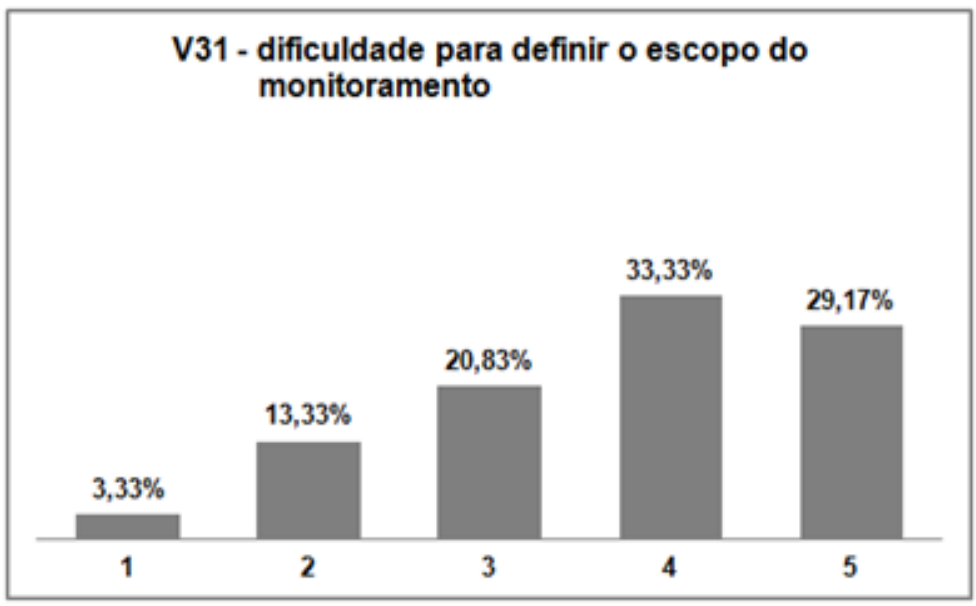

Média

3,72

Mediana

4,00

Moda

4,00

Desvio padrão

1,12

Assimetria

$-0,57$

Curtose

$-0,54$

Coef. de variação

$30,2 \%$

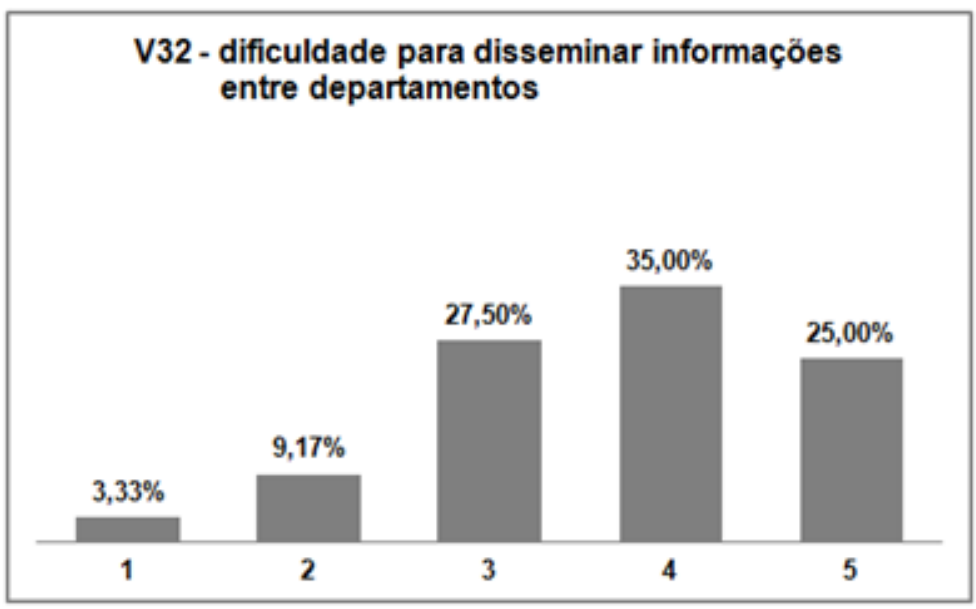

Média

3,69

Mediana

4,00

Moda

4,00

Desvio padrão

1,05

Assimetria

$-0,54$

Curtose

$-0,22$

Coef. de variação

$28,5 \%$ 


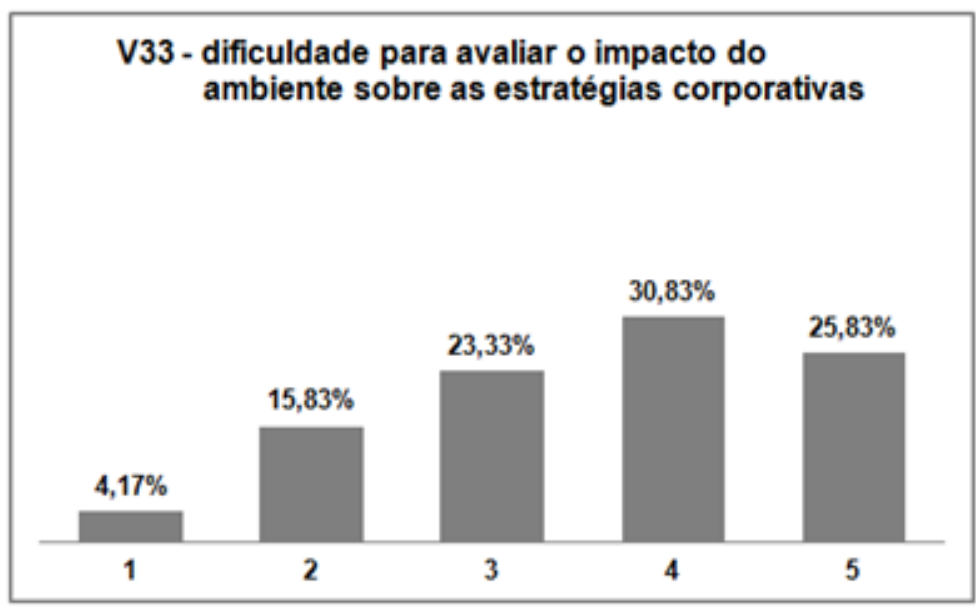

Média

3,58

Mediana

Moda

4,00

Desvio padrão

1,16

Assimetria

$-0,42$

Curtose

$-0,75$

Coef. de variação

$32,3 \%$

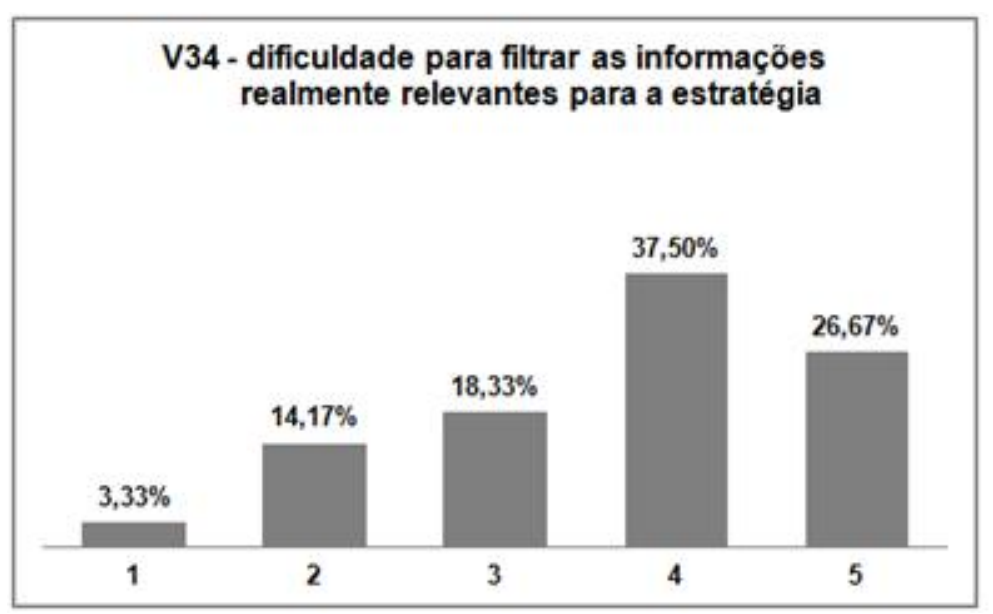

Mèdia

3,70

Mediana

4,00

Moda

4,00

Desvio padrão

1,11

Assimetria

$-0,61$

Curtose

$-0,47$

Coef. de variação

$30,1 \%$

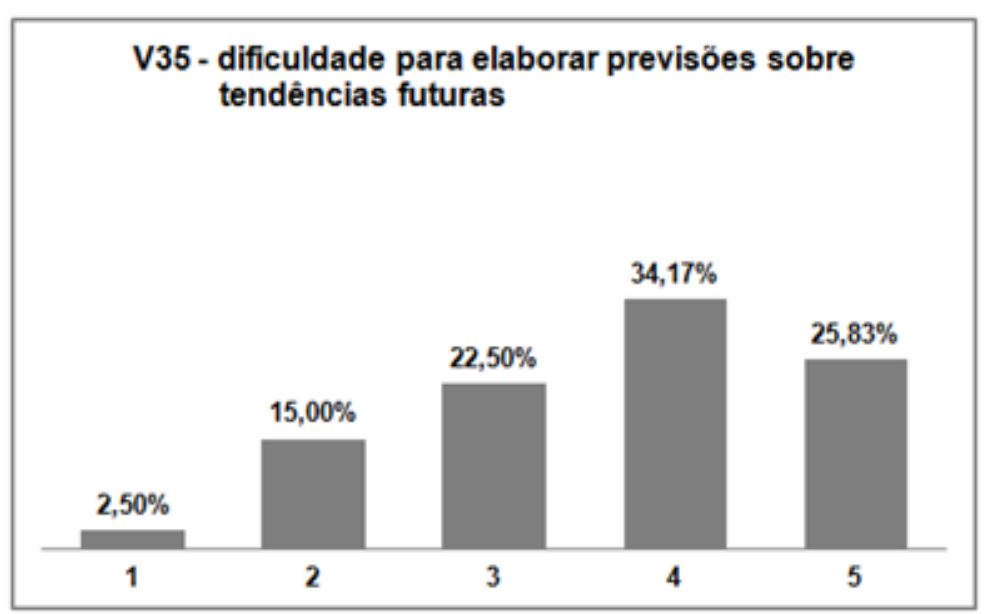

Média

3,66

Mediana

4,00

Moda

4,00

Desvio padrão

1,10

Assimetria

$-0,45$

Curtose

$-0,68$

Coef. de variação

$30,0 \%$ 


\section{APÊNDICE 07: DIFICULDADES ADICIONAIS DO MONITORAMENTO}

A seguir, listam-se as respostas da pergunta aberta e opcional do bloco 04:

"Caso você deseje citar outros problemas relevantes, utilize o espaço a seguir:".

- Falta de foco.

- Ainda não se dá importância para pesquisas com clientes potenciais e já existentes.

- O primeiro item "falta de apoio dos gestores", especialmente, ALTOS EXECUTIVOS, é um fator crucial pois a área de IM precisa de um sponsor que enxergue os benefícios desse departamento, pois ele irá defender contratações de alto nível, treinamento constante e investimento em softwares de apoio a estudos, por exemplo.

- Gestores sem conhecimento profundo do tema.

- Resistência da alta direção à necessidade de mudança de rumo ou direcionamento estratégico, uma vez que o monitoramento indica problemas para a continuidade naquele caminho. $\mathrm{Ou}$ seja, quando se cai no "eu sei o que é melhor".

- Também gostaria de levantar a importância do relacionamento dentro da empresa para a área de IC. Na empresa alfa consegui as informações mais relevantes dentro da área de Engenharia, Comercial e Fusão/Aquisição. Além disso, como ponto negativo saliento a falta de reconhecimento dos funcionários. Todos os departamentos precisam da informação gerada por IC, mas não somos os primeiros a ser reconhecidos.

- Dificuldade de definir processos e rotinas.

- Eu não consegui identificar claramente nas opções acima, portanto vou escrever aqui. Infelizmente, muitas empresas não especificam bem um foco de atuação e, consequentemente, não direcionam adequadamente suas áreas de Inteligência (quando as empresas as possuem). A falta de foco e de uma estratégia clara e definida é a maior dificuldade para o monitoramento do Ambiente de Negócios, pois quando isso é claro e a área de Inteligência trabalha alinhada aos objetivos estabelecidos, o monitoramento é eficaz e, em maior ou menor grau, agrega valor para os executivos e, de alguma forma, exerce uma influência neste processo.

- A informação gerada costuma mostrar erros de gestão, e por muitas vezes chegam a ser modificadas para maquiar resultados ou se tornar tendenciosas.

- Acuracidade e veracidade de informações.

- Depende muito da Empresa e de como Inteligência de Mercado ou Inteligência Competitiva é tida na estrutura organizacional. Quando em fases iniciais o principal 
- Desafio é torná-la visível e "aceita". É sempre muito importante a liderança comprar a ideia, seja da criação, desenvolvimento e da própria importância e papel dessa área na tomada de decisão.

- As empresas brasileiras de um modo geral não estão acostumadas a se planejar de forma realmente estruturada em análise e projeção de dados, informações e cenários.

- Relacionamento menos burocrático entre áreas - ocultação de informações

- Falta de planejamento da direção. Tudo é pedido para ontem conforme a febre da semana.

- Dificuldade para conseguir colaboração e informações relevantes para a estratégia provindas de outras áreas da empresa.

- Falta de maturidade da organização para lidar com o tema.

- A empresa não faz ativamente um esforço a fim de monitorar a concorrência. Não faz parte da cultura.

- Atividade muito focada em estudos ad hoc.

- Além da eventual falta de apoio dos gestores, muitas vezes há também desconhecimento ou falta de apoio de pares.

- Dificuldade na clareza da missão e visão para empresa ou até mesmo de um planejamento estratégico claro para saber como podemos alcançar nossa visão (onde desejamos estar). Conceitualmente muitos conhecem, porém na prática esse conhecimento se torna somente empírico e não prático.

- Desenvolvemos projetos de consultoria. Durante a "venda" do projeto e definição do "escopo", nem sempre é dada a devida importância para os impactos futuros e tendências no Ambiente de Negócios. Como forma de aprofundamento do projeto, adiciono análises ligadas à movimentações da Indústria e Ambientes de Negócio, de maneira a pontuar possíveis impactos não mensurados.

- Não diria apenas falta de apoio dos gestores. É preciso haver apoio da alta administração das empresas. Elas precisam entender que essas atividades são necessárias e devem ser vistas como "investimentos", e não como "despesa".

- Dificuldade de localizar fonte de informação que atenda segmentos mais específicos. 


\section{APÊNDICE 08: NORMALIDADE, MISSINGS E OUTLIERS}

Quadro 1 - Resultados do teste de Kolmogorov Smirnov

\begin{tabular}{|c|c|c|}
\hline Variáveis & $\begin{array}{c}\text { Kolmogorov Smirnov } \\
\mathrm{Z}\end{array}$ & $\begin{array}{c}\text { Significância } \\
\text { (bi-caudal) }\end{array}$ \\
\hline V01 & 2,056 & ,000 \\
\hline V02 & 1,893 & ,002 \\
\hline V03 & 1,864 & ,002 \\
\hline V04 & 2,489 & ,000 \\
\hline V05 & 2,117 & ,000 \\
\hline V06 & 2,563 & ,000 \\
\hline V07 & 1,985 & ,001 \\
\hline V08 & 2,278 & ,000 \\
\hline V09 & 2,759 & ,000 \\
\hline V10 & 2,262 &, 000 \\
\hline V11 & 2,428 & ,000 \\
\hline V12 & 2,523 & ,000 \\
\hline V13 & 2,590 & ,000 \\
\hline V14 & 1,894 & ,002 \\
\hline V15 & 2,040 &, 000 \\
\hline V16 & 2,795 & ,000 \\
\hline V17 & 2,249 & ,000 \\
\hline V18 & 2,705 & ,000 \\
\hline V19 & 2,348 &, 000 \\
\hline V20 & 2,677 & ,000 \\
\hline V21 & 3,189 & ,000 \\
\hline $\mathrm{V} 22$ & 1,926 & ,001 \\
\hline V23 & 2,387 &, 000 \\
\hline $\mathrm{V} 24$ & 1,898 & ,001 \\
\hline V25 & 2,292 & ,000 \\
\hline V26 & 1,955 & ,001 \\
\hline $\mathrm{V} 27$ & 2,088 &, 000 \\
\hline V28 & 2,589 & ,000 \\
\hline V29 & 2,377 & ,000 \\
\hline V30 & 2,022 & ,001 \\
\hline V31 & 2,459 & ,000 \\
\hline V32 & 2,359 & ,000 \\
\hline V33 & 2,271 &, 000 \\
\hline V34 & 2,717 & ,000 \\
\hline V35 & 2,436 & ,000 \\
\hline
\end{tabular}

Pelos resultados do teste não paramétrico de Kolmogorov Smirnov mostrados no quadro acima, a hipótese de distribuição normal foi rejeitada com nível crítico de significância de 0,05 para todas as variáveis de V01 a V35. 
Nas 120 observações selecionadas, encontraram-se apenas 23 missings values entre as variáveis V01 e V35 totalizando 0,55\% de todas as respostas fechadas $(23 /(120 \times 35)=$ $0,55 \%)$. No quadro a seguir, mostram-se as observações e variáveis relativas aos missing values.

Quadro 2 - Observações com missing values

\begin{tabular}{|c|c|}
\hline $\begin{array}{c}\text { Número da } \\
\text { observação }\end{array}$ & Variáveis \\
\hline 22 & V01, V02 e V28 a V35 \\
\hline 33 & V15 \\
\hline 79 & V10 \\
\hline 93 & V09 \\
\hline 99 & V02 e V10 \\
\hline 200 & V11 \\
\hline
\end{tabular}

Para não eliminar estas observações das análises, optou-se por substituir os missing values pelo valor central 3 da escala de Likert que corresponde à neutralidade (HAIR JR. et al., 2006).

Para a verificação de observações outliers, utilizou-se a detecção multivariada tomando-se a variável V35 como dependente e as variáveis V01 a V34 como independentes. A medida D² de Mahalanobis dividida por 34 graus de liberdade apresentou o valor máximo de 2,16 entre as 120 observações. Segundo Hair Jr. et al. (2006), para este tamanho de amostra, somente observações com valores acima de 3 são consideradas outliers, resultando que nessa amostra não se consideraram observações atípicas. 
APÊNDICE 09: TESTE DE MANN-WHITNEY (ANÁLISE DE CONGLOMERADOS)

Quadro 3 - Teste de Mann-Whitney para diferenciação dos conglomerados

\begin{tabular}{|c|c|c|}
\hline Variáveis & $\begin{array}{c}\text { U de } \\
\text { Mann-Whitney }\end{array}$ & $\begin{array}{c}\text { Significância } \\
\text { (bilateral) }\end{array}$ \\
\hline V07 & 209,000 & 0,000 \\
\hline V13 & 380,500 & 0,000 \\
\hline V11 & 415,500 & 0,000 \\
\hline V06 & 477,000 & 0,000 \\
\hline V12 & 512,000 & 0,000 \\
\hline V05 & 513,000 & 0,000 \\
\hline V10 & 562,000 & 0,000 \\
\hline V08 & 630,000 & 0,000 \\
\hline V14 & 689,500 & 0,000 \\
\hline V01 & 765,500 & 0,000 \\
\hline V15 & 794,500 & 0,000 \\
\hline V09 & 869,000 & 0,000 \\
\hline V03 & 906,500 & 0,000 \\
\hline V04 & 997,000 & 0,001 \\
\hline V02 & $1.303,500$ & 0,110 \\
\hline & & \\
\hline & & \\
\hline
\end{tabular}

No quadro acima, mostra-se o resultado do teste não paramétrico de Mann-Whitney para verificar a diferenciação entre os dois grupos gerados pela Análise de Conglomerados. Assim como na ANOVA, aceitou-se a igualdade de distribuição entre os grupos PF e PI com nível crítico de significância 0,05 apenas para a variável V02. 
APÊNDICE 10: MATRIZ DE CORRELAÇÕES DE PEARSON (ANÁLISE FATORIAL)

\begin{tabular}{|c|c|c|c|c|c|c|c|c|c|c|c|c|c|c|}
\hline & V01 & V03 & V04 & V05 & V06 & V07 & V08 & V09 & V10 & V11 & V12 & V13 & V14 & V15 \\
\hline V01 & 1,000 & & & & & & & & & & & & & \\
\hline V03 & $\underline{-0,309}$ & 1,000 & & & & & & & & & & & & \\
\hline V04 & $\underline{0,346}$ & $-0,019$ & 1,000 & & & & & & & & & & & \\
\hline V05 & $\underline{-0,333}$ & $\underline{0,267}$ & $\underline{-0,284}$ & 1,000 & & & & & & & & & & \\
\hline V06 & $\underline{-0,413}$ & $\underline{0,233}$ & $\underline{-0,263}$ & $\underline{0,407}$ & 1,000 & & & & & & & & & \\
\hline v07 & $\underline{-0,488}$ & $\underline{0,381}$ & $\underline{-0,318}$ & $\underline{0,561}$ & $\underline{0,622}$ & 1,000 & & & & & & & & \\
\hline V08 & $\underline{-0,322}$ & $\underline{0,318}$ & $\underline{-0,447}$ & $\underline{0,418}$ & $\underline{0,404}$ & $\underline{0,571}$ & 1,000 & & & & & & & \\
\hline V09 & $-0,098$ & $\underline{0,160}$ & $\underline{-0,176}$ & $\underline{0,231}$ & $\underline{0,415}$ & $\underline{0,390}$ & $\underline{0,412}$ & 1,000 & & & & & & \\
\hline V10 & $\underline{-0,357}$ & 0,251 & $\underline{-0,275}$ & $\underline{0,313}$ & $\underline{0,408}$ & $\underline{0,491}$ & $\underline{0,424}$ & $\underline{0,265}$ & 1,000 & & & & & \\
\hline V11 & $\underline{-0,312}$ & 0,146 & $\underline{-0,184}$ & $\underline{0,404}$ & $\underline{0,317}$ & $\underline{0,554}$ & $\underline{0,407}$ & $\underline{0,374}$ & $\underline{0,307}$ & 1,000 & & & & \\
\hline V12 & $\underline{-0,348}$ & $\underline{0,290}$ & $\underline{-0,397}$ & $\underline{0,496}$ & $\underline{0,442}$ & $\underline{0,523}$ & $\underline{0,503}$ & $\underline{0,503}$ & $\underline{0,369}$ & $\underline{0,469}$ & 1,000 & & & \\
\hline V13 & $\underline{-0,392}$ & $\underline{0,267}$ & $\underline{-0,338}$ & $\underline{0,533}$ & $\underline{0,581}$ & $\underline{0,582}$ & $\underline{0,417}$ & $\underline{0,529}$ & $\underline{0,393}$ & $\underline{0,498}$ & $\underline{0,567}$ & 1,000 & & \\
\hline V14 & $\underline{-0,313}$ & $\underline{0,287}$ & $\underline{-0,271}$ & $\underline{0,211}$ & $\underline{0,328}$ & $\underline{0,403}$ & $\underline{0,363}$ & $\underline{0,186}$ & $\underline{0,418}$ & $\underline{0,256}$ & $\underline{0,250}$ & $\underline{0,316}$ & 1,000 & \\
\hline V15 & $\underline{-0,259}$ & $\underline{0,268}$ & $\underline{-0,197}$ & $\underline{0,439}$ & $\underline{0,396}$ & $\underline{0,405}$ & $\underline{0,238}$ & $\underline{0,242}$ & $\underline{0,190}$ & $\underline{0,300}$ & $\underline{0,371}$ & $\underline{0,379}$ & $\underline{0,188}$ & 1,000 \\
\hline
\end{tabular}




\section{APÊNDICE 11 - COEFICIENTES DA FUNÇÃO DISCRIMINANTE}

Quadro 3 - Coeficientes da função discriminante

\begin{tabular}{|c|c|}
\hline Variáveis & Coeficientes \\
\hline V01 - de caráter ocasional. & 0,027 \\
\hline V02 - exploratória, pois busca hipóteses mais do que confirmações. & 0,161 \\
\hline V03 - focada em informações qualitativas (ex.: percepções, motivações, etc.). & 0,123 \\
\hline V04 - não direcionada a informações específicas, sendo análoga a um radar. & 0,020 \\
\hline V05 - que busca sinais antecipativos de oportunidades e ameaças. & 0,157 \\
\hline V06 - formal e gerenciada por departamento(s) específico(s). & 0,345 \\
\hline V07 - planejada e sistemática. & 0,286 \\
\hline V08 - direcionada a informações específicas, colocando questões objetivas. & $-0,007$ \\
\hline V09 - focada em informações quantitativas (ex.: consumo, demanda, frequências, preços, etc.). & $-0,212$ \\
\hline V10 - que utiliza dados gerados por sistemas de gestão da informação. & 0,274 \\
\hline V11 - regular (periodicidade seja anual, mensal, etc.). & 0,422 \\
\hline V12 - focada em fontes de informação claramente determinadas (clientes, concorrentes, etc.). & 0,270 \\
\hline V13 - que busca tendências e projeções estatísticas. & 0,274 \\
\hline V14 - que tem caráter de levantamento de dados (usa questionários, formulários, etc.). & 0,198 \\
\hline V15 - que gera estudos e relatórios especiais não rotineiros. & 0,010 \\
\hline (Constante) & $-7,883$ \\
\hline
\end{tabular}




\section{APÊNDICE 12 - TESTES DE MANN-WHITNEY (V16 A V35)}

Os dois grupos de modos de monitoramento PF e PI foram comparados através das questões dos blocos relativos a fontes de informação, escopo do monitoramento e dificuldades do monitoramento. Para verificar a existência de diferença significativa destas variáveis entre os grupos, utilizou-se a prova não paramétrica de Mann-Whitney com nível crítico de significância 0,05 . Nos quadros deste apêndice, mostra-se para cada variável, o posto média em cada grupo. O grupo que apresentar maior posto médio tende a apresentar escores em escala Likert mais elevados para a variável. Quanto maior a diferença dos postos médios de uma variável entre os grupos, mais distintos eles tendem a ser quanto a essa variável.

Nos quadros a seguir, apresentam-se também a estatística Mann-Whitney U e o valor Z (normal) correspondente. Para as variáveis que apresentaram significância ( $p$-value) inferior a 0,05 , rejeitou-se a igualdade entre os grupos PF e PI - vide valores destacados em negrito.

\begin{tabular}{|c|c|c|c|c|c|}
\hline \multirow{2}{*}{\multicolumn{2}{|c|}{ Estatísticas }} & \multicolumn{4}{c|}{ Fontes de Informações } \\
\cline { 3 - 6 } & \multicolumn{2}{|c|}{ Pessoais } & \multicolumn{2}{c|}{ Impessoais } \\
\cline { 2 - 6 } & $\begin{array}{c}\text { Externas } \\
(\mathrm{V} 16)\end{array}$ & $\begin{array}{c}\text { Internas } \\
(\mathrm{V} 17)\end{array}$ & $\begin{array}{c}\text { Externas } \\
(\mathrm{V} 18)\end{array}$ & $\begin{array}{c}\text { Internas } \\
(\mathrm{V} 19)\end{array}$ \\
\hline \multirow{2}{*}{ Posto médio } & Procura Formal (n=81) & 73,30 & 70,36 & 69,31 & 69,97 \\
\cline { 2 - 6 } & Procura Informal (n=39) & 33,92 & 40,01 & 42,19 & 40,83 \\
\hline \multicolumn{2}{|c|}{ Diferença entre os postos médios } & 39,38 & 30,35 & 27,12 & 29,14 \\
\hline \multicolumn{2}{|c|}{ Mann-Whitney U } & $1.323,000$ & $1.560,500$ & $1.645,500$ & $1.592,500$ \\
\hline \multicolumn{2}{|c|}{ Z } & $-6,051$ & $-4,627$ & $-4,220$ & $-4,481$ \\
\hline \multicolumn{2}{|c|}{ Sig. Assintótica (bicaudal) } & $\mathbf{0 , 0 0 0}$ & $\mathbf{0 , 0 0 0}$ & $\mathbf{0 , 0 0 0}$ & $\mathbf{0 , 0 0 0}$ \\
\hline
\end{tabular}

\begin{tabular}{|c|l|c|c|c|}
\hline \multirow{2}{*}{} & \multicolumn{3}{c|}{ Aspectos ambientais de mercado } \\
\cline { 3 - 5 } & $\begin{array}{c}\text { Clientes } \\
\text { Estatísticas }\end{array}$ & $\begin{array}{c}\text { Concorrentes } \\
(\text { V21 })\end{array}$ & $\begin{array}{c}\text { Fornecedores } \\
\text { (V22) }\end{array}$ \\
\hline \multirow{2}{*}{ Postos médios } & Grupo PF (n=81) & 71,88 & 71,99 & 69,45 \\
\cline { 2 - 5 } & Grupo IF (n=39) & 36,86 & 36,64 & 41,91 \\
\hline Diferenças entre os postos médios & 35,02 & 35,35 & 27,54 \\
\hline \multicolumn{2}{|c|}{ Mann-Whitney U } & $1.427,500$ & $1.429,000$ & $1.634,500$ \\
\hline \multicolumn{2}{|c|}{ Z } & $-5,427$ & $-5,657$ & $-4,185$ \\
\hline \multicolumn{2}{|c|}{ Sig. Assintótica (bicaudal) } & $\mathbf{0 , 0 0 0}$ & $\mathbf{0 , 0 0 0}$ & $\mathbf{0 , 0 0 0}$ \\
\hline
\end{tabular}




\begin{tabular}{|c|c|c|c|c|c|c|}
\hline \multirow{2}{*}{\multicolumn{2}{|c|}{ Estatísticas }} & \multicolumn{5}{|c|}{ Aspectos macroambientais } \\
\hline & & $\begin{array}{c}\text { Econômicos } \\
\text { (V23) }\end{array}$ & $\begin{array}{c}\text { Tecnológicos } \\
\text { (V24) }\end{array}$ & $\begin{array}{c}\text { Regulatórios } \\
\text { (V25) }\end{array}$ & $\begin{array}{l}\text { Sociocultu- } \\
\text { rais (V26) }\end{array}$ & $\begin{array}{c}\text { Políticos } \\
\text { (V27) }\end{array}$ \\
\hline \multirow{2}{*}{ Postos médios } & Grupo PF $(\mathrm{n}=81)$ & 69,48 & 71,18 & 68,24 & 68,67 & 67,17 \\
\hline & Grupo IF $(n=39)$ & 41,86 & 38,32 & 44,42 & 43,53 & 46,64 \\
\hline \multicolumn{2}{|c|}{ Diferenças entre os postos médios } & 27,62 & 32,86 & 23,82 & 25,14 & 20,53 \\
\hline \multicolumn{2}{|c|}{ Mann-Whitney U } & 853,500 & 714,500 & 952,500 & 917,500 & $1.039,000$ \\
\hline \multicolumn{2}{|c|}{$\mathrm{Z}$} & $-4,234$ & $-4,998$ & $-3,639$ & $-3,842$ & $-3,128$ \\
\hline \multicolumn{2}{|c|}{ Sig. Assintótica (bicaudal) } & $\mathbf{0 , 0 0 0}$ & $\mathbf{0 , 0 0 0}$ & $\mathbf{0 , 0 0 0}$ & $\mathbf{0 , 0 0 0}$ & $\mathbf{0 , 0 0 2}$ \\
\hline
\end{tabular}

\begin{tabular}{|c|c|c|c|c|c|c||}
\hline \multirow{2}{*}{} & \multicolumn{5}{c||}{ Dificuldades organizacionais } \\
\cline { 3 - 7 } \multicolumn{2}{|c|}{ Estatísticas do teste } & $\begin{array}{c}\text { Apoio } \\
\text { (V28) }\end{array}$ & $\begin{array}{c}\text { Recursos } \\
\text { (V29) }\end{array}$ & $\begin{array}{c}\text { Atribuição } \\
\text { (V30) }\end{array}$ & $\begin{array}{c}\text { Escopo } \\
\text { (V31) }\end{array}$ & $\begin{array}{c}\text { Deptos. } \\
\text { (V32) }\end{array}$ \\
\hline \multirow{2}{*}{ Postos médios } & Grupo PF (n=81) & 58,72 & 63,33 & 57,25 & 61,89 & 61,41 \\
\cline { 2 - 7 } & Grupo IF (n=39) & 64,19 & 54,63 & 67,24 & 57,62 & 58,62 \\
\hline \multicolumn{2}{|c|}{ Diferenças entre os postos médios } & $-5,47$ & 8,70 & $-9,99$ & 4,27 & 2,79 \\
\hline \multicolumn{2}{|c|}{ Mann-Whitney U } & $1.435,500$ & $1.350,500$ & $1.316,500$ & $1.467,000$ & $1.506,000$ \\
\hline \multicolumn{2}{|c|}{ Z } & $-0,848$ & $-1,331$ & $-1,528$ & $-0,655$ & $-0,429$ \\
\hline \multicolumn{2}{|c|}{ Sig. Assintótica (bicaudal) } & 0,397 & 0,193 & 0,127 & 0,513 & 0,668 \\
\hline
\end{tabular}

\begin{tabular}{|c|c|c|c|c|}
\hline \multicolumn{2}{|c|}{ Estatísticas do teste } & \multicolumn{3}{c|}{ Dificuldades técnicas } \\
\cline { 2 - 5 } & $\begin{array}{c}\text { Avaliação } \\
(\mathrm{V} 33)\end{array}$ & $\begin{array}{c}\text { Seleção } \\
\text { (V34) }\end{array}$ & $\begin{array}{c}\text { Previsão } \\
\text { (V35) }\end{array}$ \\
\hline \multirow{2}{*}{ Postos médios } & Grupo PF $(\mathrm{n}=81)$ & 62,47 & 62,42 & 61,02 \\
\cline { 2 - 5 } & Grupo IF $(\mathrm{n}=39)$ & 56,41 & 56,51 & 59,41 \\
\hline Diferenças entre os postos médios & 6,06 & 5,91 & 1,61 \\
\hline \multicolumn{2}{|c|}{ Mann-Whitney U } & $1.420,000$ & $2.204,000$ & $2.317,000$ \\
\hline \multicolumn{2}{|c|}{ Z } & $-0,923$ & $-0,909$ & $-0,247$ \\
\hline \multicolumn{2}{|c|}{ Sig. Assintótica (bicaudal) } & 0,356 & 0,364 & 0,805 \\
\hline
\end{tabular}




\section{APÊNDICE 13 - TESTES DE FRIEDMAN (V16 A V35)}

Os grupos PF e PI foram descritos através das questões dos blocos relativos a fontes de informação, escopo do monitoramento e dificuldades do monitoramento. Para verificar a existência de diferenças significativas entre as variáveis de cada bloco dentro dos grupos, utilizou-se a prova não paramétrica de Friedman para $k$ amostras dependentes com nível crítico de significância 0,05 .

Por exemplo, no quadro a seguir, rejeitou-se a igualdade entre as quatro variáveis relativas às fontes de informação no grupo procura informal, pois a significância ( $p$-value) de 0,024 é inferior a 0,05. Porém, no grupo procura formal, aceitou-se a igualdade dessas variáveis, pois a significância (p-value) de 0,105 é superior a 0,05, não se constando diferenças entre a frequência de utilização das fontes quando comparadas dentro do grupo procura formal.

\begin{tabular}{|c|c|c|c|c|}
\hline \multicolumn{5}{|c|}{ Fontes de Informação } \\
\hline \multirow{3}{*}{ Grupo } & Variável & Posto Médio & \multicolumn{2}{c|}{ Estatísticas do teste } \\
\hline \multirow{3}{*}{ Procura Formal } & V16 & 2,40 & $\mathrm{n}$ & 81 \\
\cline { 2 - 5 } & V17 & 2,34 & $\chi^{2}$ & 6,132 \\
\cline { 2 - 5 } & V18 & 2,67 & g.l. & 3 \\
\cline { 2 - 5 } & V19 & 2,60 & Sig. Assint. & 0,105 \\
\hline \multirow{3}{*}{ Procura Informal } & V16 & 2,14 & $\mathrm{n}$ & 39 \\
\cline { 2 - 6 } & V17 & 2,41 & $\chi^{2}$ & 9,430 \\
\cline { 2 - 6 } & V18 & 2,87 & g.l. & 3 \\
\cline { 2 - 6 } & V19 & 2,58 & Sig. Assint. & $\mathbf{0 , 0 2 4}$ \\
\hline
\end{tabular}

Para identificar os pares de variáveis que diferiram entre si no grupo procura informal, aplicou-se novamente o teste de Friedman para cada par de variáveis desse grupo. Essas comparações estão sumarizadas em um quadro para todos os blocos de questões que apresentaram diferenças significativas para o grupo PI e outro para o grupo PF ao final deste apêndice.

A seguir, mostram-se os quadros comparativos para cada um dos blocos de questões, destacando-se em negrito os valores de significância ( $p$-value) inferiores com nível crítico de 
significância 0,05. Para esses casos, as variáveis serão comparadas aos pares nos quadros ao final deste apêndice.

\begin{tabular}{|c|c|c|c|c|}
\hline \multicolumn{5}{|c|}{ Aspectos ambientais de mercado } \\
\hline Grupo & Variável & Posto Médio & Estatística & teste \\
\hline \multirow{4}{*}{ Procura Formal } & V20 & 2,07 & $\mathrm{n}$ & 81 \\
\hline & $\mathrm{V} 21$ & 2,35 & $\chi^{2}$ & 39,129 \\
\hline & V22 & 1,58 & g.l. & 2 \\
\hline & & & Sig. Assint. & 0,000 \\
\hline \multirow{4}{*}{ Procura Informal } & V20 & 2,10 & $\mathrm{n}$ & 39 \\
\hline & V21 & 2,22 & $\chi^{2}$ & 9,056 \\
\hline & $\mathrm{V} 22$ & 1,68 & g.l. & 2 \\
\hline & & & Sig. Assint. & 0,110 \\
\hline
\end{tabular}

\begin{tabular}{|c|c|c|c|c|}
\hline \multicolumn{5}{|c|}{ Aspectos ambientais de mercado } \\
\hline \multirow{3}{*}{ Grupo } & Variável & Posto Médio & \multicolumn{2}{c|}{ Estatísticas do teste } \\
\hline \multirow{3}{*}{ Procura Formal } & V20 & 2,07 & $\mathrm{n}$ & 81 \\
\cline { 2 - 5 } & V21 & 2,35 & $\chi^{2}$ & 39,129 \\
\cline { 2 - 5 } & V22 & 1,58 & g.l. & 2 \\
\cline { 2 - 5 } & & & Sig. Assint. & $\mathbf{0 , 0 0 0}$ \\
\hline \multirow{3}{*}{ Procura Informal } & V20 & 2,10 & $\mathrm{n}$ & 39 \\
\cline { 2 - 6 } & V21 & 2,22 & $\chi^{2}$ & 9,056 \\
\cline { 2 - 6 } & V22 & 1,68 & g.l. & 2 \\
\cline { 2 - 6 } & & & Sig. Assint. & 0,110 \\
\hline
\end{tabular}

\begin{tabular}{|c|c|c|c|c|}
\hline \multicolumn{5}{|c|}{ Dificul dades organi zacionais do moni toramento } \\
\hline \multirow{4}{*}{ Grupo } & Variável & Posto Médio & \multicolumn{2}{c|}{ Estatísticas do teste } \\
\hline \multirow{4}{*}{ Procura Formal } & V28 & 3,23 & $\mathrm{n}$ & 81 \\
\cline { 2 - 5 } & V29 & 3,10 & $\chi^{2}$ & 9,859 \\
\cline { 2 - 5 } & V30 & 2,61 & g.1. & 4 \\
\cline { 2 - 5 } & V31 & 3,06 & Sig. Assint. & $\mathbf{0 , 0 4 3}$ \\
\cline { 2 - 5 } & V32 & 2,99 & \multicolumn{2}{|c|}{} \\
\hline \multirow{4}{*}{ Procura Informal } & V28 & 3,49 & n & 39 \\
\cline { 2 - 5 } & V29 & 2,60 & $\chi^{2}$ & 9,743 \\
\cline { 2 - 5 } & V30 & 3,13 & g.l. & 4 \\
\cline { 2 - 5 } & V31 & 2,90 & Sig. Assint. & $\mathbf{0 , 0 4 5}$ \\
\cline { 2 - 5 } & V32 & 2,88 & & \\
\hline
\end{tabular}




\begin{tabular}{|c|c|c|c|c|}
\hline \multicolumn{5}{|c|}{ Dificuldades técnicas do monitoramento } \\
\hline Grupo & Variável & Posto Médio & \multicolumn{2}{|c|}{ Estatísticas do teste } \\
\hline \multirow{4}{*}{ Procura Formal } & V33 & 2,01 & $\mathrm{n}$ & 81 \\
\hline & V34 & 2,06 & $\chi^{2}$ & 1,194 \\
\hline & V35 & 1,93 & g.l. & 2 \\
\hline & & & Sig. Assint. & 0,551 \\
\hline \multirow{4}{*}{ Procura Informal } & V33 & 1,88 & $\mathrm{n}$ & 39 \\
\hline & V34 & 2,05 & $\chi^{2}$ & 1,162 \\
\hline & V35 & 2,06 & g.l. & 2 \\
\hline & & & Sig. Assint. & 0,559 \\
\hline
\end{tabular}

\section{Comparação dos pares de variáveis:}

\begin{tabular}{|c|c|c|c|c|c|c|}
\hline \multicolumn{7}{|c|}{ Grupo Procura Formal } \\
\hline Variáveis & \multicolumn{2}{|c|}{ Pares de Variáveis } & \multicolumn{2}{|c|}{ Postos médios } & \multirow{2}{*}{$\frac{\mathbf{x}^{2}}{8,100}$} & \multirow{2}{*}{$\frac{\text { sig. Assint }}{0,004}$} \\
\hline \multirow{3}{*}{$\begin{array}{c}\text { Aspectos } \\
\text { de Mercado }\end{array}$} & V20 & V21 & 1,39 & 1,61 & & \\
\hline & V20 & V22 & 1,69 & 1,31 & 18,750 & 0,000 \\
\hline & V21 & V22 & 1,73 & 1,27 & 26,741 & $\mathbf{0 , 0 0 0}$ \\
\hline \multirow{10}{*}{$\begin{array}{c}\text { Aspectos } \\
\text { Macroambientais }\end{array}$} & V23 & V24 & 1,58 & 1,42 & 3,314 & 0,069 \\
\hline & V23 & $\mathrm{V} 25$ & 1,52 & 1,48 & 0,191 & 0,662 \\
\hline & V23 & V26 & 1,72 & 1,28 & 23,143 & $\mathbf{0 , 0 0 0}$ \\
\hline & V23 & $\mathrm{V} 27$ & 1,78 & 1,22 & 40,692 & $\mathbf{0 , 0 0 0}$ \\
\hline & V24 & V25 & 1,46 & 1,54 & 1,195 & 0,274 \\
\hline & V24 & V26 & 1,70 & 1,30 & 18,458 & 0,000 \\
\hline & V24 & $\mathrm{V} 27$ & 1,72 & 1,28 & 20,903 & 0,000 \\
\hline & $\mathrm{V} 25$ & V26 & 1,73 & 1,27 & 23,203 & $\mathbf{0 , 0 0 0}$ \\
\hline & V25 & V27 & 1,74 & 1,26 & 26,684 & 0,000 \\
\hline & V26 & $\mathrm{V} 27$ & 1,56 & 1,46 & 0,692 & 0,405 \\
\hline \multirow{10}{*}{$\begin{array}{c}\text { Dificuldades } \\
\text { Organizacionais }\end{array}$} & V28 & V29 & 1,54 & 1,46 & 0,720 & 0,396 \\
\hline & V28 & $\mathrm{V} 30$ & 1,64 & 1,36 & 11,255 & 0,001 \\
\hline & V28 & V31 & 1,53 & 1,47 & 0,532 & 0,466 \\
\hline & V28 & V32 & 1,52 & 1,48 & 0,164 & 0,686 \\
\hline & V29 & V30 & 1,60 & 1,40 & 5,565 & 0,018 \\
\hline & V29 & V31 & 1,49 & 1,51 & 0,021 & 0,884 \\
\hline & V29 & V32 & 1,55 & 1,45 & 1,231 & 0,267 \\
\hline & V30 & V31 & 1,42 & 1,58 & 3,449 & 0,063 \\
\hline & V30 & V32 & 1,43 & 1,57 & 2,373 & 0,123 \\
\hline & V31 & V32 & 1,51 & 1,49 & 0,019 & 0,891 \\
\hline
\end{tabular}




\begin{tabular}{|c|c|c|c|c|c|c|}
\hline \multicolumn{7}{|c|}{ Grupo Procura Informal } \\
\hline Variáveis & \multicolumn{2}{|c|}{ Pares de Variáveis } & \multicolumn{2}{|c|}{ Postos médios } & \multirow{2}{*}{$\frac{\chi^{2}}{1,500}$} & \multirow{2}{*}{$\begin{array}{c}\text { sig. Assint. } \\
0,221\end{array}$} \\
\hline \multirow{6}{*}{$\begin{array}{c}\text { Fontes } \\
\text { de Informação }\end{array}$} & V16 & V17 & 1,42 & 1,58 & & \\
\hline & V16 & V18 & 1,33 & 1,67 & 6,760 & 0,009 \\
\hline & V16 & V19 & 1,38 & 1,62 & 3,000 & 0,083 \\
\hline & V17 & V18 & 1,38 & 1,62 & 3,240 & 0,072 \\
\hline & V17 & V19 & 1,45 & 1,55 & 0,667 & 0,414 \\
\hline & V18 & V19 & 1,59 & 1,41 & 2,333 & 0,127 \\
\hline \multirow{3}{*}{$\begin{array}{l}\text { Aspectos } \\
\text { de Mercado }\end{array}$} & V20 & V21 & 1,45 & 1,55 & 8,100 & 0,004 \\
\hline & V20 & V22 & 1,65 & 1,35 & 5,143 & $\mathbf{0 , 0 2 3}$ \\
\hline & V21 & V22 & 1,67 & 1,33 & 6,760 & 0,009 \\
\hline \multirow{10}{*}{$\begin{array}{c}\text { Aspectos } \\
\text { Macroambientais }\end{array}$} & V23 & V24 & 1,58 & 1,42 & 1,500 & 0,221 \\
\hline & V23 & V25 & 1,51 & 1,15 & 0,034 & 0,853 \\
\hline & V23 & V26 & 1,73 & 1,27 & 11,571 & $\mathbf{0 , 0 0 1}$ \\
\hline & V23 & V27 & 1,71 & 1,29 & 8,533 & 0,000 \\
\hline & V24 & V25 & 1,42 & 1,58 & 1,286 & 0,257 \\
\hline & V24 & V26 & 1,65 & 1,35 & 5,538 & 0,019 \\
\hline & V24 & V27 & 1,64 & 1,36 & 5,762 & 0,016 \\
\hline & V25 & V26 & 1,65 & 1,35 & 5,143 & $\mathbf{0 , 0 2 3}$ \\
\hline & V25 & V27 & 1,68 & 1,32 & 7,000 & 0,008 \\
\hline & V26 & V27 & 1,53 & 1,47 & 0,154 & 0,695 \\
\hline \multirow{10}{*}{$\begin{array}{l}\text { Dificuldades } \\
\text { Organizacionais }\end{array}$} & V28 & V29 & 1,69 & 1,31 & 7,759 & 0,005 \\
\hline & V28 & V30 & 1,59 & 1,41 & 2,333 & 0,127 \\
\hline & V28 & V31 & 1,59 & 1,41 & 1,960 & 0,162 \\
\hline & V28 & V32 & 1,62 & 1,38 & 3,240 & 0,072 \\
\hline & V29 & V30 & 1,38 & 1,62 & 3,522 & 0,061 \\
\hline & V29 & V31 & 1,46 & 1,54 & 0,360 & 0,549 \\
\hline & V29 & V32 & 1,45 & 1,55 & 0,727 & 0,394 \\
\hline & V30 & V31 & 1,55 & 1,45 & 0,727 & 0,394 \\
\hline & V30 & V32 & 1,55 & 1,45 & 0,727 & 0,394 \\
\hline & V31 & V32 & 1,50 & 1,50 & 0,000 & 1,000 \\
\hline
\end{tabular}

